VICTORIA UNIVERSITY OF WELLINGTON

Te Whare Wānanga o te Ūpoko o te Ika a Māui

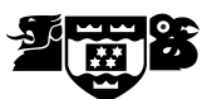

\title{
SOLAR PHOTOVOLTAICS IN PACIFIC ISLAND NATIONS: AN ANALYSIS OF RURAL HOUSEHOLD ELECTRIFICATION STRATEGIES IN THE RMI AND VANUATU
}

\author{
by \\ Juliana Ungaro \\ Thesis \\ ENVIRONMENTAL STUDIES 593
}

[2012]
A 90-point thesis submitted to Victoria University of Wellington, as partial fulfilment of requirements for the degree of Master of Environmental Studies

School of Geography, Environment and Earth Sciences

Victoria University of Wellington

[May, 2012] 


\title{
SOLAR PHOTOVOLTAICS IN PACIFIC ISLAND NATIONS: AN ANALYSIS OF RURAL HOUSEHOLD ELECTRIFICATION STRATEGIES IN THE RMI AND VANUATU
}

by

Juliana Ungaro

\begin{abstract}
Rural electrification of Pacific Island Countries (PICs) through renewable energy is necessary for poverty alleviation, energy security, improved health, and to mitigate the effects of climate change, with solar PV being the preferred technological solution. However, electrification projects in PICs have had a high rate of failure, which has led to the adoption of various electrification strategies. This research has analysed the essential criteria for creating effective and enduring electrification models for rural household-scale electrification in PICs. A case study on self-initiated solar PV home systems (SHSs) demonstrated rural end-users' ability and desire to maintain SHSs of their own accord, while at the same time liberating their community of reliance on kerosene. The results suggested that market solutions that pay sufficient attention to social dimensions of project design and implementation are more likely to be successful in meeting end-users needs and providing enduring results. Such approaches have fewer organizational layers, allow for end-user participation and education, and encourage self-initiative. The need for such social solutions is well documented in the development literature, yet many of the electrification programs in PICs did not allocate sufficient funds to understanding and incorporating these social aspects. This research concludes that a proper balance in the overarching program design between the technical and social focus of projects is required, as each are equally important for project effectiveness and durability.
\end{abstract}

Key words: renewable energy, solar PV household systems, rural electrification methods, participatory practices, evaluation indicators, Pacific Islands, Vanuatu, Marshall Islands. 


\section{Acknowledgments}

I would like to express my gratitude to everyone and everything that has helped to guide and support me during my Masters journey. First, thank you to Wellington with its late night cafes, yoga studios, mountainous beauty, and numerous beaches, which gave me inspiring places to both work in and take breaks.

Of course, thank you to my supervisor, Dr. Sean Weaver, for his patience with me and encouraging words.

Thank you to my family - my Mom, for her always "looking it over one more time," and to both of my parents for their endless love and support. And thanks to my brother Craig, for sharing our Masters journey together from across the world.

Thank you to Island Eco, for their help in carrying out this research -- through much guidance and assistance with collecting data. And thanks to the respondents in Vanuatu and the Marshall Islands for their time and honesty, and to my 'second family' in Vanuatu - Henry, Fiona, Edna, Julie, Sophie, and Elvina- who helped my love and understanding of the Pacific to grow.

Also, I would like to thank my many fun-loving and supportive friends who have been with me the last two years in Wellington: Alejandra, Veruska, Euginia, Fei, Seema, Alejo, Lukas, Scott, Amar, Shakil, and many others. Finally, I would like to thank Dr. Ray for the late night laughter, walks on the beach, and metta charges which has kept me both grounded and energized during this journey.

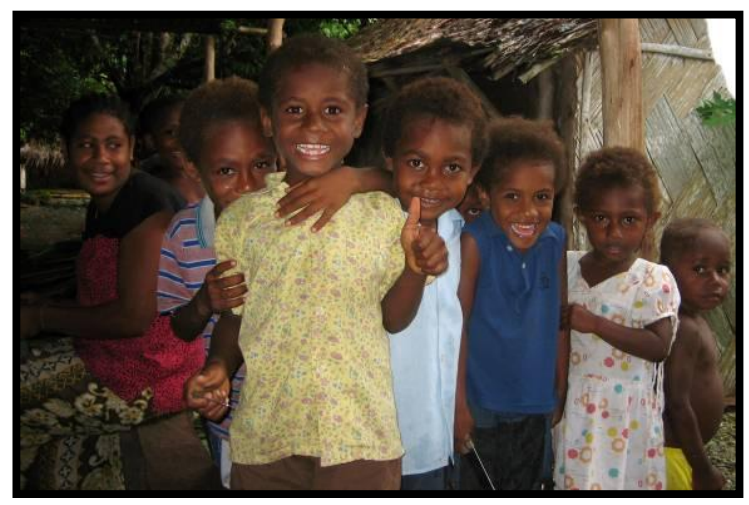




\section{Table of Contents}

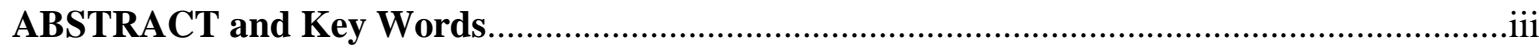

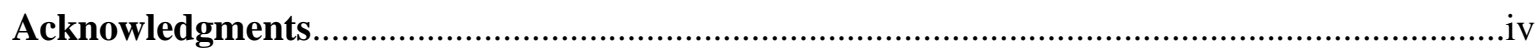

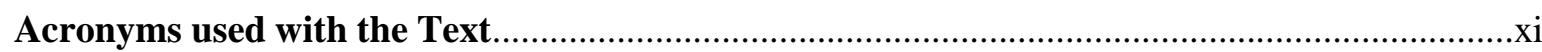

\section{Chapters:}

\section{Chapter 1: Introduction to Renewable Energy in the Pacific Islands}

1.1 Renewable Energy Project Challenges........................................................................ 1

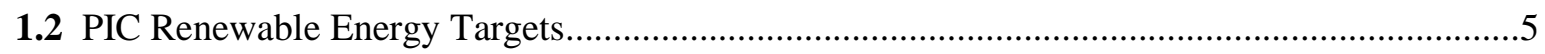

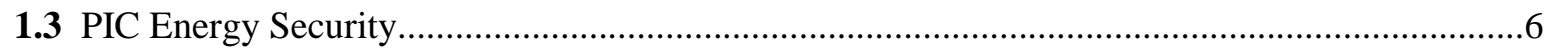

1.4 Renewable Energy Demand: Health, Poverty Eradication, and Climate Change ......................9

1.5 Renewable Energy Supply: Technical Opportunities and Challenges......................................11

1.6 Renewable Energy Project Implementation: Socio-cultural Challenges....................................13

1.7 Implications for this Thesis....................................................... 16

\section{Chapter 2: Research Purpose and Aim}

2.1 Research Focus: Rural PV Electrification Strategies..........................................................17

2.1.1 Variations in Electrification Models................................................ 17

2.1.2 Differences in the Electrification Strategies........................................... 19

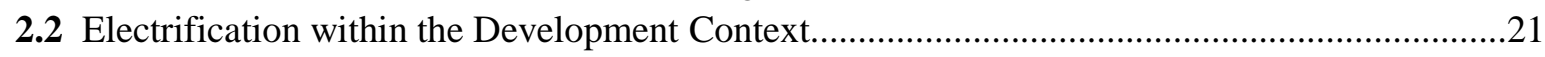

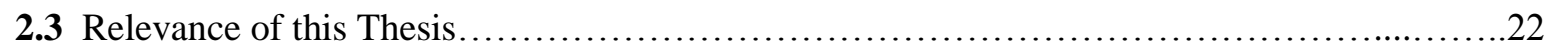

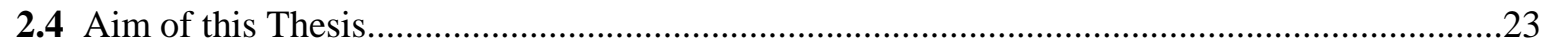

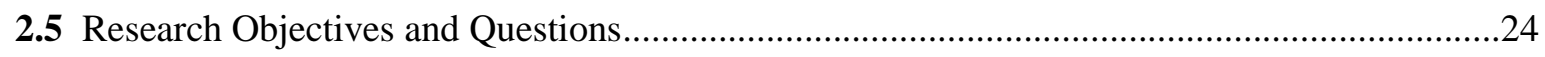

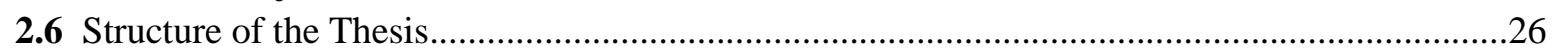

\section{Chapter 3: A Review of the Literature on Indicators, Challenges, and Successes}

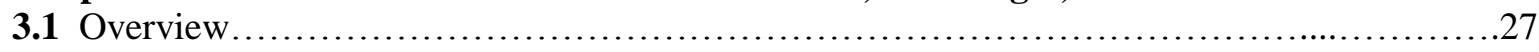

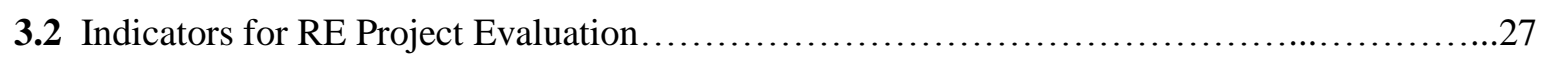

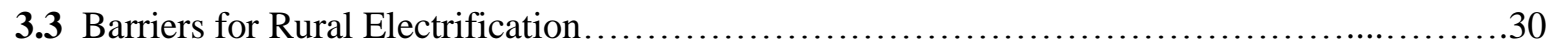

3.4 Barriers and Recommendation for Each Indicator...................................... 32

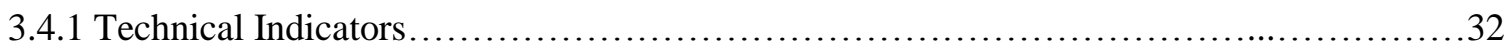

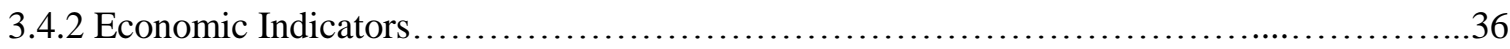

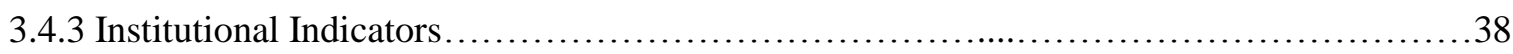

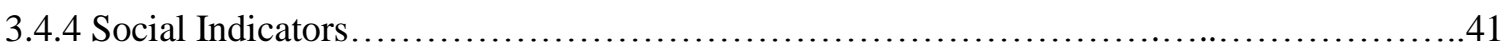

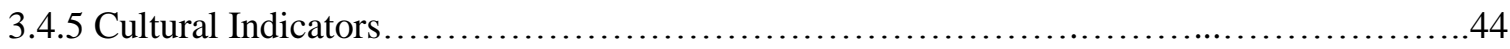

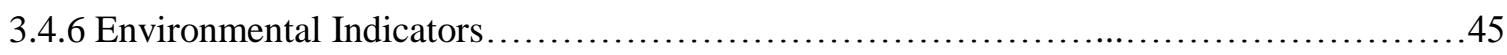

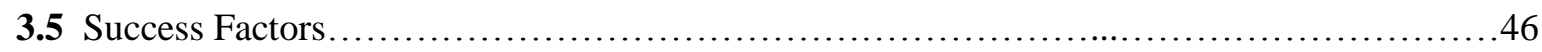

Chapter 4: Research Methodology

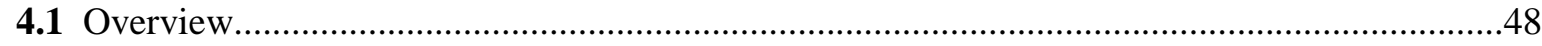

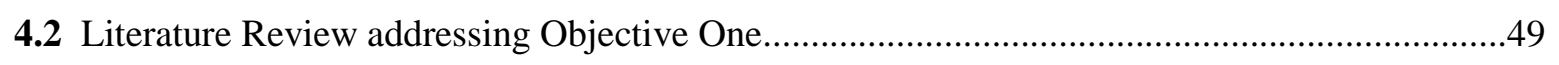




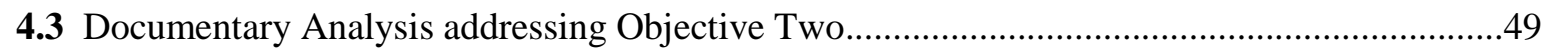

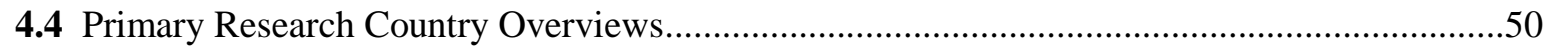

4.5 Questionnaires addressing Objective Three..........................................................................52

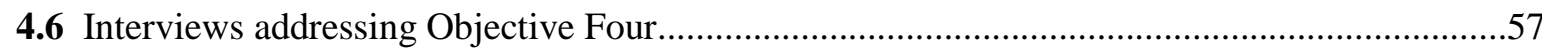

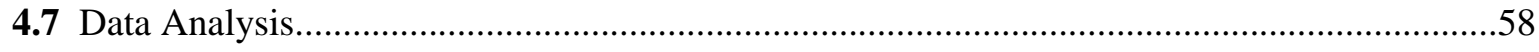

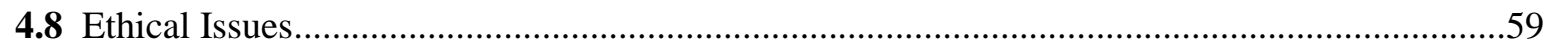

Chapter 5: An Analysis of SHS Projects Implemented in PICs

5.1 A Global Summary of SHS Implementation Models........................................60

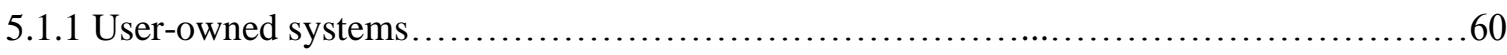

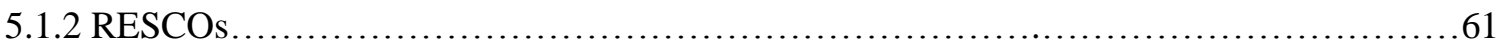

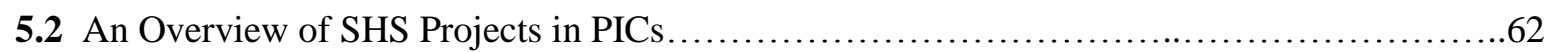

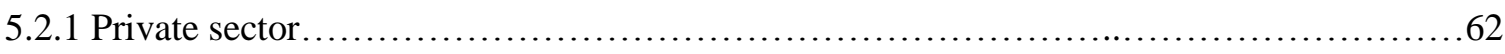

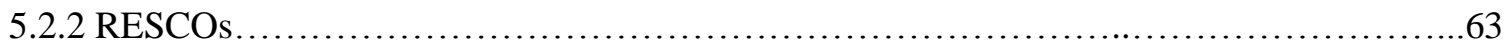

5.2 .3 Community-based approaches ................................................64

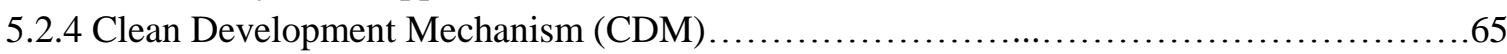

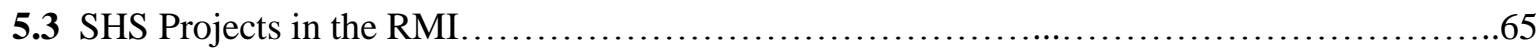

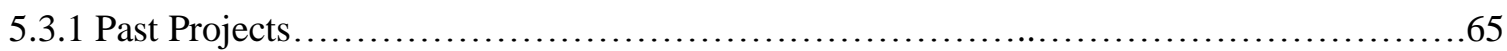

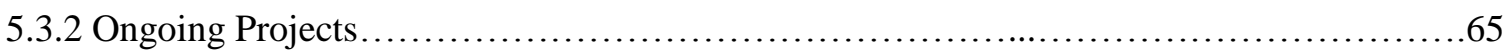

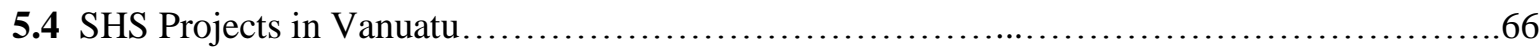

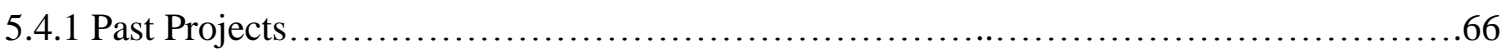

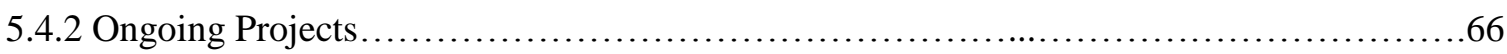

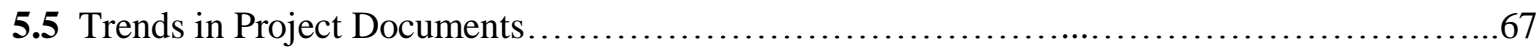

5.6 Lessons Learned as Stated in PIC Project Documents....................................... 70

Chapter 6: The Quantitative Data Results and Analysis

6.1 Results of the Quantitative Questionnaire by Indicators....................................74

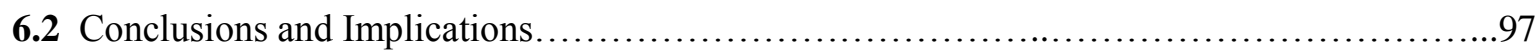

Chapter 7: The Qualitative Data Results and Analysis

7.1 Results of the Qualitative Interviews by Indicators..................................100

7.2 Interviewees' Beliefs on Electrification Strategies and Essential Factors.....................111

7.3 Implications of the Qualitative Data Analysis...........................................114

Chapter 8: Recommendations and Discussion

8.1 Recommendations on Electrification Strategies......................................116

8.2 Recommendations for Reducing Project Risk...................................... 123

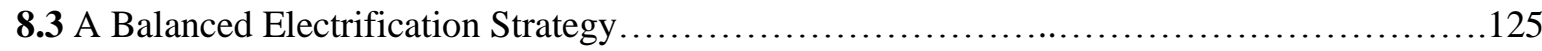

8.4 Limitations of the Research.............................................................. 137

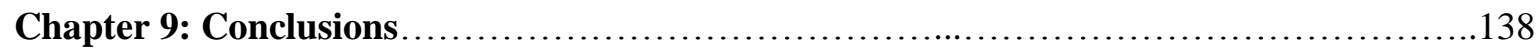

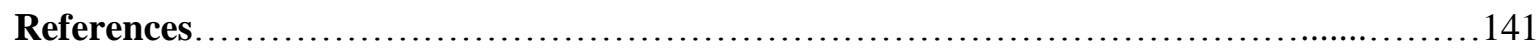

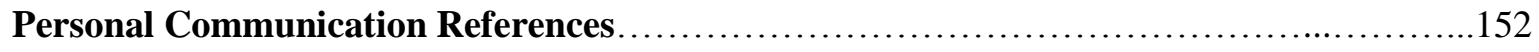




\section{Tables:}

Table 1.1.1: Human Poverty Index and Human Development Index for PICs

Table 1.3.1: The Marshall Islands' and Vanuatu's retail fuel and electricity prices and those of nearby developed countries: the United States and Australia as of mid-2011 8

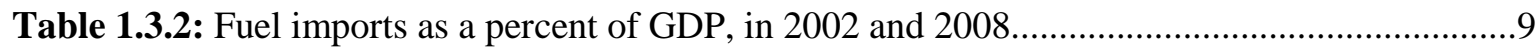

Table 2.1.1.1: A summary of the variations on the two implementation strategies, as cited in the literature.

Table 3.2.1: Evaluation indicators for case-study evaluation, compiled from the

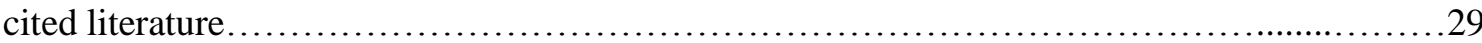

Table 3.5.1: A summary of the success factors cited in the literature by indicator......................46

Table 4.1.1: Research Objectives and Corresponding Methods, and the chapter wherein the methodology is carried out.

Table 4.4.1: A comparison of the RMIs' and Vanuatu's national statistics and geography .51

Table 4.4.2: Urbanization trends in the Marshall Islands and Vanuatu..........................................52

Table 5.6.1: Lessons learned as stated in project documents in PICs...........................71

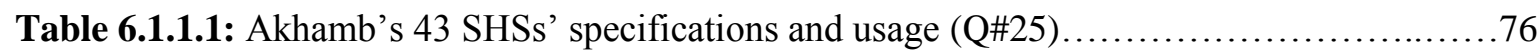

Table 6.1.4.1: A comparison of the cost per $\mathrm{kW}$ hour of the systems managed by MEC and those installed on Akhamb Island.......................................... 80

Table 6.2.1: Conclusions and implications of the quantitative data analysis.........................98

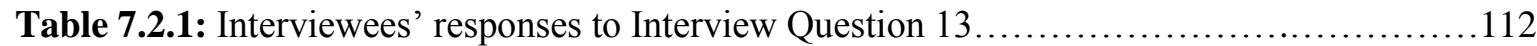

Table 7.3.1: Implications of the Qualitative Data Analysis....................................113

Table 8.1.1: Positive and negative aspects of each electrification model, based on the literature, project documents, case studies, and interviews........................118

Table 8.2.1: Success factors for enduring results

\section{Figures:}

Figure 1.1.1: The components of a solar PV home system...................................

Figure 1.2.1: Excerpt from the RMI National Energy Policy .....................................................5

Figure 1.3.1: Map of the Oceania region, including the North and South Pacific Islands

Figure 1.5.1: Solar module price trends over the past decade.

Figure 1.5.2: Examples of pre-wired systems designed for remote settings, from small to large scale

Figure 1.6.1: Suggested socio-cultural factors and solar PV project implications in rural Vanuatu and RMI communities.

Figure 2.1.1.1: The common features of the RESCO and user-owned electrification models

Figure 2.1.1.2: A flow-chart demonstrating the differences between system procurement by private companies and project development through the government.

Figure 2.2.1: A Ladder of Citizen Participation...................................................................22 
Figure 3.3.1: Barriers cited in the literature for rural RE electrification of PICs. 31

Figure 3.4.1.1: A 12-volt DC powered energy efficient TV, which consumes less power than standard TVs and are ideal for SHS applications............................. 34

Figure 3.4.1.2: The Rural Electricity Ladder......................................... 35

Figure 4.5.1: A map of Namdrik Atoll and its location in the RMI...........................................53

Figure 4.5.2: The cover of the Marshallese Solar Training Manual..............................................54

Figure 4.5.3: A photograph of Akhamb Island, a map of Malekula with Akhamb Island highlighted, and its location in Vanuatu.

Figure 5.5.1: Positive and Negative Results found in RESCO and User-owned PIC project documents by the number of occurrences of each indicator.

Figure 6.1.1.1: Which Parts had been Replaced in the SHSs at the Time of

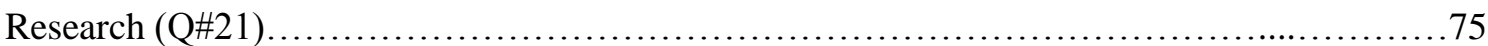

Figure 6.1.2.1: Other Power Sources Households have in Addition to their

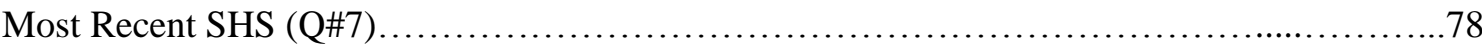

Figure 6.1.2.2: What Appliance Users Would Like to Add to their SHS (Q\#26)...................78

Figure 6.1.4.1: Amount Akhamb SHS Owners Spend on their System per Year (Q\#18)..... .81

Figure 6.1.5.1: Activities that SHS Owners use their Solar Powered Lights for by Percentage $(\mathrm{Q} \# 9)$

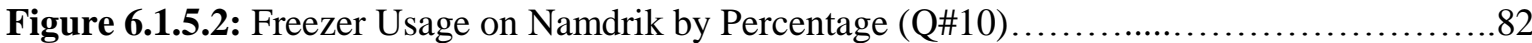

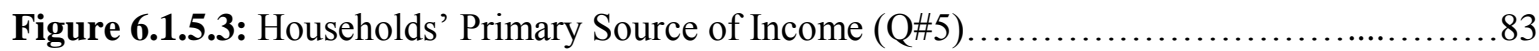

Figure 6.1.6.1: User's Confidence in being able to Fix or Get Help to Fix their SHS, by Location (Q\#28-30)...

Figure 6.1.6.2: How Well Users feel their SHS has been Maintained (Q\#23 and 40) 84

Figure 6.1.6.3: How Well Users feel their Lights have Worked (Q\#24 and 41).................85

Figure 6.1.8.1: Did Someone in the Household Participate in the SHS Installation? (Q\#27)

Figure 6.1.9.1: Number of Men and Women in Total that feel Confident Fixing a SHS (more than one per family) (Q\#45 and 46)...

Figures 6.1.10.1: Average Biweekly Income per Household (USD) on Namdrik Atoll; Average Biweekly Income per Household (USD) on Akhamb Island $(\mathrm{Q} \# 4)$

Figure 6.1.10.2: Do you Spend More or Less on your SHS than on your Previous Power Source? (Q\#19)

Figures 6.1.10.3: Namdrik Household Source of Lighting before their IE-installed SHS; Akhamb Household Source of Lighting before their Most Recent SHS (Q\#8)

Figure 6.1.11.1: The Highest Level of Education of Respondents by Percentage (Q\#6)

Figure 6.1.11.2: How did Respondents that felt Confident Fixing a SHS Learn? (Q\#47).

Figure 6.1.12.1: Who Maintains the Previous and Current SHSs in the Two Case Studies? (Q\#14 and 32).... 93 
Figure 6.1.12.2: Trends in Participation and Ownership..................................94

Figure 6.1.13.1: Reasons Respondents Purchased their Most Recent SHS (Q\#11)................95

Figure 6.1.13.2: How Willing Users were to Spend Money to Fix their Current

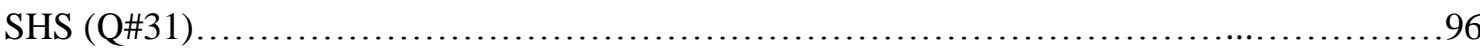

Figure 7.2.1: Interviewees' responses to Interview Question $12 \ldots \ldots \ldots \ldots \ldots \ldots \ldots \ldots \ldots \ldots \ldots \ldots \ldots$

Figure 8.3.1: A Project Risk Mitigation Framework for identifying threats to

SHSs in PICs, and suggested actions to mitigate these threats...........................127

\section{Photographs:}

Photograph 1.2.1: Banner announcing the launch of the Vanuatu National

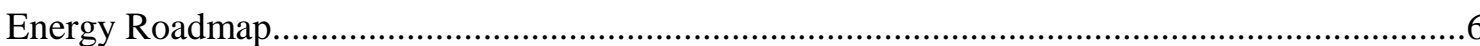

Photograph 3.4.2.1: A SHS located at a local school in Vanuatu, which provides

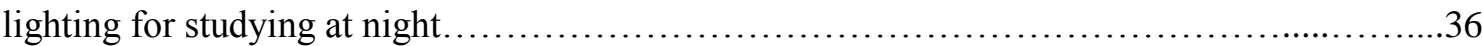

Photograph 3.4.3.1: A training session for women at Utrok Atoll, Marshall

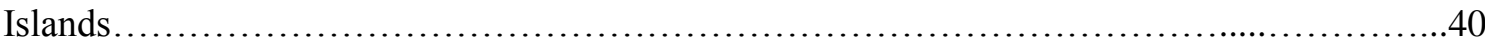

Photograph 3.4.4.1: A rural RMI household receives a new solar-powered refrigerator, which will help to decrease women's workload.

Photograph 3.4.6.1: Erosion poses a serious threat to low-lying islands, and thus GHG emissions may directly threaten PIC communities

Photograph 4.5.1: A local family with their SHS, and a chief of Akhamb Island

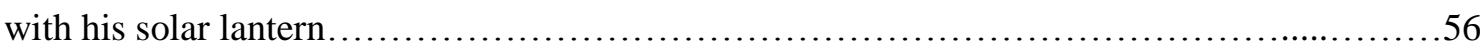

Photograph 5.2.2.1: A SHS installed through the EU's REP-5 Project.......................62

Photographs 6.1.1.1: SHSs installed by IE (top) and managed by MEC (bottom) on Namdrik Atoll.................................................................

Photograph 6.1.8.1: End-users on Namdrik helping with the IE system installation.

Photograph 6.1.14.1: The 1.62kW community system installed on Akhamb Island....

Photograph 7.1.1.1: An indoor light being placed outdoors with an undersized indoor wire powering it

Photograph 7.1.4.1: An example of a solar power board. 104

\section{Appendices:}

Appendix 1: Twenty-one PICs and their Renewable Energy Targets 153

Appendix 2: PIC electrification characteristics and opportunities for solar power.................154

Appendix 3: Ilskog's (2008) thirty-six indicators for evaluating RE projects' effects on sustainable development globally.

Appendix 4: Chow's (2010) five factors for sustainable development, adapted from McConville (2006). 158

Appendix 5: Urmee \& Harries' (2009) indicators for successful program implementation. 
Appendix 6: Questionnaires for SHS users in the case study communities of

Namdrik Atoll and Akhamb Island. .160

Appendix 7: Interview questions for key stakeholders in Vanuatu and the

Marshall Islands and the indicators each question addressed

Appendix 8: A summary of the history of SHS projects implemented in the RMI, based on information in the literature and project documents.

Appendix 9: A summary of the history of SHS projects implemented in Vanuatu, based on information in the literature and project documents.

Appendix 10: A summary of RESCO projects in 3 PICs utilizing SHSs, based on information in the literature and project documents

Appendix 11: A summary of the private SHS market in PNG, based on information in the literature and project documents.

Appendix 12: A summary of the co-operative model implemented in Tuvalu, based on information in the literature and project documents

Appendix 13: Descriptions of four ongoing regional projects and efforts in PICs

which directly affect rural RE electrification 
Acronyms used with the Text:

AusAid: Australian Aid Program

CC: Climate Change

CDM: Clean Development Mechanism

$\mathrm{CO}_{2}$ : Carbon Dioxide

$\mathrm{CO}_{2} \mathbf{e}$ : Carbon Dioxide Equivalent

EE: Energy Efficient

EU: European Union

ESMAP: Energy Sector Management Assistance

Program

FSM: Federated States of Micronesia

GEF: Global Environment Fund

GHG: Greenhouse Gases

GSM: Global System for Mobile Communication

GW: Gigawatt

IAEA: International Atomic Energy Association

IDCOL: Infrastructure Development Company Limited

IEA: International Energy Agency

IE: Island Eco

IRENA: International Renewable Energy Agency

$\mathbf{k W}$ : Kilowatt

LCDS: Low-carbon Development Strategies

MAEC: Marshalls Alternative Energy Company

MDGs: Millennium Development Goals

MEC: Marshalls Energy Company

MW: Megawatt

NAMAs: Nationally Appropriate Mitigation Actions

NGO: Non-Government Organization

North REP: North Renewable Energy Project

O\&M: Operations and Maintenance

ODA: Official Development Assistance

PICs: Pacific Island Countries

PIGGAREP: Pacific Islands Greenhouse Gas

Abatement through Renewable Energy Project

PREFACE: Pacific Renewable Energy France

Australia Common Endeavor

PNG: Papua New Guinea

PV: Photovoltaic

RE: Renewable Energy

REAP: Renewable Energy for rural Access Project (Mongolia)

REEEP: Renewable Energy and Energy Efficiency

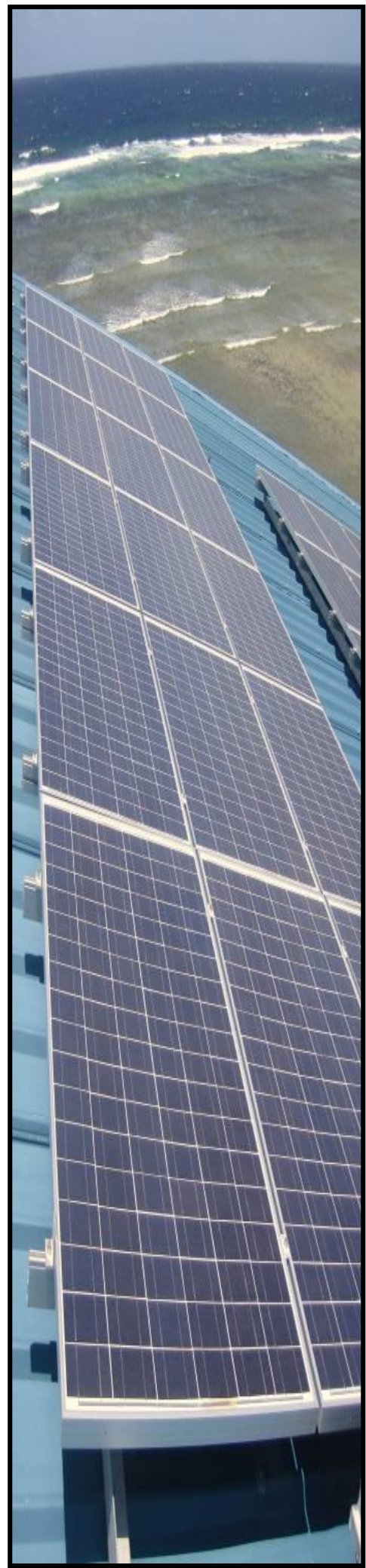

Partnership 
REP-5: Renewable Energy Project for Five ACP

Pacific Islands

RESCO: Renewable Energy Service Company

RETs: Renewable Energy Targets

RMI: Republic of the Marshall Islands

RMI ESP: Republic of the Marshall Islands Energy Services Program (Ministry of Research and Development)

SEC: Solar Energy Company (Kiribati)

SEIAPI: Sustainable Energy Industry Association of the Pacific Islands

SOPAC: South Pacific Applied Geoscience Commission

SHS: Solar (PV) Home System

SPC: Secretariat of the Pacific Community

US: United States

USDA-RUS: United States Department of Agriculture - Rural Utilities Program

VERD: Vanuatu Electricity for Rural Development

VEU: Vanuatu Energy Unit (Ministry of Lands and Natural Resources)

WB: World Bank

W: Watts

WSSD: World Summit on Sustainable Development 


\section{Chapter 1: \\ Introduction to Renewable Energy in the Pacific Islands}

\subsection{Renewable Energy Project Challenges}

Beginning in 1999, the Vanuatu Energy Unit (VEU) undertook a pilot project aided by the Japanese government and installed hundreds of solar photovoltaic (PV) home systems (SHSs) in communities on three islands (Efate, Malekula, and Umbae) (see a diagram of a SHS, Figure 1.1.1). The system design was conservative, with the design aim being to minimize operations and maintenance (O\&M) costs (Chow, 2010). The VEU collected rental fees of $\$ 15$ USD per month from the beneficiaries, which was used to maintain and repair the SHSs. Yet, after a few years, many end-users consistently failed to complete their payments, and after 2005, most had stopped paying altogether, and thus the VEU could no longer afford to maintain the systems (VEU, Respondent 1, 2011 ${ }^{1}$ ).

The beneficiaries were unsatisfied as the SHSs were not designed to meet all of their electricity demands, and they provided only limited lighting, with each light's recommended usage being only three hours per day (Chow, 2010). In addition, the users felt the monthly fee was too high, and as a result the government gave options for lowering the cost based on the number of lights in use. However, many end-users still failed to pay regularly as they were concerned about the payments being continuous; they didn't understand the reasons why VEU demanded never-ending payments when the project was donor-funded. Thus, many end-users preferred to own rather than rent their SHS, and the government accommodated by announcing that once they had paid \$850 USD in total (the original cost of the system was $\$ 1000$ ), the system would be theirs; however, only a few reached this point as many systems were already non-operational. Furthermore, those that did purchase their system did not have the knowledge to repair or maintain it, as the endusers were not trained through the project except in basic system operations (VEU, Respondent 1, 2011).

\footnotetext{
${ }^{1}$ Personal communication with respondents will hereafter be referenced by the person's general role, followed by 'Respondent' and a numeric identifier, and the year, and with the full citation listed within the references section of the thesis.
} 
Thus, many system breakdowns were due to users' failure to pay monthly fees, as well as the fees under-representing the total cost required for O\&M. As a result, the government did not have enough funds for replacement parts, especially when the batteries reached their life expectancy (around the five-year mark). In addition, prepayment meters were installed on the systems on Efate Island, which allowed end-users to pay their electricity bill in advance for the month much like a prepay mobile phone. However, those meters needed to be removed after a few years at an additional cost, as the only VEU technician who understood how to operate the meters relocated without training a replacement (VEU, Respondent 1, 2011). After the majority of the SHSs failed, rehabilitation became too expensive for the government, and many end-users bought home generators as a replacement, despite the fact that they are more costly in the long-term.

Figure 1.1.1: The components of a solar PV home system. Systems generally range from 15 to $200 \mathrm{~W}$ in size.

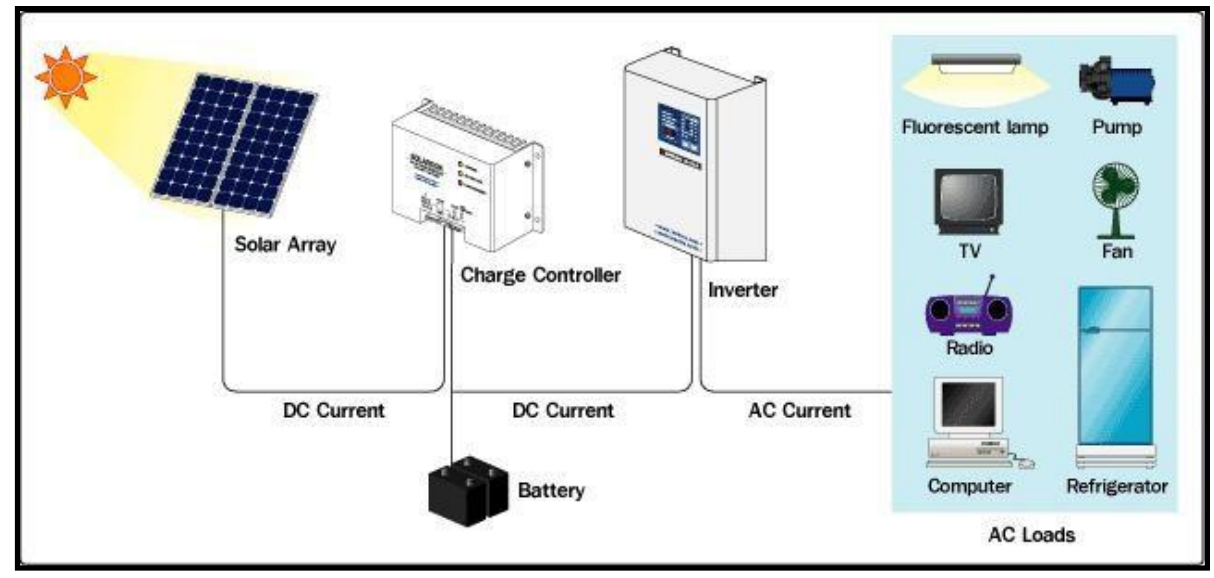

Source: Leonics Co. Limited (2009).

A similar story can be told in the Republic of the Marshall Islands (RMI), where SHSs were installed in remote communities by the Marshalls Energy Company (MEC), the state-owned utility, starting in 2003. Again, end-users failed to complete their monthly fees for their rented SHSs, and as a result the government reduced the fee from $\$ 12$ to $\$ 5$ per month, well below the price of O\&M. In addition, the government is now allowing endusers to pay with local resources such as bags of copra (dried coconut meat) in order to try to encourage the users to pay their fees on time (RMI Energy Services Program (ESP), Respondent 2, 2011).

At first glance, these accounts may indicate that solar PV is too costly for electrifying rural Pacific communities, even with subsidies. Yet, other reasons for PV 
project failure can be seen in both these accounts, including: a deficit of in-country trained personnel, minimal involvement of end-users in project design, systems not satisfying users' energy needs, lack of continual education and training for users, cultural incompatibility regarding financing, poor communication between stakeholders, and the electrification strategy not matching user preferences.

Unfortunately, these situations from the RMI and Vanuatu are not uncommon: in fact, since the 1980s, many renewable energy (RE) electrification projects in Pacific Island countries (PICs) have had minimal impact and a high rate of failure. A large percentage of these previous projects were not designed sufficiently to produce enduring outcomes (i.e., donor-funded equipment-based demonstrations or lack of planned involvement after installation) and are now non-operational (Akker, 2006). Despite many lessons learned and technological improvements over the years, even well-funded and large-impact RE electrification projects implemented today continue to face durability issues. For example, the Fiji Renewable Energy Service Company (RESCO) program is one of the latest attempts in PICs to promote solar-based rural electrification through a rental or fee-forservice electrification model; yet, major flaws have already been identified, related to poor stakeholder involvement in project design and lack of government support and ownership (Dornan, 2011). In short, many of these failed initiatives have been quick technological fixes that have not addressed the underlying issues required for longevity ${ }^{2}$.

Solar PV project collapse is an important issue for energy consumers, governments, and project funders in PICs, as reducing the risk of project failure enhances the quality of life for users and improves the cost-effectiveness of RE project investments by governments and donors. Therefore, research on essential practices and appropriate electrification strategies for SHS projects in the RMI and Vanuatu has the potential to reduce complications for future electrification. Furthermore, as the RMI's and Vanuatu's country profiles and rural energy needs are similar to those of other Pacific Island Countries (PICs) (see Table 1.1.1), such research on the two nations becomes relevant for the electrification of other PICs as well.

\footnotetext{
${ }^{2}$ The numerous financial, technical, policy, market, institutional, and informational barriers to implementing enduring RE projects in PICs, as well as the strategies taken to overcome them thus far, are reviewed in detail in Chapter 3.
} 
Table 1.1.1: Human Poverty Index and Human Development Index for PICs.

Table 1.20 Human Poverty Index for Pacific Island Countries, 1998

\begin{tabular}{|c|c|c|c|c|c|c|c|}
\hline Country & $\begin{array}{r}\text { Percentage of } \\
\text { people not } \\
\text { expected } \\
\text { to survive to age } \\
40 \\
(\mathrm{Pl}) \\
\end{array}$ & $\begin{array}{r}\text { Percentage } \\
\text { of adults } \\
\text { who are } \\
\\
\text { illiterate } \\
\text { (P2) }\end{array}$ & $\begin{array}{r}\text { Percentage of } \\
\text { people } \\
\text { without } \\
\text { access to } \\
\\
\text { safe water } \\
\text { (P3) } \\
\end{array}$ & $\begin{array}{r}\text { Percentage of } \\
\text { people } \\
\text { without } \\
\text { access to } \\
\text { health } \\
\text { services } \\
\text { (P3) }\end{array}$ & $\begin{array}{r}\text { Percentage of } \\
\text { children } \\
>5 \text { who are } \\
\\
\text { underweight } \\
\text { (P3) } \\
\end{array}$ & $\begin{array}{l}\text { Combined } \\
\text { P3 Value }\end{array}$ & $\begin{array}{l}\text { Human } \\
\text { Poverty } \\
\text { Index }\end{array}$ \\
\hline Niue & 6.7 & 3 & 0 & 0 & 2 & 0.7 & 4.8 \\
\hline Tonga & 8.4 & 1 & 5 & 0 & 2 & 2.3 & 5.9 \\
\hline Cook Islands & 6.4 & 6.8 & 5 & 0 & 10 & 5 & 6.1 \\
\hline Tuvalu & 9.8 & 5 & 15 & 0 & 0 & 5 & 7.3 \\
\hline Tokelau & 8.3 & 9 & 6 & 0 & 0 & 2 & 7.6 \\
\hline Fiji Islands & 7.4 & 7.1 & 23 & 0 & 7.9 & 10.3 & 8.5 \\
\hline Samoa & 10.3 & 4.3 & 10 & 0 & 17 & 9 & 8.6 \\
\hline Palau & 7.3 & 8.6 & 14 & 20 & 8 & 14 & 10.8 \\
\hline Nauru & 17.4 & 5 & 0 & 0 & 0 & 0 & 12.1 \\
\hline Kiribati & 16.3 & 7.8 & 20 & 0 & 12.9 & 11 & 12.6 \\
\hline Marshall Islands & 13.2 & 25.6 & 23.5 & 5 & 17 & 15.2 & 19.5 \\
\hline FSM & 10.5 & 28.7 & 56 & 25 & 15 & 32 & 26.7 \\
\hline Vanuatu & 12.2 & 66.5 & 13 & 20 & 23 & 18.7 & 46.6 \\
\hline $\begin{array}{l}\text { Solomon Islands } \\
\text { Papua new }\end{array}$ & 13.7 & 69.7 & 36 & 20 & 21 & 25.7 & 49.1 \\
\hline Guinea & 22.6 & 71.8 & 76 & 5 & 29 & 36.7 & 52.2 \\
\hline
\end{tabular}

Source: UNDP, Pacific Human Development Report 1999

Table 1.21 Human Development Index for Pacific Island Countries, 1998

\begin{tabular}{|c|c|c|c|c|c|c|}
\hline Country & $\begin{array}{r}\text { Adult } \\
\text { literacy }(\%)\end{array}$ & $\begin{array}{r}\text { Combined } \\
\text { gross } \\
\text { enrolment } \\
(\%) \\
\end{array}$ & $\begin{array}{r}\text { Life } \\
\text { Expectancy } \\
\text { at birth }\end{array}$ & $\begin{array}{r}\text { GDP } \\
\text { per } \\
\text { capita } \\
\text { (US\$) }\end{array}$ & $\mathrm{HDI}$ & $\begin{array}{r}\text { Global } \\
\text { HDI } \\
\text { Rank* }\end{array}$ \\
\hline Palau & 91.4 & 83.4 & 69.0 & 8027 & 0.861 & 46 \\
\hline Cook Islands & 93.2 & 84.8 & 72.0 & 4947 & 0.822 & 62 \\
\hline Niue & 97.0 & 83.6 & 74.0 & 3714 & 0.774 & 70 \\
\hline Fiji Islands & 92.9 & 81.3 & 66.5 & 2684 & 0.667 & 101 \\
\hline Nauru & 95.0 & 79.5 & 58.2 & 3450 & 0.663 & 103 \\
\hline Tonga & 99.0 & 83.3 & 68.0 & 1868 & 0.647 & 107 \\
\hline Samoa & 95.7 & 85.7 & 66.6 & 1060 & 0.59 & 117 \\
\hline Tuvalu & 95.0 & 74.0 & 67.0 & 1157 & 0.583 & 118 \\
\hline FSM & 71.3 & 71.4 & 65.7 & 2070 & 0.569 & 120 \\
\hline Marshall Islands & 74.4 & 71.7 & 65.0 & 1182 & 0.563 & 121 \\
\hline Kiribati & 92.2 & 67.8 & 61.6 & 702 & 0.515 & 129 \\
\hline Vanuatu & 33.5 & 57.4 & 65.8 & 1231 & 0.425 & 140 \\
\hline Solomon Islands & 30.3 & 34.7 & 64.7 & 926 & 0.371 & 147 \\
\hline Papua New Guinea & 28.2 & 28.6 & 54.0 & 1196 & 0.314 & 164 \\
\hline Tokelau & 91.0 & 88.3 & 69.0 & n.a & n.a & n.a \\
\hline
\end{tabular}

Note: The per capita income figures do not match with the ADB estimates.

Source: UNDP, Pacific Human Development Report 1999 


\subsection{PIC Renewable Energy Targets}

Despite these overall discouraging experiences described above, the RMI and Vanuatu national governments recognize the potential of RE in alleviating fuel poverty and electrifying their rural islands. Thus, the RMI government has set a renewable energy target (RET) of $20 \%$ of electricity produced from renewable sources by 2020 . However, many barriers to achieving this goal have been identified in the RMI National Energy Policy, such as inadequate training, inconsistencies in government programs, and inappropriate scales for meeting energy demands (see Figure 1.2.1). In Vanuatu, the national government is currently developing a National Energy Roadmap, to be completed in 2012 (see

Photograph 1.2.1), while the Vanuatu Power Utility (UNELCO) has set itself a goal of 33\% of its electricity from RE sources by 2013.

Figure 1.2.1: Excerpt from the RMI National Energy Policy.

\section{Issues and Objectives for Expanded Energy Use of Renewable Energy}

Issues:

- Lack of information on indigenous renewable energy resources, particularly wind and wave energy

- Inadequate training for those developing RE project proposals, trainers of those who manage outer island systems and trainers of household users in the proper operation and maintenance of solar installations

- Different and incompatible management systems for various government programs implementing rural renewable energy installations

- High initial costs and, for some RE resources and locations, imprecise knowledge of likely energy production (e.g. kWh output per year)

- Although grid-connected renewable energy may be important in the future, there is very limited experience with it in the Marshall Islands, with two small grid-connected systems operating in mid 2009

- Outer island household electrification schemes have a "one size fits all" mentality but actual needs can vary widely

- Poor access to land suitable for indigenous energy development

- Promoters visiting the RMI sometimes advocating and trying to sell unproven or untried RE systems or those of doubtful quality. At best this causes confusion and wastes time; at worst it result in investment of funds for energy projects that cannot provide promised results

Objectives:

- Improved capacity within the RMI to plan, develop, implement and manage renewable energy systems (small and medium-scale rural; large scale urban)

- Provision of $20 \%$ of electrical energy through indigenous renewable resources by 2020

- Outer island energy development to be through indigenous energy sources where technically practical and economically attractive

Source: RMI National Energy Policy (2009). 
Photograph 1.2.1: Banner announcing the launch of the Vanuatu National Energy Roadmap.

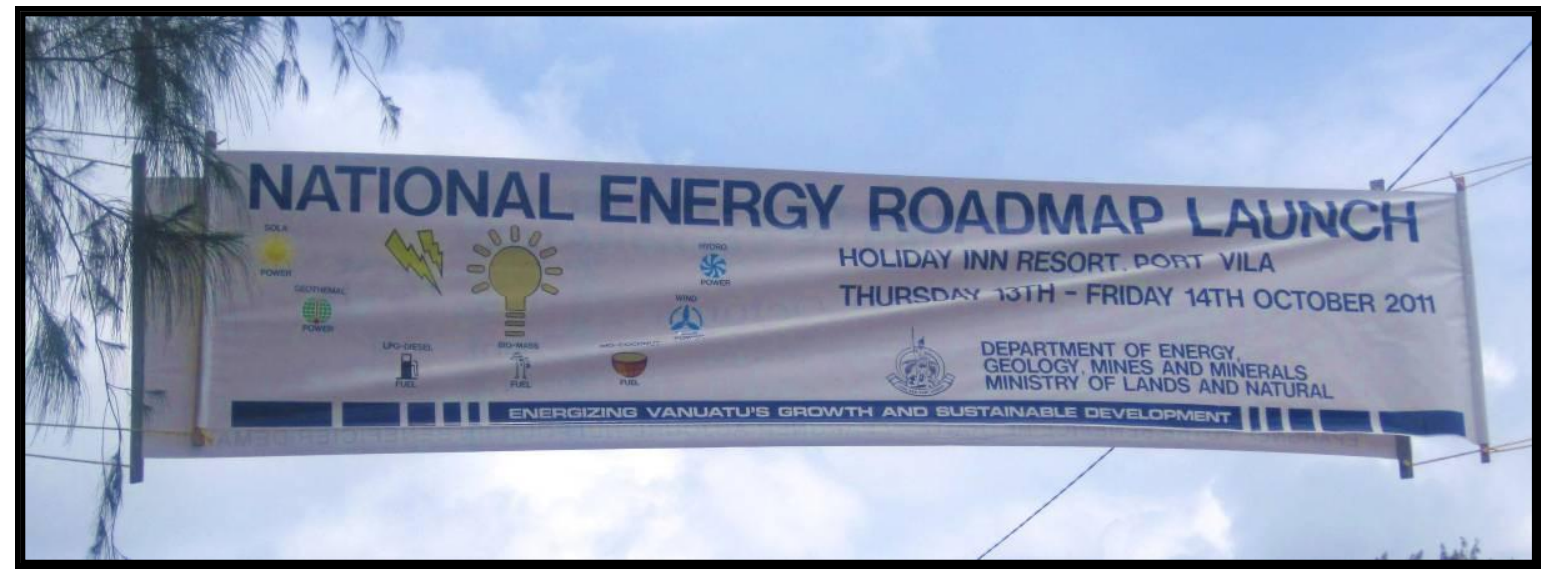

Source: Photography by Juliana Ungaro (2011).

Other PIC governments also recognize the benefits of utilizing their country's RE resources, as can be seen by many of the nations' RETs, which are described fully in Appendix 1. Furthermore, RETs have been established at a regional scale through climate change (CC) mitigation projects, such as the Pacific Islands Greenhouse Gas (GHG) Abatement through Renewable Energy Project (PIGGAREP), which aims to use RE to reduce GHG emissions 33\% by 2015 in eleven southern PICs. Additionally, the North Pacific ACP Regional Energy Project (North REP) has been established in five of the northern PICs, with similar goals of electrification and mitigation through $\mathrm{RE}^{3}$.

The purpose of these national and regional RETs is three-fold: 1. to decrease reliance on imported fossil fuels, 2. to provide reliable and affordable electricity to the region, and 3. to mitigate the regional effects of $\mathrm{CC}$. Thus, $\mathrm{RE}$ projects have the potential to benefit both rural communities and governments alike, making RE project permanence of interest to multiple sectors.

\subsection{PIC Energy Security}

Electrification of PICs is necessary for development, as $70 \%$ of the 10 million people living in PICs do not have access to electricity (SPREP, 2010). A substantial portion of this non-electrified population lives in rural, isolated islands, where grid establishment is

\footnotetext{
${ }^{3}$ The PIGGAREP project is described in detail in Appendix 13 and the North REP project is explained in Chapter 5.
} 
uneconomical and development projects are significantly constrained (Connell \& Waddell, 2007). In fact, 55\% of PICs' population lives in non-urban areas, many of which face irregular access to transportation, telecommunication, markets, and imported goods and services (see regional map, Figure 1.3.1) (PRISM, 2010). The ratio of land to sea area for PICs varies between $0.003-2.45 \%$, which is indicative of the tremendous distances between islands and the resulting isolation (Maharaj, 1999).

Figure 1.3.1: Map of the Oceania region, including the North and South Pacific Islands.

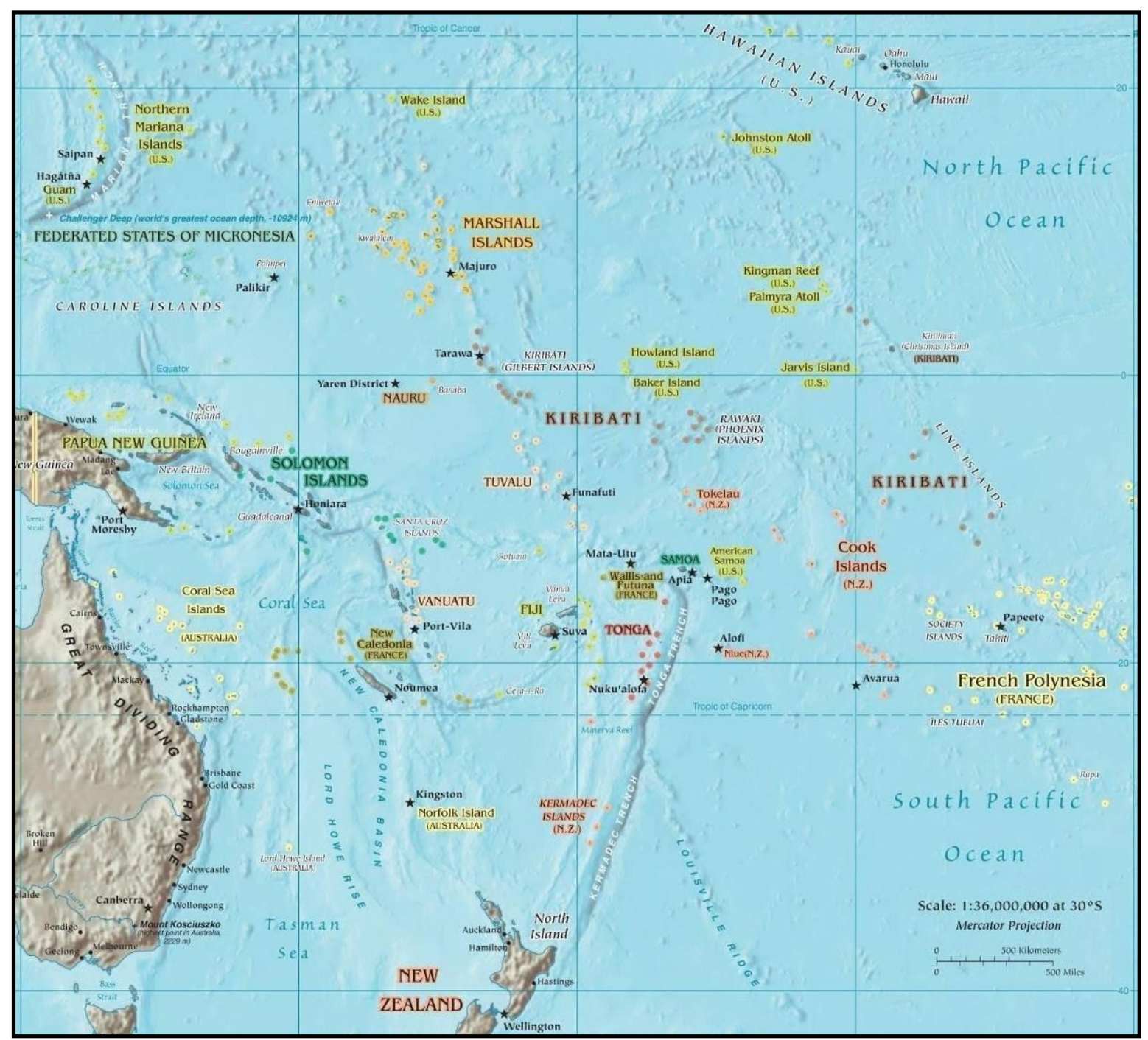

Source: CIA (2009). This map is part of public domain and may be copied without permission. 
Fossil fuel and electricity prices in both urban and rural areas in PICs are significantly higher than those of nearby developed countries (see Table 1.3.1), and development levels are significantly lower, with an average per capita income of $\$ 2,443$ regionally (see Table 1.1.1) (UNDP, 1999). Growing populations, coupled with changes in development levels and lifestyle requirements, have exponentially increased demand-side power consumption across the region, despite rapidly increasing fuel costs (UNICEF, 2009). The result has caused many to face fuel poverty, unreliable electricity, unpaid power bills, and disconnection of grid-tied electric supply. The rural regions are especially susceptible to fuel poverty, as fossil fuels' prices in such areas can be nearly double that of the already expensive urban prices (see Table 1.3.1). However, regional published data on average household energy expenditures is not available, and thus one can only estimate the percentage that fuel poverty affects.

Table 1.3.1: The Marshall Islands' and Vanuatu's retail fuel and electricity prices and those of nearby developed countries: the United States and Australia as of mid-2011.

\begin{tabular}{|l|l|l|l|l|}
\hline Country & $\begin{array}{l}\text { Petrol } \\
\text { (USD/litre) }\end{array}$ & $\begin{array}{l}\text { Diesel } \\
\text { (USD/litre) }\end{array}$ & $\begin{array}{l}\text { Kerosene } \\
\text { (USD/litre) }\end{array}$ & $\begin{array}{l}\text { Residential } \\
\text { electricity } \\
\text { (USD/kWh) }\end{array}$ \\
\hline RMI & $\begin{array}{l}\text { \$1.32 urban } \\
\$ 1.98 \text { rural }\end{array}$ & $\begin{array}{l}\text { \$1.27 urban } \\
\$ 1.72 \text { rural }\end{array}$ & $\begin{array}{l}\$ 1.32 \text { urban } \\
\$ 1.72 \text { rural }\end{array}$ & $\begin{array}{l}\$ 0.30-0.33 \\
\text { urban }\end{array}$ \\
\hline Vanuatu & $\begin{array}{l}\$ 1.93 \text { urban } \\
\$ 2.72-3.26\end{array}$ & $\begin{array}{l}\$ 1.89 \text { urban } \\
\text { rural }\end{array}$ & $\begin{array}{l}\$ 2.72-4.07 \\
\text { rural }\end{array}$ & $\begin{array}{l}\$ 0.44-0.70 \\
\text { urban }\end{array}$ \\
\hline US & $\$ 0.89-1.01$ & $\$ 1.00-1.03$ & $\begin{array}{l}\text { Not sold } \\
\text { regularly in } \\
\text { small } \\
\text { quantities }\end{array}$ & $\$ 0.11-0.12$ \\
\hline Australia & $\$ 1.35-1.47$ & $\$ 1.38-1.50$ & $\$ 0.12-0.25$ \\
\hline
\end{tabular}

Source: KUTh Energy Limited (2009); Origin Energy (2011); Personal Observation (May to September, 2011); USEIA (2011); Vanuatu's Energy Roadmap Launch (2011).

These electricity concerns, combined with rising food, fuel, and transportation costs, have the potential to contribute to an economic decline across PICs if not confronted in the near future (UNICEF, 2009). Virtual monopolies of fuel supply leave PICs additionally vulnerable to market changes. This is especially true as PICs' transport and electricity sectors rely on nearly $100 \%$ fossil fuels, and their imports as a percentage of GDP are increasing rapidly (see Table 1.3.2) (GEF Council, 2005; Jafar, 2000). 
Additionally, shortages in global fossil fuel supply are expected to further increase global oil prices, as it is estimated that a 40-60 year supply of proven oil and gas reserves remain (BP, 2009). Accordingly, energy security and autonomy are significant driving factors for reducing fossil fuel consumption and increasing the uptake of RE power generation in PICs.

Table 1.3.2: Fuel imports as a percent of GDP, in 2002 and 2008.

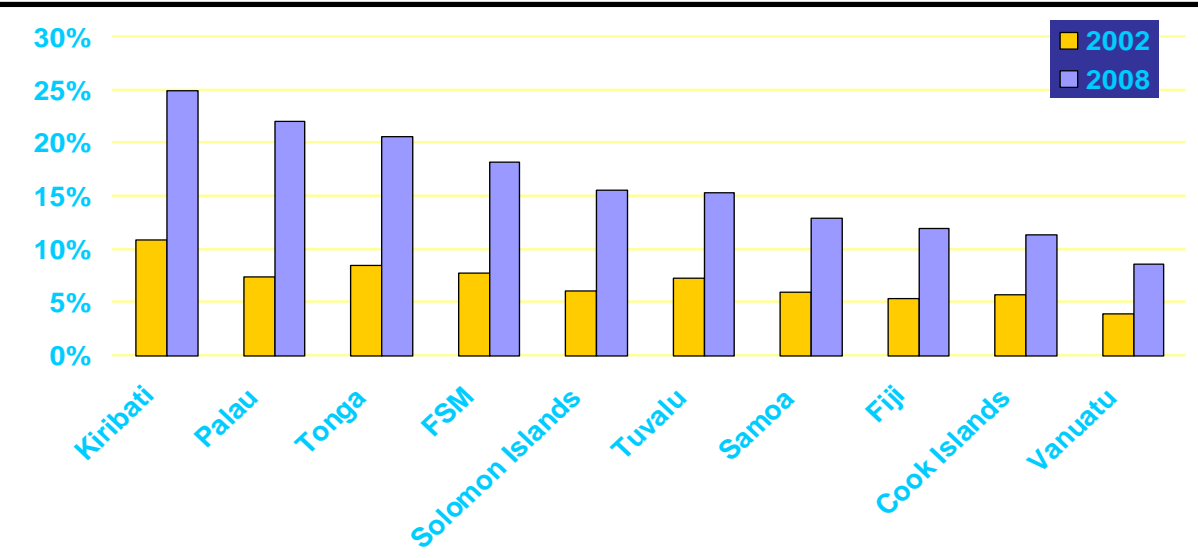

Source: Roper (2009)

\subsection{Renewable Energy Demand: Health, Poverty Eradication, and Climate Change}

Per capita energy consumption is closely linked to per capita GDP of PIC

economies, resulting in differing energy needs according to varying levels of development. Currently, many rural communities are reliant upon kerosene lanterns for lighting, and in some areas diesel generators for electricity, both of which are associated with negative health effects due to air pollution (Holdren et al., 2000). Furthermore, kerosene lanterns offer low efficiency and poor quality light, as they give off up to 100 times less light than electric lights (REN21, 2011).

Demand for RE in PICs is also driven by the underlying goal to meet the basic needs of the poor, and, therefore, rural electrification strategies must be considered in terms of the positive effects on marginalized groups. In the World Summit on Sustainable Development (WSSD), where the Millennium Development Goals (MDGs) were decided upon, energy services were identified as essential in poverty eradication, with RE being the most sustainable method of electrification. Electrification has been shown to reduce 
poverty through improved economic activity, literacy, education, healthcare, gender equality, and social benefits; however, these changes are often unpredictable and depend upon favourable conditions (Cabraal et al., 2005; Chakrabarti, 2002; Martinot et al., 2002).

Furthermore, the regional demand for RE for electrification is derived from PICs' extreme vulnerability to the effects of $\mathrm{CC}$, with increasing threats from sea-level rise and severe weather events, such as earthquakes, cyclones, floods, and droughts. The 2007 IPCC report predicts global sea levels to rise between 0.28 and 0.43 meters by 2100 , which would result in substantial yet unpredictable changes in PICs coastal areas due to the redistribution of sediment (IPCC, 2007; Webb \& Kench, 2010). These effects are likely to include saltwater inundation and flooding, deterioration of agriculture and mariculture viability, decline in coral reef health, damage to existing infrastructure, and depletion of small islands' freshwater lens (Mimura, 1999). Such changes threaten communities' livelihoods, and, therefore, sea-level rise poses a threat to PICs' economies and societies, and is likely to result in increased poverty (IPCC, 2007).

In contrast to their vulnerability, PICs do not have a significant carbon footprint, given their small population ( $0.1 \%$ of the global total) and minimal infrastructure. In fact, in 2007, energy usage in all of the PICs combined resulted in only $0.04 \%$ of global carbon dioxide $\left(\mathrm{CO}_{2}\right)$ emitted and only $0.08 \%$ of global petroleum consumed (USEIA, 2007). Therefore, reducing PICs' reliance on fossil fuels will not directly prevent the effects of $\mathrm{CC}$; however, the nations may be able to set an example for more industrialized countries to decrease their carbon emissions.

The 2009 Cancun Agreements under the UNFCCC included a number of key elements in relation to mitigation action by developing countries. These included encouragement to develop low-carbon development strategies (LCDS), and an agreement that developing countries will take nationally appropriate mitigation actions (NAMAs) aimed at achieving a reduction in GHG emissions relative to 'business as usual' emissions by 2020. LCDS and NAMAs present an opportunity for developing countries ('Non-Annex 1 Countries' in the UNFCCC lexicon) to attract climate change mitigation finance, rather than relying on more traditional official development assistance (ODA) financing for strategic development in the energy sector.

In the context of LCDS or NAMA development, enduring solar PV projects have the potential to reduce carbon emissions by displacing fossil energy generation, in 
particular fossil fuel-powered generators, electricity grids, and kerosene lanterns. This is because the lifecycle $\mathrm{CO}_{2} \mathrm{e}$ emissions released by solar $\mathrm{PV}$ to produce $1 \mathrm{~kW}$ of electricity are approximately $90 \%$ less than that released by fossil fuels to produce the same amount of electricity (Fthenakis et al., 2008; Sovacool, 2008). Similarly, the UK Parliamentary Office for Science and Technology (2006) calculated the 'carbon footprint' of solar PV to be approximately $35 \mathrm{~g} \mathrm{CO}_{2}$ per $\mathrm{kWh}$ of electricity at 30 degrees latitude, compared to 15-20 times as much for fossil fuels.

Yet, life cycle emission savings of SHSs for rural electrification can be hard to predict, as household energy demands often increase with the installation of a SHS; still, a net decrease in $\mathrm{CO}_{2}$ emissions is likely to occur given the significant disparity. Additionally, SHSs often replace the desire for rural households to use fossil fuel sources for their future energy needs (Wade, 2005a).

\subsection{Renewable Energy Supply: Technical Opportunities and Challenges}

Rapid growth of energy demand, regionally competitive RE prices in comparison with fossil fuels, the need for energy security, and the regional susceptibility to climate change makes RE technologies an ideal option for PICs. RE technologies have the potential to provide rural electrification while at the same time acting as a cleaner, more reliable, and cost-effective energy service (SPREP, 2010).

In the past two decades, solar PV systems have become the most widely adopted RE technology for rural electrification in PICs, due to the widespread availability of solar insolation and the flexibility in scale of the systems. In fact, the literature indicates that SHSs represent the most cost-effective technological option for remote communities in PICs and globally, where demand for electricity is low, the population is small, and fuel costs are high (Chaurey \& Kandpal, 2009; Nguyen, 2007; Woodruff, 2007). Furthermore, the price of solar modules has declined significantly over the past decade (see Figure 1.5.1), with prices having dropped by $20 \%$ for each doubling in cumulative production (Jol et al., 2008). Costs are forecasted to further decline over the next decade, creating a wider market for solar PV systems in PICs. 
Figure 1.5.1: Solar module price trends over the past decade.

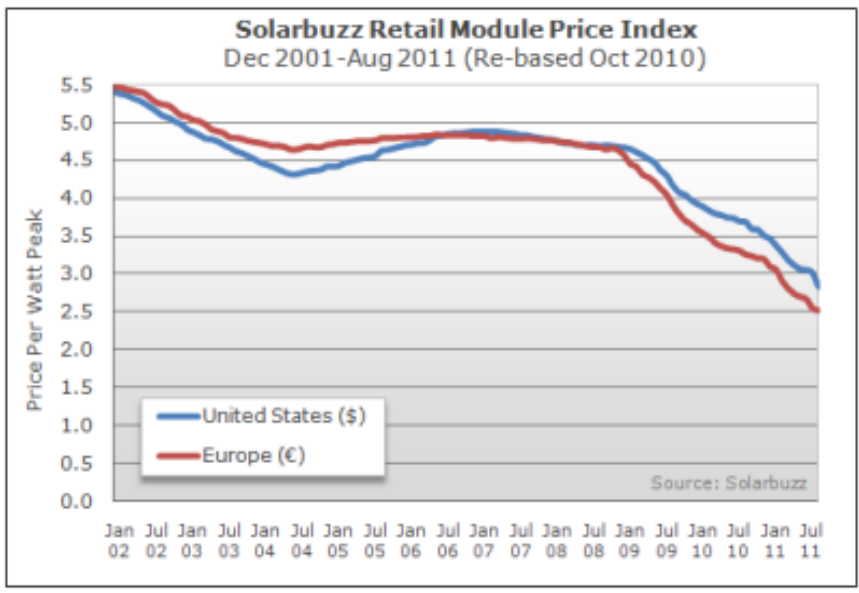

Source: Solarbuzz (2011).
Additionally, solar systems have become a more appropriate technology for rural electrification, with a large portion of the industry now designing systems with rural end-users in mind. For example, 'pre-wired,' 'plug-and-play,' or 'turn-key' systems are offered by numerous companies for smallscale lighting and mobile charging devices to battery charging stations to stand-alone micro-grids (see Figure 1.5.2). Many companies

are also now offering equipment specifically designed for harsh tropical and oceanic conditions, such as sealed inverters, anti-rust mounting frames, marine grade lights and wires, and maintenance-free batteries, resulting in more reliable solar equipment for PICs. With appropriate equipment, installation, and maintenance, solar PV systems can be expected to last 25-30 years, with the batteries requiring replacement approximately every 7-10 years (Lewis, 2007).

Figure 1.5.2: Examples of pre-wired systems designed for remote settings, from small to large scale.

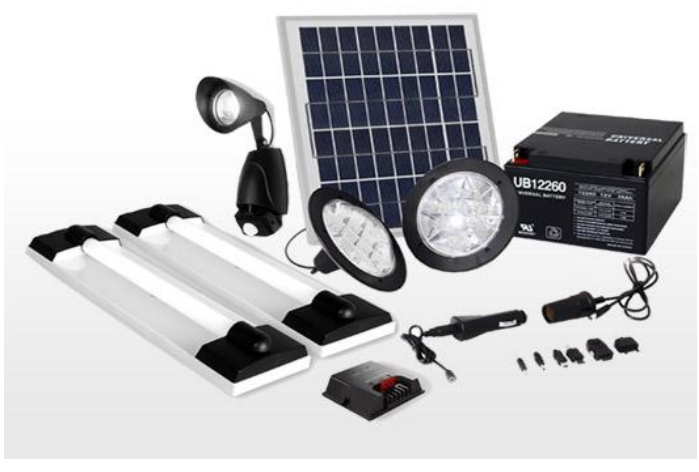

Source: Barefoot Power Limited (2011).

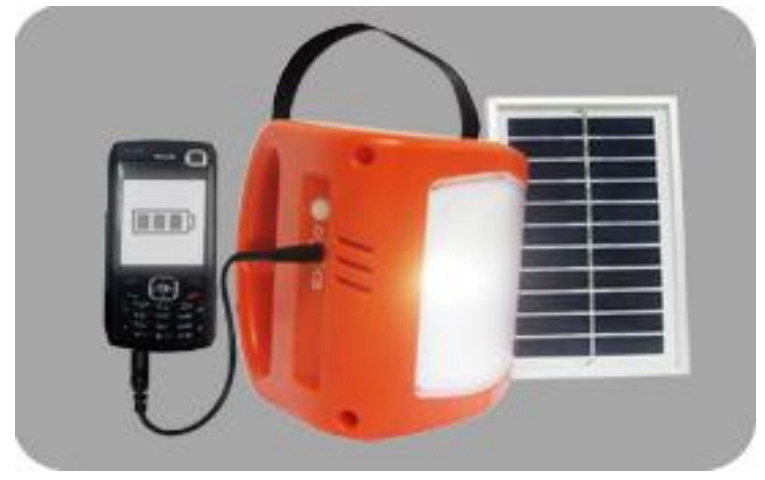

Source: D.lite design (2011). 


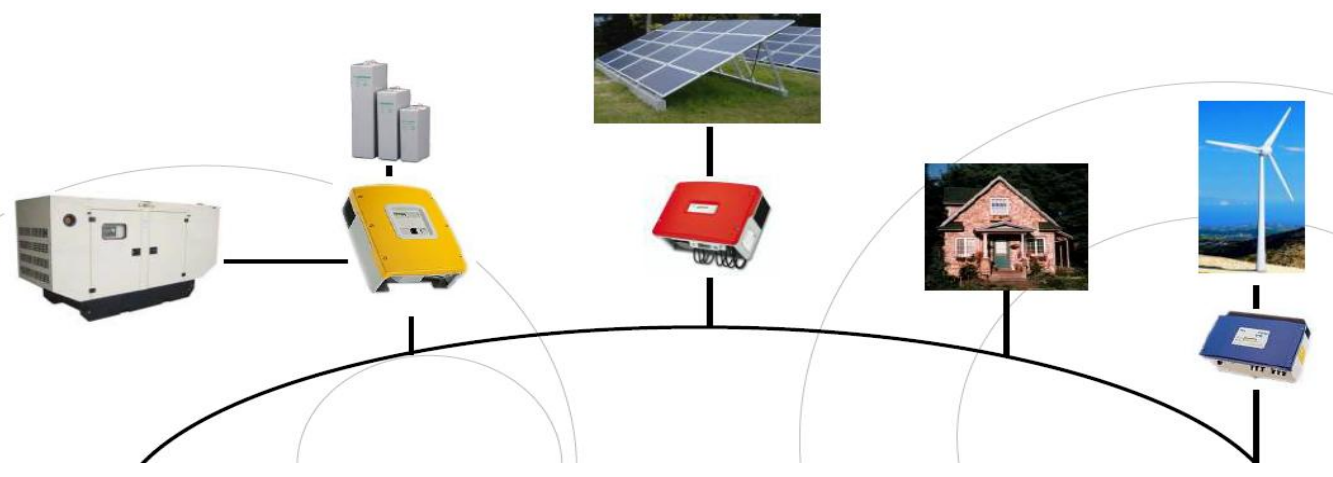

Source: Alphatron (2011).

Therefore, given solar PV's flexibility in scale and carbon offsetting qualities, as well as recent improvements in affordability, reliability, and user-friendliness, its usage has the potential to effectively contribute toward 100\% electrification of PICs. However, many PICs have a long way to go before reaching this goal. PICs' current economic and energy situations and the potential role of solar PV are summarized in Appendix 2.

\subsection{Renewable Energy Project Implementation: Socio-cultural Challenges}

Any electrification project to be implemented in PICs needs to be mindful of the socio-cultural context into which the technological solutions will be integrated. This context differs not only within each nation but also within each island and community, and thus it is necessary that project designers and implementers are familiar with the social and cultural dimensions of the beneficiaries. Despite these complexities, there are some general factors in the rural communities of both the RMI and Vanuatu that have implications for SHS project design (see Figure 1.6.1). Some factors may not hold true for all communities in Vanuatu and the RMI, yet it is obvious that there are a range of socio-cultural challenges that need to be met if technical solutions are to endure.

Figure 1.6.1: Suggested socio-cultural factors and solar PV project implications in rural Vanuatu and RMI communities. 


\section{Socio-cultural Factors}

Extended families often live near each other and share resources.

Local people are familiar with modern technologies and have experience with various electrical appliances, yet not necessarily a SHS.

Education levels and knowledge of the English language are limited for many people.

Women and men often have distinctly separate roles in society and do not regularly intermix in public.

In general women spend more time in the home, and are often the ones to look after children.

A large amount of aid has been given to both countries, with many products being

given for free or for

discounted rates.

Income is not generated on a regular schedule for farmers, fisherman, and handicraft makers, as work is seasonal and depends on access to markets.

\section{Many of the rural} communities have access to local food and building

materials, and thus a mixture of local and imported products are often used.

Many people have limited knowledge of bookkeeping and finances.
Solar PV Project Implications

- A solar system often provides power to more people than just those who live in the household.

- Solar systems that provide power for more than just lighting are often desired.

-Basic wiring is not new to many people.

-End-users would benefit from training specifically focused on SHSs.

- Training may not be sufficiently understood unless it is conducted in the local language and with the average educational level in mind.

-People may be more responsive to hands-on training.

-It is important that women and men are trained separately, preferably by a trainer of the appropriate gender.

- Electrical wiring is generally seen as a male task and thus some people may not be interested in women being trained in PV installation.

-Women use the SHSs' lights and appliances more often than men.

- Discounts may be expected for equipment.

- Beneficiaries do not have a high level of respect for donated items.

-End-users may have trouble making regular, timely payments.

-Although incomes are low in rural areas, the cost of living is also relatively low and can vary seasonally.

- The life-cycle cost of items may not be taken into account, and thus the cheaper upfront cost may be preferred.

- Extensive financial planning for the future is not a common practice, and thus people find it a challenge to save for large purchases. 
Higher income earners and

those with superior products,

opportunities, or power may be

regarded with jealousy.
-Paid local technicians, those who manage project money, and those with large SHSs may be disrespected or may face theft or vandalism.
A mimicking culture exists in

that once a new technology or

product is used successfully by

a few people in a community,

often many others will

purchase one too.

Having unique knowledge is

viewed as a secret and a way to

generate income.
- This can be advantageous for widespread dissemination of solar PV, in that once it is accepted and a minimum knowledge level is reached, locals are likely to desire a system themselves.

Many of these factors apply to other PICs as well, and need to be considered in addition to geographical, institutional, technical, and financial limitations for enduring SHS project design. However, socio-cultural factors are often overlooked in the regional literature, or are only briefly mentioned. One exception is an article by Sovacool et al. (2011), which effectively describes the socio-cultural challenges faced in Papua New Guinea (PNG), which are similar to those described above. They identified social barriers for SHS projects to be: unrealistic expectations about SHSs' capacity, jealousy, theft and vandalism, and unfamiliarity with the technology. Their interview results indicated that a SHS may not work one year later because "it is seen as belonging to everyone and therefore no-one" and there is a "complete lack of maintenance culture."

Sovacool et al. (2011) further described locals as "perpetually living in the present," with money not being part of their culture, as they are "just learning how to use it now." A survey in the RMI by Empower (2005) supports this, stating villagers were unaware of how much they spend on daily necessities, could not remember the ages of their parents or children, or how many years they had attended school. They suggest this is partly due to the unimportance of enumerating things in a semi-subsistence society. The authors conclude that poverty in PICs has a nature of its own, as it is not characterized by hunger and disease, but rather by isolation, low-education levels, communal living, lack of access 
to modern services, and lack of access to markets (Empower, 2005; Sovacool et al., 2011). Therefore, attempts to promote SHSs in PICs have suffered as a result of not appreciating the importance of such socio-cultural factors.

\subsection{Implications for this Thesis}

This thesis will examine the factors that are necessary to incorporate into SHS projects, in order to create project permanence in the rural communities of the RMI, Vanuatu, and other PICs, thus working toward creating more successful rural electrification programs in the region. The focus will be on the technical, financial, logistical, sociocultural, and environmental criteria for increasing the probability of project success, in terms of results for end-users. The results will have implications for the most compatible implementation strategies for PICs and other essential success criteria for project permanence. 


\section{Chapter 2: \\ Research Purpose and Aim}

\subsection{Research Focus: Rural PV Electrification Strategies}

\subsubsection{Variations in Electrification Models:}

Historically, rural electrification was considered the responsibility of the government in developing countries; however, this has been changing over the past few decades with the involvement of private companies, NGOs, and financing institutions (Vleuten et al., 2007). Consequently, multiple rural PV electrification strategies have been established in order to attempt to reduce the failure rate of energy projects, with two broad supply-side strategies commonly used with SHS projects in PICs (See Figure 2.1.1.1).

Figure 2.1.1.1: The common features of the RESCO and user-owned electrification models.

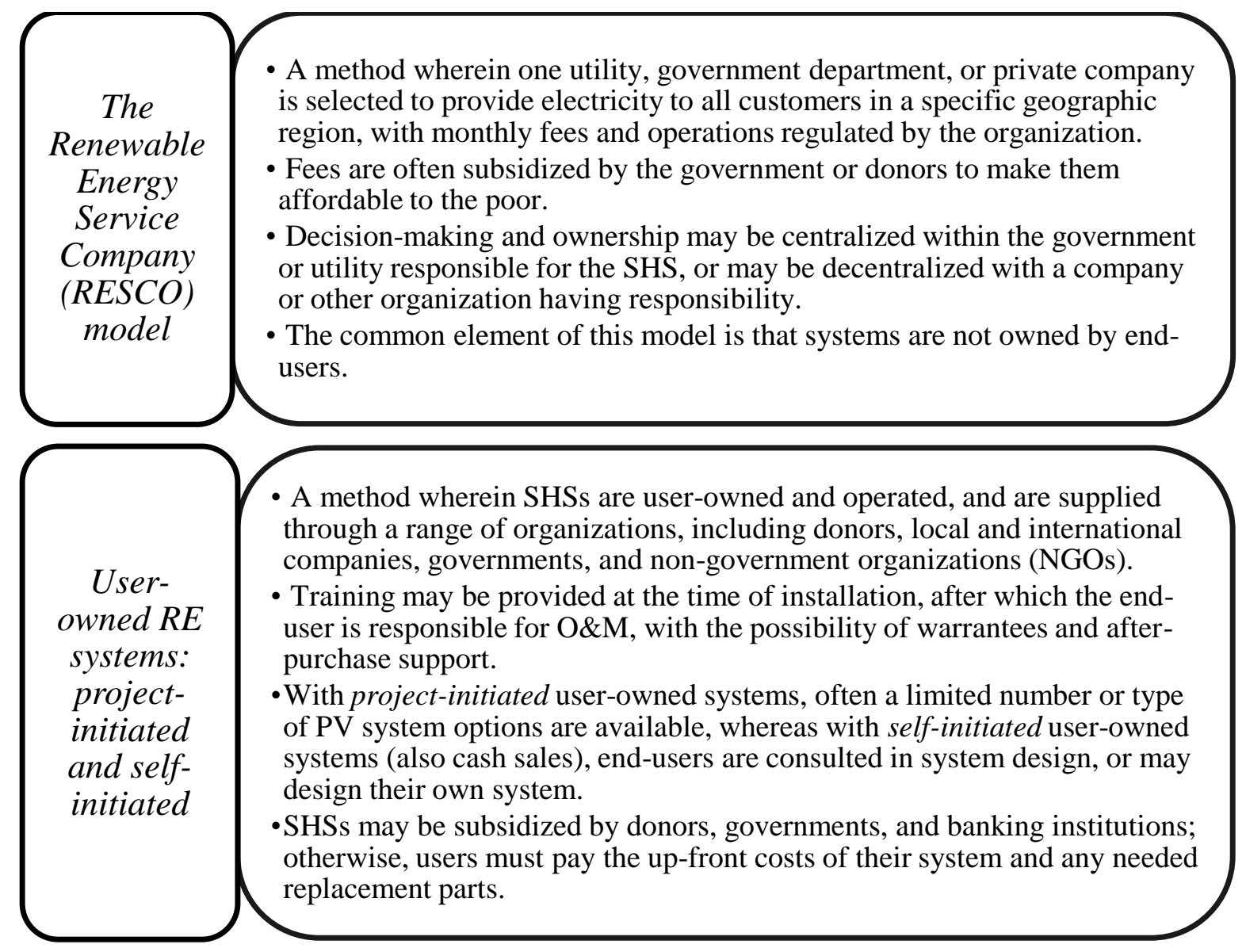


Given the variety of project initiators in both electrification strategies, a relevant query is whether rural electrification implemented by private companies and NGOs or by government utilities and donors (following the conventional approach) is more effective in the long-term (Ilskog, 2008). Another similar question is whether SHSs self-organized by end-users within the commercial market are more or less effective than those externally organized within a project framework. The differences between these two models are described in Figure 2.1.1.2.

Figure 2.1.1.2: A flow-chart demonstrating the differences between system procurement by private companies and project development through the government.

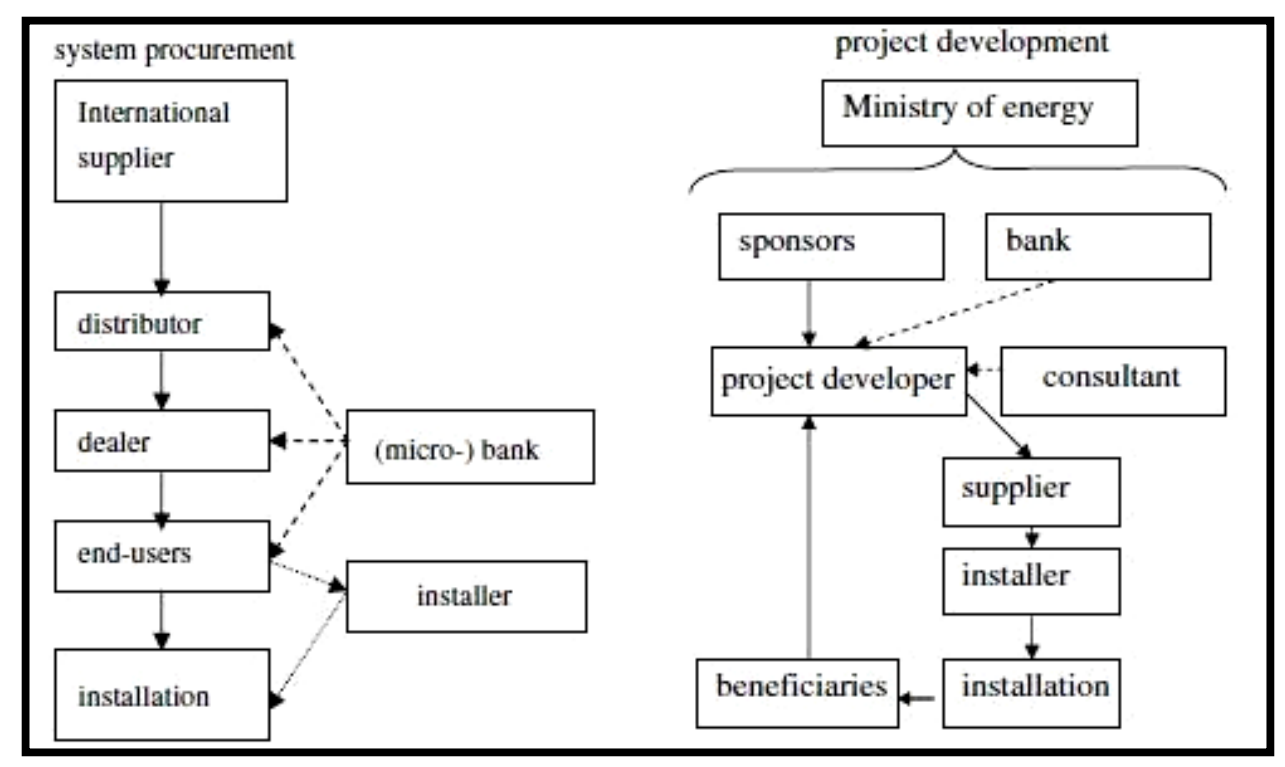

Source: Vleuten et al. (2007).

Both electrification models have benefits and limitations, with variations existing in order to adapt to local conditions and overcome negative consequences. Existing variations on the two overarching dissemination strategies can be seen in Table 2.1.1.1, although for reasons of comparative analysis, the two models will be the focus of this research. 
Table 2.1.1.1: A summary of the variations on the two implementation strategies, as cited in the literature.

\begin{tabular}{|c|c|c|c|c|c|c|}
\hline Models & Ownership & Initiator & $\begin{array}{l}\text { System } \\
\text { Design }\end{array}$ & $\begin{array}{l}\text { Financing/ } \\
\text { Subsidy }\end{array}$ & Installer & $\begin{array}{l}\text { Maintenance } \\
\text { and Repair }\end{array}$ \\
\hline $\begin{array}{l}\text { User- } \\
\text { owned: } \\
\text { Cash sales }\end{array}$ & End-user & End-user & $\begin{array}{l}\text { End-user } \\
\text { with the } \\
\text { aid of } \\
\text { solar } \\
\text { company }\end{array}$ & $\begin{array}{l}\text { None, or by } \\
\text { the end-user; } \\
\text { often must pay } \\
\text { tax }\end{array}$ & $\begin{array}{l}\text { End-user } \\
\text { or solar } \\
\text { company }\end{array}$ & $\begin{array}{l}\text { End-user or } \\
\text { solar } \\
\text { company }\end{array}$ \\
\hline $\begin{array}{l}\text { User- } \\
\text { owned: } \\
\text { Donation }\end{array}$ & End-user & Donor & $\begin{array}{l}\text { Donor } \\
\text { and } \\
\text { supplier/ } \\
\text { solar } \\
\text { company }\end{array}$ & $\begin{array}{l}\text { Donor, maybe } \\
\text { a small amount } \\
\text { by end-user, } \\
\text { no tax }\end{array}$ & $\begin{array}{l}\text { Supplier/ } \\
\text { solar } \\
\text { company }\end{array}$ & End-user \\
\hline $\begin{array}{l}\text { User- } \\
\text { owned: } \\
\text { Credit }\end{array}$ & End-user & Varies & Varies & $\begin{array}{l}\text { Donor, } \\
\text { financing } \\
\text { institution, } \\
\text { supplier, or } \\
\text { solar company }\end{array}$ & Varies & Varies \\
\hline $\begin{array}{l}\text { RESCO: } \\
\text { Fee-for- } \\
\text { service }\end{array}$ & $\begin{array}{l}\text { Renewable } \\
\text { Energy } \\
\text { Service } \\
\text { Company } \\
\text { (private) }\end{array}$ & RESCO & RESCO & $\begin{array}{l}\text { Fee-for- } \\
\text { service, often } \\
\text { aided by } \\
\text { donors and } \\
\text { financing } \\
\text { institutions }\end{array}$ & RESCO & $\begin{array}{l}\text { RESCO, } \\
\text { sometimes } \\
\text { train local } \\
\text { technicians }\end{array}$ \\
\hline $\begin{array}{l}\text { RESCO: } \\
\text { Concession }\end{array}$ & $\begin{array}{l}\text { Government } \\
\text { utility } \\
\text { RESCO }\end{array}$ & RESCO & RESCO & $\begin{array}{l}\text { Fee-for- } \\
\text { service, often } \\
\text { aided by } \\
\text { donors } \\
\text { channelled } \\
\text { through the } \\
\text { government }\end{array}$ & RESCO & $\begin{array}{l}\text { RESCO, } \\
\text { sometimes } \\
\text { train local } \\
\text { technicians }\end{array}$ \\
\hline
\end{tabular}

Sources: Martinot et al. (2002); Nieuwenhout et al. (2001); Vleuten et al. (2007); Wade (2005a).

\subsubsection{Differences in the Electrification Strategies:}

The general aim of the RESCO strategy is to remove the high initial costs associated with solar PV systems and to make spare parts and technicians readily available (Beck \& Martinot, 2004). Thus, this policy is useful in that costs are dispersed over time, yet such programs have not always been beneficial in PICs, as a tendency of failure to make payments and to misuse SHSs have often hindered success (see Chapter 5) 
(UNESCAP, 2001). In part, this is due to inadequacies on the supply-side, where availability of support, spare parts, and timely maintenance has been an issue, due to inadequate infrastructure, poor planning, and lack of resources (Dornan, 2011).

The use of this model avoids the need for extensive user education, as users are not responsible for maintaining or repairing the system. In fact, this strategy often aims to make the SHS inaccessible to end-users in order to prevent mistreatment, with only the utility's technician having access to the PV equipment; yet alterations and abuse still frequently occur. Consequently, RESCOs hinder user participation and ownership of the SHS, in that end-users are not able to design or expand their systems with changing energy demands, nor are they able to maintain and repair the systems as required (Mala et al., 2008).

In contrast, the user-owned strategies include varying degrees of owner participation; yet generally users are consulted in the design process and some form of training takes place. Thus, through this model, end-users are given ownership over their SHS, and they are often able to expand, repair, and maintain their system as required. In fact, private ownership has been shown to "reduce maintenance costs, overcome tampering, reduce overuse of the system, and maximize the benefits" (Urmee \& Harries, 2009).

However, many user-owned systems implemented in the 1980s and 1990s in PICs had a high failure rate due to:

- Lack of a long-term O\&M plan

- Maintenance costs being left unaddressed

- Lack of access to spare parts

- Training being inadequate or overlooked

- Project implementers being overly optimistic about the skills and reliability needed for system longevity

- Project objectives not being clearly defined in terms of social benefits and productive users

(Akker, 2006; Jafar, 2000; Urmee et al., 2009)

Many of these inadequacies were attributed to the electrification strategy, and resulted in the assumption that users were not able to successfully own and maintain a SHS (Jafar, 2000; Liebenthal et al., 1994). 
Yet, factors involved in implementing successful user-owned SHSs have changed over time, including:

- Local technological knowledge and familiarity with solar PV has significantly increased

- Solar training resources have been improved (including in local languages)

- Solar PV technicians and organizations now have extensive regional experience

- Government and donor support for RE has increased due to external factors

- PV equipment has improved in quality, affordability, and user-friendliness

- Spare parts are more consistently available due to larger markets ${ }^{4}$

(RMI Entrepreneur, Respondent 3, 2011; SPC, Respondent 4, 2011).

Nevertheless, user-owned SHSs have been predominantly overlooked in recent PIC electrification projects, despite continual recommendations in the literature for increased participation, training, and projects centred on community energy needs (Beck \& Martinot, 2004; Urmee \& Harris, 2009; Yu et al., 1996). Rather, the primary electrification strategy in PICs continues to be RESCO projects, and is the recommended mode of delivery by many national and regional PIC organizations (RMI-ESP, Respondent 2, 2011; SPC, Respondent 4, 2011).

\subsection{Electrification within the Development Context}

The RESCO model and the self-initiated user-owned model represent two ends of the participatory development spectrum, with the former being a 'top-down' approach, by curtailing users' involvement in their system design and maintenance, and the latter being a 'bottom-up' approach, with users' needs being central. The project-initiated user-owned model falls within these two extremes, with all three representing a range of participatory practices, as demonstrated by Arnstein's ladder of citizen participation, wherein each rung corresponds to the extent of citizen participation (see Figure 2.2.1).

The consensus in the literature on development practices suggests that ideally the level of participation and ownership in development projects should be in the upper levels of the ladder with 'partnership', 'delegated power' or 'citizen control.' Yet, pragmatically,

\footnotetext{
${ }^{4}$ The last two bullet points are described in detail in Chapter 1.
} 
full participation and project ownership by RE users often becomes cumbersome to project implementers, as such practices are both costly and timely. Thus, it becomes useful to understand the threshold of diminishing returns, beyond which participatory and ownership practices are no longer effective in increasing project permanence.

Figure 2.2.1: A Ladder of Citizen Participation.

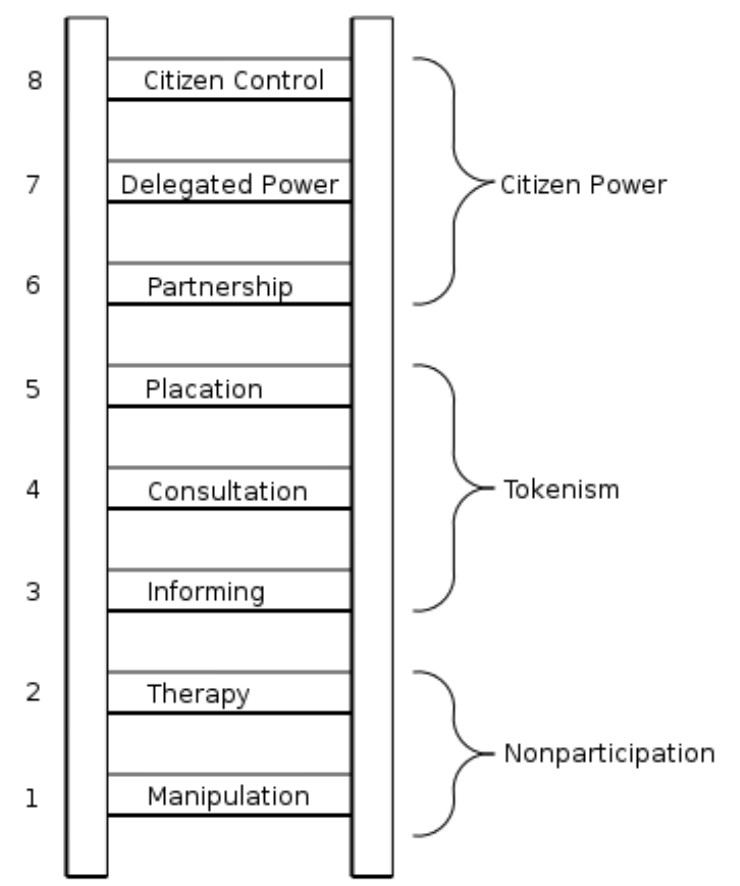

Source: Arnstein (1969).

\subsection{Relevance of this Thesis}

The essential practices and strategies for successfully electrifying rural PIC communities with SHSs provide the foundation for this research, which tests the hypothesis that increasing the usage of participatory and ownership practices through a user-owned electrification model currently has the potential to increase project permanence as a result of properly addressing users' needs. Additionally, this research will help to address the gap in the literature on PICs regarding rural electrification through user-owned SHSs, as little information is available on the success of this model in the region. By providing 
recommendations for essential practices and electrification strategies, future project failure may be reduced through the use of more appropriate project design and consideration of users' needs. In order to make such conclusions transparent, a framework for mitigating risks and increasing the longevity of PIC electrification projects was developed.

Reducing SHS failure is imperative for rural users, especially for women, who are the primary users of electrical appliances, as much of their responsibilities are within the home. Furthermore, environmental benefits increase with project permanence, as future $\mathrm{CO}_{2}$ emissions are avoided and PV batteries and other equipment are not discarded unnecessarily. Enduring project outcomes are also advantageous for project development, implementation, and funding entities, as they are able to gain reputational benefits from successful projects, and maximize return on investments.

In fact, performance-based funding is becoming increasingly common in donor and government-funded projects, with funds being released over time, based on the demonstration of having met key performance indicators, in order to reduce nonpermanence risk. Consequently, non-permanence risk has become a key consideration in project design by governments, utilities, public and private sector funding agencies, carbon project designers operating under the Clean Development Mechanism (CDM) of the Kyoto Protocol, and for voluntary carbon markets. Therefore, an evaluation of the key practices and strategies for rural electrification of PICs is desirable by multiple stakeholders.

\subsection{Aim of this Thesis}

The aim of this research is to answer the following question: "What are the most important technical, economic, institutional, socio-cultural, and environmental criteria for increasing the probability of success and longevity of household-scale solar PV initiatives in remote Pacific Island settings?" The intention is to suggest appropriate electrification strategies and essential practices for project permanence in PICs, through a project riskmitigation framework that aims to reduce project failure. 


\subsection{Research Objectives and Questions}

Objective 1: To define a comprehensive set of indicators for evaluating rural SHS projects' ability to meet users' needs and produce enduring outcomes, through reviewing the global literature on evaluation indicators, barriers, and success factors for rural RE electrification projects in developing nations.

Research Questions:

1. What does the literature suggest as indicators for evaluating rural RE electrification projects in developing countries? What is the resulting compilation of these indicators that are relevant for this research (in that they apply to PICs and focus on results for end-users)? (Section 3.2)

2. What are the major barriers cited in the literature for rural electrification through solar PV? (3.3)

3. How do the barriers that directly impact end-users apply to each evaluation indicator, and what are the recommendations in the literature to overcome them?

4. What are the overall success factors for project longevity, as recommended in the literature? (3.5)

Objective 2: To determine the success rate of user-owned and RESCO SHS projects, through examining the strengths and weaknesses of electrification strategies implemented in PICs and globally, with the findings assembled into a set of lessons learned for each indicator, as a way to guide solar PV project rollout in PICs.

\section{Research Questions:}

1. What variations on the two overarching electrification strategies have been attempted internationally, and which has proven to be the most successful for remote communities in developing countries? (5.1) 
2. What variations on the three overarching electrification strategies have been attempted in PICs, and what are the positive and negative effects of each model? (5.2)

3. What electrification strategies have been attempted in the RMI and Vanuatu, and what is the current context into which the case studies examined fit? (5.3 and 5.4)

4. Which indicators could be considered keystones to producing enduring benefits for users in PICs, and which indicators are often overlooked by projects? (5.5)

5. What are the strengths and weaknesses of each electrification model in addressing each indicator in project implementation? (5.5)

6. What are the lessons learned that can be derived from an analysis of PIC project documents? (5.6)

Objective 3: To evaluate the success rate of two existing household solar PV case studies in the RMI and Vanuatu, through utilizing the indicators developed in Objective 1.

\section{Research Questions:}

1. What are the strengths and weaknesses of each case study as analysed in terms of the incorporation of the evaluation indicators? (6.1)

2. How do the case studies compare with each other? (6.1)

3. What implications do the case studies have for appropriate electrification strategies in these locations and in other PICs? (6.2)

4. Which indicators have been crucial in producing enduring benefits for end-users and which, when omitted, have hindered project success? (6.2)

Objective 4: To determine the viewpoints of solar PV project stakeholders and experts in the RMI and Vanuatu on the essential factors for project permanence, focusing specifically on their opinions of appropriate electrification strategies and key criteria that result in enduring benefits for users. 


\section{Research Questions:}

1. What key features have the stakeholders identified that result in enduring benefits for users by indicator, and what are the best ways to implement these features in their opinion? (7.1)

2. What are the beliefs of the stakeholders regarding the most effective electrification strategies and the most essential criteria for project permanence?

3. What are the lessons learned that can be applied to future PV project development and electrification in the RMI, Vanuatu, and other PICs in order to reduce project failure? (7.3)

\subsection{Structure of the Thesis}

Chapter 1: The introduction, which presented an overview of the Pacific Islands' energy context and the benefits of electrification through SHSs.

Chapter 2: The rationale, the purpose, the objectives, and the corresponding research questions.

Chapter 3: The literature review, in which a set of evaluation indicators for rural RE projects is developed and discussed.

Chapter 4: The methodology, which presents the research approach, the data collection methods and locations, and data analysis strategies.

Chapter 5: The document analysis, which analyses SHS project reports published on the various electrification methods, through the evaluation indicators developed.

Chapter 6: The research results and analysis of the quantitative data collected from two solar PV case studies in the RMI and Vanuatu.

Chapter 7: The research results and analysis of the qualitative data collected from experts and stakeholders involved in solar PV projects in the RMI and Vanuatu.

Chapter 8: The discussion, which discusses key findings and presents a project risk mitigation framework for solar PV project design.

Chapter 9: The conclusions on essential practices and appropriate electrification strategies for SHS project endurance in the RMI, Vanuatu, and other PICs. 


\section{Chapter 3: \\ A Review of the Literature on Indicators, Challenges, and Successes}

\subsection{Overview}

Although both the direct and indirect benefits of SHSs have been well-documented in the short-term, the long-term benefits, in terms of sustainable development for users, remain unforeseen in PICs and to a large extent globally (Mala et al., 2008; Nieuwenhout et al., 2001). In fact, most rural SHSs in PICs have not been evaluated in terms of the appropriateness of the technology or its long-term effects on beneficiaries, nor have there been extensive comparisons between the various electrification strategies and their contribution to project permanence (Ilskog, 2008; Mala et al., 2008). Rather, the literature has generally focused on identifying the numerous barriers, technical options, and donor experiences for RE technology rollout in PICs, with a focus on recommendations at the national and regional levels. This chapter will first identify indicators that can serve to evaluate long-term project success, then cite the multiple barriers and experiences that have been identified in the global literature based on the indicators, and finally compile a list of success factors for rural electrification project permanence.

\subsection{Indicators for RE Project Evaluation}

Systematic evaluations of RE project implications in both the short and long-term would be helpful to further understand the effects on beneficiaries (Nieuwenhout et al., 2001). Evaluation indicators have the potential to create an understanding of the strategies and methods that make solar PV projects sustainable in the long-term. This can result in reduced program costs and project longevity, through more appropriate technology use, financing schemes, maintenance strategies, and compatibility with the socio-cultural context (Ilskog, 2008). In addition, indicators can lead to an improved understanding of the changing needs of rural electrification over time.

The use of indicators for evaluating rural electrification has been rare, with a few exceptions in the literature. Lists of indicators have been developed by different organizations, such as the World Bank (WB), the International Energy Agency (IEA), the 
International Atomic Energy Association (IAEA), and the Energy Sector Management Assistance Program (ESMAP); however, these indicators are often general in design, do not always apply to PICs, and often are aimed at the national and regional levels rather than addressing the local context (Ilskog, 2008).

Indicators have been developed in the literature on rural electrification by the following:

- Ilskog (2008), who created thirty-six indicators for sustainability evaluations of projects worldwide (see Appendix 3).

- Mala et al. (2008), who developed five indicators (suitability, effectiveness, livelihood resilience, livelihood diversification, and environmental protection) to evaluate the contribution of projects towards sustainable livelihoods.

- Chow (2010), who applied social, economic, and environmental sustainability indicators to various stages of project life-cycles (see Appendix 4).

- The World Bank (2003), who developed indicators for project evaluations by donors.

- Yu et al. (1997), who developed a framework for RE policy-making.

- Urmee \& Harries (2009), who formulated indicators for evaluating project implementing agencies based on research in the Asia-Pacific region (see Appendix 5).

Indicators were then applied to evaluate projects by Chow (2010); by Ilskog \& Kjellstrom (2008); by Urmee \& Harries (2009); by the World Bank (2003); and by Yu et al. (1997). Factors for evaluating projects' results for end-users were also used by Mala et al. (2009) and Urmee et al. (2009), with a focus on the Pacific region, yet these factors were not designed to be comprehensive.

Many of the indicators cited are focused on the implementing institution and the compatibility at the national level (Ilskog, 2008; Urmee \& Harries, 2009; World Bank, 2003; and Yu et al., 1997). Furthermore, the compatibility of projects with the sociocultural aspects of beneficiaries is generally overlooked, with Chow (2010) and Yu et al. (1997) being the major exceptions. Thus, there is a noticeable gap in the literature regarding comprehensive indicators for evaluating the effects of electrification on 
beneficiaries in PICs. Still, previously developed indicators provide a strong basis for formulating such evaluation indicators.

Table 3.2.1 attempts to compile those indicators previously cited in the literature, with the incorporation of cultural factors and a focus on results for end-users in PICs, in order to formulate indicators appropriate for evaluating the case studies examined in this research (addressing Research Objective 1). End-users are focused on, as it is essential to analyze the importance of energy services to end-users, given that this is the key focus of all rural electrification projects (Vleuten et al., 2007). Each indicator is designed to address the factors which may potentially lead to project disruptions and collapses (Ilskog, 2008). They include an evaluation of the technical, economic, and institutional sustainability of the project, the accessibility of the project by most social groups, the cultural compatibility, and the impact on other sectors, such as education or the environment.

Table 3.2.1: Evaluation indicators for case-study evaluation, compiled from the cited literature.

\begin{tabular}{|c|c|c|}
\hline Categories & Description & Evaluation Indicators \\
\hline Technical & $\begin{array}{l}\text { Focus on maintaining energy } \\
\text { services during the system's } \\
\text { lifespan through appropriate } \\
\text { equipment use, effectiveness, and } \\
\text { expansion. }\end{array}$ & $\begin{array}{l}\text { 1. Appropriate equipment use } \\
\text { 2. Effectiveness in meeting } \\
\text { users' needs } \\
\text { 3. Ability to satisfy expanding } \\
\text { energy demands }\end{array}$ \\
\hline Economic & $\begin{array}{l}\text { Focus on the appropriateness of the } \\
\text { system's cost, including subsidies, } \\
\text { operational costs, and parts } \\
\text { replacement. }\end{array}$ & $\begin{array}{l}\text { 4. Cost-effectiveness } \\
\text { 5. Effectiveness in changing } \\
\text { community livelihoods }\end{array}$ \\
\hline Institutional & $\begin{array}{l}\text { Focus on quality and the ability of } \\
\text { the organization/ project to offer } \\
\text { training and support to end-users for } \\
\text { the lifespan of their systems. }\end{array}$ & $\begin{array}{l}\text { 6. Availability of resources and } \\
\text { support } \\
\text { 7. Availability of system } \\
\text { components } \\
\text { 8. Capacity building }\end{array}$ \\
\hline$\overline{\text { Social }}$ & $\begin{array}{l}\text { Focus on equitable distribution of } \\
\text { the benefits offered by } \\
\text { electrification, and the societal } \\
\text { familiarity with technology. }\end{array}$ & $\begin{array}{l}\text { 9. Gender inclusiveness } \\
\text { 10. Affordability } \\
\text { 11. Familiarity with the } \\
\text { technology }\end{array}$ \\
\hline Cultural & $\begin{array}{l}\text { Focus on the compatibility of the } \\
\text { project within the cultural context, }\end{array}$ & $\begin{array}{l}\text { 12. Participation and ownership } \\
\text { 13. Willingness to pay }\end{array}$ \\
\hline
\end{tabular}




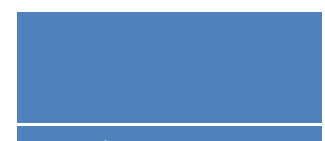

Environmental which may help or hinder the project's success.

Focus on how the project positively or negatively affects the environment.
14. Effectiveness in improving the environment

\subsection{Barriers for Rural Electrification}

The barriers as noted in the literature have been summarized into the categories of the indicators in Figure 3.3.1, with the addition of political barriers, which are focused at the national level. Some of these barriers are the responsibilities of governments, donors, financial institutions, and RE dealers to overcome, such as a need for: government policies which reflect the true cost of RE; policies supporting the use of appropriate RE technologies; long-term energy research and project support; and capacity building in the public and private sectors. Others are due to the nature of PICs, such as small markets, rural isolated communities, harsh environmental conditions, limited infrastructure, and expensive transportation costs, which affect all sectors. These barriers vary in intensity across the Pacific Island region and from urban to rural areas (Painuly, 2001). Those barriers relevant to this research, in that they directly affect end-users, are in bold in Figure 3.3.1 (while all the barriers indirectly affect end-users). The bolded barriers are described in section 3.4 according to the indicators, along with related experiences and successes that have been referred to in the literature. 
Figure 3.3.1: Barriers cited in the literature for rural RE electrification of PICs. Barriers which directly affect end-users are in bold.
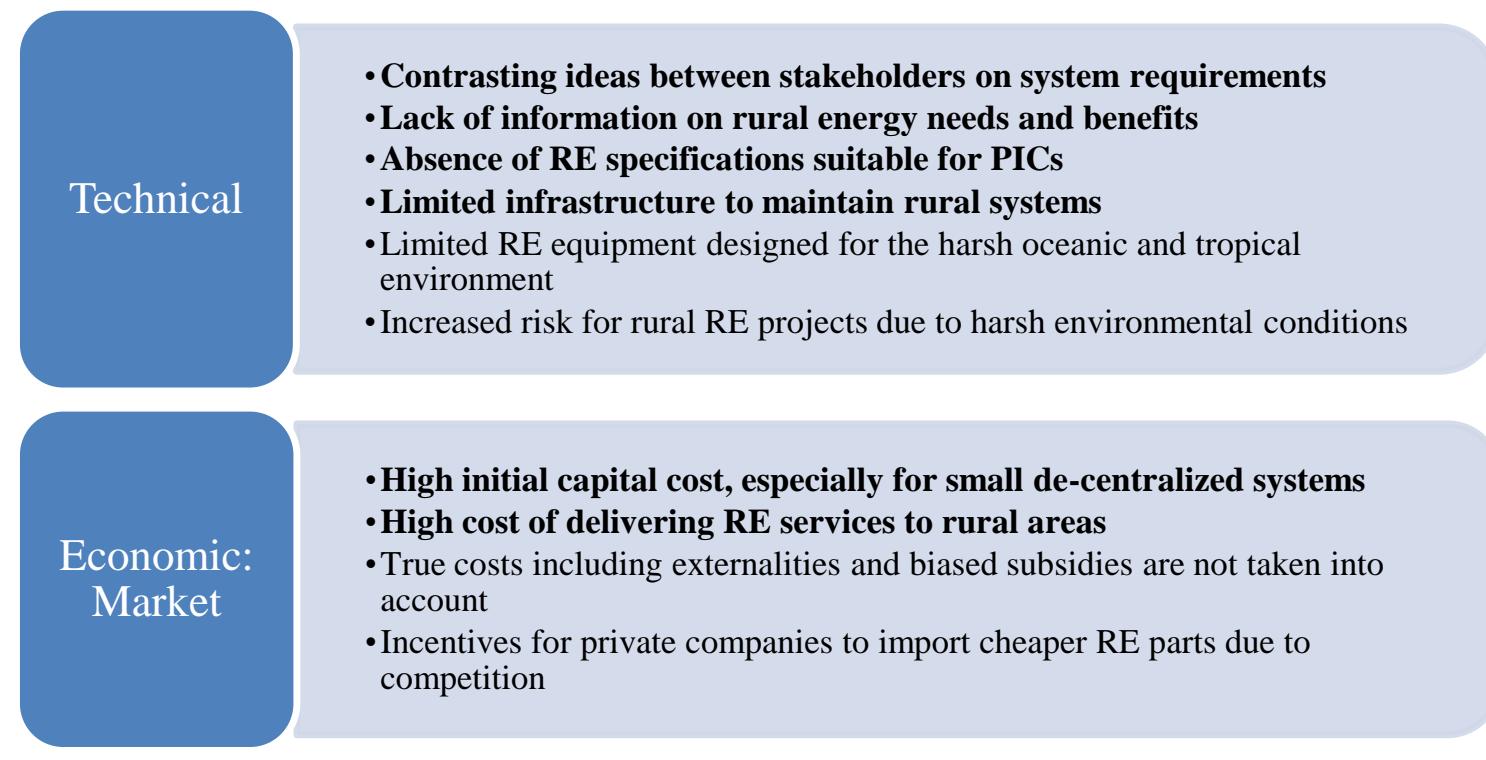

-High initial capital cost, especially for small de-centralized systems

- High cost of delivering RE services to rural areas

- True costs including externalities and biased subsidies are not taken into account

- Incentives for private companies to import cheaper RE parts due to competition

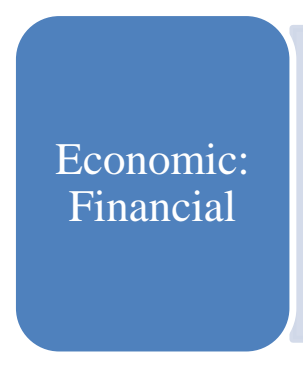

- Lack of access to credit for both consumers and investors

- Difficulty in estimating the benefits of RE for income generation

- High rates of poverty amongst rural users

- Lack of confidence by investors in RE projects

- Difficulty in estimating future fuel-price risk

- Over-dependence on donor funding

- Donor funding often for short-term projects

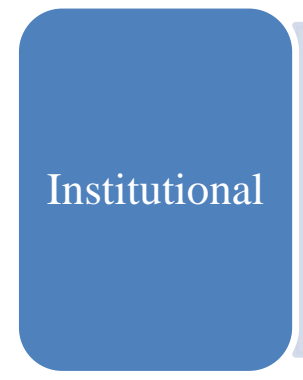

- Lack of focus on the long term benefits to users due to institutional deadlines

- Limited capacity for research and training

- Limited RE equipment available in rural areas

- Lack of government, private, and rural expertise for installation and maintenance of $\mathbf{R E}$

- High turnover of technical personnel

- Lack of co-ordination between RE stakeholders

Social

- Inadequate or lack of public awareness campaigns

- Lack of focus on women and low-income groups

- Lack of trust and understanding of RE technologies

- Lack of knowledge in rural areas regarding financing 


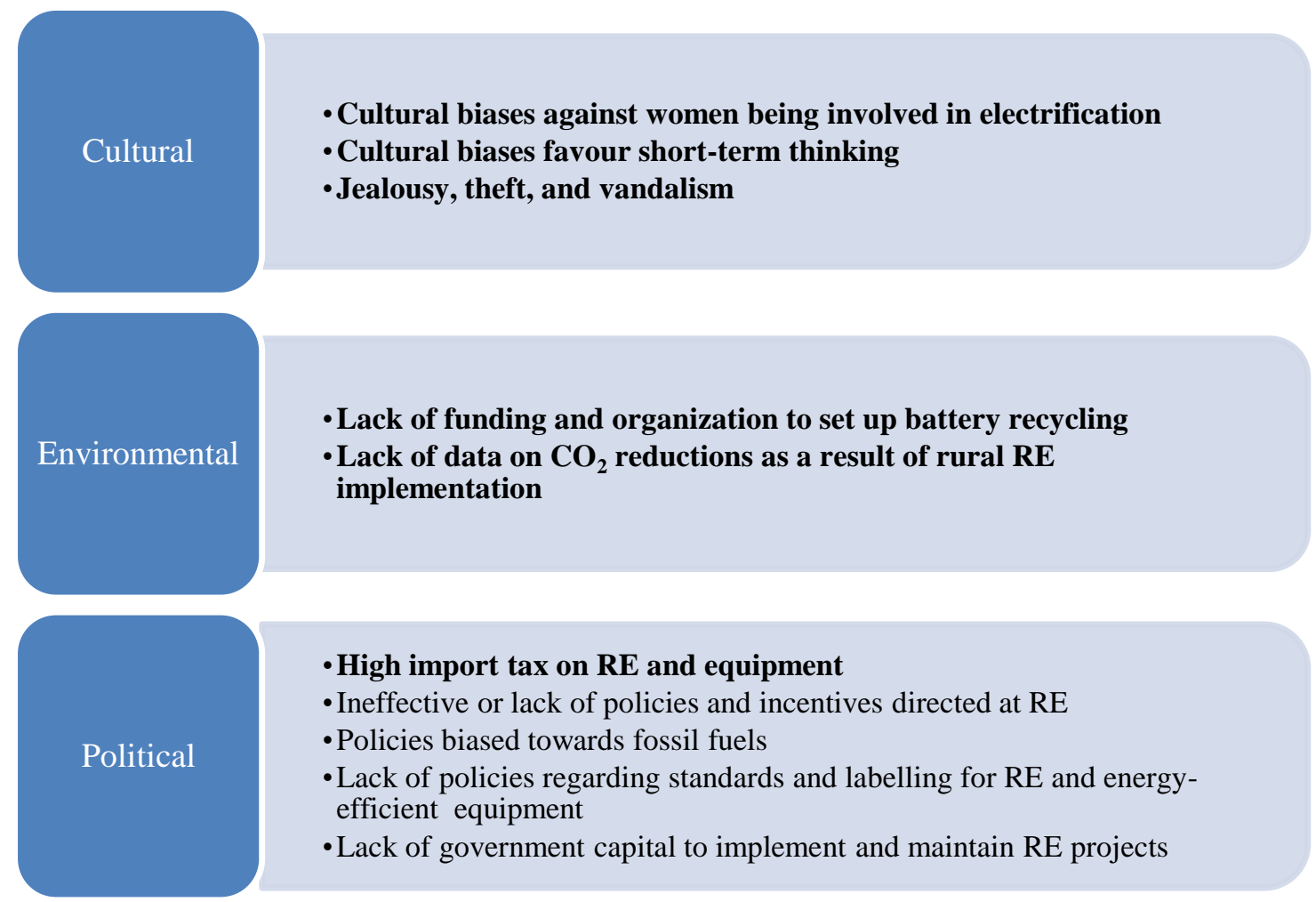

Sources: Akker (2006); Beck \& Martinot (2004); Jafar (2000); Martinot et al. (2002); Painuly (2001); Sovacool et al. (2011); Urmee et al. (2009); Urmee \& Harries (2009); van Alphen et al. (2008); Vanuatu's Energy Roadmap Launch (2011); Wade et al. (2004); Yu et al. (1997).

\subsection{Barriers and Recommendations for Each Indicator}

\subsubsection{Technical Indicators:}

\section{Appropriate equipment use:}

Although allowing end-users to choose the best electricity solutions for their needs has been reported as a success factor, this is rarely the case in SHS projects that are externally driven (Urmee et al., 2009; Vleuten et al., 2007). Barriers to appropriate equipment use include contrasting values between donors, governments, and other international organizations, who often believe the highest quality equipment is necessary in order to ensure longevity, as compared to RE companies and end-users, who are more concerned about its functioning adequately and its cost.

Yet, quality control is essential as consumers lack knowledge regarding quality RE equipment, and some entrepreneurs will try to cut costs by selling poor or faulty equipment 
and not providing after-sales service (Urmee \& Harries, 2009; Vleuten et al., 2007). Poor quality parts, poor installation and maintenance, and systems being sold by imparting unrealistically high expectations to users all have been cited as barriers to project success and durability (Martinot \& Reiche, 2000). Thus, equipment standards and certifications for dealers, as well as after-sales service and education of consumers, are necessary to ensure appropriate project design. The Sustainable Energy Industry Association of the Pacific Islands (SEIAPI), created in 2009, was designed with this issue in mind, and has been working to standardize installation and equipment standards, and train RE stakeholders around PICs.

\section{Effectiveness in meeting users' needs:}

It has been noted that an objective assessment of users' needs, as well as various design options for solar PV projects, is often absent (Jafar, 2000). Urmee \& Harries (2009) support this claim through a survey that indicates that project designers rarely base their programs on lessons previously learned or on specific benefits for end-users, despite a consensus of their value in the literature. For example, user choice in SHS size is often very restricted in donor-funded projects, and the focus is mainly on providing lighting, whereas many end-users have reported other services, specifically television and mobile charging, to be as much if not more of a priority (Nieuwenhout et al., 2001). Yet, adequate data on end-user priorities and preferences are often absent, and many project designers are unable to obligate the time or funds to carry out an analysis of end-user priorities and preferences, despite data that shows that doing so increases a system's reliability, lifespan, and overall benefits (Urmee et al., 2009). Sovacool et al. (2011a) suggests an alternative, in that projects should provide options of solar lanterns and a range of SHS sizes in order to allow the benefits to be both affordable and based on users' needs. Fortunately, SHSs have the unique ability to meet users' specific energy requirements at the speed and manner specific for each household (Smith, 2000).

Meeting end-users' requirements also depends on adequate training in order to dispel unrealistic expectations of the services provided by SHSs. Many rural users think that even a small SHS provides enough electricity to power a TV, freezer, computer, 
photocopy machine, etc. (Sovacool et al., 2011). This misunderstanding is derived from a lack of knowledge about how much energy a SHS can produce versus how much energy an appliance consumes. Combined with this is a lack of understanding of the benefits of energy-efficient (EE) products, which may consume less than $50 \%$ of the energy than that of normal appliances (see Figure 3.4.1.1). The energy efficiency of products in developing countries is generally poor; yet, the efficiency is slowly improving following the affordability of technological improvements in industrial countries (Jochem, 2000).

As a result, users have been found to be more satisfied with larger SHSs, which have been found to be more cost-effective and are less limited in their applications (Nieuwenhout et al., 2001). This is especially needed as in most PICs, a large degree of communal control is retained over resources, and therefore the benefits of SHSs are often shared (Yu et al., 1997). Thus, conservative systems-sizing and increased awareness of the limits of a SHS and the consequences of overusing it (i.e., battery failure) have the potential to increase users' Figure 3.4.1.1: A 12-volt DC powered energy efficient TV, which consumes less power than standard TVs and are ideal for SHS applications.

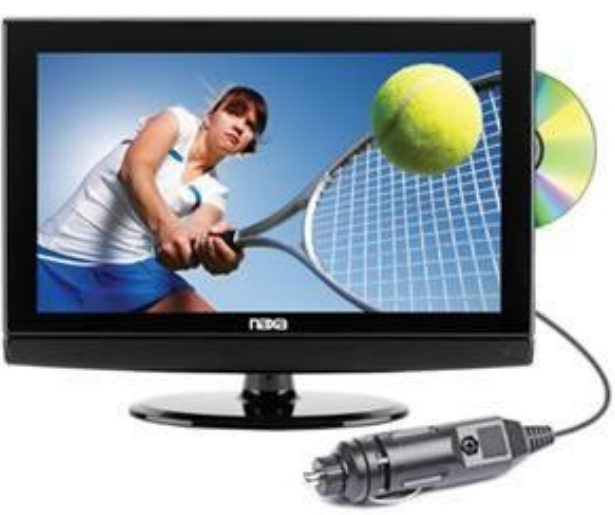

Source: Twelve-volt travel (2012). satisfaction with their systems.

\section{Ability to satisfy expanding energy demands:}

Many SHS projects have not taken expanding energy demands into consideration even though rural electricity requirements are growing. For example, Gustavsson (2007) illustrated that SHS users acquire a growing number of appliances over time, and often exceed the capacity of their SHS. Therefore, SHSs need to be designed to cater to everchanging needs. One technical option to compensate for this is to increase the number of panels and batteries over time as needed, and to take possible expansion into consideration when sizing other system components initially. Another option is to train users not only 
before but after installation, as at this time end-users will be better able to understand the limits of their SHS, and be able to apply the information that is relevant for them to regulate their electricity demand (Gustavsson, 2007).

A third recommendation by Vleuten et al. (2007) describes energy access as not a single event, but rather as a "dynamic development process that will continuously create further demand and investments." This process is portrayed in the rural electricity ladder in Figure 3.4.1.2, which is a suggested hierarchy of rural electrification, although not every community will experience every step. For example, in this figure, micro-grids are above SHSs in the ladder, yet, micro-grids are limited in that they require close proximity of households and a certain degree of community cohesiveness (particularly in relation to collective financial management), and, therefore, they may be inappropriate for some areas (Martinot \& McDoom, 2000). The electricity ladder implies that SHSs not only need to be flexible in their own design, but need to serve as a rung in the ladder toward more permanent forms of electricity. Figure 3.4.1.2: The Rural Electricity Ladder \begin{tabular}{||l||}
\hline \multicolumn{1}{||}{ - Grid connection, which is unlikely to } \\
happen in many of the rural areas of \\
PICs in the near future \\
\hline \hline -Micro-grids, include RE and fossil \\
fuel power, can be distributed \\
generation \\
\hline \hline -Self-generation: \\
- SHS, often using vehicle batteries \\
- Small fossil fuel-powered generators \\
- Micro-scale hydro and wind \\
\hline \hline -Central charging station where \\
batteries are recharged and returned \\
to the house for electricity use \\
\hline \hline -Solar PV powered lanterns, may \\
include radio or mobile charging \\
\hline \hline -Kerosene lanterns or \\
-Standard dry cell batteries for \\
torches and lanterns \\
\hline \hline
\end{tabular} Thus, in order to make SHSs sustainable, the equipment needs to be reusable, either in Sources: Sovacool et al. (2011a); VEU, Respondent 1 (2011); Vleuten et al. (2007). higher technical solutions or by those that still require a SHS. 


\subsubsection{Economic Indicators:}

\section{Cost-effectiveness:}

Unfavourable financial, institutional, and regulatory environments, along with market distortions, suggest that government involvement is required to promote and support RE deployment (Painuly, 2001). Government's failure to address market barriers can result in unnecessarily high prices for PV equipment and reduce its cost-effectiveness (van Alphen et al., 2007). For example, the Vanuatu government recently made the import duty on solar PV batteries equal to vehicle batteries, stating that it was challenging for customs officials to recognize the difference between the battery types (Vanuatu Entrepreneur, Respondent 5, 2011). Such a law can decrease PV uptake and discourage users from replacing their batteries with higher quality ones when needed.

Beck \& Martinot (2004), Martinot et al. (2001), and Urmee \& Harries (2009) indicate that programs which include users in their maintenance programs and develop enduser awareness have fewer technical problems and lower operating costs per system. In fact, Urmee et al. (2009) reported that $90 \%$ of system implementers of a successful program in Bangladesh agreed that O\&M costs had been reduced due to customer consultation and by allowing users to own their systems.

Overall projects that utilized local RE dealers often are more cost-effective as local competition between dealers comes into play, and funds are often more limited, resulting in dealers providing the most cost-effective option for their customers. On the other hand, RESCO projects are frequently more costly due to high quality imported parts, contracting out equipment supply to overseas companies, and

Photograph 3.4.2.1: A SHS located at a local school in Vanuatu, which provides lighting for studying at night.

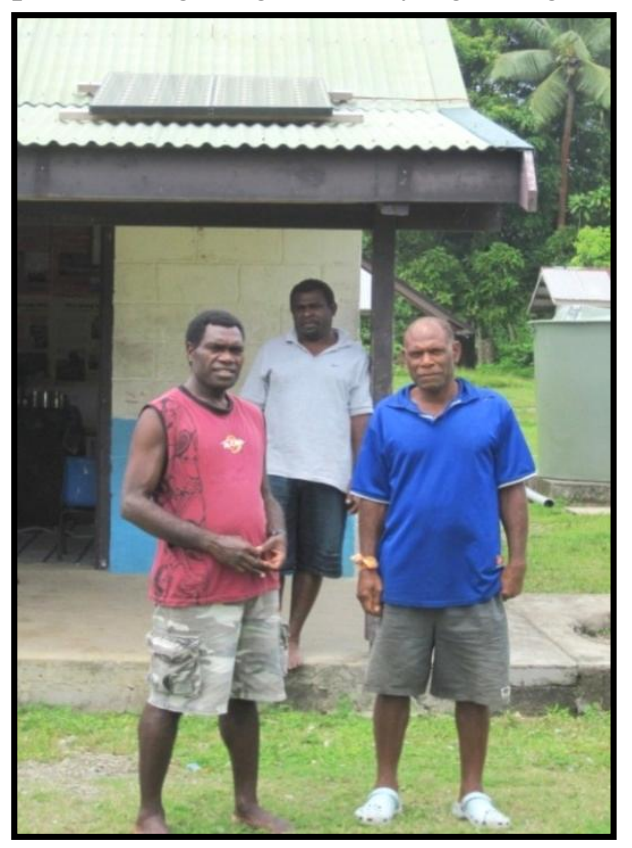

Source: Photography by Juliana Ungaro (2011). 
costly fee collection and maintenance programs. One method to lessen the cost of collecting fees has been to install prepayment meters on each SHS, which enables users to pay monthly fees themselves rather than rely on the visits of technicians. However, these meters have had many technical difficulties in PICs, and at times have ended up increasing rather than deceasing project costs (Wade, 2005a).

\section{Effectiveness in changing community livelihoods:}

Mala et al. (2009) and Ilskog \& Kjellstrom (2008) concluded that SHSs may not be a feasible option for generating household income. Similarly, a study by Urmee \& Harries (2009) indicated that programs' implementers thought that while SHSs increased gender equality, social activities, access to information, and total working hours, they did not significantly affect employment or income.

In contrast, Mapako \& Prasad (2007) found that both the number of enterprises and employees increased significantly as a result of rural electrification in Zimbabwe.

Additionally, Chakrabarti (2002) showed significant positive educational, economic, and health impacts four years after rural electrification in India, and Mala et al. (2008) cited convenience, increased employment, reduction in work hours, and reduction of urban drift as benefits in Kiribati (see educational benefits, Photograph 3.4.2.1).

Martinot et al. (2002) suggest economic development from SHSs is more likely to occur in communities where the economy is already expanding, which may explain why opinions are varying. Additionally, Vleuten et al. (2007) concluded income-generating activities utilizing electricity take time to develop, yet over time PV will effectively contribute to changing livelihoods. Furthermore, Cabraal et al. (2005) suggests that without electricity there are limits to any type of economic growth in rural areas. Thus, rural electrification projects should be coupled with economic development endeavours in order to have a higher chance of increasing local employment (Sovacool et al., 2011a). Still, more studies are needed to address the long-term effects of SHSs on community livelihoods. 


\subsubsection{Institutional Indicators:}

6. Availability of resources and support:

Lack of expertise has been cited as a barrier to rural electrification, yet most of the projects reviewed by Jafar (2000) were deficient in training users and technicians in O\&M skills. Nieuwenhout et al. (2001) found that maintenance and repair are often underestimated in terms of the cost and time required, and users frequently cite them as areas where programs are lacking, despite their being viewed as necessary for project endurance. In fact, inadequate maintenance is the most common cause of SHS failure in PICs (Wade, 2005). Vleuten et al. (2007) suggests this trend is due to the limitations of donors to move beyond their traditional approaches of a desire for quick success and large impacts, thus overlooking long-term O\&M. Syngellakis et al. (2010) further explains that donor staff are often under pressure to spend funds that have been allocated to specific projects, and as a result are unable to concentrate on time-intensive activities or long-term project support. Consequently, Vleuten et al. (2007) suggests that local SHS dealers have the potential to provide better after-sale support than governments and donors.

However, local users are viewed as undependable in properly managing their SHSs, and, therefore, many project designers and dealers have relied upon technicians from urban areas to visit the systems regularly or have made efforts to place or train technicians locally (Nieuwenhout et al., 2001). However, this method is also limited. For example, in Kiribati, lack of access to telecommunication resulted in difficulties contacting the appointed technician, and users often had to wait for his visits to have their SHS repaired (Mala et al., 2009).

\section{Availability of system components:}

The availability of system components has been largely overlooked in the literature, other than indicating that a lack of spare parts available locally hinders success, and recommending that spare parts should be available in rural areas (Jafar, 2000; Urmee et al., 2009; Urmee \& Harries, 2009). One project that brought spare parts and after-sales service 
closer to the end-user was the Renewable Energy for rural Access Project (REAP) project in Mongolia, which expanded SHS retail centres into rural areas (Sovacool et al., 2011a). Still, it is high-risk and low-return for dealers and utilities to have multiple retailers in rural areas, and thus external support is needed for the creation of such infrastructure.

Another program used the technological solution entitled SIMbaLink, which is a device which connects to SHSs and allows solar dealers to remotely monitor installed systems (Schelling et al., 2010). This technology allows technicians to understand how a SHS is malfunctioning, and then they can send the required replacement part without requiring a maintenance visit, thus reducing costs. Such a device also has implications for training users on how to properly manage their available electricity (Schelling et al., 2010). However, the data for this device is transmitted over GSM (Global System for Mobile Communication) networks, and thus it is limited to only certain regions in PICs.

\section{Capacity building:}

A study by Urmee \& Harries (2009) of rural electrification programs in AsiaPacific indicated that capacity building was provided to both technicians and system users only $15 \%$ of the time, despite a lack of technical skills being identified as hindering program success. Mario (2003) also found that in PICs, capacity building programs have been delivered in an unplanned and informal way, due to the absence of a long-term training plan, and have been focused on the energy sector, with little training for private companies or users.

Capacity building is a long-term task and thus long-term program goals and institutional support need to be available at all levels. Martinot et al. (2002) highlighted this, suggesting that the amount of RE installed is insignificant, compared to sustainable and replicable business, credit, and implementation models. Capacity building was successfully carried out at the dealer level in Bangladesh, through providing financing, and technical, logistical, promotional, and training assistance to the organizations (Urmee et al., 2009). Yu et al. (1996) and Yu \& Taplin (1997) echo the need for such projects, which increase human resource capacity nationally, rather than relying on external experts. Capacity building on the rural level has also been proven to be successful, such as in a 
RESCO project in Zambia, which found that training decreased end-users' overuse of their SHSs (Krithika \& Palit, 2011).

At the local level, Sovacool et al. (2011) indicates that training provides the biggest challenge to PNG SHS initiatives, yet it has not been done. They suggest training, if done correctly, should take up to $90 \%$ of project efforts, as it "is laborious, time consuming, long-term, hard, and essential." Chow (2010) summarized the need for local capacity building in Vanuatu by attributing project success to its ability to increase end-users' understanding, ability, and desire to carry out O\&M requirements, as current levels are inadequate overall.

A variety of training methods can be used to impart needed skills to end-users, including hands-on trainings, workshops, newspaper articles, TV programs, DVDs, radio programs, brochures, manuals, websites, and text messages, yet funding is required for all of these techniques (see Photograph 3.4.3.1) (Sovacool et al., 2011). The cost of capacity building has been justified in projects globally; however, local dealers often are unable to spend significant funds on training because it provides minimal return, and donors often are unable to obligate long-term funding or funding with uncertain returns (Wade, 2005). Furthermore, donor-funded capacity building has been uncoordinated with other training and has lacked follow-up (Wade, 2005). Thus, while it is acknowledged that local capacity building is needed, it is rarely carried out to the degree required.

Photograph 3.4.3.1: A training session for women at Utrok Atoll, RMI.

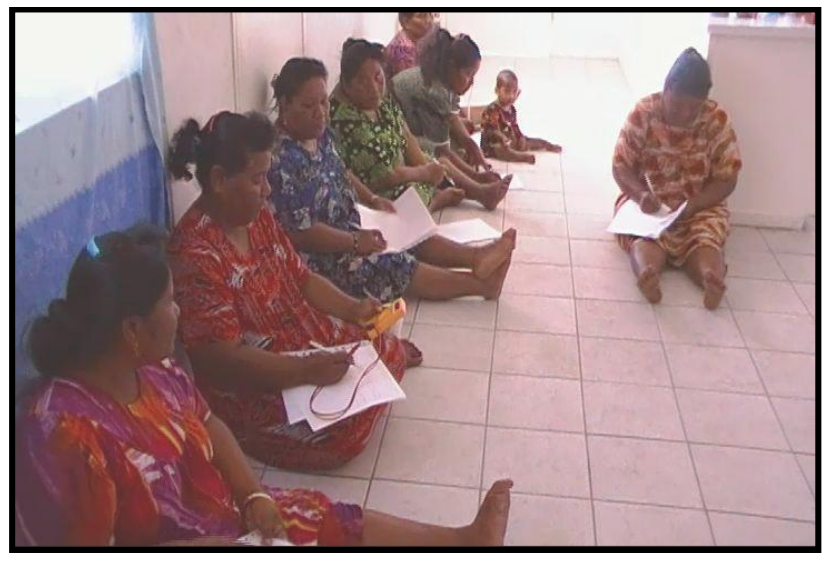

Source: Photography by Juliana Ungaro (2011). 


\subsubsection{Social Indicators:}

\section{Gender inclusiveness:}

Women represent over half of the world's poor, and studies indicate that women are the group most affected by energy scarcity and related health issues (Smith, 2000). Yet, much of women's work in PICs, such as cooking, laundry, sewing, childcare, collecting firewood, and growing food, is unpaid and undervalued in society, which results in electrification projects often overlooking their affect on women (Cecelski, 2000). Additionally, SHS projects are regarded as using complex technologies, which are culturally managed by men, often leaving no room for women to become skilled (Cecelski, 2000).

Yet, SHSs have the potential to improve women's quality of life, specifically by decreasing the time and energy required for daily tasks (through refrigeration, electric cookers, sewing machines, washing machines, water pumps, mobile charging, and computers), by increasing their available working hours (through lighting at night), and by creating a role for them to properly manage their families' electricity (see Photograph 3.4.4.1) (Cecelski, 2000; Smith, 2000). As women are already procurers of energy, through collecting firewood and earning funds for lighting, it becomes essential to include women in all stages of electrification projects in order to ensure effective project design. In fact, participation of women in project design has been shown to improve project outcomes and increase the likelihood of enduring results (ESMAP, 2003). However, more research is required on this topic, to better understand how best to include women in project design and implementation, as well as the benefits of doing so, as documentation thus far is limited (Cecelski, 2000). 
Photograph 3.4.4.1: A rural RMI household receives a new solarpowered refrigerator, which will help to decrease women's workload.

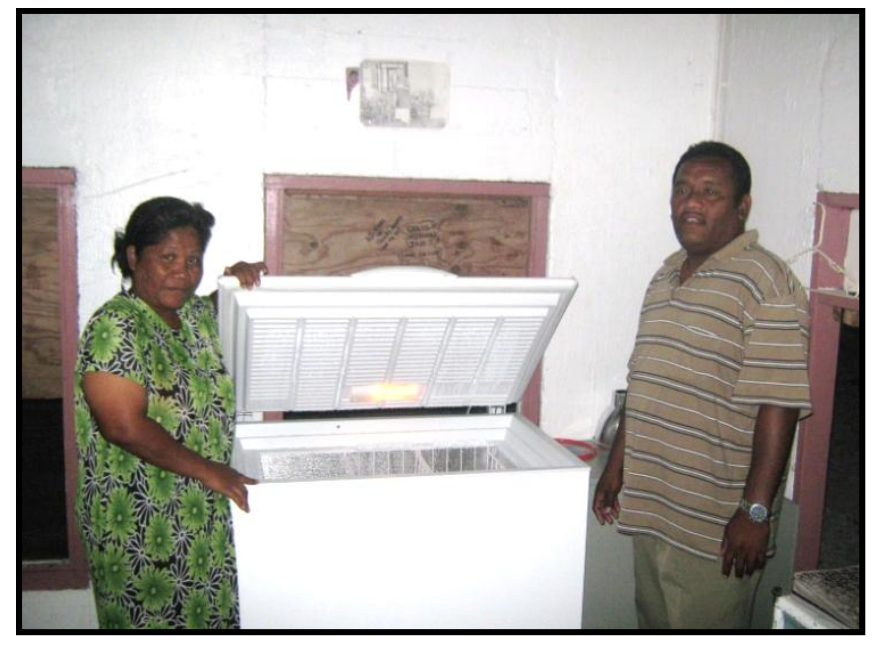

Source: Photography by Juliana Ungaro (2011).

\section{Affordability:}

The affordability of SHSs for rural families is often derived from diverting earnings from other needs, as they do not often have significant savings (Mala et al., 2009). Many donor-funded projects assume that users cannot afford to spend more on energy than their current expenditures (Martinot \& Reiche, 2000). Research indicates that end-user income levels and the prices of the SHSs they purchase do not generally correspond, although the incomes of owners are normally above average (Nieuwenhout et al., 2001). Thus, much of the literature cites limited availability of financing, through access to credit for end-users, to be a barrier for making SHSs available to low-income groups (Beck \& Martinot, 2004; Urmee et al., 2009).

This is especially true for self-initiated projects, as high investment requirements can create market failure (van Alphen et al., 2008). For example, Sovacool et al. (2011) pointed out that many people in PNG do not consider the cost over time, as they have a limited understanding of savings, credit, interest, or even the meaning of money, making the preliminary cost of a SHS inhibiting. Thus, financial literacy and access to financing may be more of a barrier to affordability than the actual cost to end-users. 
Financing often originates from donors and banking institutions, as governments and private companies are often unwilling to provide a significant amount of backing, due to rural electrification often being high-risk and minimally profitable (Sovacool et al., 2011a; Vleuten et al., 2007). Financial mechanisms that have been successfully used to make SHSs affordable to end-users include:

- Providing long-term credit or loans for consumers

- Supplying subsidies for initial costs

- Providing rebates once systems are installed satisfactorily

- Offering fee-for-service electricity

- Promoting smaller systems that are designed for the possibility of expansion

- Providing trade-in or resell options

- Reducing import duties on RE and EE equipment

- Offering saving facilities for end-users

- Reducing interest rates on loans through subsidies

- Using 'smart subsidies,' which are self-eliminating due to increasing the number of systems sold, thus reducing the cost per unit and eliminating the need for the subsidy

(Martinot et al., 2002; Martinot \& McDoom, 2000; Urmee \& Harries, 2009; Wade, 2005).

Still, the appropriate credit mechanisms must be based on local conditions, including cultural, legal, and financial factors (Martinot et al., 2002).

\section{Familiarity with the technology:}

Many locals learn about SHSs from other solar users in their community and may purchase a system similar to their neighbours, rather than based on information from the government, dealers, or the media (Nieuwenhout et al., 2001; Sovacool et al., 2011a). Thus, they may or may not gain the skills needed for proper installation and maintenance. However, locals in most PICs already have some degree of familiarity with technology, which may include handling and maintaining generators, power tools, radios, stereos, TVs, mobiles, stoves, and other household appliances. These skills provide a basis to allow users to become familiar with SHSs, with proper training.

Yet, any effort at training needs to be culturally appropriate and considerate of educational levels. Chow (2010) expressed frustration after training users in Vanuatu, as 
some users did not understand how to read the charge controller after its being explained twice, and others had lost their operation manuals. Possible causes for this could be a lack of interest by users, the timing of the training (perhaps before installation), the language used, the method of training (hands-on, power point, etc.), the incongruence between the manual and reading levels, and an unfamiliarity with keeping track of paperwork. Rather, in order for training to be successful, it must be based on the end-user's level of technological familiarity.

\section{$\underline{3.4 .5 \text { Cultural Indicators: }}$}

\section{Participation and ownership:}

Urmee \& Harries (2009) indicate that only $25 \%$ of solar PV program implementers considered that involving users was important in their program design. Thus, there has been a trend for project ideas to originate externally, rather than through end-user needs' assessments and community opinions (Jafar, 2000). Sometimes this has resulted in recipients not being committed to project outcomes, and the equipment being stolen, abused, or abandoned (Jafar, 2000).

A study from Mongolia suggests participation of both the private sector and endusers in rural electrification leads to project success (Sovacool et al., 2011a). Inclusion of end-users fosters a sense of ownership, which has been shown to reduce cases of mistreatment, overuse, and neglect (Urmee et al., 2009). Nieuwenhout et al. (2001) expands on this by suggesting that users feel more responsible for SHSs that are selfinitiated and for which they have contributed a significant percentage of the cost. Wade (2005) agrees, suggesting users need to be self-designated, as there needs to be a commitment of end-users to properly operate and maintain their systems. SHSs are unique in that they allow energy services to be close to the end-user, making it possible for users to have full control of their electricity, from design to consumption, if projects allow for such (Smith, 2000).

\section{Willingness to pay:}


Ilskog \& Kjellstrom's (2008) research shows that rural users are willing to pay a significant amount for electricity through SHSs if they are highly satisfied with the electricity. Furthermore, user-satisfaction affects the rate at which end-users pay back loans (Nieuwenhout et al., 2001). Satisfaction, and thus willingness to pay, is based on users' expectations, desires, and ease of use, whereas users' ability to pay is affected by income levels, access to financing, and financial discipline (Chow, 2010; Nieuwenhout et al., 2001).

Thus, cultural factors have an effect on willingness to pay, as demonstrated by Mala et al. (2009) in their analysis of the Kiribati RESCO project. In this project, users were required to pay $\$ 9$ per month (50\% was subsidized), which was on average less than their previous energy expenditures on fuels. However, users were required to pay the RESCO fee on a monthly basis, whereas previously their fuel costs were paid in small amounts on a daily basis. This change made the fee unaffordable to many, as it did not fit in with their cultural norms.

\subsubsection{Environmental Indicators:}

\section{Effectiveness in improving the environment:}

SHSs have significant potential to improve the environment by $\mathrm{CC}$, through replacing and dissuading future use of harmful fossil fuels (see Photograph 3.4.6.1). This positive effect has been accepted as one of the advantages of using SHSs, and is often mentioned in the literature, although the amount of $\mathrm{CO}_{2}$ emissions avoided by implementing SHSs has been measured infrequently.

However, other environmental effects, including the disposal of defunct solar batteries and
Photograph 3.4.6.1: Erosion poses a serious threat to low-lying islands, and thus GHG emissions may directly threaten PIC communities.

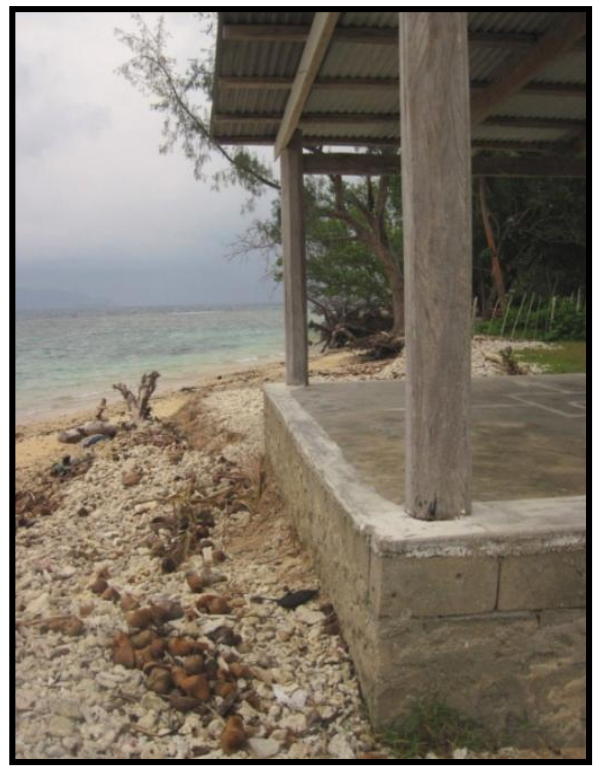

Source: Photography by Juliana Ungaro (2011). 
the need to cut down trees to prevent shading of PV panels, are rarely mentioned. If PV panels are pole-mounted, which most SHSs are, they can often be placed in areas of least shading in order to avoid tree removal, although shading will change throughout the year. Studies of large PV arrays do cite tree removal as a negative environmental consequence, although they find the cumulative impacts to have negligible effects (DOE-EA, 2009).

Regarding batteries, a paper by Yu et al. (1997) suggested that even small batteries can result in significant environmental problems in PICs. Although some governments and entrepreneurs have cited a need to set up battery recycling programs, the funds to do so are rarely available. As one SHS dealer in Vanuatu stated, "Used battery collection is needed, yet it cannot be prioritised as there are currently more pressing issues" (Vanuatu Entrepreneur, Respondent 5, 2011).

\subsection{Success Factors}

The factors for project success cited in the literature, many of which are previously mentioned in section 3.4, are summarized in table 3.5.1. These success factors are used in recommendations on electrification strategies and in the creation of a project riskmitigation framework in chapter 8.

Table 3.5.1: A summary of the success factors cited in the literature by indicator.

\begin{tabular}{|c|c|}
\hline Indicator & Success Factors \\
\hline 1. Appropriate equipment use & $\begin{array}{l}\text { - Using technically and commercially proven } \\
\text { - technologies } \\
\text { - Equipment appropriate for the location } \\
\text { - Minimal maintenance required } \\
\text { - End-users able to choose their electricity solutions } \\
\text { - Edrong equipment standards and certifications } \\
\text { - Education of consumers }\end{array}$ \\
\hline $\begin{array}{l}\text { 2. Effectiveness in meeting users? } \\
\text { needs }\end{array}$ & $\begin{array}{l}\text { - Objective assessment of local needs } \\
\text { - A range of SHS sizes available } \\
\text { - Conservative systems-sizing } \\
\text { - Training on services provided and on SHS } \\
\text { - Primitations }\end{array}$ \\
\hline $\begin{array}{l}\text { 3. Ability to satisfy expanding } \\
\text { energy demands }\end{array}$ & $\begin{array}{l}\text { Expanding energy demands considered in system } \\
\text { size }\end{array}$ \\
\hline
\end{tabular}




\begin{tabular}{|c|c|}
\hline & $\begin{array}{l}\text { Users trained after installation on energy } \\
\text { efficiency and regulating their demand } \\
\text { - SHSs viewed as part of an electrification } \\
\text { development process }\end{array}$ \\
\hline 4. Cost-effectiveness & $\begin{array}{l}\text { - Government regulations promote RE } \\
\text { - Users included in maintenance program } \\
\text { - Need for maintenance visits by technicians } \\
\text { reduced }\end{array}$ \\
\hline $\begin{array}{l}\text { 5. Effectiveness in changing } \\
\text { community livelihoods } \\
\end{array}$ & $\begin{array}{l}\text { - SHSs linked to productive uses } \\
\text { - Services provided by SHSs match community } \\
\text { needs }\end{array}$ \\
\hline $\begin{array}{l}\text { 6. Availability of resources and } \\
\text { support }\end{array}$ & $\begin{array}{l}\text { - Reliable after-sales service } \\
\text { - Continual institutional support } \\
\text { - Regular monitoring } \\
\text { - Adequate service strategy locally }\end{array}$ \\
\hline $\begin{array}{l}\text { 7. Availability of system } \\
\text { components }\end{array}$ & $\begin{array}{l}\text { - Spare parts available locally } \\
\text { - Strong supply chain } \\
\text { - Institutional support }\end{array}$ \\
\hline 8. Capacity building & $\begin{array}{l}\text { - Funding set aside for training } \\
\text { - Training at both the local and institutional levels } \\
\text { - A variety of media tools used } \\
\text { - Training is culturally appropriate and considerate } \\
\text { of educational levels }\end{array}$ \\
\hline 9. Gender inclusiveness & $\begin{array}{l}\text { Women included in all project stages } \\
\text { - Women trained on how to use and manage their } \\
\text { SHSs }\end{array}$ \\
\hline 10. Affordability & $\begin{array}{l}\text { - Financing available to end-users } \\
\text { - Low initial investment required } \\
\text { - Training on financial literacy provided } \\
\text { - Low-income families included }\end{array}$ \\
\hline $\begin{array}{l}\text { 11. Familiarity with the } \\
\text { technology }\end{array}$ & $\begin{array}{l}\text { Training based on end-users' level of } \\
\text { technological familiarity }\end{array}$ \\
\hline 12. Participation and ownership & $\begin{array}{l}\text { - Participation of local stakeholders } \\
\text { - Users contribute to the cost of their system } \\
\text { - Users have a sense of ownership over their } \\
\text { - Pystems } \\
\text { - Participation of both the private sector and end- } \\
\text { users }\end{array}$ \\
\hline 13. Willingness to pay & $\begin{array}{l}\text { - Payment methods fit within cultural norms } \\
\text { - Systems meet user expectations and desires }\end{array}$ \\
\hline $\begin{array}{l}\text { 14. Effectiveness in improving the } \\
\text { environment }\end{array}$ & $\begin{array}{l}\text { - A battery recycling program is set up } \\
\text { - Systems able to be reused } \\
\text { - Systems replace the need for fossil fuels }\end{array}$ \\
\hline
\end{tabular}




\section{Chapter 4: Research Methodology}

\subsection{Overview}

This research was undertaken as a form of applied human geography focusing on the social dimensions of clean technology projects and programmes in two PICs. The overall goal of the research was to address the aim of determining "the most important technical, economic, institutional, socio-cultural, and environmental criteria for increasing the probability of success and longevity of household-scale solar PV initiatives in remote Pacific Islands." This aim was achieved by analysing information gathered during the fulfilment of each of four research objectives. The information sought in each of these objectives was gathered using separate methods for each objective, as demonstrated in Table 4.1.1.

Table 4.1.1: Research Objectives and Corresponding Methods, and the Chapter wherein the Methodology is carried out.

\begin{tabular}{l|l|l|}
\hline Objective & Method & Chapter \\
\hline $\begin{array}{l}\text { One: to define a comprehensive set of } \\
\text { indicators for evaluating rural SHS } \\
\text { projects in PICs }\end{array}$ & $\begin{array}{l}\text { A literature review of indicators and } \\
\text { how they have been applied in SHS } \\
\text { projects }\end{array}$ & Three \\
\hline $\begin{array}{l}\text { Two: to determine the positive and } \\
\text { negative results of SHS projects in } \\
\text { PICs, and the lessons to be learned }\end{array}$ & $\begin{array}{l}\text { A documentary analysis of SHS projects } \\
\text { in seven PICs }\end{array}$ & Five \\
\hline $\begin{array}{l}\text { Three: to evaluate the success rate of } \\
\text { two existing household solar PV case } \\
\text { studies }\end{array}$ & $\begin{array}{l}\text { Questionnaires of SHS end-users in two } \\
\text { case studies from the RMI and Vanuatu }\end{array}$ & Six \\
\hline $\begin{array}{l}\text { Four: to determine the viewpoints of } \\
\text { solar PV project stakeholders and } \\
\text { experts on essential criteria for project } \\
\text { permanence }\end{array}$ & $\begin{array}{l}\text { Semi-structured interviews with solar } \\
\text { PV stakeholders and experts in the RMI } \\
\text { and Vanuatu }\end{array}$ & Seven \\
\hline
\end{tabular}

As table 4.1.1 implies, this research used both qualitative and quantitative data collection, as well as a documentary analysis, which allowed for the triangulation of data in the research results. The document analysis consisted of evaluating significant private and 
donor-funded SHS project reports in seven PICs, in order to answer the research questions under Objective Two. Primary data was obtained from two selected rural case studies in the RMI and Vanuatu through questionnaires designed to address research Objective Three, and through semi-structured interviews carried out in the urban areas of each nation following research Objective Four. Evaluation indicators developed through the literature review (see Chapter 3) were used to evaluate the interviews, questionnaires, and project documents, thus resulting in comparative outcomes. The results were used to determine essential practices and recommended electrification strategies for SHS projects in PICs, which then aided in the development of a project risk mitigation tool for PV rollout.

\subsection{Literature Review addressing Objective One}

To determine the evaluation criteria for the project reports, case studies, and interviews, a literature review was carried out examining off-grid RE electrification projects in PICs and in developing countries worldwide. This included the literature on rural RE evaluation indicators, barriers to RE implementation in PICs and recommendations to overcome them, and overall success factors, thus answering the research questions under Objective One. The compilation of indicators from the literature resulted in the development of evaluation criteria in order to assess which factors were critical in successful project design (see indicators Table 3.2.1). These indicators were then applied to the project documents and the primary data collected from the selected case studies and interviews. The indicators were divided into the overarching topics of technical, economic, institutional, social, cultural, and environmental, in order to simplify analysis.

\subsection{Documentary Analysis addressing Objective Two}

The document analysis first examined the literature on the successes and failures of various electrification methods implemented in developing countries globally, in order to provide a context for examining project documents from PICs. Thirty project reports and documents from PICs' private, governmental, and donor organizations were examined, thus addressing the research questions under Objective Two. Many project documents were examined at once, as it was taken into consideration that projects' documents are 
often the opinion of one person or organization at one point in time, and therefore may not address the full effects of a project.

SHS projects implemented in Fiji, Kiribati, Tonga, PNG, Tuvalu, Vanuatu, and the RMI were studied in depth, as well as regional reports relating to implementing SHSs. These countries were selected as they have the most experience with solar PV for rural electrification in PICs, and represent a large variety of electrification models. The RMI represents a RESCO managed by a government utility, Kiribati and Fiji represent a RESCO managed by a private company with government input, and Tonga represents decentralization of the RESCO with management by a community committee. Kiribati's program was successful overall, whereas Fiji's program faced numerous issues. PNG contains the largest private sector for SHSs in PICs, and Vanuatu represents a country whose primary implementation model changed from RESCOs to user-owned systems over the past decade. Particular attention was paid to historical and ongoing projects in the RMI and Vanuatu in order to provide background information for the case-study analysis. Following the analysis, the lessons learned as stated in all of the project documents were assembled into a chart.

It would have been desirable to focus equally on the private sector for reasons of comparative analysis; however, very little information is available in the literature or project documents regarding the number, size, or longevity of user-owned SHSs installed in PICs. In addition, RESCOs are the preferred implementation model for many PICs, and thus they are the focus of many project documents. Therefore, this analysis has included more RESCO projects, yet patterns in the successes and failures of each model can still be seen. These patterns were developed through enumerating the evaluation indicators addressed by the project results of each electrification model. Therefore, this document analysis provided insights into the potentials and limitations of various electrification methods for Vanuatu, the RMI, and other PICs.

\subsection{Primary Research Country Overviews}

The primary data from the RMI was collected during the period of February-April 2011, while the data in Vanuatu was collected during October 2011. The RMI and 
Vanuatu were selected because they have a long history with solar PV, with both user and utility owned SHSs, electrification highly reliant on international aid, and extremely isolated islands, many of which are still in need of electrification (see Table 4.4.1). Their levels of development are similar, with the RMI ranking slightly above Vanuatu in their Human Development Index and Human Poverty Index for PICs (see Table 1.1.1). Further similar qualities include high unemployment rates and uneven income distribution, with a relatively high level of poverty in the rural islands (UNDP, 1999).

In addition, their urban areas have comparable populations, with the two nations facing a high rate of population growth and urbanization (see Tables 4.4.2), and the RMI also undergoing high rates of emigration to the US. The urban areas of both nations are electrified by a single utility company through diesel-powered generators, with electricity prices per kilowatt-hour being extremely high, and Vanuatu's being among the highest globally (see Table 1.3.1).

Table 4.4.1: A comparison of the RMIs' and Vanuatu's national statistics and geography.

\begin{tabular}{|c|c|c|}
\hline Indicator & $R M I$ & Vanuatu \\
\hline Geography & $\begin{array}{l}29 \text { coral atolls with hundreds of } \\
\text { islets and five single islands }\end{array}$ & An archipelago of 83 islands \\
\hline Capital Latitude & 7 degrees North & 17 degrees South \\
\hline Capital Population & 30,000 residents & 44,040 residents \\
\hline Climate and landscape & Tropical, low-lying coral atolls & $\begin{array}{l}\text { Tropical, volcanic mountains, } \\
\text { fringing reefs }\end{array}$ \\
\hline Land area & 181 sq. km. & 12,190 sq. km. \\
\hline$\overline{\text { Population }}$ & 59,667 & 234,023 \\
\hline GDP & $\$ 161.7$ million & \$647 million \\
\hline Per capita income & $\$ 2,258$ & $\$ 1,339$ \\
\hline Fuel \% of total imports & $20 \%$ & $18 \%$ \\
\hline $\begin{array}{l}\text { Annual population } \\
\text { growth rate }\end{array}$ & $2.14 \%$ (lower due to emigration) & $2.5 \%$ \\
\hline Percent electrified & $32 \%$ & $33 \%$ \\
\hline
\end{tabular}

Sources: RMI National Energy Policy (2009); Trading Economics (2011); Trading Economics (2011a); USDOS (2011); USDOS (2011a); Vanuatu's Energy Roadmap Launch (2011). 
Tables 4.4.2: Urbanization trends in the Marshall Islands and Vanuatu.

\begin{tabular}{c|cc|cc}
\multicolumn{2}{c}{ Rural vs. Urban Population: 1948-1999 } \\
\hline \multirow{2}{*}{$\begin{array}{c}\text { Census } \\
\text { year }\end{array}$} & \multicolumn{2}{|c|}{ Population } & \multicolumn{2}{c}{ Percentage } \\
\cline { 2 - 5 } & rural & urban & rural & urban \\
\hline 1948 & 7,362 & 2,364 & $76 \%$ & $24 \%$ \\
1958 & 8,761 & 4,699 & $65 \%$ & $35 \%$ \\
1967 & 9,261 & 8,789 & $51 \%$ & $49 \%$ \\
1973 & 8,325 & 15,759 & $35 \%$ & $65 \%$ \\
1980 & 11,192 & 18,415 & $38 \%$ & $62 \%$ \\
1988 & 13,078 & 28,975 & $31 \%$ & $69 \%$ \\
1999 & 14,657 & 34,578 & $30 \%$ & $70 \%$ \\
\hline
\end{tabular}

Source: RMI census (1999).

VANUATU URBAN MIGRATION TRENDS:

$\begin{array}{lrrrrrrrrrrr}\text { DEMOGRAPHY } & 1985 & 1990 & 1995 & 2000 & 2005 & 2010 & 2015 & 2020 & 2025 \\ \text { Total population (000s) } & 132 & 149 & 169 & 192 & 217 & 245 & 275 & 305 & 334 \\ \text { Urban population (000s) } & 24 & 27 & 32 & 38 & 47 & 59 & 74 & 92 & 111 \\ \text { Rural population (000s) } & 108 & 122 & 137 & 153 & 170 & 186 & 201 & 213 & 223 \\ \text { Urbanization level(\%) } & 18.1 & 18.2 & 18.9 & 20.1 & 21.7 & 24.0 & 27.0 & 30.1 & 33.4\end{array}$

Source: UN Habitat (2005).

\subsection{Questionnaires addressing Objective Three}

The research on the two selected case studies was carried out in the rural villages of Namdrik Atoll in the RMI and Akhamb Island in Vanuatu. These communities were chosen because of their unique history with solar PV (described below), their remote locations and small populations (under 800 inhabitants in each) and their combined display of the three implementation strategies described in Chapter 2 (RESCO, project-initiated user-owned, and self-initiated user-owned).

Namdrik Atoll is a small atoll in the Ralik Chain of the RMI, consisting of two islands with its total land area being only 2.8 square kilometres, and its lagoon encompassing an area of 8.4 square kilometres (see Figure 4.5.1). It has a population of 772 people with 118 homes (MEC, 2005), and was first electrified in 1996 by Marshalls Alternative Energy Company (MAEC), which installed 80W SHSs to all households using a RESCO model. However, most of these systems failed, and in 2001, the Pacific Renewable Energy France Australia Common Endeavor (PREFACE) project funded 
rehabilitation, with the Marshalls Energy Company (MEC) taking over the RESCO in 2004 (See Appendix 8 for full details). These systems are to be replaced in 2012 through the European Unions' North REP project (RMI Utility Company, Respondent 19, 2012).

Figure 4.5.1: A map of Namdrik Atoll and its location in the RMI.

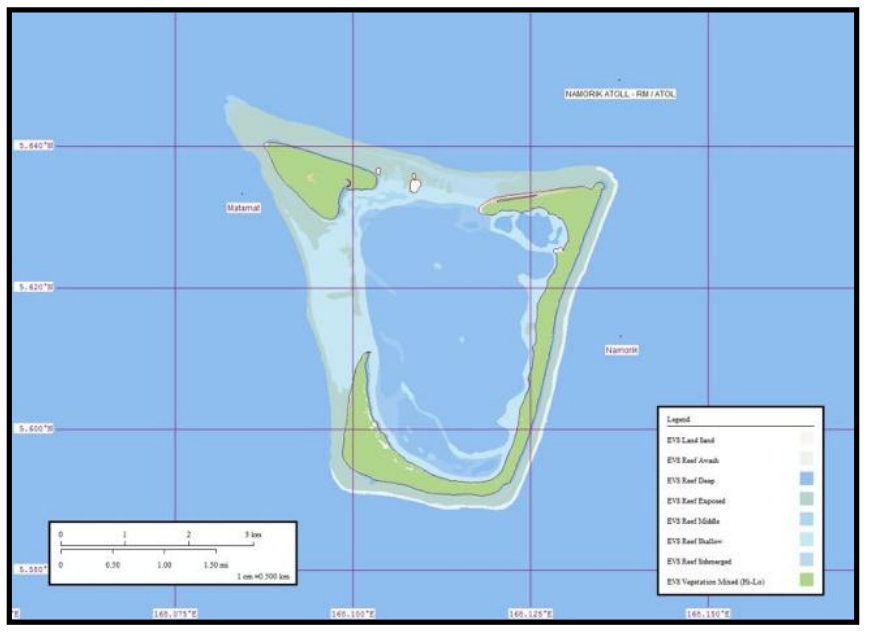

Source: Minton (2007).

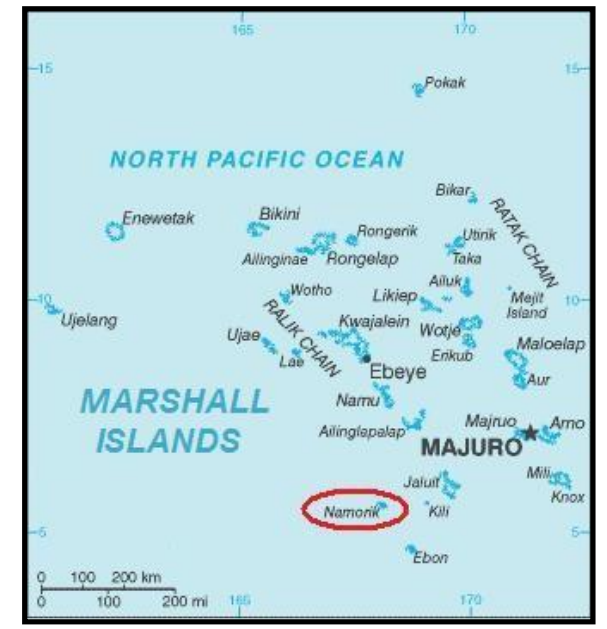

Source: CIA (2009a).

In 2010, a private solar company, Island Economic and Environmental Co. (Island Eco) installed thirty-three 320W SHSs with refrigeration units on Namdrik Atoll, with 75\% of the funding being provided by the United States Department of Agriculture Rural Utility Service (USDA-RUS) and $25 \%$ by local community members. The Namdrik Atoll local government was also involved, and aided the beneficiaries in financing their portion of the project, as well as paying for some logistical costs. Many of the household members were involved in the installation, and a local language training book, the Marshallese Solar Manual, was provided to project participants (see Figure 4.5.2). The SHSs are owned by the solar company for the first two years after installation, in order to further train endusers and ensure that the systems are working properly, after which the users will own the systems, following a project-initiated user-owned model. 
Figure 4.5.2: The cover of the Marshallese Solar Training Manual.

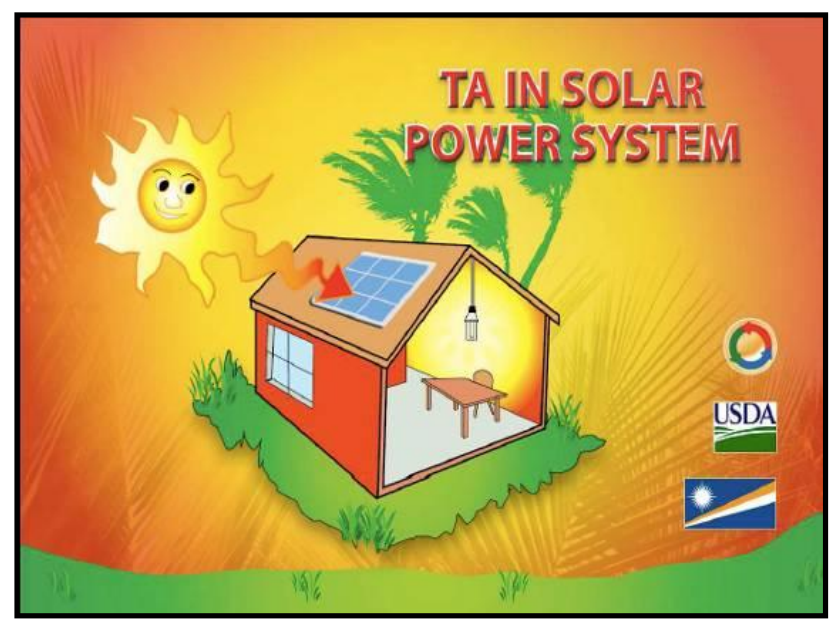

Source: Nathan (2010).

The second case study was located on Akhamb Island, which is one square kilometre in size and is located approximately 1.8 kilometres off the south coast of Malekula, the second largest island in Vanuatu (see Figure 4.5.3). The community on Akhamb had very little experience with solar until 2007, when the researcher, then a US Peace Corps Volunteer, supplied equipment and trained interested families to install their own SHS, held community trainings on solar equipment, wiring, and maintenance, and provided information in the local language on where to purchase quality parts.

In addition, the Global Environment Fund (GEF) provided funding for a $1620 \mathrm{~W}$ community solar system that provides electricity for lights and appliances for four public buildings. This system was installed in 2010 by a local RE company, Energy4All, and at the same time the company owner and technician provided advice to locals with SHSs on how to maintain and improve their systems (Akhamb Technician, Respondent 6, 2011). Consequently, the number of SHSs on Akhamb Island and the neighbouring villages (Farun and Rembae) increased from 4 to 43 during the five-year period of 2006 to 2011, without any subsidies, financing schemes, or regular technical support, following a user-owned self-initiated model. 
Figure 4.5.3: A photograph of Akhamb Island, a map of Malekula with Akhamb Island highlighted, and its location in Vanuatu.
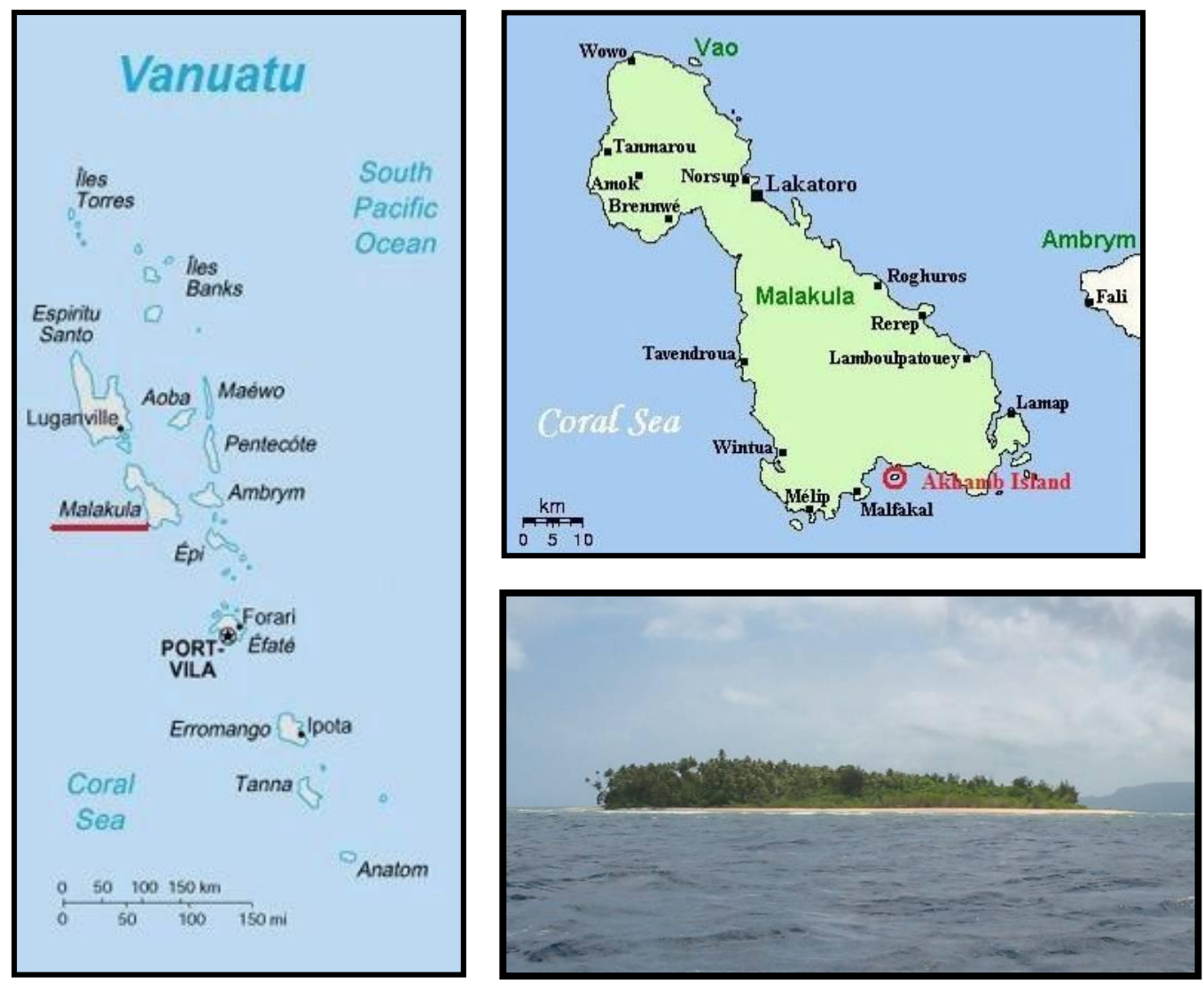

Sources: Malekula map - Wikimedia Commons (2006); photograph above by Juliana Ungaro; Vanuatu map - CIA (2009b).

In addition, an Australian Aid (AusAid) program provided a subsidy for solarpowered lanterns and collaborated with local NGOs to make the lanterns available in Akhamb and other communities (see Photograph 4.5.1 and Appendix 9 for full details). As a result of the lanterns and SHSs, as of January 2010, kerosene ceased to be sold or used on Akhamb Island and in the neighbouring communities. It is likely that this is the first community in Vanuatu to no longer rely on imported kerosene for lighting, as the national government, NGOs, and solar companies interviewed were not aware of any other community that had reached this milestone. 
Photograph 4.5.1: A local family with their SHS, and a chief of Akhamb Island with his solar lantern.
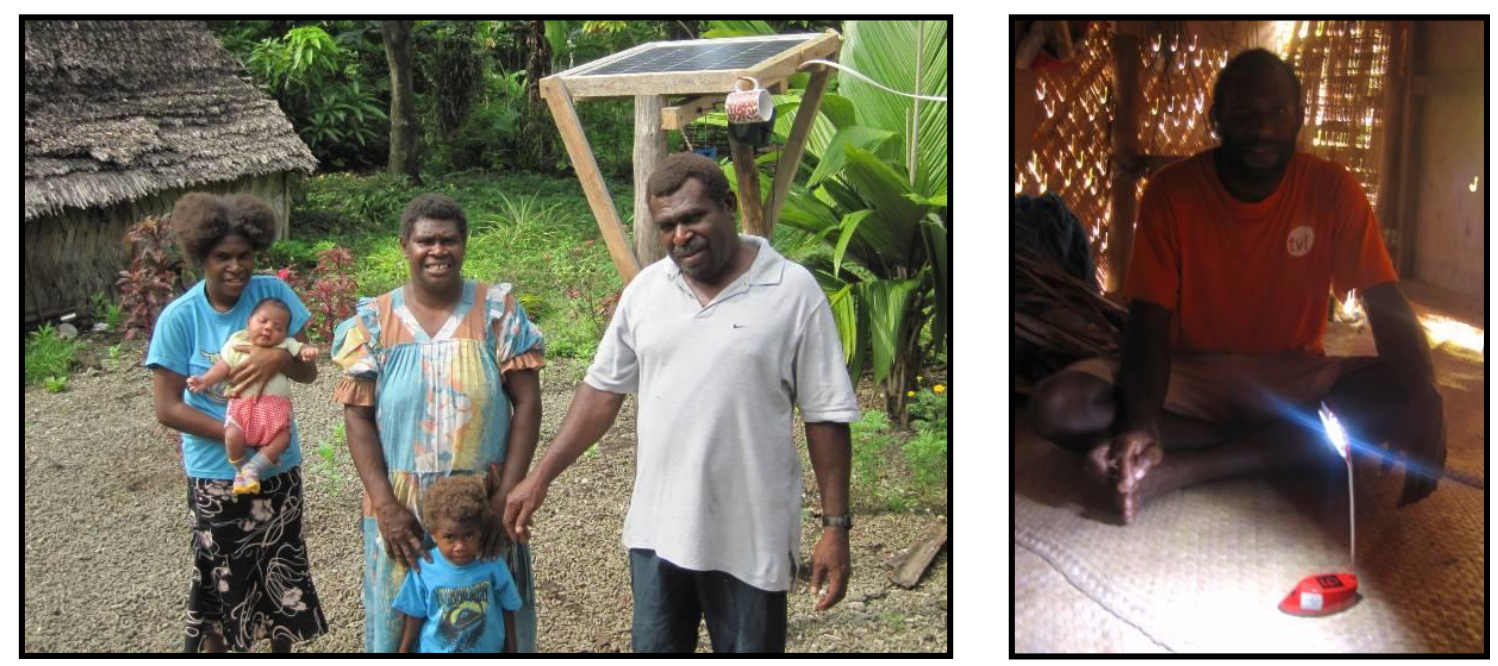

Source: Photography by Juliana Ungaro (2011).

Quantitative questionnaires were utilized in order to analyse the needs and preferences of the SHS end-users in the two case studies, with questions being analogous, resulting in comparable data. The surveys had a comparative design, which aimed to generate insights into existing theories on the methods of electrification through contrasting findings, as well as to give insights into essential practices for project durability. This approach was appropriate for the purpose of understanding in detail the experiences and preferences of rural Marshallese and Ni-Vanuatu regarding SHS design, implementation, and maintenance.

In the case of this research, this approach allowed the researcher to seek quantifiable information from all of the households with SHSs in the two selected communities, although not all of the questionnaires were returned or fully completed. In Namdrik Atoll, self-completion questionnaires, written in both Marshallese and English, were given out to all households with SHSs, and end-users were given three weeks to return them. The questionnaires were reviewed by locals for clarity before being dispersed. Using this method, only 18 out of 33 were returned fully complete. In Vanuatu, a different approach was taken, as the researcher was fluent in the local language. Thus, the 
questionnaires could be administered verbally by visiting each household with a SHS. It is likely that this method provided higher quality answers as respondents were able to seek clarification, and 39 out of 43 houses were able to be fully surveyed (four of the respondents were unavailable at the time of data collection). Yet, both questionnaires provided indicative data, and did not aim to obtain statistically significant results, due to the purpose of the questionnaire and the size of the sample, and thus useful conclusions can be drawn from both data sets.

The questionnaires were specifically designed to answer the research questions under Objective Three, with each question addressing at least one evaluation indicator. The full questionnaire and the indicators which each question corresponds to are described in Appendix 6. To simplify analysis, the questionnaires contained all closed-ended questions, with the option for respondents to choose 'other' and insert their own answer in several questions. Some questions asked respondents to choose all answers that applied, to choose the most relevant answer, or asked for ranking of the value of a statement, from 'not important' to 'very important'. These various types of questions resulted in interval, ordinal, nominal, and dichotomous variables (Bryman, 2008, p. 321).

\subsection{Interviews addressing Objective Four}

Qualitative semi-structured interviews were conducted in the capitals of each nation: Port Vila (Vanuatu) and Majuro (RMI). These were carried out at the local and national governmental levels, as well as in the private sector and with aid donors. Purposive sampling was utilized to select the respondents, all of whom were identified as holding key positions in the RE fields. Contact was made prior to executing the interviews.

Port Vila has seven solar PV companies, two NGOs, the National Energy Unit, and an AusAid organization office that are currently involved in rural electrification through solar PV. All but one solar company owner, both NGOs, two government representatives, a representative from AusAid, and an outer island solar technician were interviewed. The researcher was familiar with several solar company owners through previous experience, and snowball sampling was utilized in order to identify other interviewees. In addition, Vanuatu's Energy Roadmap Launch Conference was attended by the researcher, and the information that was presented regarding Vanuatu's energy context is cited in this research. 
In the RMI, more time was available so initial scoping exercises were carried out in order to identify key respondents, which included conversations with the national energy office, local government officials, a private solar company owner, and the RMI's national President. Additionally, an energy internship was carried out by the researcher in the RMI, which gave insight into the Island Eco project on Namdrik and its energy situation. Through this internship, regional information was acquired via a scoping conversation with the Secretariat of the Pacific Community (SPC). Energy stakeholders in Majuro are comprised of one private solar company, the national Resource and Development Office under which the Energy Service Programme (ESP) is located, the national utility company, many local atoll government leaders, and one NGO. A representative from the solar company, three local government representatives, and one national government representative were interviewed.

All of the interview questions were designed in advance; however, topics were flexible and able to be modified within the conversation in order to obtain more detailed information on emerging issues and also to make them more appropriate for the particular context and interviewee (Robson, 1993). This allowed for interviewees to state their opinions in depth on the topic at hand. Questions covered topics such as the interviewee's experience with RE, including implementation and maintenance strategies and lessons learned, their opinions on the importance of user training and involvement, essential practices that they have identified, and their trust in RE technologies. All of the interview questions were specifically designed to answer the research questions under Objective Four, with interview Questions 12 and 13 specifically addressing research Question 2. In addition, each interview question corresponded to at least one evaluation indicator (see Appendix 7).

\subsection{Data Analysis}

The quantitative data analysis utilized univariate and bivariate analysis in order to identify patterns in the data. The responses were first coded, and then entered into a widely-used statistical computer program entitled Statistical Package for Social Sciences 
(SPSS), in order to identify patterns, compare variables, calculate averages, and display the quantitative information graphically (see Chapter 6).

The qualitative data analysis used an inductive approach through an iterative process, oscillating back and forth between data and theory (Bryman, 2008, p. 545). This 'Grounded Theory' approach to data analysis was used as a strategy for generating theory from data, where data collection, analysis, and the resulting conclusions are closely related. In the case of this research, this approach enabled the researcher to organise disaggregated or incomplete pieces of information into codes to categorise data (open code), put it in a different way (axial code), and interrelate or validate it (selecting code) (Bryman, 2008, p. 543). Therefore, patterns could be identified in the data, allowing for the generation of the theories (see Chapter 7).

Both the qualitative and quantitative data results were then compared by indicator to the lessons learned through the literature review and to the success factors determined by the documentary analysis, in order to draw conclusions regarding appropriate electrification methods and critical practices for solar PV projects in PICs. These conclusions were used to create a project risk mitigation framework for solar PV project rollout, which provides insights into good practice guidance for project design, implementation, and maintenance (see Chapter 8).

\subsection{Ethical Issues}

The Victoria University's Human Ethics Committee granted approval for this research. Each respondent was given information prior to the interview or questionnaire about the thesis purpose and methods, and interviewees were given the chance to state their preferences for confidentiality. As a result of some preferences, the names of respondents are not mentioned in this thesis, only their positions and the nation in which they are located. 


\section{Chapter 5: \\ An Analysis of SHS Projects Implemented in PICs}

\subsection{A Global Summary of SHS Implementation Models}

\subsubsection{User-owned systems:}

At the end of 2010, approximately $40 \mathrm{GW}$ of solar PV had been implemented worldwide (REN21, 2011). Estimates of the largest examples of SHS installations globally include:

- More than 500,000 in Africa as of 2007

- More than 125,000 in Sri Lanka as of 2010

- More than 600,000 SHSs and 800,000 solar lanterns in India as of 2010

- More than 400,000 SHSs in north-western China (purchased through China's Renewable Energy Development Project) (REN21, 2011).

An estimated one-third of the SHSs installed in developing countries are funded by donors and two-thirds have been supplied by commercial dealers (Nieuwenhout et al., 2001).

Successful SHS commercial markets world-wide include those found in Kenya, Morocco, Sri Lanka, India, Western China, and Zimbabwe (Vleuten et al., 2007). Surveys of self-initiated SHSs in Kenya suggest systems are $25 \mathrm{~W}$ on average and are $80-90 \%$ operational, which is average or better than average for developing countries (Nieuwenhout et al., 2001). A survey by Nieuwenhout et al. (2001) indicates that many users prefer a market-based approach, as $93 \%$ of respondents in Namibia and 95\% in Swaziland prefer to own rather than rent a SHS.

Many donors and governments also acknowledge the role of the private sector as a key element in driving development and designing creative electrification solutions (Vleuten et al., 2007). Thus, for more than a decade, donor-initiated user-owned projects have become popular, focusing on enhancing market forces to promote electrification through increased access to financing (REN21, 2011). However, at times this model has confused markets and even served as competition for dealers (Vleuten et al., 2007). One successful method to overcome this has been to fund local financing institutions that are 
committed to rural RE projects, which in turn provides financing to private companies, concessionaires, NGOs, and microfinance groups involved in the solar market. This occurred in the Infrastructure Development Company Limited (IDCOL) program in Bangladesh, where a local financial institution supported by donors provided refinancing, channelling of grants, setting of equipment standards, and capacity building for 30 local organizations who have now sold over 750,000 SHSs (Krithika \& Palit, 2011; REN21, 2011). Similarly, rapid market growth occurred in Sri Lanka as a result of such a program, where donors and local financial institutions supported the private sector by providing credit to end-users and strengthening their organization (Krithika \& Palit, 2011).

Grants and loans, which aid public and private organizations directly, have also become a common method to support SHS markets globally. Furthermore, some projects have financed rural electrification by combining grid extension and off-grid electrification into the same project, as off-grid electrification projects are often too small and too risky to be considered for substantial financial loans (REN21, 2011).

\subsubsection{RESCOs:}

Examples of RESCOs implemented worldwide include those in Zambia, Mali, Senegal, Sri Lanka, Dominican Republic, and the Comoros Islands (Krithika \& Palit, 2011; REN21, 2011). The RESCO in Mali and Senegal was run directly by the government utility, whereas the RESCO in Zambia was implemented by the government but run by the private sector. Initially, the RESCO in Zambia served most of the population; however, research indicates that many users without a steady source of income have been disconnected due to defaulting on fees, and mainly government workers remain (Krithika $\&$ Palit, 2011). This fading interest of end-users over time has been noted in a number of RESCO projects globally, and was seen in both countries examined in this research (Vleuten et al., 2007).

Furthermore, even if users do continue to make timely payments, in many RESCOs the fees are too low to cover the equipment and maintenance costs of the SHS. Rather, such projects are often subsidized in order to include low-income users, and fees are often set based upon affordability (Martinot \& Reiche, 2000). This can be viewed as a strength in 
that RESCOs make SHSs and their required O\&M affordable for the world's poor. Still, being able to recover O\&M costs is necessary for most projects to create lasting outcomes (Krithika \& Palit, 2011). However, not all RESCOs require subsidies; for example, the SOLUZ RESCO in the Dominican Republic is reported to be cash-flow positive (Martinot et al., 2002; Nieuwenhout et al., 2001). The company attributes its success to excellent maintenance and after-sales service, low-cost of collecting fees through boxes installed in each village, and having strong repossession rules for non-payment.

\subsection{An Overview of SHS Projects in PICs}

\subsubsection{Private sector:}

Donor aid to the private sector is especially needed in PICs, as few RE businesses in the region have survived for more than five years (Wade, 2005). Wade (2005) attributes failure to poor business management skills and lack of proper training on the technology, although other barriers occurring in PICs also contribute to the problem, such as a malfunctioning legal system, political corruption and instability, insufficient and unreliable infrastructure, limited access to finance, lack of qualified staff, and cultural biases (Vleuten et al., 2007). Additionally, PIC solar vendors may be limited by the local utility company by being prohibited to sell electricity and, therefore, must rely on one-time equipment sales.

Furthermore, competition from overseas dealers to carry out donor-funded projects has been a factor in certain PICs. For example, the tender for the EU's Renewable Energy Project for Five ACP Pacific Islands (REP-5) project proved difficult for local businesses to apply, as they required three quotes for nearly every piece of equipment, and required parts to be purchased from the EU (see the supplied SHS, Photograph 5.2.2.1) (Syngellakis et al.,
Photograph 5.2.2.1: A SHS installed through the EU's REP-5 Project.

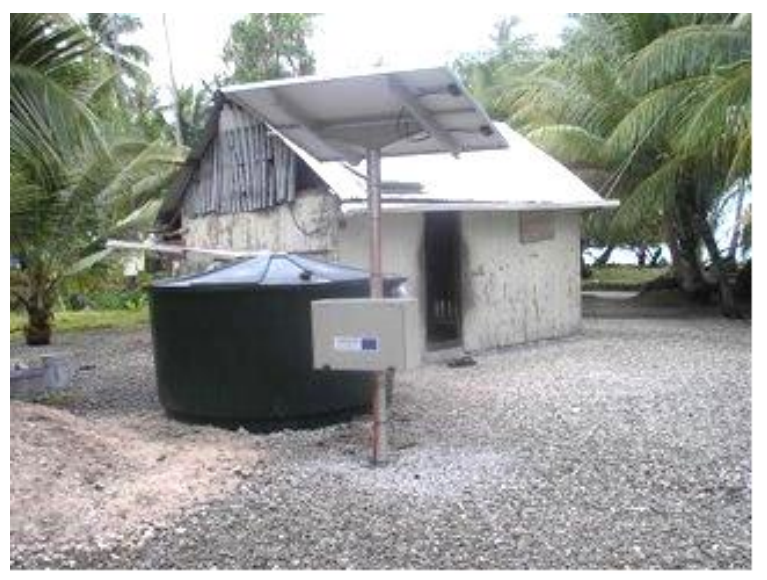

Source: REP-5 (2010) 
2010). In addition, local RE entrepreneurs are often overlooked by donor-funded projects, and such projects can undermine local market initiatives to the point of putting local dealers out of business (Vleuten et al., 2007). A solar PV company in the RMI described this experience of needing to diversify their products in order to stay in business, due to competition from externally-funded projects supplying SHSs at a subsidized rate through overseas companies (RMI Entrepreneur, Respondent 3, 2011). Furthermore, consumers have come to expect subsidized costs as a result of donor aid, and may refuse to pay market prices, thus undercutting local dealers (Martinot et al., 2002).

The Kiribati Solar Energy Company (SEC) was unsuccessful with private sales of SHSs to end-users from1984-1989 (specifics are described in Appendix 10). This is often cited as an example of why private markets are not the most-effective method of electrification in PICs (Nieuwenhout et al., 2001; Wade, 2005). Yet, as noted in Chapter 1, cost, quality, and user-friendliness of SHSs have dramatically changed in the past 20 years, as have users' familiarity with technology. Furthermore, there are a number of experiences in PICs that have shown that the involvement of local companies is an efficient and effective way to transfer technology, especially in Vanuatu, Fiji, and PNG. However, very little information is available in the literature or project documents regarding the number, size, or longevity of SHSs installed through the private sector in PICs, and thus the success of self-initiated user-owned projects in PICs is hard to quantify. The documented positive and negative experiences and lessons learned from the commercial market in PNG are described in detail in Appendix 11.

\subsubsection{RESCOs:}

RESCOs are the preferred option for many PICs, such as Fiji, Kiribati, Tonga, the Federated States of Micronesia (FSM), and the RMI, with Kiribati and Fiji's RESCOs being managed by local entrepreneurs acting as service companies, while FSM and the RMI's RESCOs are managed by government-run utility companies (Wade, 2005). Tonga's RESCO utilized a different approach, in that village-based Solar Energy Committees were set up to handle program and financial decisions, fee collections, and basic O\&M, with the government energy sector providing only technical backup and supply of spare parts. 
However, RESCOs in PICs continue to face difficulties, especially with fees failing to cover the cost of the program, slow and ineffective maintenance programs, and users overusing the systems as they are rewarded for system failure by receiving new equipment (Dornan, 2010; Wade, 2005a). In addition, RESCOs often rely on overseas dealers for equipment supply, sometimes resulting in difficulties after installation in obtaining spare parts and technical assistance (Yu \& Taplin, 1997). This was the case in the RMI, where spare lamps for the hundreds of SHSs installed by the government-run RESCO were unavailable nationwide at the time of this research.

Kiribati's SEC has been the exception, in that it has been fully functional since 1992, and has grown significantly as a result of successful management and donor support. It has now electrified nearly 4,000 households in Kiribati, with SHSs powering lights and radios. A summary of the history of RESCO electrification projects in Fiji, Kiribati, and Tonga, as recorded in project documents to date, as well as their positive and negative results and lessons learned, are described in more detail in Appendix 10.

\subsubsection{Community-based approaches:}

Co-operative management of SHS electrification was attempted in Tuvalu with the Tuvalu Solar Energy Co-operative, which was subsidized by grants, with systems maintained by locally-trained technicians. However, problems with money management caused the co-operative to dissolve after 10 years, which highlighted a major weakness of co-operative management, in that financial discipline is too weak. As a result, co-operative management has not been readily accepted in PICs or globally (Wade, 2005). The details of the project in Tuvalu are illustrated in Appendix 12.

Another community-based approach has been 'focal point' electrification, in which solar PV gives power to community facilities, such as a community laundromat or entertainment centre, rather than to individual homes. This model was used in Namdrik Atoll in the RMI for six community refrigeration systems; however, as no community building was available for the systems, they were installed in the chiefs' houses (Empower, 2005). Community members were uncomfortable entering the chiefs' houses to use the systems, and thus the systems were used mainly by the chiefs' families (see a full 
description of the project in Appendix 8). This model also has been ineffective in other sites, as maintenance of the systems has generally been poor due to a lack of clear ownership and responsibility for O\&M.

\subsubsection{Clean Development Mechanism (CDM):}

Carbon credits are a growing source of project finance among developing countries globally; however, no SHS projects have been carried out under the CDM in PICs. It has been suggested that small-scale community-level CDM projects are the most likely to result in poverty alleviation and livelihood changes (Subbarao, 2010). At the same time, the small scale is one of the biggest challenges for implementing CDM projects in PICs, in order to overcome project development and transaction cost barriers. However, there is still a significant potential for PIC SHS projects to be executed under the CDM.

\subsection{SHS projects in the RMI}

\subsubsection{Past Projects:}

The RMI has a long history of rural electrification through solar PV, which is portrayed more fully in Appendix 8. Most of the recent projects have been implemented through a RESCO model managed by the Marshalls Energy Company (MEC), and some have been met with limited success. The only existing private company focused on RE is Island Eco (IE), which has been selling solar lanterns and SHSs to individuals since 2001. The current status of their electrification project on Namdrik Atoll is described in detail in Chapter 6.

\subsubsection{Ongoing Projects:}

The EU's North REP project is the follow-up to its REP-5 electrification project for the North Pacific Islands. Under the North REP project, 1,500 SHSs are to be installed in the RMI of $200 \mathrm{~W}$ each, powering 5 lights per system (SPC, 2011). In addition, 700 of the 
SHSs are to have inverters for powering AC appliances. Equipment is to arrive in Majuro in the middle of 2012, after which it will be installed in the outer islands by MEC, with O\&M being managed by them as well, through a RESCO scheme.

\subsection{SHS Projects in Vanuatu}

\subsubsection{Past Projects:}

The Vanuatu Energy Unit (VEU) experimented with the RESCO model for rural electrification from 1999 to 2005, and was met with limited success (see Appendix 9). One reason for this was a lack of VEU staff to manage the project and promote RE (Matakiviti, 2006). After 2005, the private RE market gained strength and has been the primary installer of SHSs since, with nine RE companies and NGOs currently active in Port Vila. Microfinance to increase affordability of these systems has not been common, and currently only one microfinance organization, Vanwoods, has partnered with one NGO to provide financing to end-users (AusAid, Respondent 7, 2011).

\subsubsection{Ongoing Projects:}

The AusAid funded Vanuatu Electricity for Rural Development (VERD) Program will run for six years, starting in 2012 or 2013, and will partner with the new Rural Energy Unit, which is being established through Vanuatu's National Energy Plan. The aim of VERD is to have $80 \%$ of rural households use solar PV as their dominant light source at the close of the program (AusAid, 2011). This will be carried out through a 'rural lighting subsidy scheme,' which aims to: 1. Increase the affordability of small SHSs by subsidizing the initial cost; 2. Provide funds for pre-qualified vendors to help ease market constraints and create economies of scale; and 3. Provide incentives to help strengthen supply chains around Vanuatu. Thus, the project includes scope for market expansion while providing support and certifications for Vanuatu's private sector (AusAid, 2011). Also, a promotional campaign will be run to make users aware of the VERD program and which SHSs are 
eligible for subsidies, which include household SHSs up to 30W (for lighting only) (AusAid, Respondent 7, 2011).

End-users will be encouraged to use systems responsibly, and will agree to have certain responsibilities for O\&M. The project will provide education for users on system capacity and proper O\&M, and will specifically target women to operate systems, as VERD has observed that they are generally more responsible than men in managing SHSs (AusAid, 2011). A call centre will be available to aid users in repair, and systems will initially be under warrantee (AusAid, Respondent 7, 2011). In addition, vocational programs for training solar technicians will be set up in both the capital and rural areas.

Other ongoing regional projects and efforts are summarized in Appendix 13.

\subsection{Trends in Project Documents}

Project documents on the history of SHS electrification in seven PIC countries were examined, and are described in Appendices 8-12. The positive and negative results of projects that utilized a RESCO or user-owned model were categorized by indicators, with the co-operative approach excluded because it is not common or proven to be successful in PICs. Figure 5.5.1 demonstrates the number of occurrences of each indicator by electrification model. More RESCOs were considered than user-owned projects as it is the preferred electrification method in many PICs, and therefore they are more comprehensively documented. Therefore, conclusions cannot be drawn regarding one method as being preferable over another in terms of the number of positive and negative results, but, rather, the strengths and weaknesses of each model can be seen through trends. These trends include:

- Cost-effectiveness and availability of resources and support were the most cited issues overall, indicating that they are seen as essential for project success

- Participation and ownership were also often mentioned, in regards to the need for transparency and inclusion of all stakeholders from the project development stage 
- Both project models did not often consider their ability to satisfy expanding energy demands, user familiarity with the technology, gender inclusiveness, or effectiveness in improving the environment, leaving room for improvement

- Many RESCOs cited poor availability of resources and support, poor availability of system components, and poor willingness to pay by users in PICs; user-owned projects were stronger in the last two of these fields, with both types of projects lacking in providing resources and support, often due to long distances of projects from technicians and managing organizations

- RESCOs were strong in affordability, whereas user-owned projects were neutral in this regard, which was expected based on subsidies for RESCOs and costs for users being extended over time

- User-owned systems were strong in their effectiveness in changing community livelihoods, whereas this was often overlooked by RESCOs, which follows as user-owned systems vary in size and are able to join with local business efforts more easily

- Both RESCO and user-owned projects often are not very cost-effective, often due to equipment failures and systems needing to be subsidized

- Capacity building was often overlooked in both RESCOs and user-owned projects, resulting in negative results and sometimes project failure 
Figure 5.5.1 Positive and Negative Results found in RESCO and User-owned PIC project documents by the number of occurrences of each indicator.

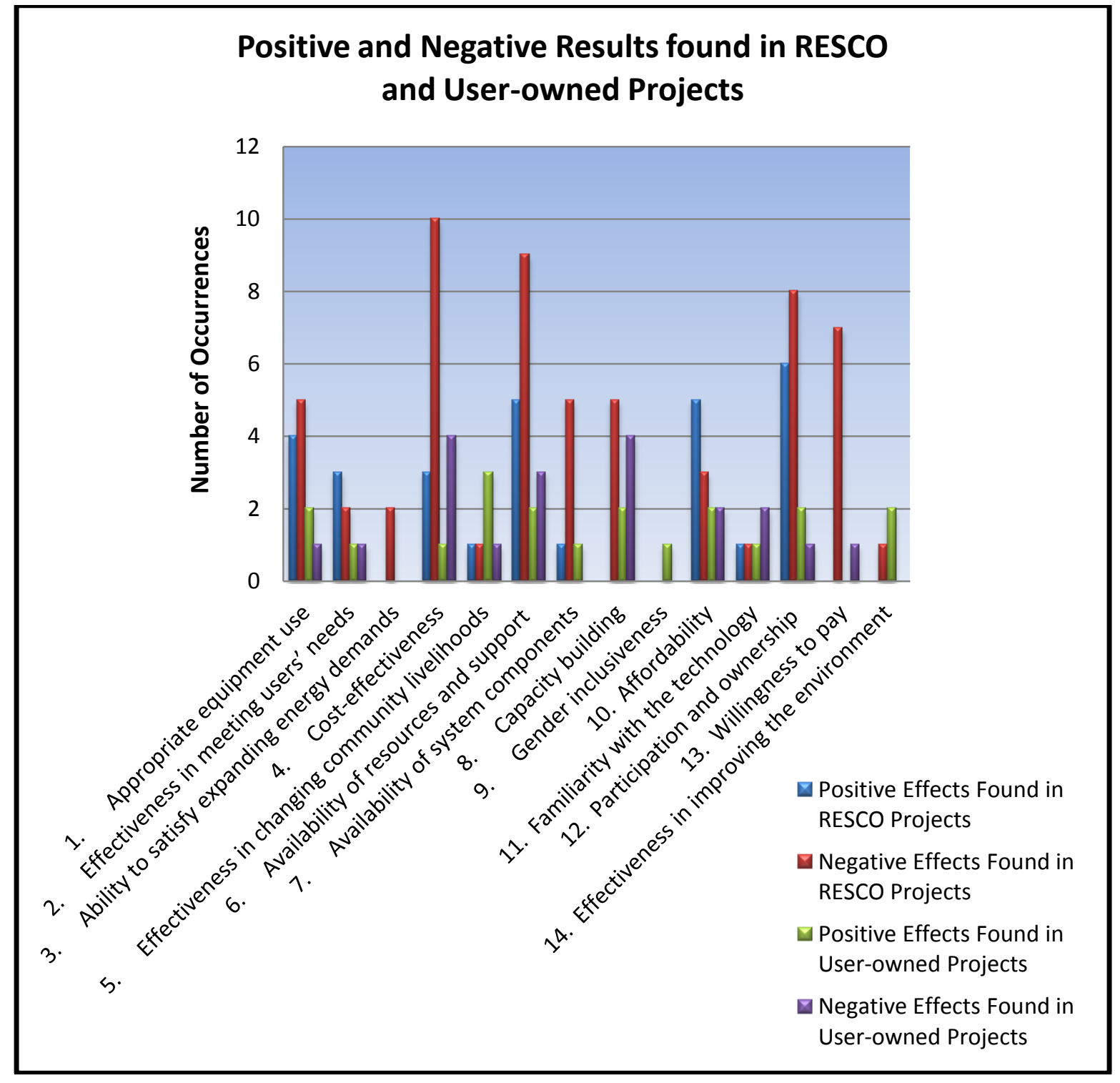




\subsection{Lessons Learned as Stated in PIC Project Documents}

The lessons learned through examining the project documents for seven PICs, as well as other more general documents regarding experiences with rural electrification in PICs, are summarised in Table 5.6.1. Some of these lessons may appear to be conflicting due to differing opinions; however, they are appropriate to the electrification model examined. Lessons that were cited twice or more are italicised, and can be considered essential in project design. In summary, the topics that were often repeated include the need to:

- have transparency and non-conflicting interests from all parties

- oversize systems and use high-quality technologies proven for PICs

- have options for system sizes that can be increased according to demand

- have a reliable maintenance plan with spare parts available locally

- make systems affordable for users by spreading costs over time

- have projects that are cash-flow positive for the long-term, to avoid reliance on subsidies

- provide training for users, and for other project stakeholders as well

- consider users with irregular incomes, as they have trouble paying regular monthly fees

- provide O\&M and contact information for users in the local language, and attach it to the systems 
Table 5.6.1: Lessons learned as stated in project documents in PICs.

\begin{tabular}{|c|c|}
\hline Indicator & Lessons Learned \\
\hline $\begin{array}{l}\text { 1. Appropriate } \\
\text { equipment use }\end{array}$ & $\begin{array}{l}\text { - End-users may purchase undersized systems and cheap replacement components if given the choice } \\
\text { - Prepayment meters appear to be a good concept in theory, but in practice they require skilled personnel to } \\
\text { maintain them } \\
\text { - High quality and maintenance-free batteries are needed to avoid issues with servicing and increase longevity } \\
\text { - Complex technologies and untested equipment for PIC environments may create maintenance issues } \\
\text { - Outdoor lights are important for remote islands and should be considered in system design }\end{array}$ \\
\hline $\begin{array}{l}\text { 2. Effectiveness in } \\
\text { meeting users' } \\
\text { needs }\end{array}$ & $\begin{array}{l}\text { - Though it is desirable to standardise equipment in order to create economies of scale, this should not come before } \\
\text { appropriate system use } \\
\text { - Systems should be oversized, as end-users often share the services provided, which is part of the Pacific culture } \\
\text { - The conservative nature of people in PICs and their general reluctance to change make it difficult to introduce } \\
\text { new technologies and operational structures } \\
\text { Lessons learned in earlier projects should be consistently applied to later projects, yet this requires a clear } \\
\text { national policy for electrification }\end{array}$ \\
\hline $\begin{array}{l}\text { 3. Ability to satisfy } \\
\text { expanding energy } \\
\text { demands }\end{array}$ & $\begin{array}{l}\text { Providing only one system size does not account for increasing energy demands, and can result in dissatisfaction } \\
\text { - Demand for consumer electronics and appliances in PICs is increasing, following global markets, and SHSs } \\
\text { should be designed to accommodate this } \\
\text { - Providing the same-sized systems for all households promotes inequity rather than fairness, as the poor often } \\
\text { cannot keep up with payments and may be disconnected, causing embarrassment. Options in system sizes would } \\
\text { solve this issue, especially if end-users are allowed to adjust the size of the system they are renting based on } \\
\text { changes in income. }\end{array}$ \\
\hline 4. Cost-effectiveness & $\begin{array}{l}\text { Oversize systems makes economic sense, in order to reduce the need for expensive battery replacements } \\
\text { - Disconnected systems need to be relocated to avoid project inefficiency } \\
\text { Fees need to be set according to project costs, rather than according to previous energy expenditures or income } \\
\text { levels, unless projects plan to be subsidized for their duration; this will help prevent distortions in the market } \\
\text { - RESCO projects can become an economic burden for the managing organization if they fail } \\
\text { - One company was successful using elders as technicians, as they were more respected in the community and } \\
\text { therefore more able to collect fees }\end{array}$ \\
\hline $\begin{array}{l}\text { 5. Effectiveness in } \\
\text { changing } \\
\text { community }\end{array}$ & $\begin{array}{l}\text { Many projects supply systems that only provide lighting and sometimes power a radio or a mobile, thus limiting } \\
\text { possibilities for productive uses } \\
\text { - Projects that provide the same sized systems hinder the employment of SHSs for productive uses }\end{array}$ \\
\hline
\end{tabular}




\begin{tabular}{|c|c|}
\hline livelihoods & - Employing rural organizations and increasing their business capacity can increase community livelihoods \\
\hline $\begin{array}{l}\text { 6. Availability of } \\
\text { resources and } \\
\text { support }\end{array}$ & $\begin{array}{l}\text { - Both installers and maintenance technicians should be based within the project country } \\
\text { - Communication between end-users and the managing organization/ vendor needs to be easily available and } \\
\text { systematic } \\
\text { - An abundance of skilled personnel aids in project endurance } \\
\text { - Technicians need to be located near to the systems they maintain in order to improve efficiency and reduce costs } \\
\text { - Wages for technicians need to be fair, and provided on an incentive basis } \\
\text { - A lack of a long-term O\&M policy leads to project failure } \\
\text { - The RESCO model increases longevity by providing regular O\&M } \\
\text { - Project policies regarding fees, disconnection, and O\&M need to be consistent locally and nationally to prevent } \\
\text { unfairness } \\
\text { - All manuals and information need to be translated into the local language and made accessible for users; this } \\
\text { may include a maintenance checklist, graphical instructions, and contact numbers for support }\end{array}$ \\
\hline $\begin{array}{l}\text { 7. Availability of } \\
\text { system components }\end{array}$ & $\begin{array}{l}\text { - Strong supply lines need to be developed to replenish spare parts } \\
\text { - Project fees should include costs of spare parts for unexpected technical problems } \\
\text { - Spare components need to be available locally to avoid delays in maintenance }\end{array}$ \\
\hline 8. Capacity building & $\begin{array}{l}\text { - Training is required at all levels for management, technicians, and end-users } \\
\text { - Training end-users can increase project longevity } \\
\text { - All rural users need to be able to maintain their SHSs, as they may not have regular access to after-sales service } \\
\text { due to the remoteness of PICs } \\
\text { - Some technicians felt their training was not adequate, reflecting the need for practical training that meets their } \\
\text { educational levels } \\
\text { - Active government support is required if they are involved in electrification projects, which is not always possible } \\
\text { due to under-resourced and under-staffed offices }\end{array}$ \\
\hline $\begin{array}{l}\text { 9. Gender } \\
\text { inclusiveness }\end{array}$ & $\begin{array}{l}\text { - Women end-users may be more responsible than men as SHSs managers, and need to be targeted for training } \\
\text { - The energy sector in PICs is male-dominated, indicating a need for training for women at all levels }\end{array}$ \\
\hline 10. Affordability & $\begin{array}{l}\text { - People with regular incomes are much more likely to pay monthly fees on time } \\
\text { - Cash-flow is generally irregular and needs-based, and therefore many rural end-users struggle to pay monthly } \\
\text { - Rees and prefer smaller, more regular payments } \\
\text { - RESCOs in some PICs have been collecting less than half of target payments, as households are not motivated to } \\
\text { pay ongoing fees } \\
\text { - SHSs are still not affordable nor a priority for many low-income families } \\
\text { - Solar lanterns may be more affordable options than small SHSs for lighting }\end{array}$ \\
\hline
\end{tabular}


- Financial literacy continues to be an issue for expanding SHS markets

- Financing options for end-users can help increase affordability and private sales

11. Familiarity with the technology

12. Participation and ownership
- Consumer electronics and entertainment are increasingly part of everyday life in PICs. Therefore, end-users' familiarity with technology is ever-increasing.

- The provision of RE systems for free does not provide an incentive to take care of the systems, as there is no investment by the end-user

- Systems that are rented may be mistreated, as end-users expect to be rewarded by receiving free replacement parts

- The co-operative model is weak in fiscal discipline, which has caused it to be unsuccessful in the past

- Community-shared systems also often do not work, due to ownership being unclear

- Participation should be voluntary in order to ensure that end-users have a desire to pay and care for their systems

- Clearly defining roles and having transparency in projects is necessary to prevent confusion and unnecessary speculation

- Contrasting interests between stakeholders can lead to project failure

- All stakeholders must be involved in project design, including adequate community consultation

- Letting local businesses share the risk, by re-selling solar PV, can increase ownership

- End-users may not retain interest in paying for systems that they do not own over a long period of time

- Installation fees should be required to be paid in full before connection

- Project sustainability is threatened by end-users not paying due to dissatisfaction

- Prepayment meters do not prevent a low rate of fee collection if users are unsatisfied

- End-users need incentives and financial mechanisms to reserve money to pay for maintenance

- End-users are generally satisfied when systems are large and fees are small

- Costs of systems have become more affordable over time and may affect users' willingness to pay

14. Effectiveness in improving the

environment
- Programmes need to include recycling of lead-acid batteries, given that lead can be toxic

- New non-toxic NaS redox flow batteries could be an alternative in the future

- Solar lanterns are a quick and effective way to decrease reliance on kerosene

Sources: APCTT-UNESCAP (2009); AusAid (2011); Dornan (2010); Empower (2007); Europeaid (2009); IRENA (2011); IRENA (2012); Johnston (2004); Johnston (2004a); Johnston (2004b); Kopi \& Lloyd (2002); Mario (2003); MEC (2008); MECC (2012); Nieuwenhout et al. (2001); Palaki et al. (2009); Soriano (2007); Sovacool (2011); Syngellakis et al. (2010); Urmee (2009); Urmee et al. (2009); Urmee \& Harries (2009); Wade (2004); Wade (2004a); Wade (2004b); Wade (2004c); Wade (2005). 


\section{Chapter 6: \\ The Quantitative Data Results and Analysis}

\subsection{Results of the Quantitative Questionnaire by Indicators}

The following results are based on answers to questionnaires from 18 respondents from Namdrik Atoll, RMI, regarding a RESCO and project-initiated user-owned project, and 39 respondents from Akhamb Island, Vanuatu, regarding their self-initiated userowned SHSs ${ }^{5}$.

\section{Appropriate equipment use:}

Ninety-two percent of the 43 SHSs installed between 2005 and 2011 on Akhamb Island were working properly at the time of research $(\mathrm{Q} \# 13 \& 20)^{6}$. For those that were not working, one owner had sent his module to be fixed by a solar company in Port Vila, and two owners were saving up funds to replace broken modules, as they were bought from a solar vendor in Port Vila that had been selling used, faulty panels. In addition, nine inverters had needed to be replaced, probably due to their being poor quality or not designed for the environment (Q\#21) (see Figure 6.1.1.1). Such experiences demonstrate the need for more appropriate PV equipment use, through the creation of certifications and standards for equipment and vendors.

Only 26\% of end-users on Akhamb were using a deep-cycle battery (designed for solar PV); the others were using vehicle batteries, due to their cheaper cost (Q\#25). However, these batteries also have a much shorter lifespan, which is probably the reason why four batteries have needed to be replaced already. AusAid (2011) suggested that a possible solution to encourage the use of deep-cycle batteries would be to subsidize their price.

The average specifications of the SHSs on Akhamb are illustrated in Table 6.1.1.1 (Q\#25). These systems were sized relatively well in terms of the ratio of module sizes to

\footnotetext{
${ }^{5}$ See Chapter 4 for background information on the projects.

${ }^{6}$ This indicates the question number(s) in the questionnaire from which the information was gathered. See Appendix 6 for the full text of the questionnaire.
} 
batteries, although some systems were undersized for the power requirements, which also may have contributed to battery failures. However, many owners said that they would like to add modules to their SHS to prevent overuse, and buy batteries designed for solar PV when their current batteries fail.

All of the surveyed SHSs installed by Island Eco (IE) on Namdrik Atoll were working at the time of research (Q\#20). Additionally, 83\% of the surveyed systems rehabilitated in 2001 through the PREFACE project, and managed by MEC since 2004, were working (Q\#37) (See Photographs 6.1.1.1). Both systems used high quality parts as compared to Akhamb, although some of the PREFACE equipment still needed replacing. In fact, only four years after refurbishment, it was reported that some of the batteries were beginning to fail (Empower, 2005).

These systems managed by MEC are 80W and powered 3 lights (MEC, 2005). The systems installed by IE were 320W, powering 2 lights and a freezer (Q\#25\&43). Both systems were well-designed to power the appliances intended; however, many end-users were found to be using additional appliances with both of the systems, thus leading to system overuse (Empower, 2005; RMI Entrepreneur, Respondent 3, 2011). Thus, the quality of equipment did not help to overcome maintenance issues faced from system overuse, which was seen in all models.

Figure 6.1.1.1 (Q\#21):

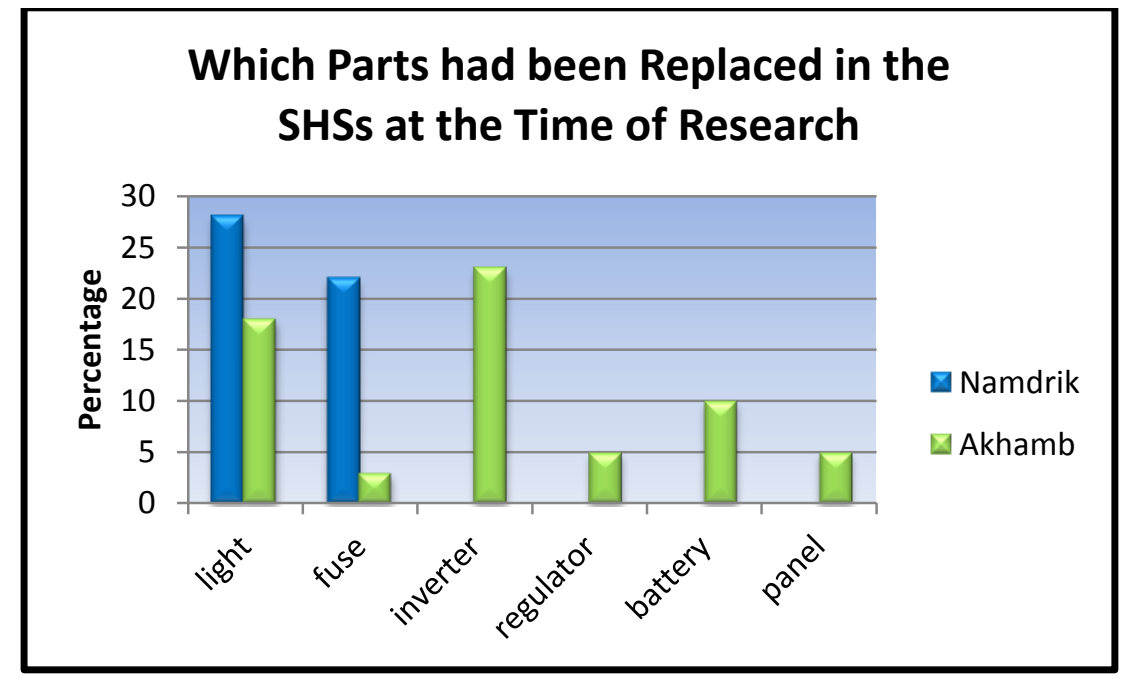


Table 6.1.1.1: Akhamb's 43 SHSs' specifications and usage (Q\#25).

\begin{tabular}{|l|l|}
\hline Average watts of modules & $66 \mathrm{~W}$ \\
\hline Range of watts of modules & $15-270 \mathrm{~W}$ \\
\hline Average battery amperage & 111 Amp hours \\
\hline Average number of lights & 2.3 lights \\
\hline Percentage of systems with a television & $67 \%$ \\
\hline Percentage of systems with a stereo & $23 \%$ \\
\hline Percentage of systems with a computer & $8 \%$ \\
\hline Percentage of systems with a printer & $8 \%$ \\
\hline Percentage of systems with a freezer & $3 \%$ \\
\hline
\end{tabular}

Photographs 6.1.1.1: SHSs installed by IE (top) and managed by MEC (bottom) on Namdrik Atoll.

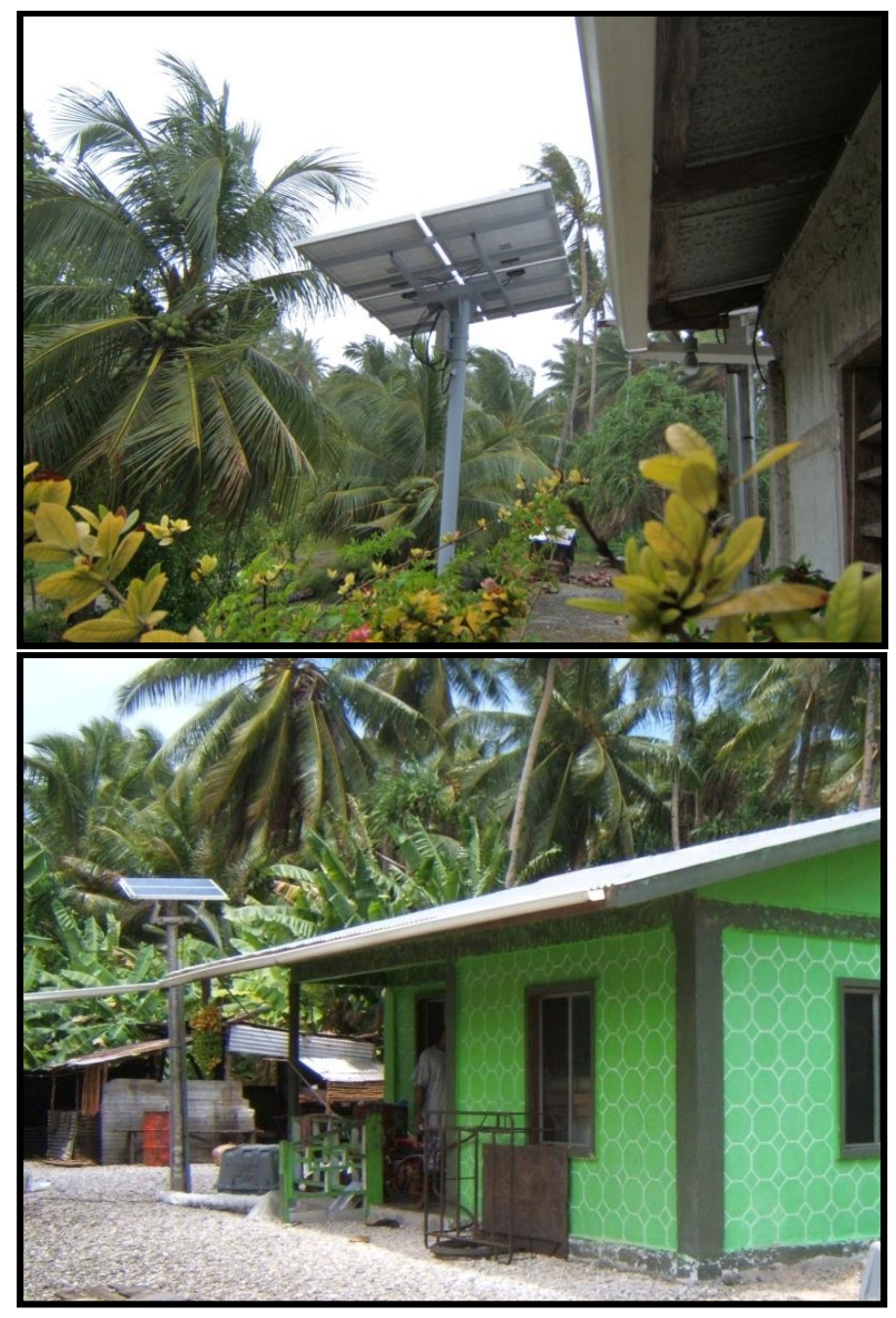

Sources: Photography by Ned Nathan (2011). 


\section{Effectiveness in meeting users' needs:}

One hundred percent of respondents from both communities reported that they preferred to be able to design and alter their systems, with all of the respondents on Akhamb Island having designed their own SHS (Q\#15\&51). Although this was not the case with the end-users of the IE systems, IE did conduct a survey of user-preferences, and based their system design on users' stated preferences for refrigeration and lighting (RMI Entrepreneur, Respondent 3, 2011).This contrasted with the PREFACE-installed systems on Namdrik Atoll, which despite some community consultation, did not include end-users preferences in the final system design (Q\#33) (Wade, 2004a). This may have caused many end-users to both alter their systems by adding inverters and appliances, and be unwilling to pay fees (Empower, 2005).

Solar PV is the main source of power in both communities, with only $3 \%$ of respondents having generators for backup power, and many respondents on Namdrik having two SHSs, due to the presence of two projects that served different needs (Q\#7) (see Figure 6.1.2.1). One hundred percent of respondents in both case studies indicated that having a SHS was very important to their family, and that they trusted solar PV as a reliable power source (Q\#52\&53). Therefore, SHSs appear to be a satisfactory and trusted technology to meet end-users' electricity needs.

On Namdrik, end-users expressed the most interest in gaining access to more lighting, a television, and a washing machine, indicating that the number of lights provided by the two projects were not enough for some households (Q\#26) (see Figure 6.1.2.2). Television was an expected response, as neither project was designed to power them, and the literature suggests television is the most desired appliance beyond lighting. Additionally, the high demand for IE's systems, considering their cost, indicates that refrigeration was a sought-after service which met many users' needs.

More lighting and television was also desired by end-users on Akhamb, followed by a freezer, stereo, computer, and power tools in descending order. Some users on Akhamb indicated that they were planning to purchase more lights or the appliance of their choice, and some had considered expanding their system to fit the additional power requirements. 
Overall, lighting and television were the most desired result of electrification in the case studies, followed by refrigeration and other appliances, depending on end-users' occupations and interests. SHSs need to incorporate these preferences, as otherwise they risk dissatisfying end-users, and users will alter and overuse their systems to meet their needs.

Figure 6.1.2.1 (Q\#7):

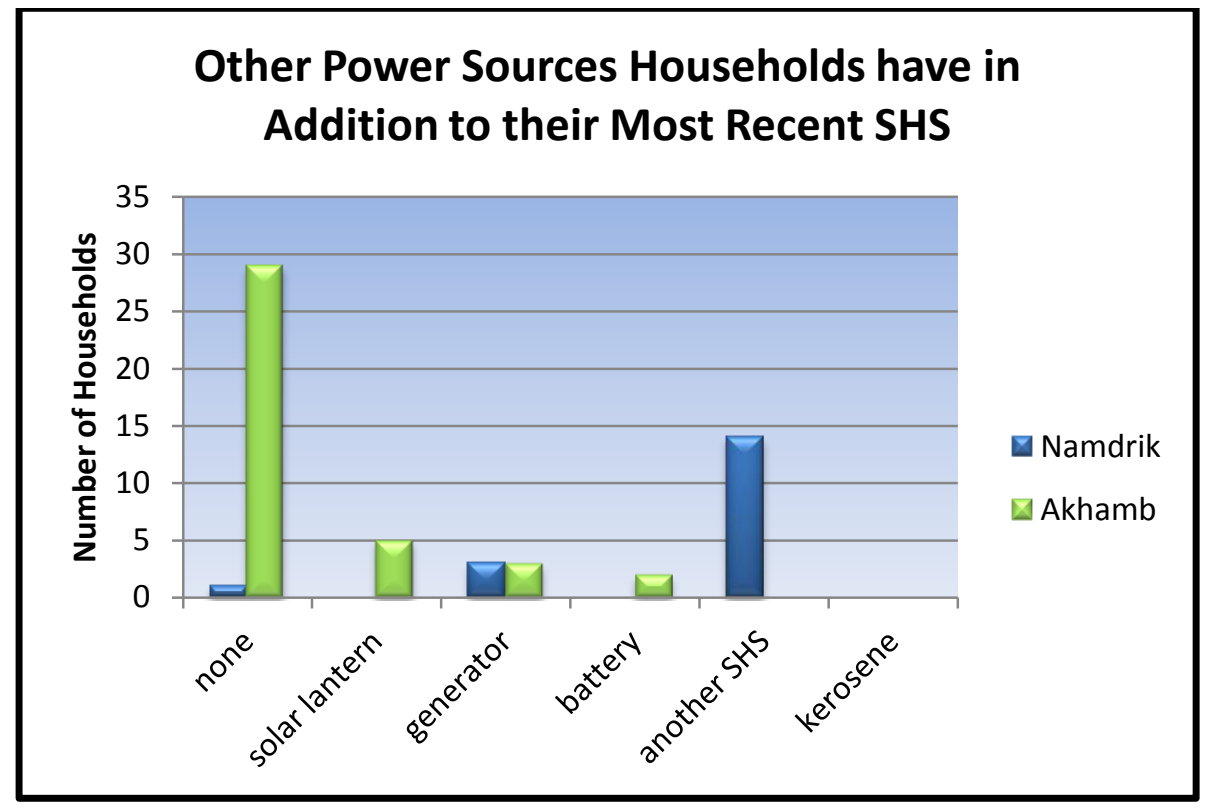

Figure 6.1.2.2 (Q\#26):

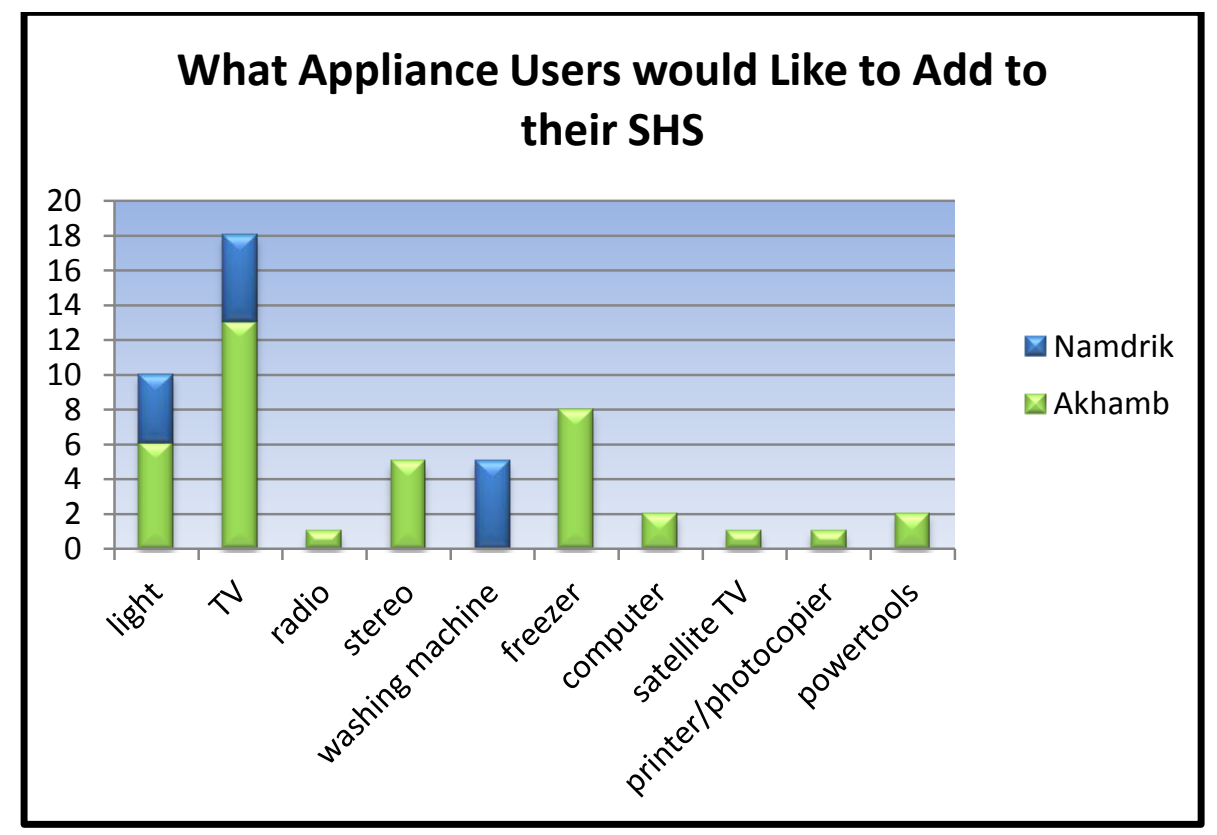




\section{Ability to satisfy expanding energy demands:}

Neither of the projects implemented on Namdrik were designed to accommodate expanding energy demands. This was especially problematic with the PREFACE systems, as electricity demands quickly increased after installation (Empower, 2005). However, the aim of the IE systems was to provide refrigeration to households that desired it, rather than to provide electrification, and thus systems were of adequate size to meet this need without expansion (RMI Entrepreneur, Respondent 3, 2011). Still, SHS end-users on Namdrik who desired power for additional services needed to purchase their own additional energy source (or alter one of the systems, against the managing organizations' recommendations) (Q\#16\&34).

This was not the case on Akhamb, as systems were initially designed by users to power the appliance of their choice, based on their ability to pay. Some systems were even designed with expanding needs in mind, depending on the SHS supplier (Vanuatu Entrepreneur, Respondent 8, 2011). In addition, one SHS owner resold his system locally and purchased a new system in order to expand his household's energy supply. Therefore, the systems on Akhamb did take expanding energy demands into account in two different ways. Overall, the case studies indicate that projects that are user-initiated are more likely to satisfy expanding energy demands and, therefore, more likely to satisfy end-users.

\section{Cost-effectiveness:}

Users were paying \$12/month to MEC to rent the systems on Namdrik, or $\$ 144$ per year, which was later reduced to $\$ 5$ temporarily (Q\#35). With the IE project, users were paying $\$ 1750$ for the initial cost, equal to $25 \%$ of the total price of the systems; however, the cost of maintenance has yet to be quantified as the systems were installed in 2010. The Namdrik local government provided financing to end-users, by allowing households to reimburse them for the initial cost over time, in order to increase affordability.

When comparing the costs, initially the IE systems appeared more costly than the MEC systems; however, this is an unfair comparison because the IE systems had provided $320 \mathrm{~W}$ systems with refrigeration, a sought-after appliance in remote tropical atolls and one that can contribute to productive uses. The system cost included maintenance for the first 
two years, beyond which ownership is transferred to users, who will then have to cover the costs. In contrast, the $80 \mathrm{~W}$ systems managed by MEC are mainly for lighting, yet fees include maintenance and component costs. In addition, no tax or import duty was paid by PREFACE on the equipment or spare parts, whereas the IE systems included tax and import duty, thus making the IE systems more costly.

On Akhamb, 67\% of end-users were paying between $\$ 0-100$ per year to maintain their systems, most of which was spent directly on spare parts (see Figure 6.1.4.1) (Q\#18). Owners who were unsure how to fix their systems may seek advice from a local technician; however, this cost was minimal (\$2-5 per visit). The other 33\% included those who had purchased poor quality parts or had more than one part break within a year. However, the average size of the systems installed on Akhamb $(66 \mathrm{~W})$ was smaller than the other two projects, and they had been installed an average of 2.1 years ago (as of October 2011), and thus maintenance costs may still increase.

A comparison of the cost-effectiveness of the MEC-managed systems and the systems installed on Akhamb is made in Table 6.1.4.1 (IE was left out as maintenance cost data is unavailable). This table indicates that since end-users on Akhamb are able to purchase parts directly, with a variety of solar vendors to choose from, and the cost of paying a local technician to visit is minimal, the systems on Akhamb have the potential to be the most cost-effective if managed correctly. In addition, it shows that the cost of maintaining a SHS is similar to that of grid-supplied residential power in Port Vila.

Given the current costs for users, all three systems are cost-effective in their own right, as one includes maintenance, one provides refrigeration, and one allows users to spend their money directly on components. However, if the subsidies on the Namdrik projects are removed (the SHSs on Akhamb were not subsidized), the self-initiated systems appear to be the most cost-effective.

Table 6.1.4.1: A comparison of the cost per $\mathrm{kW}$ hour of the systems managed by MEC and those installed on Akhamb Island.

\begin{tabular}{|l|l|l|}
\hline Project & MEC & Akhamb \\
\hline Average array output & $80 \mathrm{~W}$ & $66 \mathrm{~W}$ \\
\hline Average solar hours per day & 6 hours & 6 hours \\
\hline Total kWhrs available per & $175.2 \mathrm{kWhrs} / \mathrm{yr}$ & $144.5 \mathrm{kWhrs} / \mathrm{yr}$ \\
\hline
\end{tabular}




\section{year}

Yearly average cost (including subsidies)

Estimated per kWhr charge
$\$ 144$

$\$ 0.82 / \mathrm{kWhr}$
$\$ 95$ (85 parts and 10 for technician)

$\$ 0.66 / \mathrm{kWhr}$

Figure 6.1.4.1 (Q\#18):

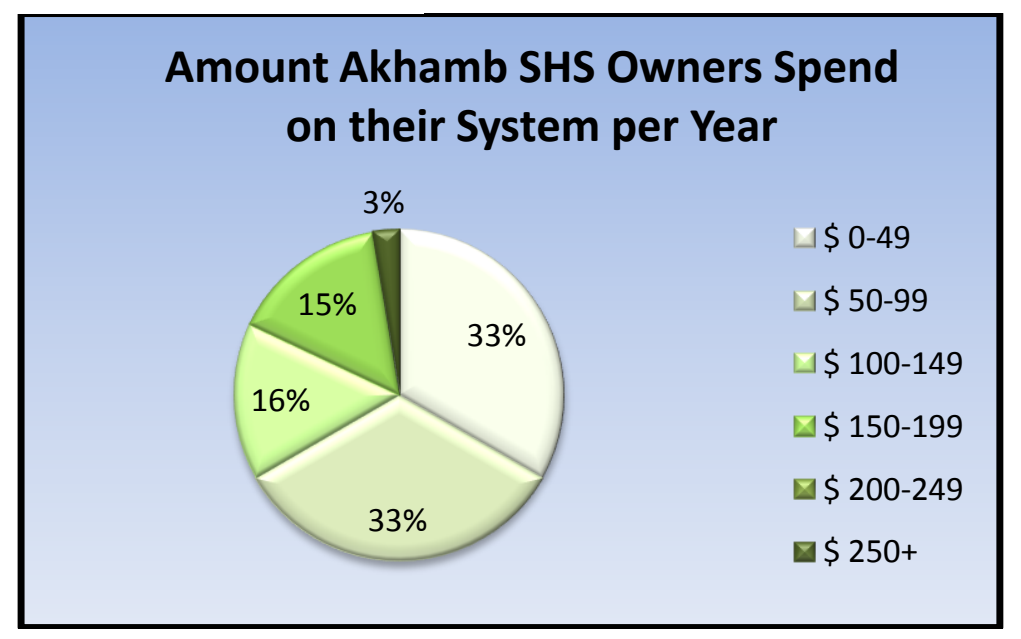

5. Effectiveness in changing community livelihoods:

Lighting was used for a variety of activities on both Akhamb and Namdrik (see Figure 6.1.5.1). The most regular use was for 'studying,' followed by 'reading,' 'eating,' and 'cooking,' with $80 \%$ or more of respondents in both communities employing their lights for these reasons $(\mathrm{Q} \# 9)$. Other purposes included 'making something to sell,' 'selling something at night,' carrying out 'business-related work,' holding 'evening meetings,' and for 'household security.' Over $80 \%$ of users on Akhamb and nearly $60 \%$ on Namdrik were 'making something to sell,' which commonly referred to women weaving handicrafts at night. 'Selling something at night' and undertaking 'business-related work' also occurred regularly in both communities. All of these responses indicate that SHS lights are already being used for productive purposes in both communities, and have undoubtedly contributed to improving community livelihoods.

The freezers installed on Namdrik were also being used for productive purposes, as $89 \%$ of respondents indicated that they were 'storing something to sell locally,' and $83 \%$ indicated that they were 'storing something to export to Majuro' (Q\#10). This reflects the primary source of income on Namdrik, which is farming and fishing (Q\#5) (see Figure 
6.1.5.3). Thus, crops, meat, and fish can be frozen until it is purchased locally or until transport is available to export it to Majuro. In addition, meat, vegetables, and infant food can be imported and stored (RMI Entrepreneur, Respondent 3, 2011). Similar uses could apply to Akhamb Island with refrigeration, as they had similar primary income sources.

SHS owners on Akhamb were already using a variety of appliances, including a computer, printer, and freezer, which indicate productive uses of the electricity beyond uses for lighting (see Table 6.1.1.1). Therefore, SHSs in both communities are already contributing towards increasing users' incomes and changing community livelihoods, despite the newness of two of the three projects.

Figure 6.1.5.1 (Q\#9):

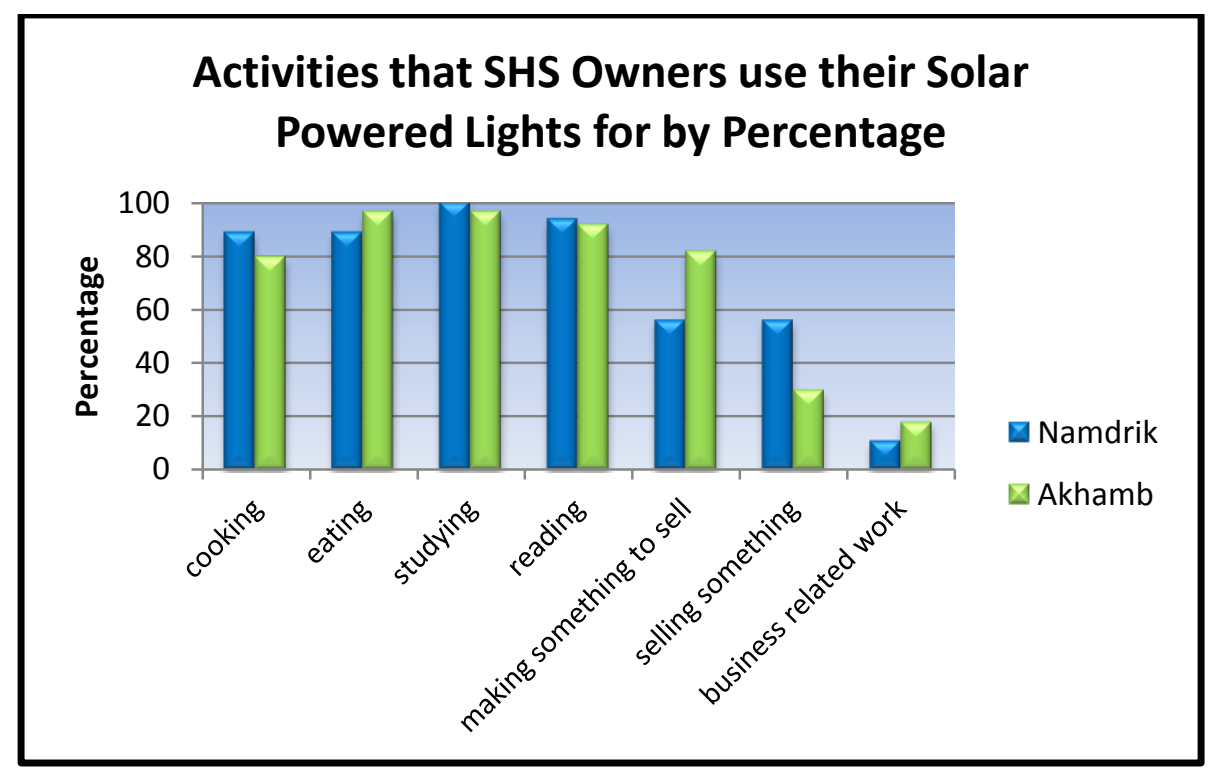

Figure 6.1.5.2 (Q\#10):

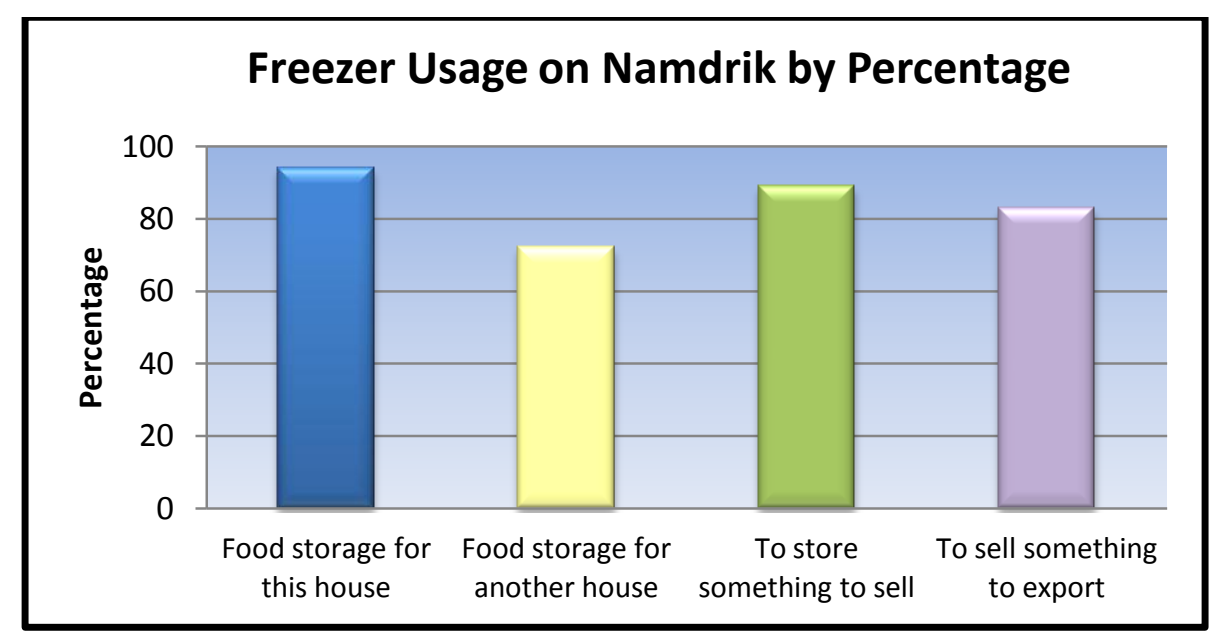


Figure 6.1.5.3 (Q\#5):

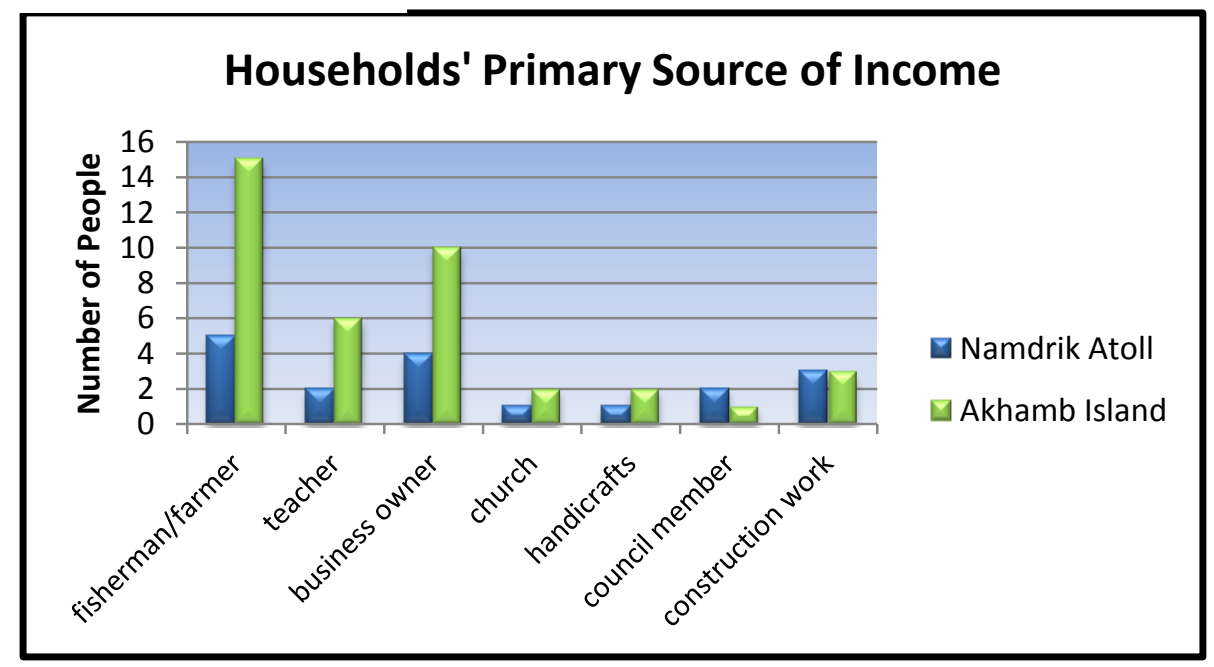

\section{Availability of resources and support:}

Figure 6.1.6.1 illustrates end-users' level of confidence that someone in their household is able to fix their SHS, and their confidence in the technical support available in their community and capital city (Q\#28-30). Eighty-two percent of SHS owners on Akhamb felt confident that someone in their community would be able to fix their system if they could not, which was notable as none of the local technicians on Akhamb had been properly trained in solar PV. Yet, confidence regarding access to technical support in Port Vila was divided, and depended on the vendor, and whether or not they felt comfortable seeking help, as many owners felt inhibited due to the reserved nature of their culture.

Overall, on Akhamb, 87\% of respondents stated that their system was maintained 'very well,' and 90\% stated that their lights had been working 'very well': an indication that the SHSs have been properly functioning (Q\#23\&24). Thus, self-organized technical support appears to be working well for the community.

In Namdrik, there were lower levels of confidence in technical support both locally and nationally. With their most recent SHSs, this was possibly due to: 1 . the system's complexity, 2. IE not stationing a technician locally, and 3. a lack of spare parts available locally.

The end-users of the MEC-managed systems that were not working at the time of research all cited the reason for failure to be "the person who was supposed to repair the 
system wasn't available," suggesting limited availability of resources and support (Q\#39). In fact, $94 \%$ of respondents cited that this system was poorly maintained and $83 \%$ of respondents stated that their lights have not worked well: an indication that the SHSs have not been properly functioning $(\mathrm{Q} \# 40 \& 41)$. However, it must be considered that these systems are older, and that fee payment rates have not been satisfactory, contributing to limited funds for technical support and components. All considered, the data indicates that end-users considered the user-owned systems on Namdrik and Akhamb to have been better maintained than the rented RESCO systems.

Figure 6.1.6.1 (Q\# 28-30):

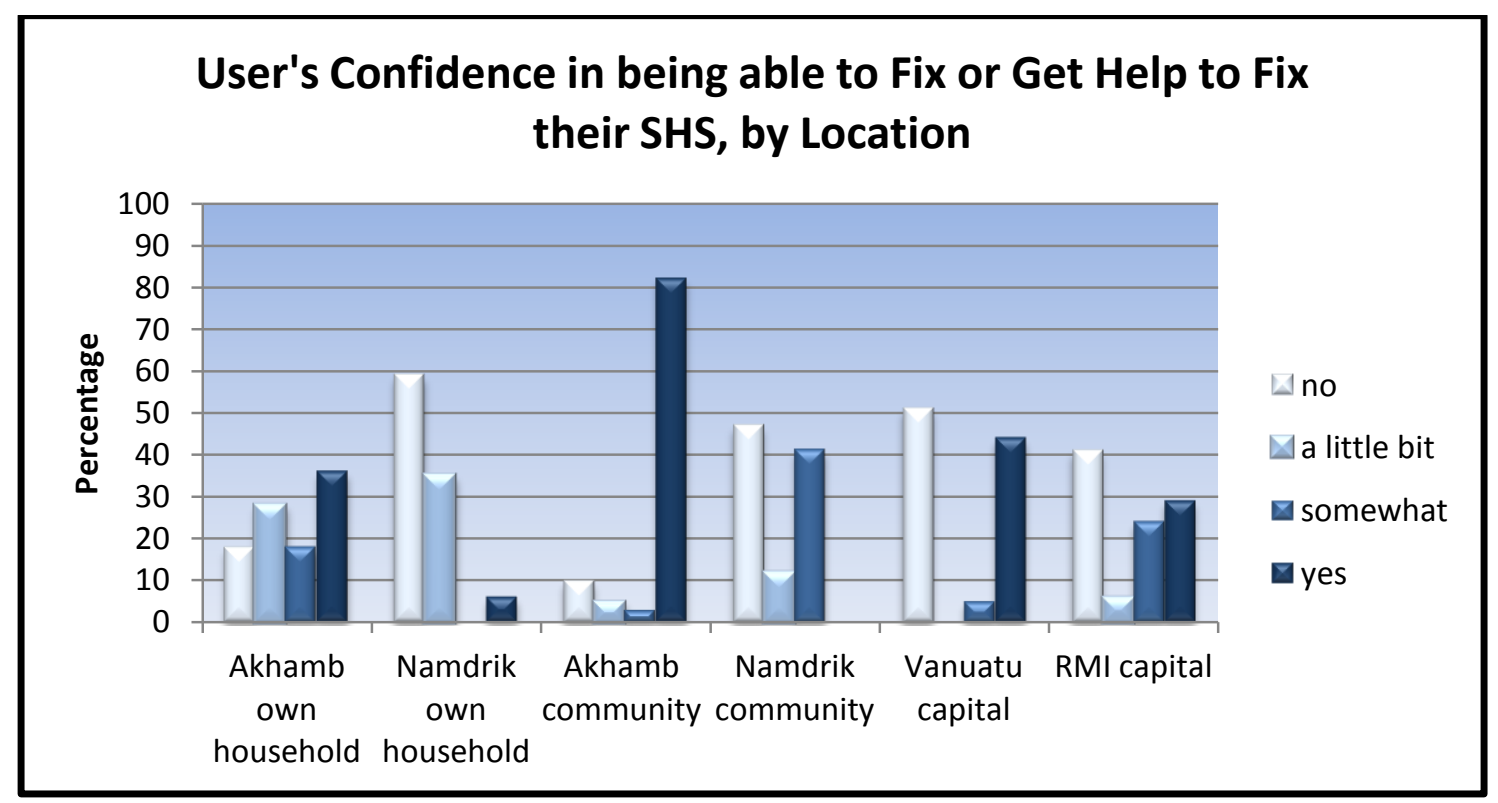

Figure 6.1.6.2 (Q\#23 and 40):

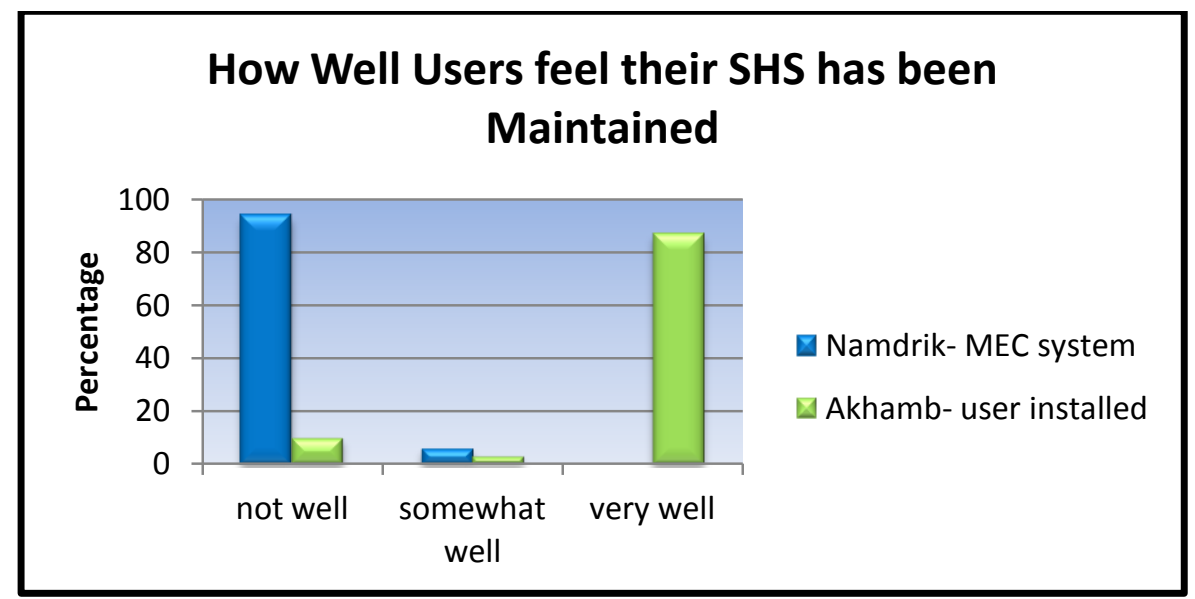


Figure 6.1.6.3 (Q\#24 and 41):

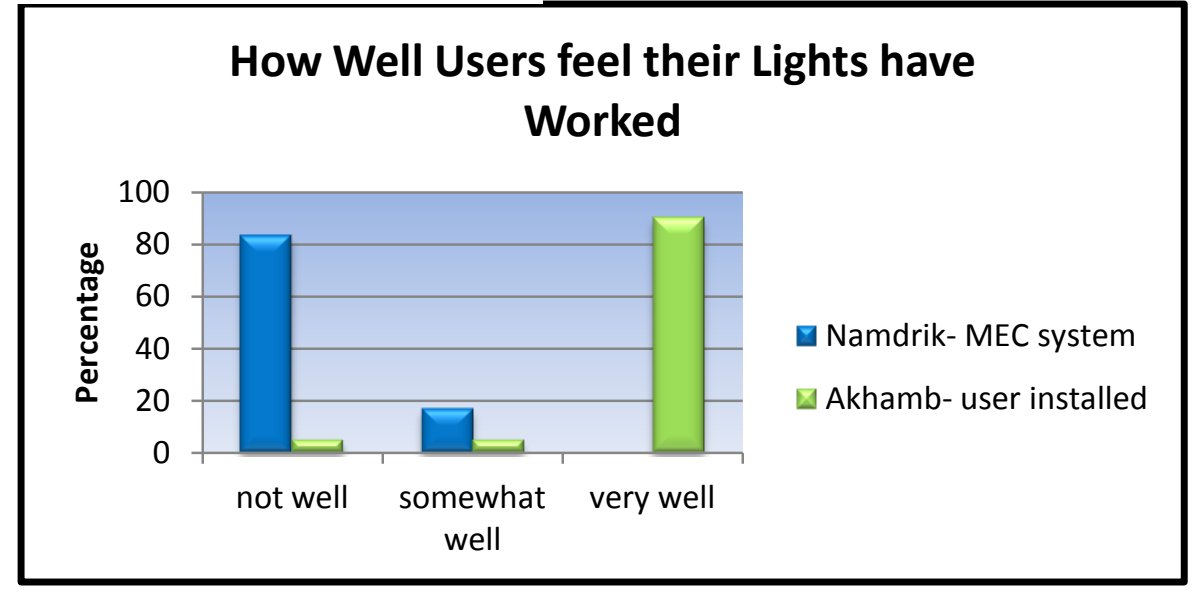

\section{Availability of system components:}

On Akhamb Island, one technician was acting as a local solar vendor, by reselling SHSs and components that are shipped from a dealer in the capital on a credit basis. This has greatly increased the availability of spare parts on the island, and at the same time has resulted in a new local business (Akhamb Technician, Respondent 6, 2011).

A similar arrangement has not happened on Namdrik, and end-users are required to acquire components, such as spare lamps, themselves, as they are not covered under system maintenance policies. This was often problematic with the MEC-maintained systems, as those specific lamps were not available nationally in either 2011 or in 2005 (Empower, 2005). For equipment that is covered by the projects, end-users must rely on technicians' visits to supply the components and repair the systems. Consequently, SHS components appear to be more readily available on Akhamb Island as compared to Namdrik.

\section{Capacity building:}

On Akhamb Island, 59\% of respondents had attended a training session in 2009 on the equipment, installation, and maintenance of an $80 \mathrm{~W}$ SHS (Q\#44). In this training, a system was assembled from scratch and the importance of maintenance and basic troubleshooting was explained. In addition, many end-users had been given technical 
advice from a visiting solar technician in 2010, who had installed a community solar system.

On Namdrik Atoll, only $11 \%$ of respondents indicated that they had attended a training session. However, $77 \%$ had participated in the installation of their new SHS installed by IE, which was encouraged and served as training for end-users (Q\#27) (See Figure 6.1.8.1 and Photograph 6.1.8.1). This was similar to rates on Akhamb, as, in total, $84 \%$ of SHS owners had participated in their systems' installation.

Ninety-five percent of respondents on Akhamb and 100\% on Namdrik indicated that they would like to attend a SHS training session if one was available in their community (Q\#48). Additionally, 95\% of SHS users in Akhamb and $94 \%$ in Namdrik indicated that it was very important for them to be able to repair and maintain their own system (Q\#50). Therefore, although some training efforts have been made, more capacity building is desired by end-users and is required for users to feel confident repairing and maintaining their SHSs.

Figure 6.1.8.1 (Q\#27):

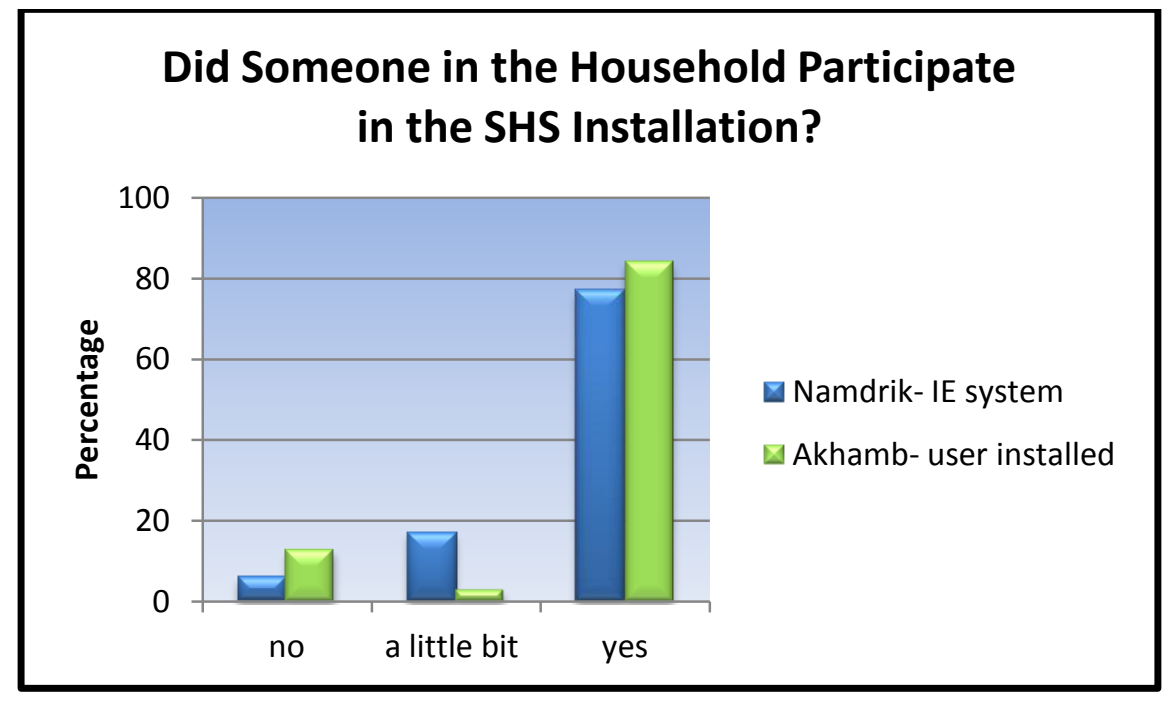


Photograph 6.1.8.1: End-users on Namdrik helping with the IE system installation.

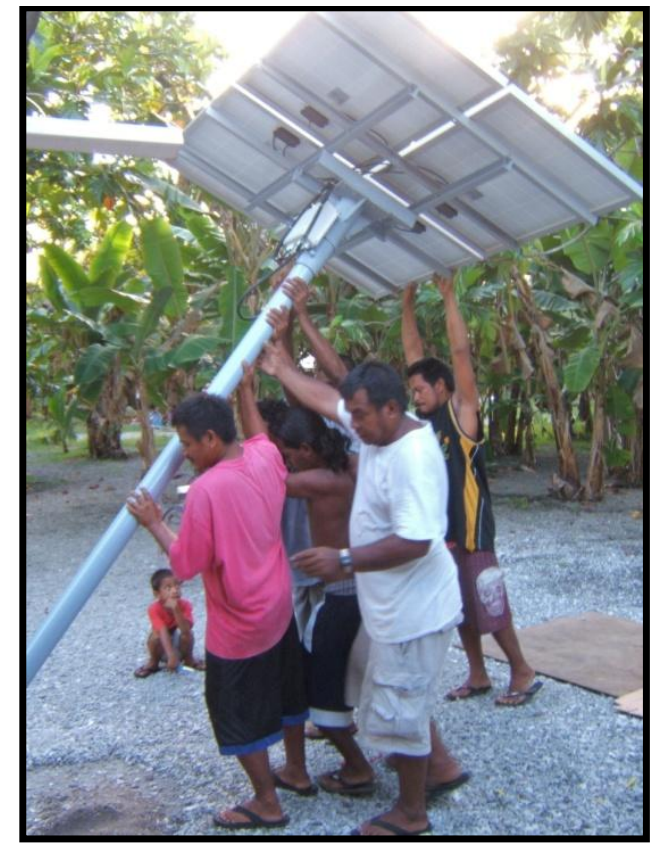

Sources: Photography by Ned Nathan (2011).

\section{Gender inclusiveness:}

On Akhamb Island, 28 out of 40 respondents were men, as the questionnaire was carried out by visiting each house, and therefore whoever was available would respond (Q\#1). However, if both partners were home, it was generally the man who chose to speak, and often the woman would express that she wasn't very knowledgeable about SHSs. Furthermore, the percentage of women that felt confident in being able to repair a SHS was much lower than that of men (2 women versus 27 men) (see Figure 6.1.9.1) (Q\#45\&46). On Namdrik, 17 out of 18 respondents were men, as families had time to choose a respondent. Yet, in these responses, a higher percentage of women compared to men (6 women versus 16 men) expressed confidence in being able to repair a SHS than on Akhamb.

Also, of the most desired appliances to be powered by a SHS, only the washing machine, which was mentioned by 5 respondents on Namdrik, and the freezer, which was mentioned by 8 respondents on Akhamb, would significantly lessen women's workload (in addition to night-time lighting) (Q\#26). Thus, currently the main desire for the power supplied is for activities that are more often utilized by males: including a stereo, computer, 
satellite TV, printer, and power tools. The appliances already used with SHSs on Akhamb have a similar focus (see Table 6.1.1.1). This differs from the IE project, which did incorporate both male and female opinions into the goal of providing refrigeration, and has contributed to lessening women's workloads (RMI Entrepreneur, Respondent 3, 2011).

Overall, these results show that women are less involved in solar electrification and are less confident overall in handling their SHSs than men, although the IE systems were more gender-inclusive.

Figure 6.1.9.1 (Q\#45 and 46):

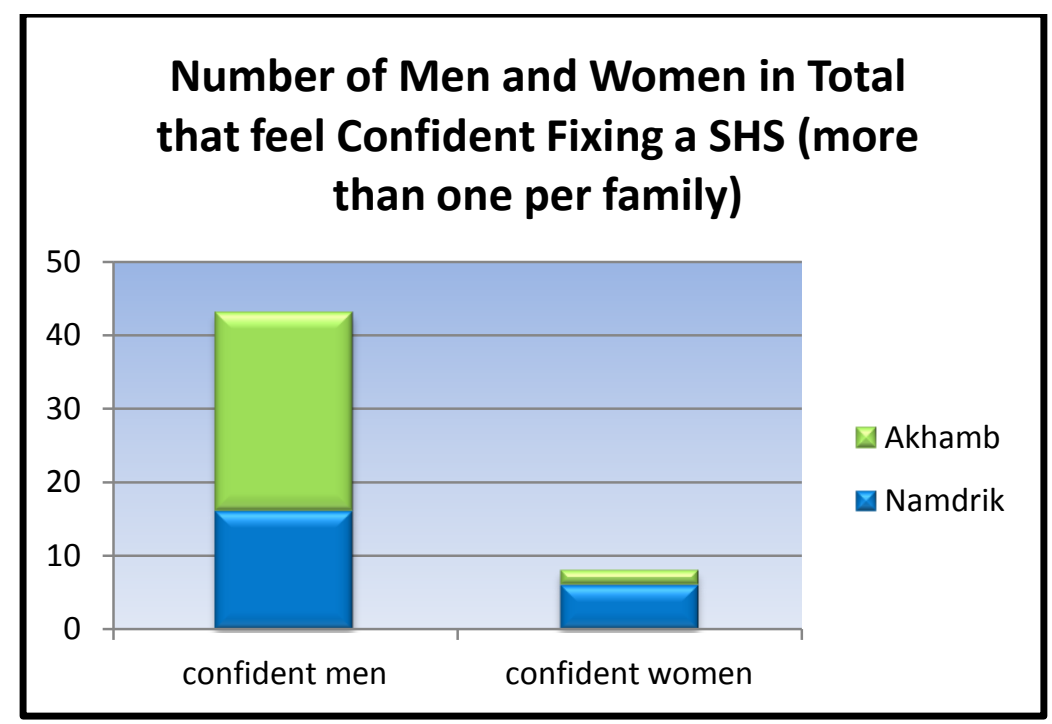

\section{Affordability:}

The average household size of the respondents on Namdrik Atoll was 5.4 people, whereas on Akhamb Island it was 4.7 people $(\mathrm{Q} \# 2)$. The data on Akhamb is comparable to that for all of Vanuatu, with an average household size of 4.8 in 2009 (VNSO, 2009). On Namdrik, the average size was shown to be 6.3 in 2005, so possibly the respondents had smaller than average families, or family sizes have decreased (Empower, 2005). Either way, Namdrik Atoll has significantly larger household sizes than Akhamb.

On average, 1.22 people per household were employed on Namdrik, whereas on Akhamb 2.18 people per household were employed. On Namdrik, this is very low compared to the average household size, indicating that only $24 \%$ of people were employed (using Empower's figure of 6.3), compared to 46\% on Akhamb (Q\#3). 
Empower (2005) measured the average yearly income on Namdrik Atoll to be $\$ 660$ USD per capita, with a median of $\$ 478$. The average income per capita in Malampa Province, where Akhamb Island is located, was calculated to be $\$ 1180$ USD per year, with Akhamb presumably being lower than the average because of its rural location ( $\mathrm{GoV}$, 2006). Figures 6.1.10.1 show the average biweekly incomes of respondents' households, which was approximately $\$ 110$ on Namdrik, or $\$ 454$ per capita per year, and approximately $\$ 150$ biweekly on Akhamb, or $\$ 831$ per capita per year (Q\#2\&4). With higher incomes on Akhamb, approximately one-third of households have already been able to purchase a SHS at the retail cost without financing, with new systems being installed monthly. Access to financing would likely increase this rate and make systems more affordable.

However, the initial cost of a SHS may be affordable on Namdrik as well, as the RMI receives a high amount of ODA per capita (\$1,525 versus $\$ 460$ in Vanuatu in 2010), in addition to US nuclear compensation funds (OECD-DCD, 2012). Furthermore, in both communities, income can be generated when needed; however, at the same time, cash can be very limited and can be slow to be received (Empower, 2005; Akhamb Technician, Respondent 6, 2011). It follows that many respondents on Akhamb commented that they preferred to pay for their electricity all at once, through purchasing a SHS, rather than on a weekly basis as they had done previously with kerosene.

Interestingly, almost all of the respondents felt that having a SHS was cheaper than their previous energy source (see Figure 6.1.10.2) (Q\#19). On Akhamb, community members suggested that they used to spend \$4-7 USD per week on kerosene, or approximately $\$ 300$ per year on average. Most respondents had relied primarily on kerosene (74\%) before having a SHS, with a few possessing backup generators and solar lanterns as well (see Figures 6.1.10.3) (Q\#8). While the funds previously allocated to kerosene per year may not cover the initial cost of a SHS, it would certainly encompass the maintenance costs of systems on Akhamb, as well as the fees to rent a system from MEC (Q\#18\&35). Thus, the SHSs were affordable following either a (subsidized) RESCO model or user-owned model, although many end-users find it preferable to pay for their power in portions when funds are available, rather than on a continual basis. 
Figures 6.1.10.1 (Q\#4):
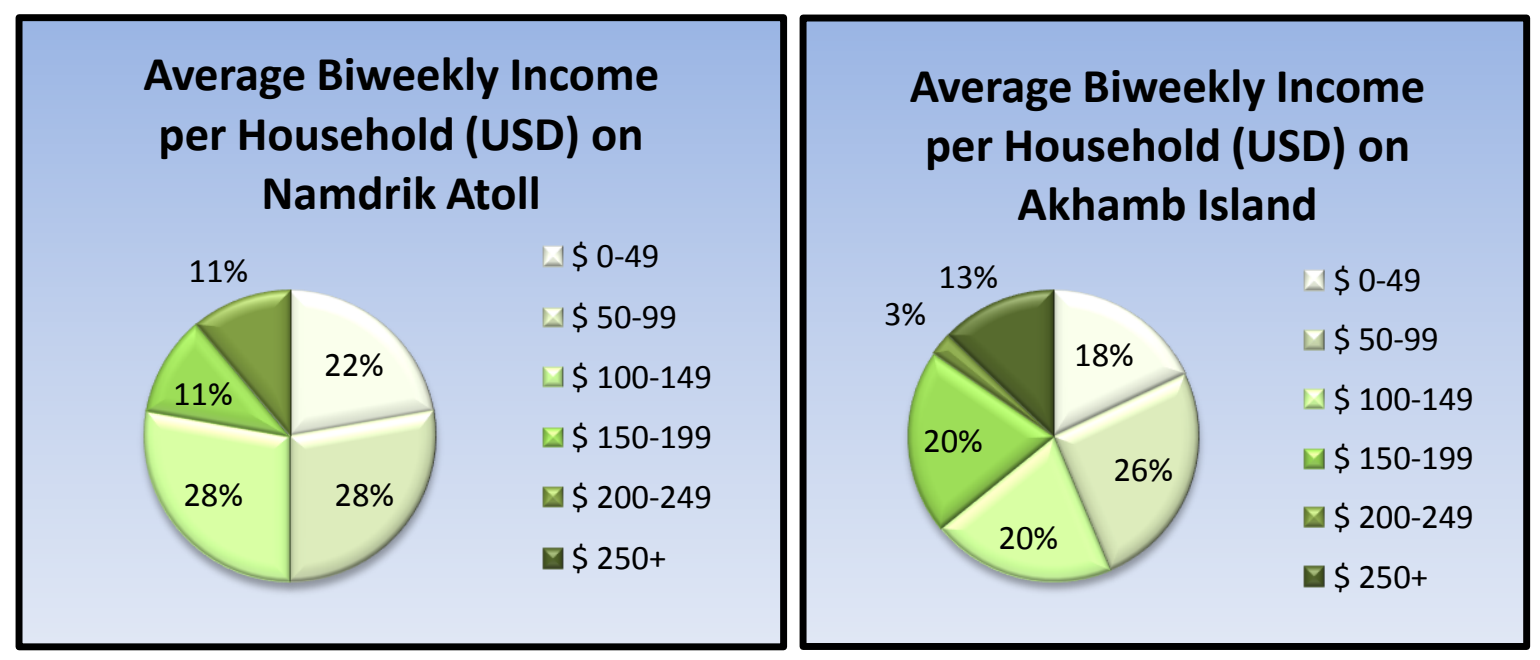

Figure 6.1.10.2 (Q\#19):

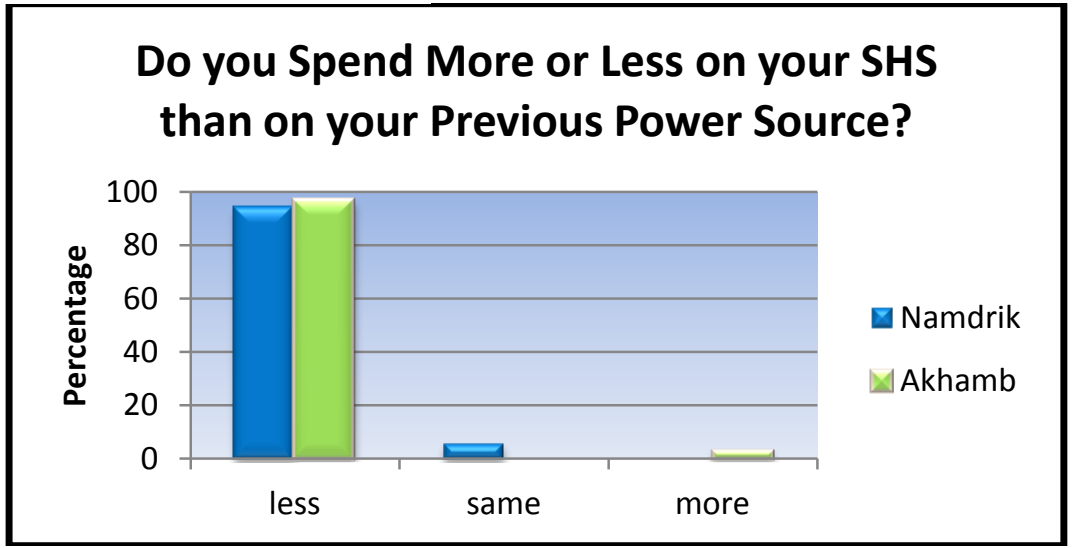

Figures 6.1.10.3 (Q\#8):
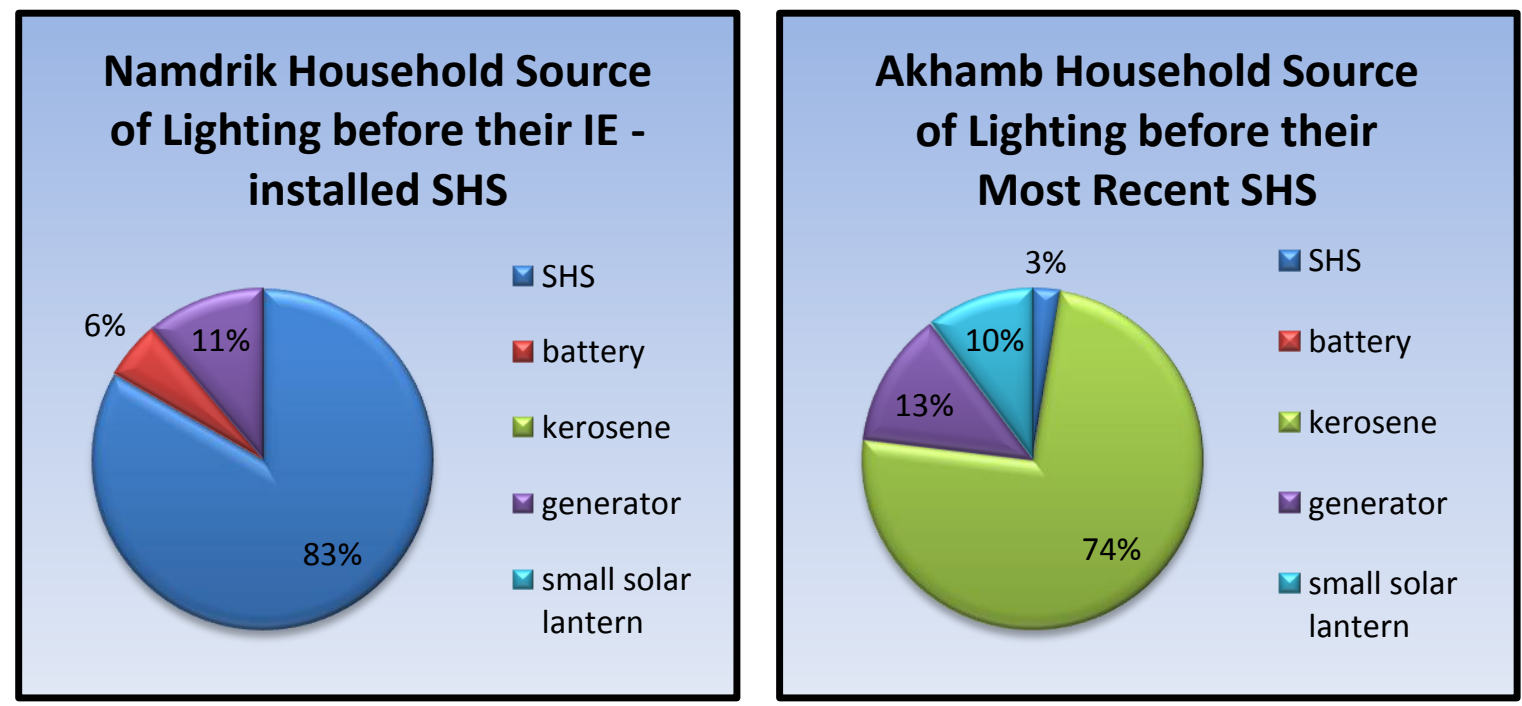


\section{Familiarity with the technology:}

Table 6.1.11.1 shows the highest level of education found in the surveyed household (Q\#6). Education levels were much higher on Namdrik than on Akhamb on average, which may increase the ability of end-users to handle a SHS properly, especially if they had studied a related field.

However, Figure 6.1.6.1 indicates that Namdrik households were unconfident overall in being able to fix their own SHS, despite being given a solar PV manual in the local language by IE (Q\#28). The number of households that indicated that they had at least one person who felt confident fixing a SHS verified this finding: only 33\% on Namdrik compared to $62 \%$ on Akhamb (Q\#45\&46). Namdrik respondents' answers may have been due to the complexity of their new $320 \mathrm{~W}$ SHSs and to a lack of training and experience maintaining a SHS, compared to Akhamb. Still, it is surprising to find low levels of confidence among Namdrik end-users, as on average respondents had had experience since 1996 with PV and two systems, compared to Akhamb's experience since 2009 on average, with a single system (Q\#12\&13).

Question \#47 addresses where confident end-users learned their skills from (see Figure 6.1.11.2). 'From a friend or family member' was the most frequent answer, followed by 'from a solar training,' 'helping someone install a SHS,' 'watching someone install a SHS,' 'repairing my own SHS,' and 'learning from other electronics' (in order of

frequency). It follows that many users' familiarity with SHS technology increases for every one person who is taught, as it is evident that information is shared among community members. Additionally, a community's familiarity is only as good as that of the person with the highest level of knowledge, which was illustrated on Akhamb, with many owners handling their SHSs in similar ways. 
Figure 6.1.11.1 (Q\#6):

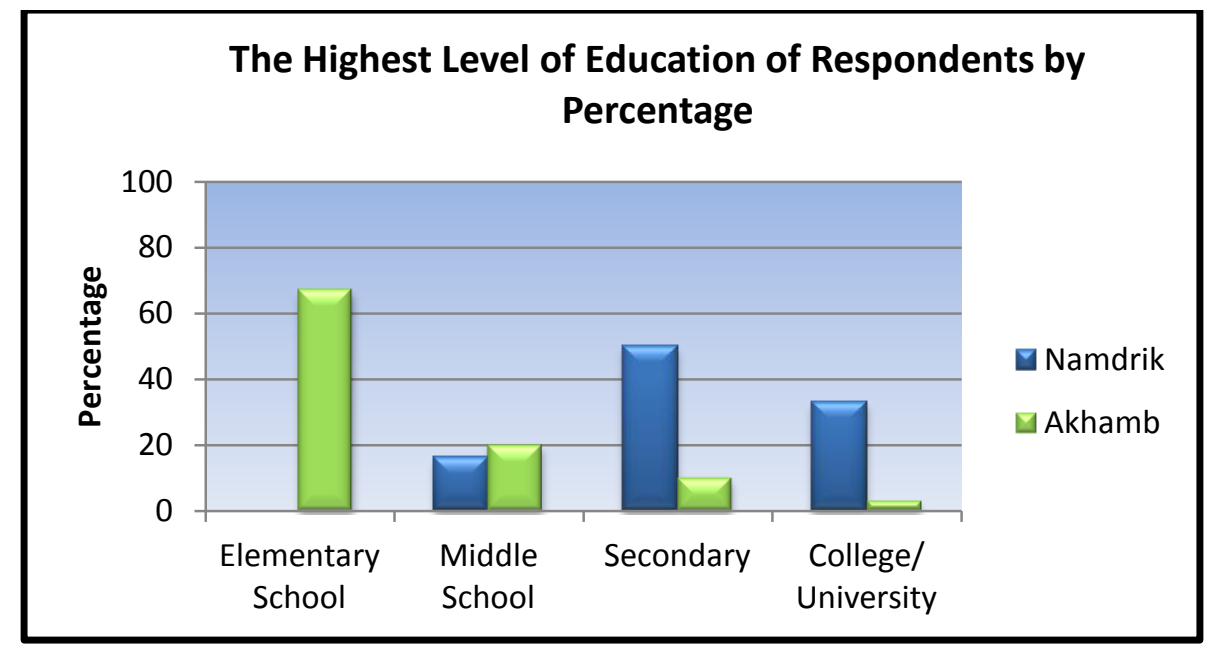

Figure 6.1.11.2 (Q\#47):

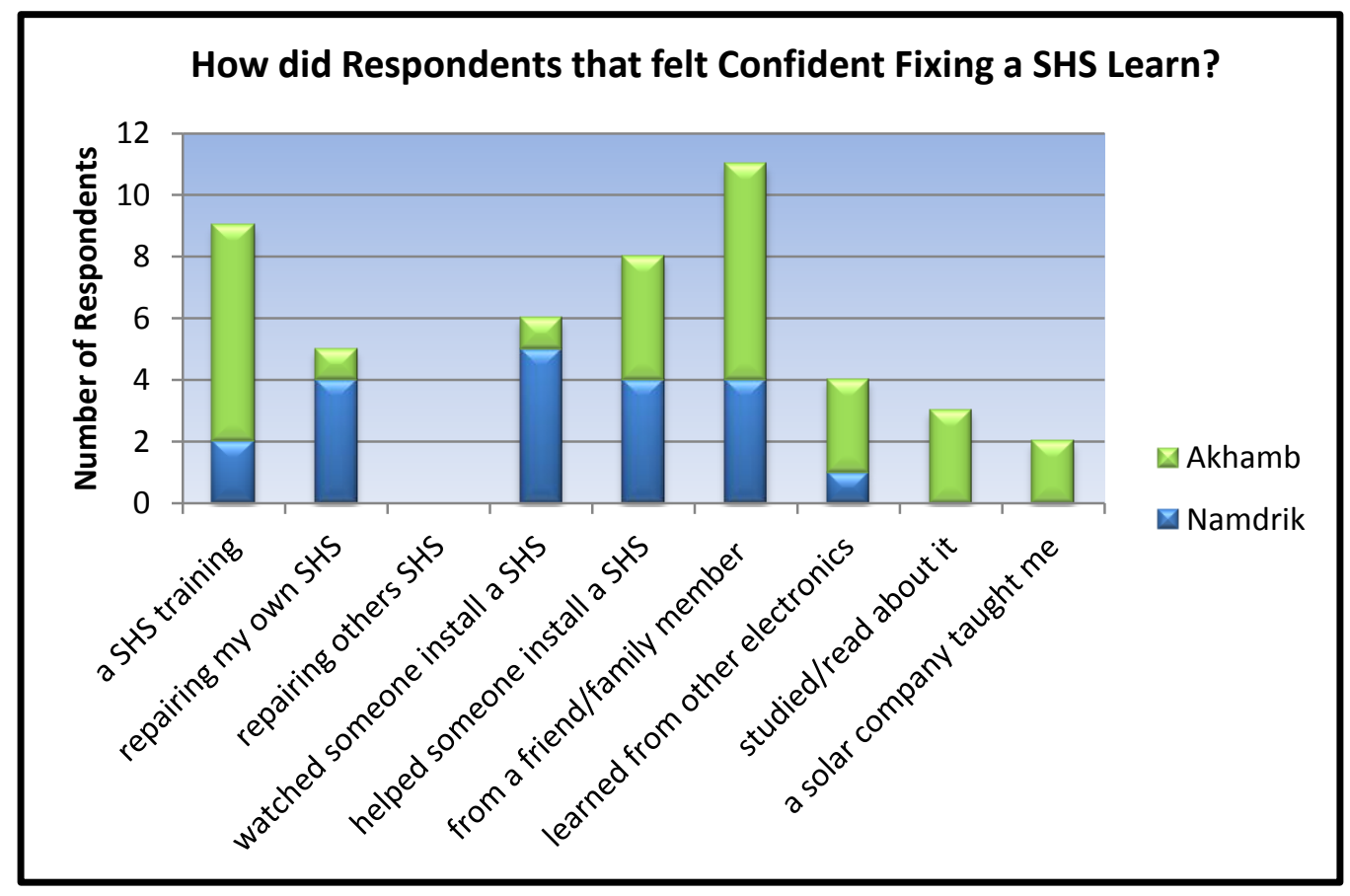

\section{Participation and ownership:}

Figure 6.1.12.1 reveals who was responsible for maintaining SHSs in the three projects (Q\#14\&32). On Namdrik, MEC owned and maintained the previous systems since 2004 through a RESCO model, with end-users not being allowed to repair or alter the systems (although alterations did happen regularly) (Q\#34). 
IE was responsible for maintaining the most recently installed systems on Namdrik, through a project-initiated user-owned model. However, with this project, ownership is to be transferred to the end-users following the completion of the two-year trial and training period, after which the owners will be fully responsible for their systems. This enables users to gain experience handling their systems with full technical support for two years.

With both of these types of projects, it would have been impractical to provide a large variety of systems, as large order quantities of equipment and spare parts were procured. However, having a few system options may have better served users' needs, and increased participation in the system design.

On Akhamb Island, systems were self-initiated and user-owned, with maintenance being divided between the owner, a community member, and a solar company, often depending on the knowledge required. All of the SHS owners reported that they were involved in the system design and were allowed to alter their system as desired (Q\#16).

Interestingly, all of the respondents in both communities reported that it was 'very important' for them to own their solar system and be responsible for it (Q\#49). Therefore, it appears that a high level of participation and ownership is desired by most end-users. The trends in the level of participation and ownership for these three projects, based on the responsible party for the SHS, are displayed in Figure 6.1.12.2, with this trend applying to many projects in PICs.

Figure 6.1.12.1 (Q\#14 and 32):

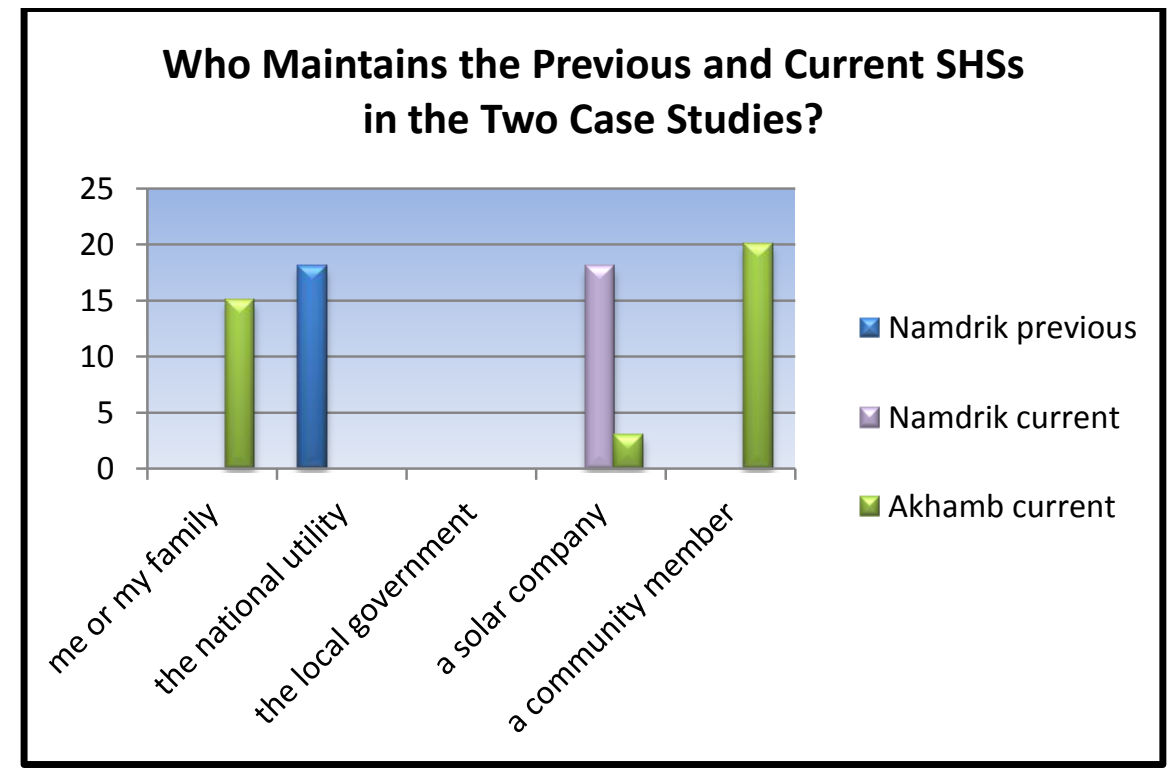


Figure 6.1.12.2: Trends in Participation and Ownership.

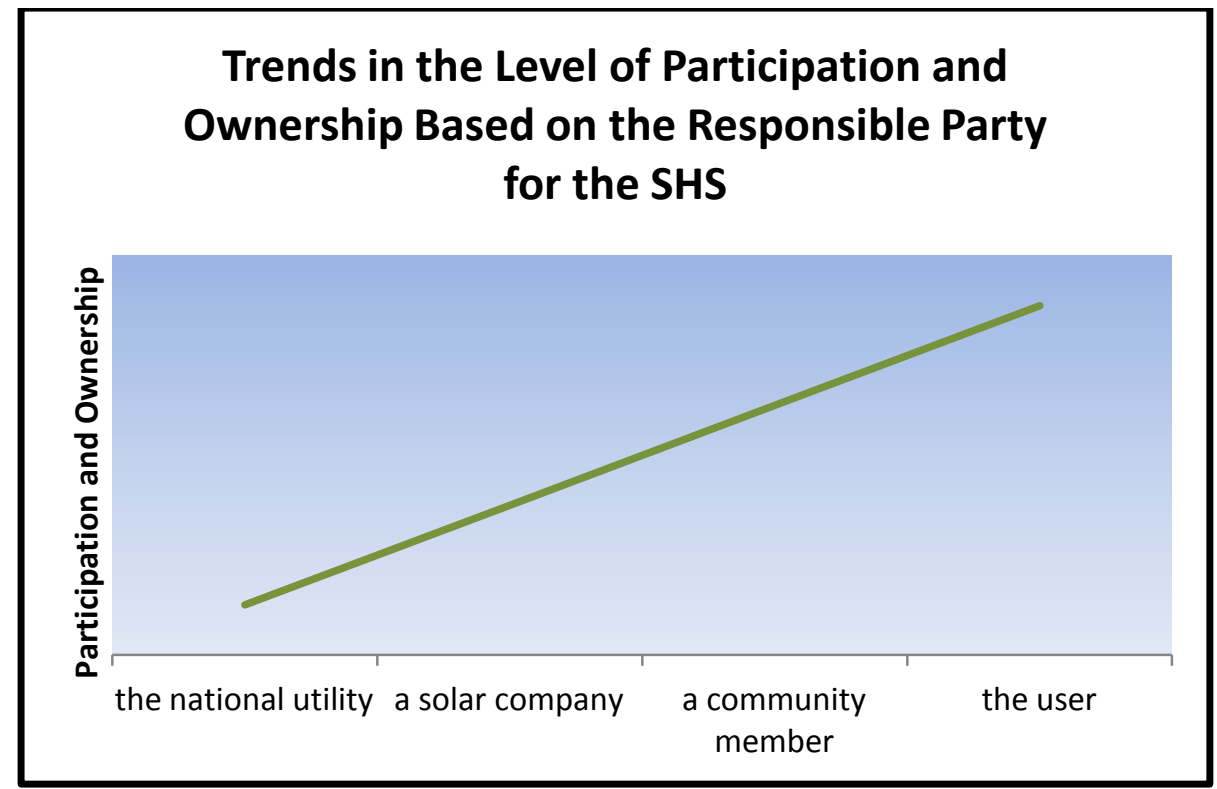

\section{Willingness to pay:}

The most common reason to purchase a SHS on Akhamb was that end-users thought SHSs would be a cheaper energy source than they had previously used, indicating that affordability was important (see Figure 6.1.13.1) (Q\#11). As most respondents reported solar to be less expensive than their previous energy source (Q\#19), it can be assumed that many end-users were satisfied with this aspect, and therefore willing to pay for maintenance. Question \#31 confirmed this, as 97\% of respondents on Akhamb reported that they were willing to pay to repair their SHS (see Figure 6.1.13.2).

On Namdrik, the most common reason to purchase the SHS installed by IE was to improve the user's income. As most end-users were benefiting from the productive uses of their solar-powered freezer (see Figure 6.1.5.2), it can also be assumed that there was satisfaction regarding this aspect of the IE systems. Question \#31 confirms this, based on the willingness to pay for maintenance, although less strongly than on Akhamb. This more varied response on Namdrik was probably due to IE's policy to pay for maintenance for two years, and due to respondents being accustomed to a RESCO model where they are not responsible for maintenance costs. 
With the MEC-managed systems, willingness to pay decreased over time, and as of $2005,45 \%$ of end-users were disconnected due to long-term non-payment. This dissatisfaction was mainly due to users misunderstanding about the system fees, lack of availability of spare lamps and ballasts, and insufficient system sizes to meet energy demands (Empower, 2005). Similar issues were still going on at the time of research, with MEC having a limited capacity for maintenance and lack of communication with rural islands (RMI National Government, Respondent 12, 2011).

End-users' overall satisfaction with solar PV, expressed in Q\#52 and 53, indicates users are very willing to pay for a SHS if it is both affordable and fits their needs. Both the IE project and the systems installed on Akhamb appear to be fulfilling end-users' motivations to purchase a SHS, indicating a willingness to pay for future repairs and systems. This was not the case with some of the MEC systems, and consequently many end-users defaulted on payments.

Figure 6.1.13.1 (Q\#11):

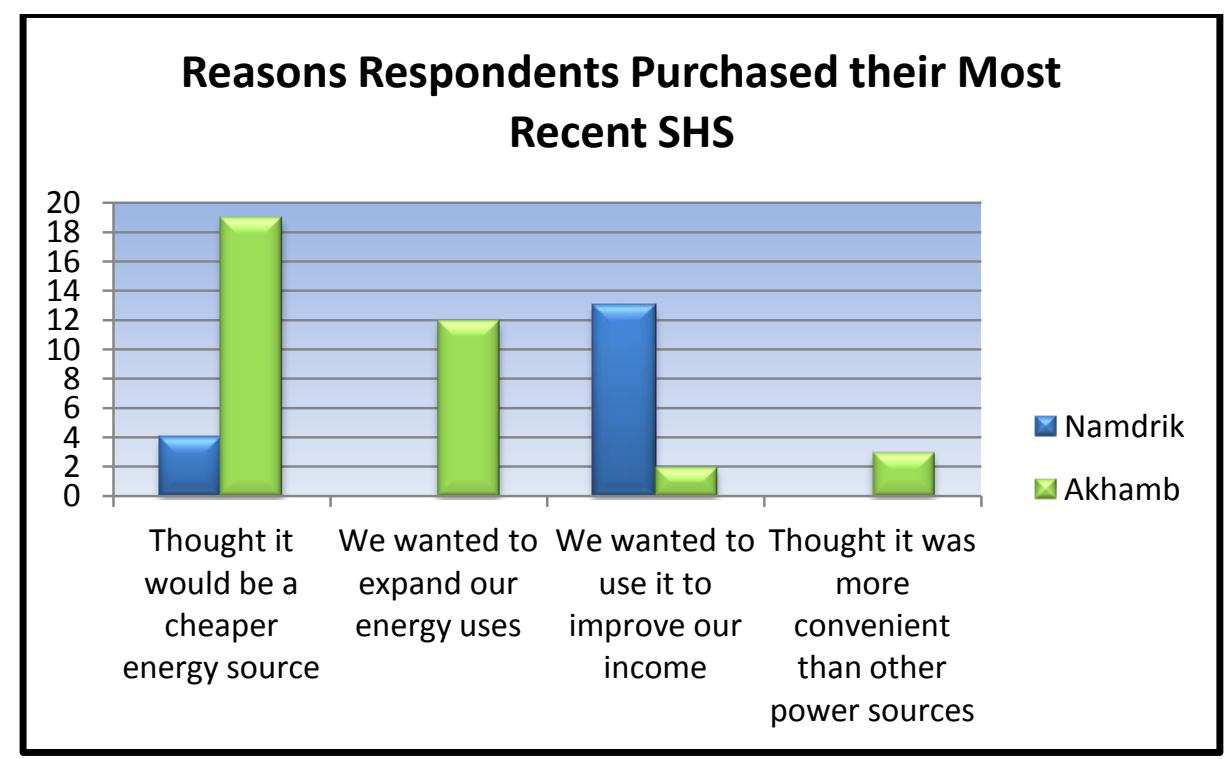


Figure 6.1.13.2 (Q\#31):

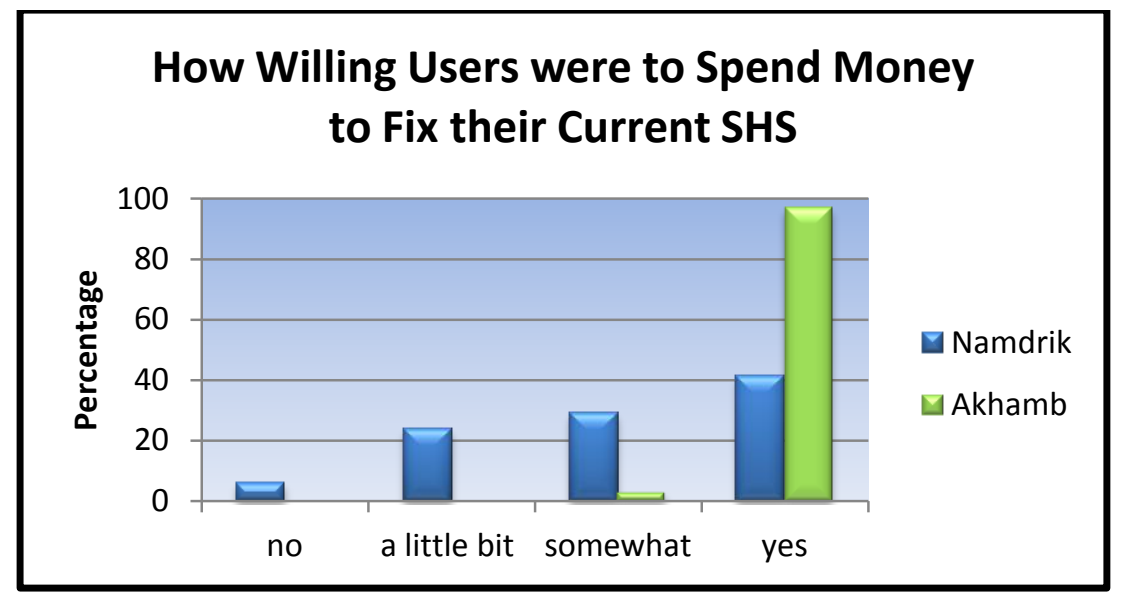

\section{Effectiveness in improving the environment:}

The number of SHSs and solar lanterns ${ }^{7}$ purchased by Akhamb's citizens were enough to phase out the need for kerosene and most generators. Only three generators remain to be used occasionally by SHS owners as backup power (see Figure 6.1.2.1). Kerosene, which was a common source of lighting in 2008 on the island, was no longer used as of January 2010, and is no longer sold in the community (Q\#8). As fossil fuels, such as kerosene, release 10-20 times more $\mathrm{CO}_{2}$ e emissions than the lifecycle emissions of solar $\mathrm{PV}^{8}$, the carbon footprint of Akhamb Island has been greatly reduced.

Syngellakis et al. (2010) relied on the conservative figure of a 100W SHS saving $475 \mathrm{kgCO}_{2} /$ year. Thus, with a total of $2.855 \mathrm{~kW}$ of SHSs installed on Akhamb as of October 2011, plus a $1.62 \mathrm{~kW}$ community solar system, approximately $21,250 \mathrm{kgCO}_{2} /$ year has been saved as a result of the recent surge in solar PV (see Photograph 6.1.14.1). This does not include the additional savings from the solar lanterns.

On Namdrik, kerosene and generators were also minimally used for lighting (Q\#7\&8), as they have had a history of SHS projects since 1996 (Q\#13). However, most of the initial SHSs failed, with only the modules being reused, resulting in much of the equipment reaching its intended lifespan, thus reducing its effectiveness in mitigating climate change (CC). Still, most of the systems installed through both projects on Namdrik were working at the time of research.

\footnotetext{
${ }^{7}$ These lanterns were funded through AusAid's Light Up Vanuatu project; see details in Appendix 9.

${ }^{8}$ See Section 1.4 for the full explanation.
} 
Thirty-three 320W SHSs were installed on Namdrik Atoll by IE, thus adding to the $11580 \mathrm{~W}$ systems installed by the PREFACE project. Therefore, $19.76 \mathrm{~kW}$ of solar has been installed on Namdrik through the two projects. Assuming 83\% of the PREFACE systems are still working (this may be inaccurate as only 18 out of the 115 MEC systems were surveyed, and data on this is not available from MEC), approximately 86, 400 $\mathrm{kgCO}_{2}$ /year are being saved (RMI Utility Company, Respondent 19, 2012).

No battery recycling programs have been set up with any of the programs. The four batteries already replaced on Akhamb are a concern for the local environment, as the systems are relatively new, indicating that some of the batteries may be expiring before their intended lifespan due to overuse and/or poor quality (Q\#21\&25). Also, a minimal number of trees were trimmed or cut down for the SHSs installed on Akhamb and the IE SHSs installed on Namdrik; rather, the systems were placed in the least shady locations.

Overall, the SHSs have had a positive effect on the environment, especially through mitigating $\mathrm{CC}$, although expired-battery recycling remains a concern.

Photograph 6.1.14.1: The 1.62kW community system installed on Akhamb Island.

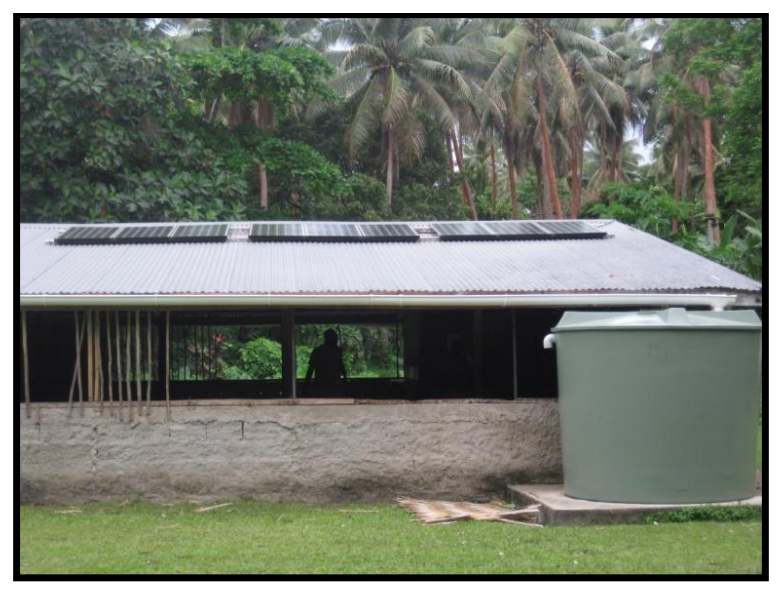

Source: Photography by Juliana Ungaro (2011).

\subsection{Conclusions and Implications}

Table 6.2.1 summarizes the conclusions that can be drawn from the two case studies. It addresses both the factors that have led to project endurance and that have hindered project success, as well as the implications for future SHS electrification projects in PICs. 
Table 6.2.1: Conclusions and implications of the quantitative data analysis.

\begin{tabular}{|c|c|}
\hline Indic & ns and Implications \\
\hline $\begin{array}{l}\text { riate } \\
\text { t use }\end{array}$ & $\begin{array}{l}\text { - There is a need for certification and standards for equipment and vendors in order to encourage more appropriate } \\
\text { equipment use in self-initiated projects. } \\
\text { - Subsidies may be a solution to promote the use of deep-cycle batteries, with education provided to users on the benefits. } \\
\text { - Overuse still affects even high quality parts, and therefore is more likely to contribute to project failure. } \\
\text { - Overuse continues to be a problem in all electrification models, although user-owned models contain a financial incentive } \\
\text { against it. }\end{array}$ \\
\hline $\begin{array}{l}\text { 2. Effectiveness in } \\
\text { meeting users' } \\
\text { needs }\end{array}$ & $\begin{array}{l}\text { - SHSs are a satisfactory and trusted technology to meet end-users' needs. } \\
\text { - Users prefer to be able to design and alter their system; RESCOs do not meet this desire. } \\
\text { - Lighting, television, and refrigeration were the most desired services in the case studies. } \\
\text { - SHS sizing needs to incorporate users' electricity demands, as otherwise users will alter their systems. } \\
\text { - Having only one size of a SHS is inappropriate for general electrification and can hinder project success. } \\
\text { - Users' preferences should be incorporated initially, as lack of participation can lead to miscommunication and systems } \\
\text { and payment methods not matching users' needs. }\end{array}$ \\
\hline $\begin{array}{l}\text { 3. Ability to satisfy } \\
\text { expanding energy } \\
\text { demands }\end{array}$ & $\begin{array}{l}\text { - Neither the RESCO nor project-initiated systems allowed for system expansion. } \\
\text { - The self-initiated systems took changing demands into account in two different ways. } \\
\text { - Users' electricity demands can increase quickly and hinder success if not allowed for in system design. }\end{array}$ \\
\hline $\begin{array}{l}\text { 4. Cost- } \\
\text { effectiveness }\end{array}$ & $\begin{array}{l}\text { - As self-initiated systems allow end-users to purchase parts directly from a variety of solar vendors, they have the potential } \\
\text { to be the most cost-effective. } \\
\text { - Subsidies result in economic biases towards project-initiated systems and RESCOs. } \\
\text { - Including subsidies, all three projects were cost-effective in their own right if managed correctly. } \\
\text { - SHSs have the potential to be similar in cost to grid electricity prices, yet they must provide a variety of services to be } \\
\text { comparable. }\end{array}$ \\
\hline $\begin{array}{l}\text { 5. Effectiveness in } \\
\text { changing } \\
\text { community } \\
\text { livelihoods }\end{array}$ & $\begin{array}{l}\text { - SHS lights are effective in allowing for productive uses, especially for handicrafts. } \\
\text { - Refrigeration is effective in changing community livelihoods, as users can store, sell, import, and export food. } \\
\text { - Self-initiated systems can be specialized to provide services based on users' occupations and interests, and thus contribute } \\
\text { - Productive uses can help users to pay for future repair costs. }\end{array}$ \\
\hline $\begin{array}{l}\text { 6. Availability of } \\
\text { resources and } \\
\text { support }\end{array}$ & $\begin{array}{l}\text { - Most RESCO and users-owned systems were working properly, indicating adequate technical support. } \\
\text { - Self-organized technical support was considered to be more effective than the RESCO's support. } \\
\text { - Users prefer to be able to repair and maintain their own SHSs. }\end{array}$ \\
\hline
\end{tabular}


- Users are capable of installing and maintaining systems, with the aid of local technicians.

- Many SHS owners were inhibited to approach solar companies, indicating a need for stronger relations.

- A lack of resources and support can quickly lead to system failure.

7. Availability of system components

8. Capacity building

9. Gender

inclusiveness

10. Affordability

11. Familiarity with the technology

12. Participation

and ownership

13. Willingness to pay

14. Effectiveness in improving the

environment
- The self-initiated systems had the best availability of SHS components.

- A lack of system components available nationally hindered the RESCO project's success.

- The supply of components locally provides a local business opportunity.

- More capacity building is desired by end-users, and is necessary to increase end-users' maintenance capabilities.

- Capacity building increases users' confidence in repairing their systems.

- Training was effective with the self-initiated systems as it increased users' confidence levels.

- Women are generally less confident than men in handling their SHSs.

- Electrical lighting can increase women's incomes, through making handicrafts at night.

- Refrigeration serves the needs of both men and women, while reducing women's workloads.

- Project-initiated systems may better serve women as they can focus on women's needs.

- SHSs were affordable following either a (subsidized) RESCO model or a user-owned model.

- Low-income households may be overlooked by user-owned projects without financing.

- End-users found it more affordable to pay for their power in portions when funds are available, rather than on a regular, continual basis.

- The maintenance costs of SHSs are less expensive than the cost of kerosene per year in Vanuatu.

- Information is shared among community members and therefore the community's familiarity with SHSs increases for every one person that is taught.

- With SHSs that have limited external support, a community's familiarity cannot exceed that of the person with the highest knowledge level.

- End-users are able to quickly become familiar with the basics of maintaining a SHS.

- User familiarity with SHSs can affect the longevity of all project types.

- A high level of participation and ownership is desired by most users.

- Self-initiated systems have the highest level of participation and ownership.

- Users are very willing to pay for a SHS if it is affordable and fits their needs, yet this willingness quickly decreases with dissatisfaction.

- The user-owned projects resulted in a higher willingness to pay due to higher levels of user satisfaction.

- Overall, SHSs have helped to mitigate CC, through decreasing dependence on kerosene and generators.

- Expired-battery recycling remains a concern, especially for poor quality batteries and overused systems. 


\section{Chapter 7: \\ The Qualitative Data Results and Analysis}

\subsection{Results of the Qualitative Interviews by Indicator}

The following results are based on replies from 15 interviews with key respondents, including five government workers, six solar PV entrepreneurs, two NGOs, one donor agency, and one community solar technician (see Chapter 4 for details).

\section{Appropriate equipment use:}

Many interviewees, especially government representatives, mentioned that they trust solar PV technology, view it as a better power source than fossil fuel, and believe it is clean, cost-effective, and user-friendly (RMI Government, Respondents 10 and 11, 2011). Furthermore, they believe solar is the future for remote, isolated islands due to the high price of fossil fuels (RMI Government, Respondents 11 and 13, 2011; RMI National Government, Respondent 12, 2011).

Regarding appropriate equipment use, one interviewee mentioned that improved battery technology is needed in order to increase SHSs' lifespan, and another mentioned that DC appliances, now available in PICs, make the need for inverters unnecessary and decrease power requirements (Vanuatu Entrepreneur, Respondent 5, 2011; Vanuatu NGO, Respondent 14,2011). A third mentioned the need to use dry-cell batteries only, in order to limit the need for maintenance (Vanuatu Entrepreneur, Respondent 15, 2011). Another viewpoint expressed by a government representative was that local materials should be used in system design, such as for solar module mounting, in order to increase ease of maintenance (RMI Government, Respondent 11, 2011).

Yet, concern with appropriate equipment use was expressed, in that some solar enterprises were selling poor quality equipment (VEU, Respondent 1, 2011). For example, one vendor in Vanuatu was struggling to sell quality solar modules, when he realized that many customers were unconcerned about quality; he now provides both high and low 
quality parts. He reports that his customers "are glad because the systems are cheap," and that most have worked well (Vanuatu Entrepreneur, Respondent 15, 2011). Another sells average quality solar modules in order to keep the price down, as the owner thinks it is unlikely for SHSs to last more than 10 years in the islands, when the efficiency of such modules decreases (Vanuatu Entrepreneur, Respondent 8, 2011). Also, inefficient appliances, such as AC lights and AC refrigerators, or providing hybrid systems with fossil fuel-powered generators to decrease the initial cost, are a concern (VEU, Respondent 1 , 2011).

One vendor carries out a power assessment for every site and installs the SHSs himself, as he claims that one of the main issues leading to SHS failure is poor design (Vanuatu Entrepreneur, Respondent 5, 2011). He suggests all vendors in RE should be certified in the field, possibly with SEIAPI providing training and certifying businesses according to their guidelines (see Chapter 3). Governments and donors could then promote these vendors, and encourage others to become certified (Vanuatu Entrepreneur, Respondent 5, 2011).

Another issue is that end-users do not properly connect their systems or use parts that are compatible (see photograph 7.1.1.1). An example described by a technician on Akhamb was that "one man bought solar equipment and a freezer, but did not ask [a technician] for advice, and he connected all different-sized panels and batteries, and ended up breaking the freezer and inverter" (Akhamb Technician, Respondent 6, 2011).

In conclusion, there is a need for standards to ensure that acceptable quality equipment is used, with systems being designed by vendors and technicians, rather than being pieced together. End-user training is needed to encourage proper equipment usage and connections. 
Photograph 7.1.1.1: An indoor light being placed outdoors with an undersized indoor wire powering it.

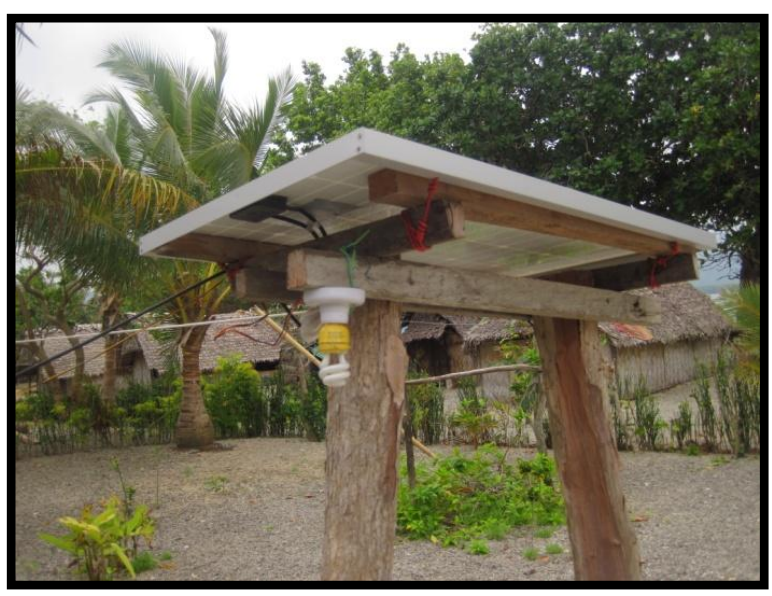

Source: Photography by Juliana Ungaro (2011).

2. Effectiveness in meeting users' needs:

There were many issues that the respondents cited as reasons why purchased SHSs do not meet users' needs, including end-users:

- Adding wires and appliances/ overusing the system

- Not cutting back trees, or placing in a shady spot

- Solar modules facing the wrong direction or being angled incorrectly

- Rusted connections and modules not being cleaned

- Not adding water to wet-cell batteries

- Not asking for advice, just replacing parts

- Not letting batteries recharge when low

(Vanuatu Entrepreneurs, Respondents 15 and 16, 2011).

All of these issues can be addressed through educating end-users; however, overuse requires behavioral changes as well, which are slow to achieve.

\section{Ability to satisfy expanding energy demands:}

One company advised its customers not to purchase large SHSs initially, but rather to buy SHSs for lighting first and then upgrade (Vanuatu Entrepreneur, Respondent 15, 
2011). His systems are set up so that the consumer can add panels over time. Two other solar companies also mentioned that their systems are able to be upgraded, either by adding parts or exchanging old systems for new ones (Vanuatu Entrepreneurs, Respondents 8 and 17, 2011). However, this was not a main concern of interviewees, as they were more concerned with ensuring lasting results of the initial SHSs.

\section{Cost-effectiveness:}

Many solar dealers are providing prewired or plug-and-play SHSs, or providing wiring diagrams for users, which allow end-users to be trained to install their own systems (RMI Entrepreneur, Respondent 3, 2011; Vanuatu Entrepreneurs, Respondents 8 and 15, 2011; Vanuatu NGO, Respondent 14, 2011). Furthermore, when equipment fails with prewired systems, the power board (containing the controller, inverter, breakers, and switches), can be shipped to Port Vila for repair (see Photograph 7.1.4.1). This creates value for money in that technicians do not need to travel to remote islands very often (Vanuatu Entrepreneur, Respondent 8, 2011).

Another three dealers were travelling to the site and were installing the SHSs themselves (Vanuatu Entrepreneurs, Respondents 5 and 17, 2011; RMI Entrepreneur, Respondent 3,2011). One company gave their customers an option: if the customer wants a two-year warrantee, they must pay for a technician to travel and install it (Vanuatu Entrepreneur, Respondent 17, 2011).

One NGO allowed rural businesses and organizations to purchase small SHSs at the wholesale price when purchasing only 12 units, and provided them with extra components. This allowed reselling in rural communities, which prevents the need for end-users to travel to purchase equipment (Vanuatu NGO, Respondent 18, 2011). This model makes systems more cost-effective for end-users.

In summary, systems that decrease the need to travel are the most cost-effective, either by teaching users to install their own systems, or by selling systems in remote communities. 
Photograph 7.1.4.1: An example of a solar power board.

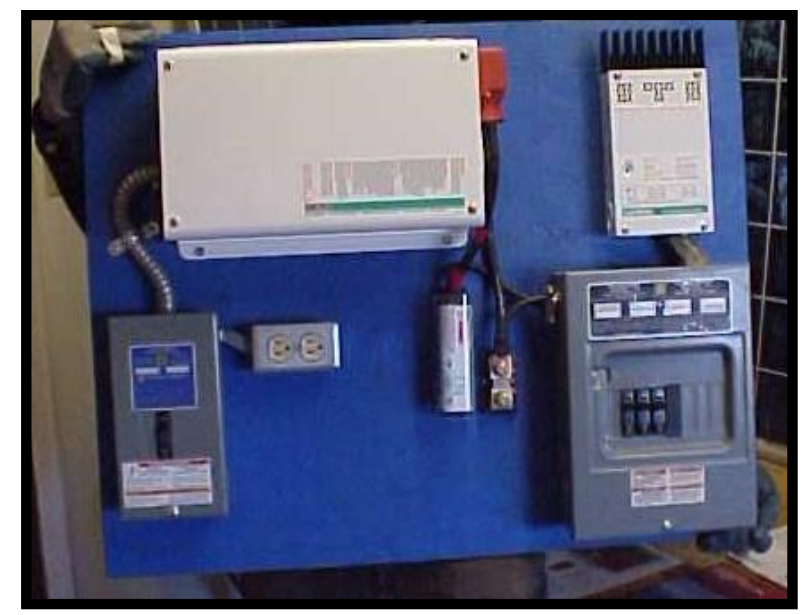

Source: SolarRay (2012).

\section{Effectiveness in changing community livelihoods:}

Two respondents commented on the positive lifestyle changes that come with SHSs, with one explaining that "before solar this was a dark country with no light at night" (Vanuatu Entrepreneur, Respondent 15, 2011). Another added that "solar is good because it provides light inside a home that was very dark before. It is easy because when you come home late at night, you can just flip the switch and at the same time be able to see clearly" (Akhamb Technician, Respondent 6, 2011).

Furthermore, solar "makes life easy... as you can have access to power for mobile phones, music, movies, freezers, computers, and you can earn money [through these appliances]" (Akhamb Technician, Respondent 6, 2011). A third interviewee explained solar PV as "the gateway" for education, health, comfort, and well-being (RMI Government, Respondent 13, 2011). He further explained that solar can power new technologies, such as internet for information and communication, GPS for safety for mariners, and refrigerators for medicines, which are "important [for the RMI] to keep up with the world." In addition, it was mentioned that refrigeration allows for food preservation, importing and exporting food, food storage during storms, storing food for infants, and selling frozen products locally (RMI Entrepreneur, Respondent 3, 2011). 
Overall, changing community livelihoods was mentioned by four interviewees, with more of a focus on lifestyle changes than on improving income levels.

\section{Availability of resources and support:}

Proper maintenance for SHSs was stated as essential, especially with the harsh environmental conditions found in PICs (RMI Government, Respondent 11, 2011; RMI National Government, Respondent 12, 2011). Some respondents cited older projects where the absence of a maintenance plan led to the systems no longer working (RMI Government, Respondent 10, 2011; Vanuatu NGO, Respondent 14, 2011). Other opinions on how to ensure that maintenance is satisfactory included having trained personnel in the field, proficient leadership, and a "holistic approach" through a "partnership between the grantee, grantor, and the community" (RMI Entrepreneur, Respondent 3, 2011; RMI National Government, Respondent 12, 2011; RMI Government, Respondent 13, 2011).

Technical support was provided in a number of ways by SHS vendors, including having a call centre where technicians are available, vendors calling to check on the status of systems, having users send in their broken parts, and sending a technician to fix the systems (Vanuatu Entrepreneurs, Respondents 5, 8, 15 and 16, 2011). Many did all four, depending on the system and the problem. In addition, many were providing system warrantees for 1-2 years (Vanuatu Entrepreneurs, Respondents 8, 16, and 17, 2011; Vanuatu NGO, Respondent 18, 2011).

One company in Vanuatu was using GPS to monitor if its purchased systems were working or not ${ }^{9}$. In addition, each system had a memory to record how well the system had been working, and automatically shut the system down with misuse, while at the same time invalidating the warrantee (Vanuatu Entrepreneur, Respondent 17, 2011). The issue with this model is that the SHSs are locked so that the end-user can't access the equipment, and therefore a technician needs to travel to repair the system, making maintenance costly.

In summary, all SHS vendors were providing technical support of their own accord, most in more ways than one, as they have an interest in systems working effectively and providing enduring outcomes.

\footnotetext{
${ }^{9}$ This is a technology similar to SIMba Link, which is described in Chapter 3.
} 


\section{Availability of system components:}

Three respondents brought up the issue of spare parts' availability. The solar technician on Akhamb stated that he stocks all of the needed spare parts locally, and has a battery tester and a generator where he can charge batteries when needed (Akhamb Technician, Respondent 6, 2011). In addition, one NGO was already providing spare parts to local businesses and organizations, while another interviewee mentioned the need for strong supply lines and locally available spare parts (Vanuatu NGO, Respondent 18, 2011; RMI Government, Respondent 10, 2011). In conclusion, although access to spare parts locally was considered important, it was not seen as essential.

\section{Capacity building:}

Capacity building for end-users was seen as important by all respondents, as "people don't have many opportunities to learn about solar in remote communities and they want to learn more" (RMI Government, Respondent 13, 2011). It was suggested that "101 solar training sessions" that are "more than just a few hours" are needed to make sure that the whole community is on the same level (RMI Government, Respondents 11 and 13, 2011).

Many interviewees suggested that users are capable of understanding the basics of their system, such as how a SHS works and the limits of the system (Akhamb Technician, Respondent 6, 2011; Vanuatu Entrepreneur, Respondent 16, 2011; RMI Entrepreneur, Respondent 3,2011). One respondent suggested building community capacity through focusing on the long-term, building on existing skills, providing continuous training and support, and looking at problems on a case-by-case basis (Vanuatu NGO, Respondent 18, 2011). Another remarked that "technology in the RMI is developing too fast, and people aren't well trained and educated yet," and, therefore, there needs to be more of a focus on training (RMI Government, Respondent 11, 2011). He suggested that local governments should be responsible for coordinating training for their communities, and a training program should be included in the installation package with SHS projects (RMI

Government, Respondent 11, 2011). 
Another viewpoint was that although there is a need for training, "no-one is willing to fund it" (Vanuatu NGO, Respondent 14, 2011). Lack of training has led to many issues, such as with the VEU systems described in Chapter 1, where end-users who did end up owning their SHSs did not know how to repair or maintain them (VEU, Respondent 1, 2011). The solar technician interviewed cited a lack of training as a central issue leading to system failure, in that users don't understand their systems (Akhamb Technician, Respondent 6, 2011).

All of the solar enterprises and NGOs, as well as the rural solar technician interviewed (nine in all), provide some form of basic training upon purchase. One was holding a training session for every group of 100 customers (Vanuatu Entrepreneur, Respondent 15, 2011). Other solar training efforts included: setting up a basic training course for technicians, writing a set of articles for the newspaper, having a set of radio broadcasts about solar, and having a microfinance workshop for distributors (Vanuatu Entrepreneurs, Respondents 5 and 8, 2011; Vanuatu NGO, Respondent 18, 2011). However, this was not enough to reach the majority of the population, and it was suggested that RE should be introduced to students in schools (Vanuatu Entrepreneur, Respondent 5, 2011).

A third NGO in Vanuatu, which was not interviewed as it was not involved in energy issues at the time of research, stated that they would be glad to assist in raising public awareness on RE (Matakiviti, 2006). This group has been successful in raising awareness on other environmental issues, through creating a traveling theater production and through educational films.

In conclusion, training was seen as very important for SHS longevity, with many grass-root initiatives already taking place, yet with a need for more funding in order to reach a large percentage of the population. On the end-users side, it was suggested that users who own their SHS care more about training because they have put a significant part of their savings into solar (Vanuatu Entrepreneur, Respondent 15, 2011). 


\section{Gender inclusiveness:}

Gender inclusiveness was only mentioned by two solar vendors. They suggested that women generally care more about their SHSs than men, as they spend more time in the house, and more than half of their customers were women (Vanuatu NGO, Respondent 14, 2011; RMI Entrepreneur, Respondent 3, 2011). However, in general, gender was overlooked as something that needed to be considered in electrification. Interestingly, 14 out of the 15 interviewees were men, indicating that mostly males hold key positions in the solar projects and organizations.

\section{Affordability:}

Many interviewees mentioned the need to decrease the upfront cost of SHSs to make them affordable. Two suggested that financing was key, and one respondent thought end-users should "slowly buy into their system, maybe with a bag of copra (coconut) per month," and at the same time gain experience in handling their system (RMI Government, Respondent 11, 2011). One solar dealer in Port Vila had implemented a similar project in a nearby village, where end-users chose which SHS package they preferred, and the systems were installed after $50 \%$ of the cost was paid, after which users completed the remainder in installments (Vanuatu Entrepreneur, Respondent 16, 2011). However, he indicated that this model would be hard to implement in remote islands.

Other respondents stated that the cost of replacing batteries was unaffordable to end-users, and this caused many systems to fail (Vanuatu Entrepreneur, Respondent 5, 2011). One government representative cited this as a reason why users should rent rather than own their system (RMI National Government, Respondent 12, 2011). However, a solar technician on Akhamb claimed that SHSs were affordable, as you do not need to "pay for your solar regularly, only every once in awhile, and it is cheaper than generators and kerosene" (Akhamb Technician, Respondent 6, 2011).

Other suggestions of increasing affordability included setting up charging stations in rural communities, so that locals can have access to power without purchasing a full SHS (Vanuatu NGO, Respondent 18, 2011). Local organizations could earn money 
through charging batteries and be responsible for O\&M. In addition, providing subsidies to decrease the cost of equipment was suggested as a way to increase the affordability (AusAid, Respondent 7, 2011). However, another respondent disagreed, stating she felt "subsidies provide a false temporary reality," as rural customers will not understand why equipment prices fall and rise again. Rather, "it's more important to help rural customers gain access to funds through microenterprise and microfinance" (Vanuatu NGO, Respondent 18, 2011).

Financing, subsidies, and battery-charging stations were all suggested as options for increasing affordability for end-users, with affordability being a concern to NGOs, dealers, and government representatives.

\section{Familiarity with the technology:}

One respondent described how the first solar project on their atoll resulted in locals feeling comfortable in handling solar systems as a result of experience (RMI Government, Respondent 13, 2011). He added that "people [in the RMI] now understand how solar works." Two solar organizations in Vanuatu and a technician on Akhamb also stated that many people already have a basic knowledge of their system, and that end-user knowledge is increasing (Akhamb Technician, Respondent 6, 2011; Vanuatu NGO, Respondent 14, 2011; Vanuatu Entrepreneur, Respondent 15, 2011). Yet, for those that have not reached that point, there is a need for more training, as "it works well for everyone to understand the basics, with technicians understanding more in-depth" and be able to assist when needed (Akhamb Technician, Respondent 6, 2011). In addition, solar technology is changing, in that it requires less user knowledge and is less expensive (Vanuatu NGO, Respondent 14, 2011). Thus, it was agreed that familiarity with SHSs is increasing in the two nations, with end-users in the RMI having reached a higher level of understanding due to their more extensive history with solar PV. 


\section{Participation and ownership:}

Many statements were made to the effect that "people should own their own system" and have an "economic stake" in it, as "if people just rent their system they don't have any pride in it" (RMI Government, Respondents 10 and 13, 2011; Vanuatu Entrepreneur, Respondent 8, 2011; Vanuatu NGO, Respondent 14, 2011). One interviewee continued that this has been shown throughout history, with the private ownership of land and also with the economic history of socialism, in that shared and free property do not last because people don't respect them (Vanuatu Entrepreneur, Respondent 8, 2011). It was proposed that private ownership results in SHSs being better managed and more respected, while one interviewee commented that "local people should be involved in projects from start to finish" (RMI Government, Respondents 11 and 13, 2011).

Another interviewee felt that private ownership was simpler, as a "RESCO model creates headaches collecting fees and going out to rural villages; rather, [self-initiated] SHSs are best for villages" (Vanuatu Entrepreneur, Respondent 8, 2011). In contrast, one respondent from the RMI suggested that MEC is easiest to work with to manage SHSs, as it is $100 \%$ government-owned (RMI National Government, Respondent 12, 2011). Additionally, three respondents mentioned that community systems are not an enduring model, as they are overused and disrespected (RMI Government, Respondent 13, 2011). Overall, a user-owned model was preferred by interviewees in order to increase end-users' respect for their SHSs.

\section{Willingness to pay:}

It appeared that most interviewees assumed end-users would be willing to purchase a SHS if it was affordable, as they trusted the technology to provide end-user satisfaction if used correctly. Thus, willingness to pay was only mentioned once, in that recently Marshallese have begun to purchase expensive cars and mobile phones, which indicates that locals now have more cash available, and may be more able to pay for solar PV (RMI Entrepreneur, Respondent 3, 2011). However, this is not currently the case in Vanuatu. 


\section{Effectiveness in improving the environment:}

Climate Change (CC) was only mentioned once by a RMI government representative who saw it as a huge issue, with RE being a way to "shout out to the world" that PICs are in danger from sea-level rise, and that they care about $\mathrm{CC}$ and are trying to improve the situation (RMI Government, Respondent 11, 2011).

Furthermore, battery collection was mentioned twice, by one interviewee who said it is needed but costly (Vanuatu Entrepreneur, Respondent 5, 2011), and by a NGO representative who is setting up battery recycling for solar lanterns and small SHSs (Vanuatu NGO, Respondent 18, 2011). Overall, environmental consequences of SHSs were not interviewees' main concern.

\subsection{Interviewees' Beliefs on Electrification Strategies and Essential Factors}

Figure 7.2.1 shows interviewees' responses to Question 12 regarding their opinions on the most effective electrification strategies. One entrepreneur did not respond clearly, and therefore was excluded. Table 7.2.1 lists the most essential factors for project permanence according to interviewees' responses to Question 13. Interestingly, training users well was the most common answer, followed by appropriate equipment used for island environments, funding available for maintenance, and a capacity for maintenance.

Figure 7.2.1: Interviewees' responses to Interview Question 12.

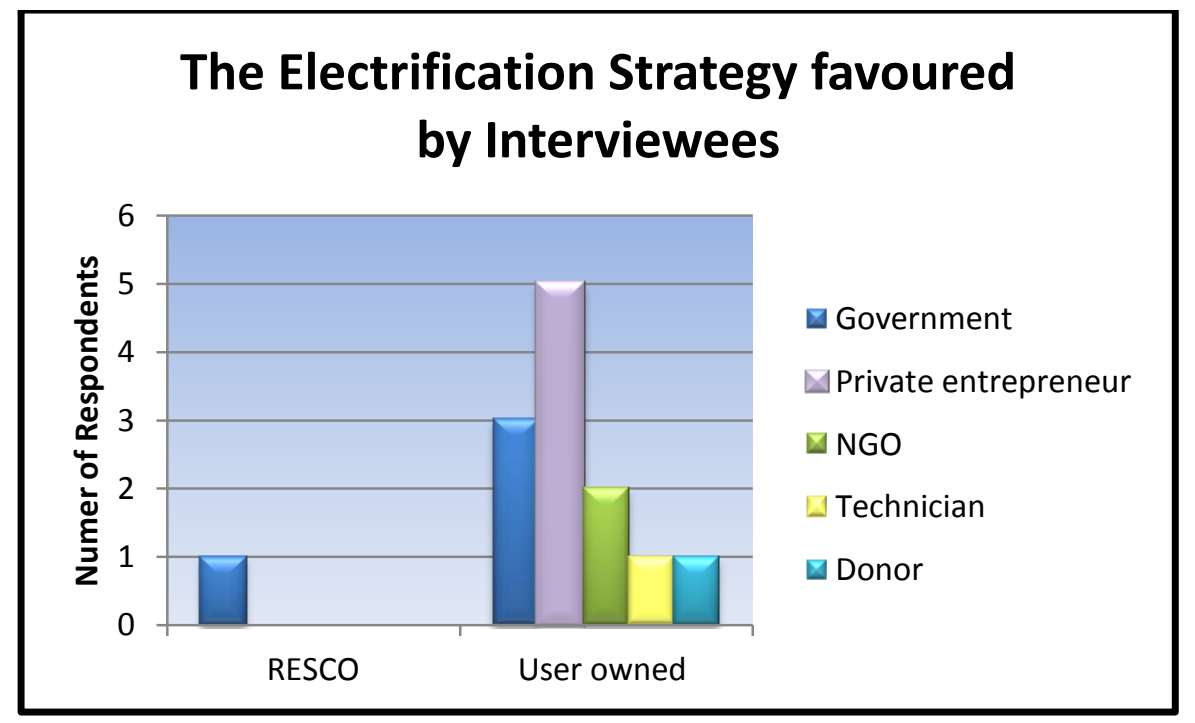


Table 7.2.1: Interviewees' responses to Interview Question 13. The top four responses are in italics.

\begin{tabular}{|c|c|c|c|c|c|c|c|}
\hline Indicator & $\begin{array}{l}\text { Most Important Factors Stated by } \\
\text { Interviewees }\end{array}$ & Donor & $\begin{array}{l}\text { Govern- } \\
\text { ment: } \\
\text { Local \& } \\
\text { National }\end{array}$ & $\begin{array}{l}\text { Private } \\
\text { Company }\end{array}$ & NGO & Technician & Total \\
\hline \multirow[t]{3}{*}{$\begin{array}{l}\text { 1. Appropriate equipment } \\
\text { use }\end{array}$} & $\begin{array}{l}\text { Correct and quality equipment used } \\
\text { for island environments }\end{array}$ & 1 & 1 & 2 & 1 & & 5 \\
\hline & Accredited installers and designers & 1 & & 1 & & & 2 \\
\hline & $\begin{array}{l}\text { Solar module placed in a safe and } \\
\text { sunny area }\end{array}$ & & & & & 1 & 1 \\
\hline $\begin{array}{l}\text { 2. Effectiveness in meeting } \\
\text { users' needs }\end{array}$ & $\begin{array}{l}\text { Solar must meet the demand of the } \\
\text { users/ a power assessment must be } \\
\text { done }\end{array}$ & & 1 & 1 & & & 2 \\
\hline $\begin{array}{l}\text { 3. Ability to satisfy } \\
\text { expanding energy demands }\end{array}$ & None & & & & & & $\overline{0}$ \\
\hline 4. Cost-effectiveness & None & & & & & & $\mathbf{0}$ \\
\hline $\begin{array}{l}\text { 5. Effectiveness in changing } \\
\text { community livelihoods }\end{array}$ & None & & & & & & $\overline{0}$ \\
\hline \multirow[t]{2}{*}{$\begin{array}{l}\text { 6. Availability of resources } \\
\text { and support }\end{array}$} & $\begin{array}{l}\text { Capacity for maintenance: better if } \\
\text { handled locally as much as possible, } \\
\text { technical support must be available }\end{array}$ & 1 & 3 & & & & 4 \\
\hline & $\begin{array}{l}\text { Having the right leaders, who have } \\
\text { experience and people look up to }\end{array}$ & & 1 & & & & $\overline{1}$ \\
\hline
\end{tabular}




\begin{tabular}{|c|c|c|c|c|c|c|c|}
\hline & $\begin{array}{l}\text { Having communication between } \\
\text { users and suppliers; technical advice } \\
\text { must be available }\end{array}$ & & 1 & 1 & & & 2 \\
\hline $\begin{array}{l}\text { 7. Availability of system } \\
\text { components }\end{array}$ & Reliable sources of spare parts & 1 & 1 & & & & 2 \\
\hline \multirow[t]{2}{*}{ 8. Capacity building } & $\begin{array}{l}\text { Must train end-users well (hands-on } \\
\text { and in the local language), so that they } \\
\text { have a good understanding of solar }\end{array}$ & 1 & 4 & 2 & 1 & 1 & 9 \\
\hline & $\begin{array}{l}\text { People aware of limitations of solar -- } \\
\text { of the power produced and how to } \\
\text { conserve }\end{array}$ & & 1 & 1 & & & 2 \\
\hline 9. Gender inclusiveness & Training both women and men & & & 1 & & & $\overline{1}$ \\
\hline \multirow[t]{3}{*}{ 10. Affordability } & $\begin{array}{l}\text { Funding available for maintenancel } \\
\text { proper payment model }\end{array}$ & & 4 & & & & 4 \\
\hline & $\begin{array}{l}\text { Help rural customers gain access to } \\
\text { funds through capacity building }\end{array}$ & 1 & & & 1 & & 2 \\
\hline & $\begin{array}{l}\text { Increase affordability through } \\
\text { subsidies }\end{array}$ & 1 & & & & & 1 \\
\hline $\begin{array}{l}\text { 11. Familiarity with the } \\
\text { technology }\end{array}$ & None & & & & & & $\mathbf{0}$ \\
\hline \multirow{2}{*}{$\begin{array}{l}\text { 12. Participation and } \\
\text { ownership }\end{array}$} & Give ownership to locals & & & & 1 & & 1 \\
\hline & Share risk with local companies & & & & 1 & & 1 \\
\hline 13. Willingness to pay & None & & & & & & $\overline{\mathbf{0}}$ \\
\hline $\begin{array}{l}\text { 14. Effectiveness in } \\
\text { improving the environment }\end{array}$ & None & & & & & & $\overline{0}$ \\
\hline
\end{tabular}




\subsection{Implications of the Qualitative Data Analysis}

Table 7.3.1 explains the interviewees' conclusive recommendations that can be applied to future PV project development and electrification.

Table 7.3.1: Implications of the Qualitative Data Analysis.

\begin{tabular}{|c|c|}
\hline Indicator & Interviewees' recommendations \\
\hline $\begin{array}{l}\text { 1. Appropriate equipment } \\
\text { use }\end{array}$ & $\begin{array}{l}\text { - Certifications and standards are needed to ensure } \\
\text { acceptable quality equipment is used. } \\
\text { - Systems should be designed by vendors and technicians. } \\
\text { User training is needed to encourage proper equipment } \\
\text { usage. }\end{array}$ \\
\hline $\begin{array}{l}\text { 2. Effectiveness in meeting } \\
\text { users' needs }\end{array}$ & $\begin{array}{l}\text { Training for end-users is needed for systems to meet users' } \\
\text { needs. } \\
\text { Overuse requires a behavioral change, and may be slow to } \\
\text { improve. }\end{array}$ \\
\hline $\begin{array}{l}\text { 3. Ability to satisfy } \\
\text { expanding energy } \\
\text { demands }\end{array}$ & $\begin{array}{l}\text { - Some solar vendors did take expanding energy demands } \\
\text { into account. } \\
\text { - This was not a main concern of interviewees. }\end{array}$ \\
\hline 4. Cost-effectiveness & $\begin{array}{l}\text { The most cost-effective systems decrease the need to travel, } \\
\text { by teaching end-users to install their own systems or by } \\
\text { selling systems in remote communities. } \\
\text { - For larger systems a technician is often needed for } \\
\text { installation. } \\
\text { - Allowing wholesale prices for rural organizations makes } \\
\text { systems more cost-effective, as retail prices can be similar } \\
\text { to urban areas. }\end{array}$ \\
\hline $\begin{array}{l}\text { 5. Effectiveness in changing } \\
\text { community livelihoods }\end{array}$ & $\begin{array}{l}\text { Interviewees focused mostly on changes that do not affect } \\
\text { income levels. } \\
\text { A focus on refrigeration was the exception. }\end{array}$ \\
\hline $\begin{array}{l}\text { 6. Availability of resources } \\
\text { and support }\end{array}$ & $\begin{array}{l}\text { All SHS vendors were providing technical support of their } \\
\text { own accord. } \\
\text { - Vendors have an interest in systems working effectively } \\
\text { and enduring, which motivates them to provide support. }\end{array}$ \\
\hline $\begin{array}{l}\text { 7. Availability of system } \\
\text { components }\end{array}$ & $\begin{array}{l}\text { Although access to spare parts locally was considered } \\
\text { important, it was not seen as essential. }\end{array}$ \\
\hline 8. Capacity building & $\begin{array}{l}\text { Training was seen as a major need, with many grass-root } \\
\text { initiatives already taking place. } \\
\text { - More funding is needed in order for training to reach a } \\
\text { large percentage of the rural population. }\end{array}$ \\
\hline
\end{tabular}




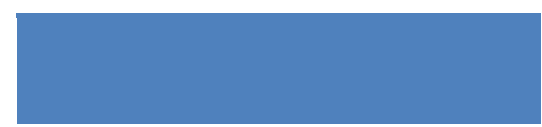

9. Gender inclusiveness

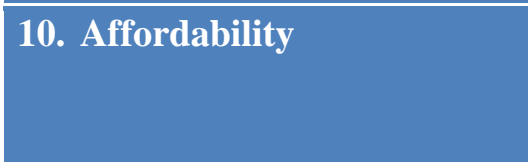

11. Familiarity with the technology

\section{Participation and} ownership

13. Willingness to pay

14. Effectiveness in improving the environment
- End-users who own their systems appear to care more about training, as they have allocated their savings to solar.

- Interviewees suggested women generally care more about their SHSs than men.

- More than half of vendors' customers were women.

- Gender was generally overlooked as something that needed to be considered in electrification.

- Most energy stakeholders are male.

- Affordability was a concern of most respondents.

- Financing, subsidies, and battery-charging stations were suggested as options for increasing affordability.

- Familiarity with SHSs was viewed as increasing in the two nations.

- End-users in the RMI have reached a higher level of understanding than in Vanuatu.

- A user-owned model was preferred by most interviewees, because it increases end-users' respect for their SHSs through incentives.

- Interviewees trusted PV technology to provide user satisfaction if properly handled.

- Willingness to pay was not of major concern.

- Environmental consequences were not interviewees' main concern. 


\section{Chapter 8: \\ Recommendations and Discussion}

This thesis has examined the essential factors for effective rural electrification in the Marshall Islands, Vanuatu, and other PICs. In this chapter, the aim of this research is addressed, by providing overarching recommendations on appropriate electrification strategies, risk mitigation approaches, and criteria for success in order to increase SHS longevity in PICs. These recommendations have been determined based on the results of the research questions, which were previously addressed. In addition, a discussion of how these research findings fit into the larger development context and the limitations of the research are presented.

\subsection{Recommendations on Electrification Strategies}

A summary of the positive and negative aspects of two electrification models: selfinitiated SHSs and RESCOs, based on the literature, project documents, case studies, and interviews, are described in Table 8.1.1. The project-initiated user-owned model has been omitted, as it covers a wide range of projects, such as Vanuatu's VERD project, where aid and support were channelled to local organizations to provide financing for SHSs under $30 \mathrm{~W}$. Island Eco's project varied in that aid was given directly to the organization, to implement systems that were $75 \%$ subsidized, all one size, and for a specific purpose. Although project-initiated user-owned strategies vary in the model used, they fall inbetween self-initiated SHSs and RESCO projects on the participatory development spectrum, and contain aspects of both projects.

The overall strengths of the RESCO electrification model, as described in Table 8.1.1 are:

- Higher quality equipment is used.

- Costs are spread out over-time.

- Equipment is subsidized, tax-free, and purchased in large quantities, making equipment more cost-effective.

- Systems are checked regularly and maintained by a technician. 
However, all of this can be accomplished through a self-initiated user-owned model as well, because:

- Equipment standards and dealer certifications can be enforced.

- End-users can be given access to financing, through vendors or financing institutions, to allow costs to be distributed over time.

- Equipment that meets standards can be subsidized, all RE equipment can be tax and duty exempt, and economies of scale can develop through encouraging market expansion.

- Quality after-sales support can be encouraged through training and certification of vendors, and can be provided in a number of ways (see Figure 8.3.1).

In addition, the strengths of the self-initiated user-owned model are that:

- A large variety of systems are available to meet users' needs

- Competition between vendors increases cost-effectiveness

- End-users are allowed to repair their own systems, which increases affordability and efficiency of maintenance

- Opportunities are provided for rural microenterprises to use SHSs for productive uses and to sell SHS components

- There is an economic incentive for end-users to take care of their systems and to attend training sessions

- End-users can dispense funds for SHSs and maintenance when it is affordable

- Management required for electrification is minimal

- End-users' desires for participation and ownership are met and they are in control of their development solutions

These strengths are generally not incorporated into rented SHS projects, and, therefore, user-owned systems have a better chance of meeting end-users' needs and providing lasting results. In contrast, RESCOs require a high level of institutional organization, do not provide an incentive for users to look after their SHSs, and can become an economic burden. In summary, projects with fewer layers, user-participation, and incentives for end-users often are more successful in making SHSs profitable and enduring. 
Table 8.1.1: Positive and negative aspects of each electrification model, based on the literature, project documents, case studies, and interviews.

\begin{tabular}{|c|c|c|c|}
\hline \multicolumn{2}{|l|}{ Indicator } & Self-initiated User-owned & RESCO/Fee-for-service \\
\hline \multirow[t]{2}{*}{$\begin{array}{l}\text { 1. Appropriate } \\
\text { equipment use }\end{array}$} & Positive & $\begin{array}{l}\text {-Large variety of sizes and differing qualities of } \\
\text { SHSs }\end{array}$ & -Often only high quality equipment \\
\hline & Negative & $\begin{array}{l}\text {-Poor quality/ faulty equipment sold by less honest } \\
\text { vendors }\end{array}$ & -Often only one size of system is supplied \\
\hline \multirow{2}{*}{$\begin{array}{l}\text { 2. Effectiveness } \\
\text { in meeting } \\
\text { users' needs }\end{array}$} & Positive & $\begin{array}{l}\text {-Full choice in system size, services, and quality } \\
\text {-Demand based on the preferences of end-users }\end{array}$ & $\begin{array}{l}\text {-End-users can sometimes afford more than one system to } \\
\text { meet multiple needs }\end{array}$ \\
\hline & Negative & $\begin{array}{l}\text {-Profit-centred model means end-users' needs may } \\
\text { be neglected }\end{array}$ & $\begin{array}{l}\text {-Lack of choice on system size and services provided } \\
\text {-End-user has a choice of renting the system and } \\
\text { finance/maintenance package or nothing }\end{array}$ \\
\hline \multirow{2}{*}{$\begin{array}{l}\text { 3. Ability to } \\
\text { satisfy } \\
\text { expanding } \\
\text { energy } \\
\text { demands }\end{array}$} & Positive & $\begin{array}{l}\text {-Systems may be able to be expanded, resold, or } \\
\text { traded in }\end{array}$ & $\begin{array}{l}\text { - The service company may upgrade the communities' } \\
\text { systems when needed }\end{array}$ \\
\hline & Negative & $\begin{array}{l}\text {-End-users may expand systems incorrectly, thus } \\
\text { lowering system efficiency }\end{array}$ & $\begin{array}{l}\text {-Expansion often not allowed } \\
\text {-End-users unable to alter their systems }\end{array}$ \\
\hline \multirow[t]{2}{*}{$\begin{array}{l}\text { 4. Cost- } \\
\text { effectiveness }\end{array}$} & Positive & $\begin{array}{l}\text {-Range of costs and qualities } \\
\text {-Market determines the price through competition } \\
\text {-End-users allowed to purchase parts directly } \\
\text {-Decreased need to travel for installation and } \\
\text { maintenance } \\
\text {-Competition can lead to innovation }\end{array}$ & $\begin{array}{l}\text {-Equipment often supplied in bulk } \\
\text {-Equipment often subsidized and not taxed }\end{array}$ \\
\hline & Negative & $\begin{array}{l}\text {-Equipment often taxed and not subsidized } \\
\text {-Poor management of systems can decrease cost- } \\
\text { effectiveness for users }\end{array}$ & $\begin{array}{l}\text {-Price fixed for end-users } \\
\text {-High-cost equipment only, due to quality } \\
\text {-Monitoring and maintenance often costly } \\
\text {-Systems can become an economic burden for the managing } \\
\text { organization } \\
\text {-End-users must continue to pay for maintenance even if not } \\
\text { required }\end{array}$ \\
\hline $\begin{array}{l}\text { 5. Effectiveness } \\
\text { in changing } \\
\text { community } \\
\text { livelihoods }\end{array}$ & Positive & $\begin{array}{l}\text {-Systems specialized to provide services based on } \\
\text { end-users' occupations and interests } \\
\text {-Allows for a variety of microenterprises in } \\
\text { communities }\end{array}$ & $\begin{array}{l}\text {-Systems may be more affordable, allowing for more end- } \\
\text { users to be affected by the services }\end{array}$ \\
\hline
\end{tabular}




\begin{tabular}{|c|c|c|c|}
\hline & Negative & $\begin{array}{l}\text {-Low-income end-users may be excluded from } \\
\text { positive livelihood changes }\end{array}$ & -Systems are generally limited in the services they provide \\
\hline \multirow[t]{2}{*}{$\begin{array}{l}\text { 6. A vailability } \\
\text { of resources } \\
\text { and support }\end{array}$} & Positive & $\begin{array}{l}\text {-Technical support is generally offered by local } \\
\text { suppliers, as endurance is in their interest } \\
\text {-Many types of support available } \\
\text {-End-users allowed to repair their systems } \\
\text {-Often a warrantee for SHSs is provided } \\
\text {-End-users prefer self-organized maintenance } \\
\text {-Self-organized support is often more efficient }\end{array}$ & $\begin{array}{l}\text {-May train a local technician or a technician may make } \\
\text { regular visits to check and repair SHSs } \\
\text {-Ideally systems are checked regularly }\end{array}$ \\
\hline & Negative & $\begin{array}{l}\text {-End-user may need to pay the cost of servicing and } \\
\text { replacement parts, making maintenance costly at one } \\
\text { time } \\
\text {-End-users may inappropriately repair their system, } \\
\text { although doing so is not their interest }\end{array}$ & $\begin{array}{l}\text {-Often overseas suppliers, which may hinder local support } \\
\text {-Service schedules may breakdown due to irregular } \\
\text { transportation and poor communication } \\
\text {-Requires a high level of attention and coordination } \\
\text {-Costly and timely, as SHSs are normally checked monthly }\end{array}$ \\
\hline \multirow[t]{2}{*}{$\begin{array}{l}\text { 7. Availability } \\
\text { of system } \\
\text { components }\end{array}$} & Positive & $\begin{array}{l}\text {-Often spare components can be shipped to end-users } \\
\text { for system repair, increasing efficiency } \\
\text {-Rural microenterprises can sell spare parts }\end{array}$ & $\begin{array}{l}\text {-End-users do not need to be concerned about acquiring } \\
\text { spare components or which ones to purchase }\end{array}$ \\
\hline & Negative & $\begin{array}{l}\text {-End-users may not have access to parts for their } \\
\text { system if suppliers are no longer in business } \\
\text {-End-users need to acquire parts themselves }\end{array}$ & $\begin{array}{l}\text {-Replacement components are generally only available from } \\
\text { one organization, and thus parts may not be available } \\
\text { nationally } \\
\text {-Requires regular transportation and supply lines, which are } \\
\text { difficult to organize in PICs }\end{array}$ \\
\hline \multirow[t]{2}{*}{$\begin{array}{l}\text { 8. Capacity } \\
\text { building }\end{array}$} & Positive & $\begin{array}{l}\text {-Often basic training is provided to the customer at } \\
\text { the time of purchase } \\
\text {-Follow-up training may be provided, which is often } \\
\text { needs-based } \\
\text {-End-users who own their systems generally care } \\
\text { more about training }\end{array}$ & $\begin{array}{l}\text {-Generally technicians are trained, and are given some } \\
\text { ongoing technical support }\end{array}$ \\
\hline & Negative & $\begin{array}{l}\text {-Training for users and technicians are generally } \\
\text { uncoordinated nationally }\end{array}$ & $\begin{array}{l}\text {-Often minimal training is available for end-users } \\
\text {-Extensive training is discouraged as systems may be locked } \\
\text { to prevent user alterations }\end{array}$ \\
\hline $\begin{array}{l}\text { 9. Gender } \\
\text { inclusiveness }\end{array}$ & Positive & $\begin{array}{l}\text {-Often a larger range of services are available, which } \\
\text { may directly help women } \\
\text {-Women have the opportunity to manage their } \\
\text { family's SHS and learn basic maintenance skills }\end{array}$ & -Have the opportunity to focus on women's needs \\
\hline
\end{tabular}




\begin{tabular}{|c|c|c|c|}
\hline & Negative & $\begin{array}{l}\text {-Women may need to contribute to the cost of } \\
\text { maintenance or spare parts }\end{array}$ & -Women may need to contribute to monthly fees \\
\hline \multirow[t]{2}{*}{$\begin{array}{l}10 . \\
\text { Affordability }\end{array}$} & Positive & $\begin{array}{l}\text {-Financing is sometimes available by dealers, } \\
\text { financing institution, or donors } \\
\text {-End-users may organize their own financing or buy } \\
\text { parts over time }\end{array}$ & $\begin{array}{l}\text {-Systems may be more affordable as they are generally } \\
\text { subsidized } \\
\text {-Costs are spread out over time, making initial and } \\
\text { maintenance costs more affordable to end-users }\end{array}$ \\
\hline & Negative & $\begin{array}{l}\text {-Low-income households may be overlooked, } \\
\text { without access to financing } \\
\text {-Often end-users pay the full initial price and full } \\
\text { price of maintenance }\end{array}$ & $\begin{array}{l}\text {-Fees are required to be paid regularly, which may be } \\
\text { difficult for those without a steady income } \\
\text {-End-users must continue to pay after they have paid for the } \\
\text { initial SHS cost } \\
\text {-The system can be disconnected if fees are not paid }\end{array}$ \\
\hline \multirow{2}{*}{$\begin{array}{l}\text { 11. Familiarity } \\
\text { with the } \\
\text { technology }\end{array}$} & Positive & $\begin{array}{l}\text {-Increases end-users' technological familiarity as a } \\
\text { result of their experience with SHSs }\end{array}$ & -End-users are not required to be familiar with their systems \\
\hline & Negative & -Some user-familiarity is required & -End-users do not gain much additional experience \\
\hline \multirow[t]{2}{*}{$\begin{array}{l}12 . \\
\text { Participation } \\
\text { and ownership }\end{array}$} & Positive & $\begin{array}{l}\text {-End-users often participate in all stages of the } \\
\text { electrification process } \\
\text {-Incentive for end-users to properly manage the SHS } \\
\text {-A high level of participation and ownership is } \\
\text { desired by most end-users }\end{array}$ & $\begin{array}{l}\text {-Utilities or companies generally have ownership, which can } \\
\text { improve system maintenance }\end{array}$ \\
\hline & Negative & $\begin{array}{l}\text {-End-users may not properly install or maintain their } \\
\text { systems }\end{array}$ & $\begin{array}{l}\text {-End-users do not have ownership of SHSs } \\
\text {-End-users generally do not participate in the electrification } \\
\text { process } \\
\text {-Damage, overuse, and theft is a burden to the RESCO } \\
\text {-No incentive to properly manage the system, as system } \\
\text { failure is rewarded by parts being replaced }\end{array}$ \\
\hline \multirow[t]{2}{*}{$\begin{array}{l}13 . \\
\text { Willingness to } \\
\text { pay }\end{array}$} & Positive & $\begin{array}{l}\text {-User-owned SHSs are preferred, resulting in a } \\
\text { higher willingness to pay due to higher user- } \\
\text { satisfaction }\end{array}$ & $\begin{array}{l}\text {-Willingness to pay may be high if users are satisfied with } \\
\text { the service provided }\end{array}$ \\
\hline & Negative & $\begin{array}{l}\text {-End-users may not be willing to pay for replacement } \\
\text { parts without financing and subsidies }\end{array}$ & $\begin{array}{l}\text {-Customers may not like paying repeatedly for something } \\
\text { that they are not able to own }\end{array}$ \\
\hline \multirow{2}{*}{$\begin{array}{l}14 . \\
\text { Effectiveness in } \\
\text { improving the } \\
\text { environment }\end{array}$} & Positive & $\begin{array}{l}\text {-The possibility for a variety of system sizes and for } \\
\text { expansion lessens the need for fossil fuel power }\end{array}$ & $\begin{array}{l}\text {-Higher quality batteries may be provided, resulting in less } \\
\text { expired batteries }\end{array}$ \\
\hline & Negative & $\begin{array}{l}\text {-Poor quality batteries may be purchased, which fail } \\
\text { quickly }\end{array}$ & $\begin{array}{l}\text {-Systems may not meet users' needs, resulting in users } \\
\text { purchasing back-up fossil fuel generators }\end{array}$ \\
\hline
\end{tabular}


For countries with ongoing RESCO projects and weak PV markets (such as the RMI, due to a long history of donor-funded projects), there is merit in continuing with the same electrification model. In this case, RESCOs should address the fact that incomes are unreliable for many rural end-users, and thus a monthly payment scheme may be unaffordable (see Figure 8.3.1 for options for alleviating this). In addition, RESCOs should have disconnection policies that are strictly enforced, as renting a SHS should be a voluntary option for households, with end-users that prefer to purchase their own power being disconnected or allowed to rent-to-own the system. Furthermore, fees for maintenance need to be set according to project costs, rather than affordability, as this will help to prevent market distortions. Fees should even be over-estimated to allow for unforeseen technical problems, as projects can become an economic burden to the RESCO organization if the systems fail.

However, for funding organizations working with countries that have existing PV markets, it is preferable for them to help strengthen the existing institutions, policies, and markets rather than creating new programs which serve as competition for local businesses. Expanding RE markets will decrease the need for future aid-dependence, as excessive donor funding can create expectations, decrease community motivation, and inhibit markets through consumers rejecting market prices.

Such a role for project finance (including government) may include:

- Facilitating rural access to electricity through providing subsidies and financing for equipment, and making users aware of these options

- Aiding small businesses and NGOs to expand their capacity for supply and after-sales support

- Funding training programs for both users and technicians in collaboration with solar vendors

- Funding supply lines to rural areas

- Facilitating the growth of rural microenterprises

- Funding the establishment of standards and certifications for RE equipment and vendors in order to avoid unreasonable product failure

- Helping to 'level the playing field' by eliminating market failures such as import duties and taxes on RE and EE equipment

- Encouraging cost-effectiveness through competition between vendors, unless there is a direct reason not to do so. 
Yet, the literature, project documents, and many past and ongoing SHS projects in PICs do not highlight this role for project/programme finance or the need for market expansion. Opponents of market approaches believe that low-income users will be financially excluded, due to users not being able to afford initial costs and maintenance. However, projects implemented in other regions demonstrate that subsidies and financing can be channelled through vendors and financial institutions, thus allowing SHSs and replacement components to be both affordable and needs-based. Such subsides and financing should be available for all types and sizes of systems in order to avoid market distortions, encourage productive uses, and at the same time provide options for lowincome households.

Opponents to market approaches also suggest end-users in PICs are unable to properly operate and maintain their own SHS. The results of this research show otherwise, where rural end-users on Akhamb Island have demonstrated their ability and desire to learn how to manage a SHS with limited resources and support. These end-users have maintained their SHS with no external initiative, limited training, and self-organized technical support. In addition, the rapid adoption rate of SHSs in the community has resulted in the island becoming nearly fossil fuel-free on its own initiative. This geographic clustering of RE growth has been documented by Bollinger \& Gillingham (2011), who suggested that 'peer effects' exist, wherein a household is on average five times more likely to convert to solar PV if one of their neighbours has. This shows that familiarization and education on solar PV is important for large-scale PV rollout.

Therefore, the results of this research, through the cases studies and recommendations from interviewees, suggest that PV market expansion is appropriate for PICs, and often addresses users' needs better than solar electrification models. This provides a challenge for PICs, to provide training and support for end-users, to trust them to be able to manage and maintain SHSs, and to acknowledge self-initiated electrification as a part of the rural development process. 


\subsection{Recommendations for Reducing Project Risk}

This research has shown that community consultation will increase user-satisfaction and enhance project endurance, while at the same time providing baseline data for project evaluations. Consultation can include participatory practices such as surveys, participatory rural analyses, representative committees, and stakeholder problem trees, and can help to give end-users ownership over their electricity solutions. However, participatory approaches are time-consuming, costly, and require trained and culturally aware staff (ESMAP, 2003).

Lessons learned from previous projects and success criteria (such as those developed in this research) have also recommended many social solutions for designing enduring outcomes, particularly education, ownership, and empowerment of beneficiaries. The success criteria described in Table 8.2.1 are a combination of recommendations from the literature review, lessons learned from project documents, and the conclusions from the qualitative and quantitative data analysis undertaken in this study. These criteria are aimed at providing enduring results for end-users, which is complementary to other success factors found in the PIC literature, in that they generally focus upon factors for national policies and project management.

Table 8.2.1: Success factors for enduring results.

\begin{tabular}{l|l|}
\hline Categories & Success Criteria for Enduring Results for End-Users \\
\hline Technical & - Simple and quality technologies proven for PICs \\
- Strong equipment standards and certifications \\
- - Training for vendors and end-users \\
- Conservative system-sizing \\
- Assessment of local needs \\
- Systems meet user desires \\
- Systems consider expanding demands \\
- Users involved and trained in maintenance \\
- Various services provided, linked to productive uses \\
- Microenterprise promoted \\
- Financing and subsidies available to end-users \\
- Training on financial literacy
\end{tabular}




\begin{tabular}{|c|c|}
\hline & $\begin{array}{l}\text { - Low initial investment required } \\
\text { - Maintenance affordable }\end{array}$ \\
\hline Institutional: & $\begin{array}{l}\text { - Reliable technical support available locally } \\
\text { - Communication between users and suppliers } \\
\text { - Parts available locally } \\
\text { - Share risk with local companies }\end{array}$ \\
\hline Socio-Cultural: & $\begin{array}{l}\text { - Communities introduced to SHSs } \\
\text { - Women trained on O\&M of SHSs } \\
\text { - Services aimed at women's needs } \\
\text { - Training culturally appropriate } \\
\text { - Costs/fees fit incomes and cultural norms } \\
\text { - Users own and contribute to system costs } \\
\text { - Participation is voluntary } \\
\text { - End-user control }\end{array}$ \\
\hline Environmental: & $\begin{array}{l}\text { - Reduction in GHG emissions } \\
\text { - Battery recycling available }\end{array}$ \\
\hline
\end{tabular}

History has shown that a full set of these success criteria usually cannot be incorporated into project design due to funding and capacity restraints. Thus, key stakeholders in electrification must decide which success factors are the most important to reduce project risk and implement enduring results. Consequently, a project risk mitigation framework has been developed as an outcome of this research to aid funders, designers, implementers, and other RE stakeholders to reduce non-permanence risk to their project (see Figure 8.3.1). Risk levels have been suggested, which take into consideration the number of times the threat has either hindered project success, or was cited as essential for project endurance in the literature, the project documents, the cases studies, and by interviewees. The risk-levels of the threats are colour-coded and are classified by:

- Very-High: Direct and short-term threat of SHS failure

- High: Long-term threat of SHS failure

- Moderate: Direct threat to the effectiveness of SHSs but unlikely to lead to overall project failure

- Low: Minimal threat to SHS effectiveness and endurance, although should be considered in project design to meet best practices 
Possible actions to reduce the risk of each threat are suggested in the final column of Figure 8.3.1. Some actions, such as: 1. training end-users and technicians, 2. providing a variety of system sizes, 3 . carrying out a community needs assessment, 4 . setting up certifications and standards, 5. conservatively sizing systems, and 6. providing access to financing, resulted in multiple risk reductions with only one action. Such actions can be seen as cost-effective because they provide multiple returns for investment. Educating endusers has the most co-benefits, and therefore in a pragmatic world, given funding and capacity constraints, it may provide the best return.

\subsection{A Balanced Electrification Strategy}

The results of this research show that self-initiated systems best allow for individuals' potentials to be actualised through customized SHSs that are under end-users' control. This corresponds with the development literature, where there is no universal truth regarding development needs: rather, community needs, expressed through participation, ownership, and capacity-building, will enhance the effectiveness and durability of the design and implementation of development projects (Berkes, 2007; Campbell \& Vainio-Mattila, 2003). This is in line with a generally accepted definition of community development, which is "a movement designed to promote better living for the whole community with the active participation and on initiative of the community" (Bhattacharyya, p.1, 1972).

In contrast, end-users' desires and capabilities are peripheral in most of the rented SHS projects implemented in PICs. A consideration of Arnstein's 'Ladder of Citizen Participation' (shown in Figure 2.2.1) can aid in visualizing the current state of PIC electrification projects. Currently, many projects are in the third rung of the ladder, where beneficiaries are 'informed' of electrification projects. Some projects are positioned on the fourth rung through carrying out 'consultation' with end-users. Yet, the self-initiated SHS model allows electrification to happen in the upper-rungs, with a variety of educational social programs, allowing end-users to entirely manage their electrification, for 'full citizen control'.

Thus, self-initiated electrification enables end-users to be independent from aid from developed countries, through a transfer of power to beneficiaries, which allows them to 
control their own development solutions. Consequently, a transfer of ownership is at the root of the distinction between projects that are empowering to users and those that are not. The benefits of such empowerment is highlighted in the UN Declaration on Rights of Indigenous Peoples, which states that "control by indigenous peoples over developments affecting them and their lands, territories and resources will enable them to maintain and strengthen their institutions, cultures and traditions, and to promote their development in accordance with their aspirations and needs" (UN General Assembly, 2007). Therefore, the key for successful rural development to occur is to allow local people "to develop their full potential and lead productive and creative lives in accordance with their specific needs and interests" (Subbarao, 2010).

These studies suggest that funding for participatory practices and capacity-building programs are important to end-users as a means to take control of their development solutions. As the literature suggests, in an ideal world, such social solutions would be maximized. Yet, the cost of such programs to aid-donors and private investors are real and also need to be considered when attempting to match ideals to funding realities. Thus, investment in full participatory approaches may be difficult to justify to some financial institutions supporting SHS projects and programs. This is because social changes are timeconsuming, costly, and difficult to measure.

Consequently, it is necessary to justify the costs of investments in participatory approaches by transparently demonstrating the benefits in reducing the risk of project failure and enhancing project and programme durability. Clearly, as with all investments, there is a point of diminishing returns, beyond which additional financial contributions to end-user participation may become difficult to justify. At this point it may be useful to consider the investment required by end-users whose co-financing of participation (e.g., inkind contributions) could help enable projects and programs to reach the highest rungs on Arnstein's ladder without exceeding funding limits.

This research has shown that a proper balance in the overarching program design between the technical and social focus of projects is required, as each are equally important for project endurance: technical solutions cannot flourish without attention to social needs, while at the same time an over-emphasis in the social dimensions (at the expense of the technical) may prevent efficient electrification initiatives from going ahead. Many of the 
programs examined did not allocate sufficient funds to understanding and incorporating the social aspects. Rather, there was a general focus on quick implementation, visible solutions, and technical rollout. Yet, such an approach was shown to decrease the probability of project success and enhance the risk of project failure. Therefore, this research suggests that many projects in PICs have not yet found the optimum tuning of balanced investment in both social and technical dimensions of solar PV electrification.

There is general agreement that conventional, technical 'top-down' development approaches have failed to deliver helpful results to beneficiaries, as often they neglect recipients' needs and disregard the creation of local ownership (Chambers, 1994; OECDDAC, 2005). Yet, purely 'bottom-up' social approaches are costly, timely, and unrealistic in a donor funded world of solar PV programs. The purpose of the Project Risk Mitigation Framework presented in this thesis is to help funders and implementers of solar PV electrification find the correct balance of technical and social investment, through enabling project designers to choose the most effective method to minimize threats, no matter if they are social or technical in nature. This balance will vary on a case-by-case basis depending on a community's development level and needs, yet more attention to social dimensions of renewable electrification is likely to increase SHS longevity in PICs.

Figure 8.3.1: A Project Risk Mitigation Framework for identifying threats to SHSs in PICs, and suggested actions to mitigate these threats. 


\begin{tabular}{|c|c|c|c|c|}
\hline Indicator & $\frac{\text { Primary }}{\text { Threats }}$ & $\frac{\text { Possible Results if }}{\underline{\text { Unaddressed }}}$ & Risk Level & Actions to Avoid Threats \\
\hline \multirow{3}{*}{$\begin{array}{l}\text { 1. } \\
\text { Appropriate } \\
\underline{\text { equipment }} \\
\underline{\text { use }}\end{array}$} & $\begin{array}{l}\text { A) No standards } \\
\text { or certifications } \\
\text { for equipment or } \\
\text { vendors }\end{array}$ & $\begin{array}{l}\text { A1) End-users purchase low- } \\
\text { quality parts unknowingly } \\
\text { A2) Vendors sell poor quality } \\
\text { systems to increase sales } \\
\text { A3) Vendors lack expertise } \\
\text { A4) Equipment may fail quickly }\end{array}$ & $\begin{array}{l}\text { A) High: Poor quality } \\
\text { equipment can lead } \\
\text { systems to fail quickly } \\
\text { and decrease } \\
\text { willingness-to-pay }\end{array}$ & $\begin{array}{l}\text { A1) Certifications and standards for } \\
\text { equipment } \\
\text { A2) Accredit installers and designers } \\
\text { A3) Subsidize appropriate equipment } \\
\text { A4) Subsidize adequately-designed systems } \\
\text { by accredited installers } \\
\text { A5) Label solar PV-appropriate and } \\
\text { energy-efficient equipment/appliances }\end{array}$ \\
\hline & $\begin{array}{l}\text { B) End-users not } \\
\text { trained on } \\
\text { appropriate } \\
\text { equipment use }\end{array}$ & $\begin{array}{l}\text { B1) End-users purchase } \\
\text { undersized systems } \\
\text { B2) End-users poorly install } \\
\text { their systems } \\
\text { B3) End-users overuse their } \\
\text { SHSs }\end{array}$ & $\begin{array}{l}\text { B) High: } \\
\text { End-users may } \\
\text { overuse their systems, } \\
\text { causing inefficiency } \\
\text { and failure }\end{array}$ & $\begin{array}{l}\text { B1) Educate consumers on system-sizing, } \\
\text { limitations, and installation } \\
\text { B2) Give end-users ownership, as it } \\
\text { provides a financial incentive against } \\
\text { overuse } \\
\text { B3) Provide long-term training to prevent } \\
\text { overuse, as it will require a behaviour } \\
\text { change }\end{array}$ \\
\hline & $\begin{array}{l}\text { C) Equipment } \\
\text { inappropriately } \\
\text { complex or not } \\
\text { designed for PIC } \\
\text { environments }\end{array}$ & $\begin{array}{l}\text { C1) Expertise may be } \\
\text { unavailable to fix complex } \\
\text { equipment } \\
\text { C2) Equipment may need to be } \\
\text { replaced regularly } \\
\text { C3) Maintenance costs can } \\
\text { increase }\end{array}$ & $\begin{array}{l}\text { C) Moderate: Many } \\
\text { experienced vendors } \\
\text { are now aware of } \\
\text { what equipment is } \\
\text { appropriate }\end{array}$ & $\begin{array}{l}\text { C1) Avoid complex technologies that } \\
\text { require a high level of maintenance } \\
\text { C2) Use technically and commercially } \\
\text { proven technologies for PICs }\end{array}$ \\
\hline
\end{tabular}




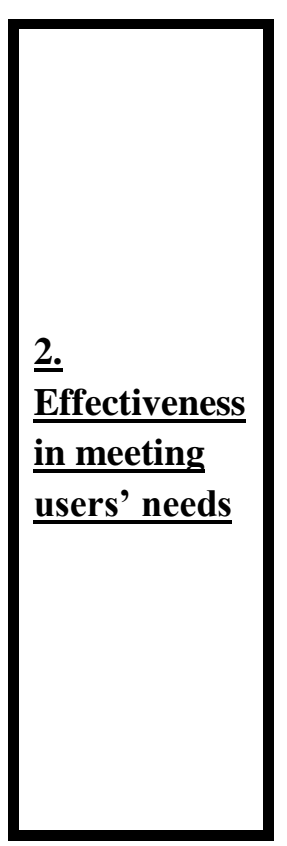

\section{Ability to}

satisfy

expanding

energy

demands

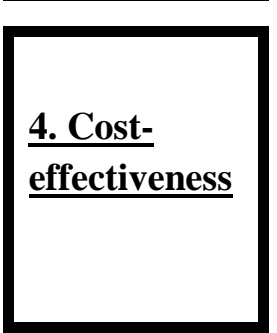

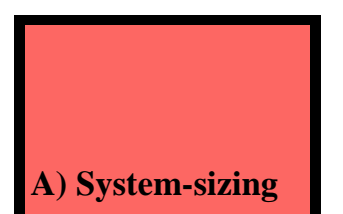

A1) End-users may alter or does not meet users' needs needs

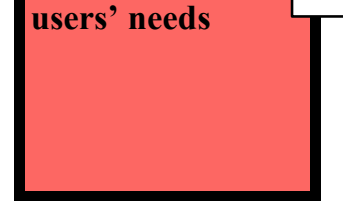

A2) Satisfaction levels are likely to be low

\section{B) External} maintenance is poor and endusers cannot access their systems for repair

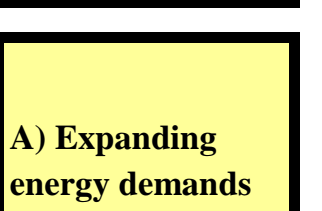 energy demands are not taken into} account

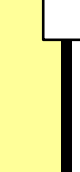

A1) End-users' electricity demands can increase and hinder project success

A2) If only one system size is provided, it can result in

inequity and user-dissatisfaction

B1) End-users may stop paying for their system or may disrespect it

B2) End-users may alter their system

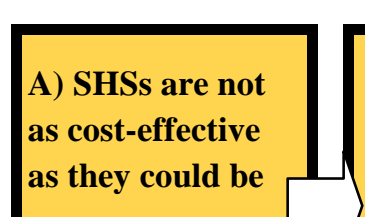

A1) End-users may not be able to afford a SHS

A2) End-users may avoid installation costs

A3) End-users may piece together systems themselves

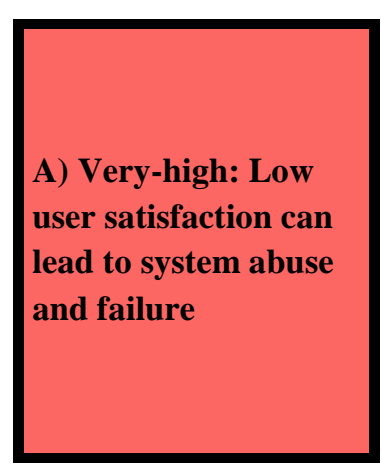

A1) Incorporate end-users' electricity demands into SHS sizing

A2) Carry-out a power assessment

A3) Provide a range of SHS sizes, and allow end-users to change sizes with rented systems

A4) Size systems conservatively, and consider that systems are likely to be shared

\section{B) Very-high: Poor} external maintenance quickly reduces endusers' willingness-topay

\section{B1) Provide very reliable external} maintenance

B2) Allow users to be involved in maintenance

B3) Provide training on system

troubleshooting and repair

A) Moderate:

Expanding demands can hinder success, but often the change is slow

A) High: Access to funding is more important for affordability, and can result in failure if end-users cannot
A1) Allow end-users to upgrade their systems

A2) Allow for a second-hand SHS market through providing varying sizes of SHSs A3) Reduce demand by training end-users on energy efficiency and conserving power A4) View SHSs as part of the

electrification process, not as a final result

A1) Decrease the need to travel, by training end-users in installation and maintenance

A2) Sell systems and parts in remote communities

A3) Allow wholesale prices for rural 


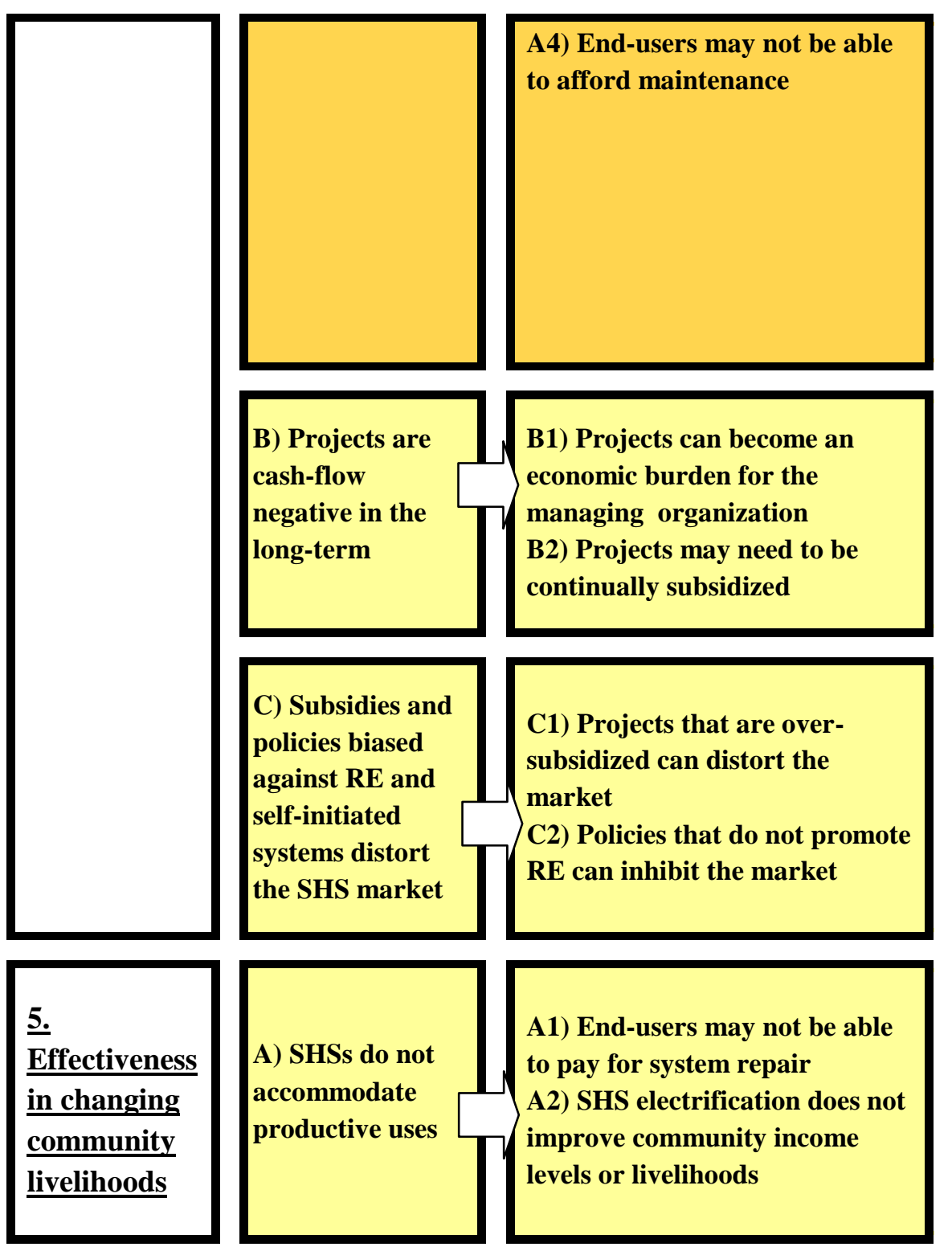

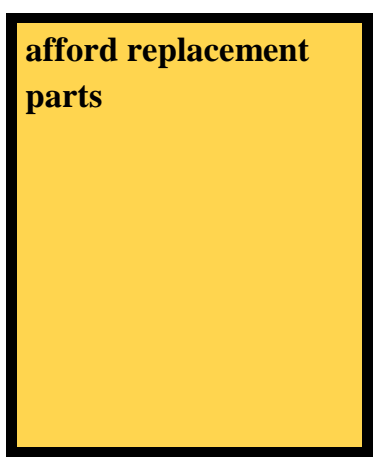

B) Moderate:

Unsustainable

projects require

lifetime financial

support, yet are often

funded

C) Moderate: Selfinitiated systems may

become expensive

\section{A) Moderate:}

SHSs are comparable

in cost to other

energy sources that

do not accommodate

productive uses organizations to decrease rural retail prices

A4) Provide SHSs that power a variety of services, not just lighting

A5) Oversize systems in order to reduce the need for expensive battery

replacements

A6) Encourage competition between solar vendors

B1) Set fees according to project costs, rather than according to affordability B2) Implement strong disconnection policies for payment defaults

C1) Encourage government regulations that promote $\mathbf{R E}$

C2) Use blanket subsidies for SHS equipment

C3) Set fees according to project costs

A1) Link services to productive uses A2) Provide a range of SHS sizes, which can be specialized for end-users' occupations and interests

A3) Employ rural organizations to sell SHSs and parts 


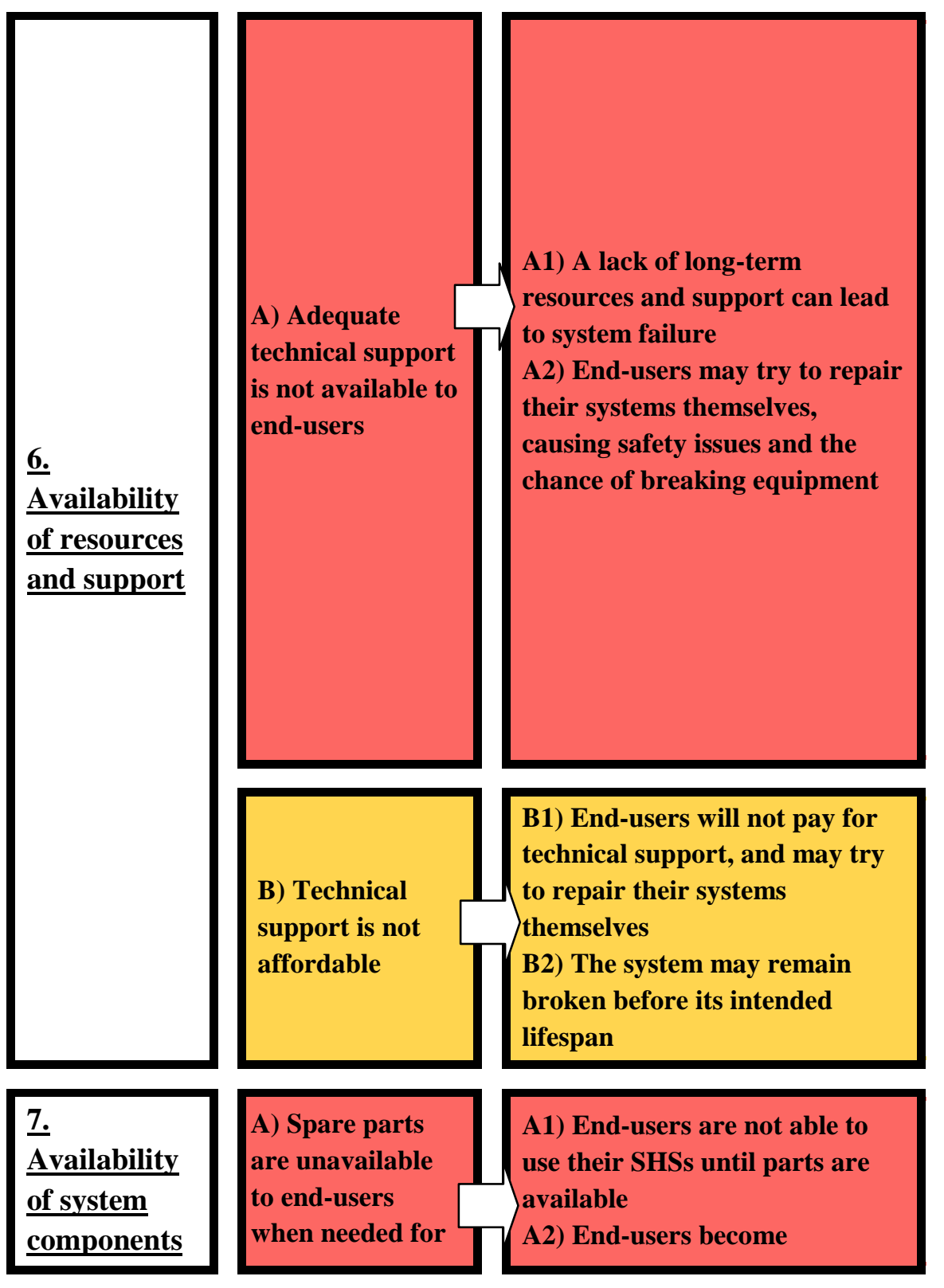

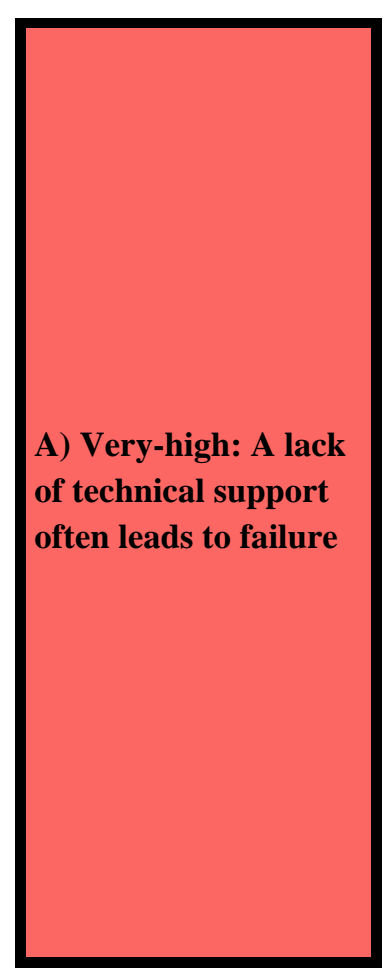

A1) Provide reliable after-sales service, through toll-free call centres, radio communication, and the option of sending broken parts to vendors for repair A2) Provide regular monitoring of systems, perhaps through GPS/ GSM devices, text messaging, telephone, and radio communication

A3) Create strong relations between suppliers and customers

A4) Support vendors to provide technical training and involve end-users in maintenance

A5) Attach basic maintenance information and how to access technical support to the SHS

A6) Create a national support centre for RE

A7) Incorporate RE education into schools and vocational centres

\section{B) High:}

Unaffordable support may result in improper repair or unused systems

A) Very-high: Spare parts are needed for system endurance
B1) Provide after sales service and repair in ways that minimize the need to travel B2) Provide technical support locally through training local technicians

B3) Train end-users to be able to handle basic maintenance and repair

A1) Create strong supply chains, both from overseas to suppliers and from suppliers to rural areas

A2) Organize local organizations to supply 

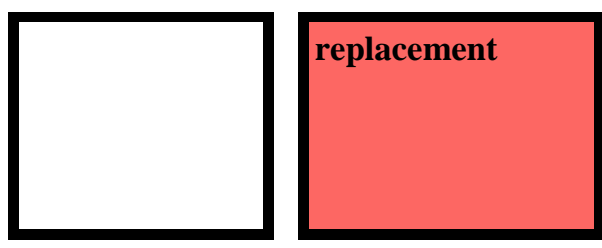

dissatisfied

A3) SHSs may remain broken

before their intended lifespan

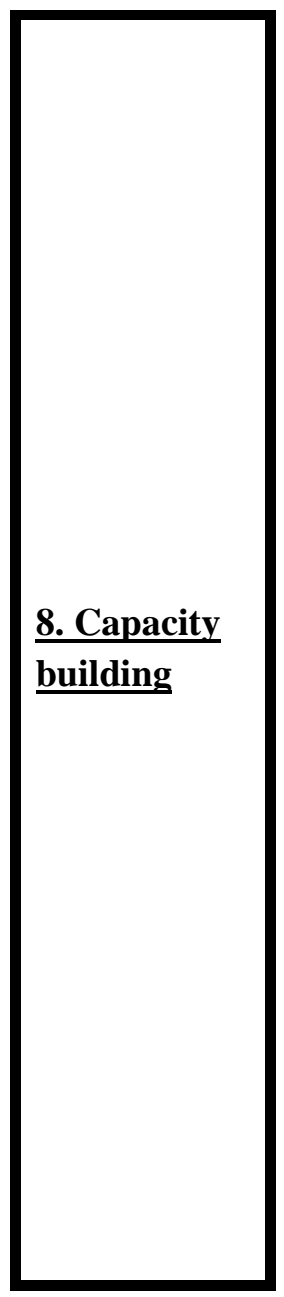

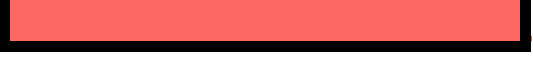

A) End-users do not understand their SHS and how to use and maintain it

\section{B) Technicians}

lack the appropriate knowledge to maintain and repair systems

A1) End-users are unable to properly maintain their SHSs A2) End-users do not properly connect wires and equipment, causing SHSs to function poorly A3) End-users do not understand the capacity of their systems

B) Technicians inappropriately connect systems, causing

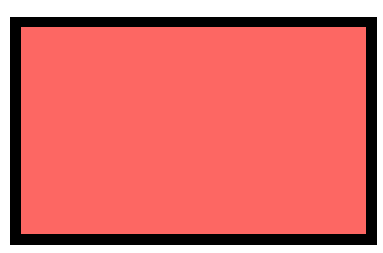

spare parts, while at the same time providing a business opportunity inefficiency and damage
A) Very-high: Lack

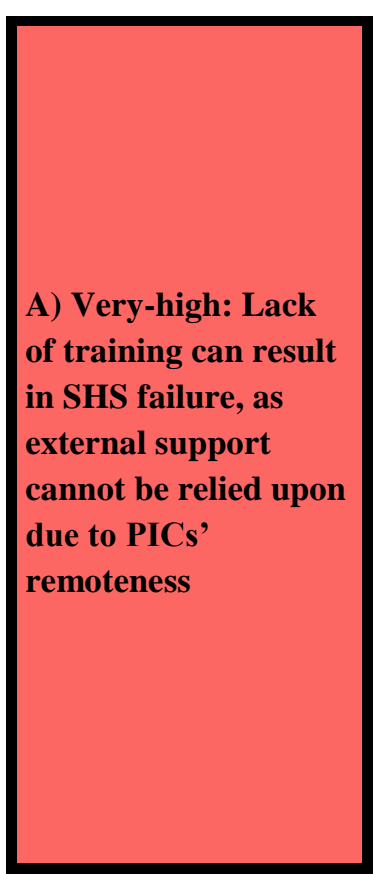

B) High: Local technicians are often the only support

rural end-users have, yet they generally have basic knowledge
A1) Provide training in communities, with its being hands-on, in the local language, and designed for community education levels

A2) Ensure that funding for training is available for the long-term, before and after installation

A3) Use a variety of media tools to reach large audiences, such as movies, radio shows, newspaper articles, travelling theatre, laminated information sheets, and text messaging

A4) Set up training programs with solar suppliers to provide to customers

A5) Provide an incentive for end-users to come to training courses, such as free voltmeters, a compass, wire connectors, electrical tape, breakers/ fuse holders, etc.

B1) Ensure technicians are on the same level by providing technical training on system sizing, installation, troubleshooting, and basic repair of components

B2) Training must accommodate technicians' education and level of understanding, be hands-on, and in the local language 


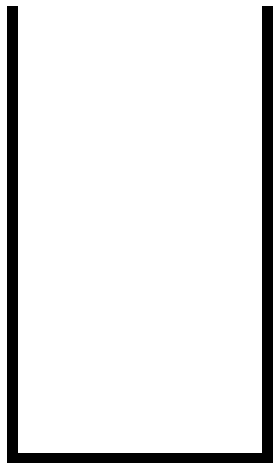

\section{C) Institutions}

lack a variety of

skills to provide adequate aftersales services,

properly size

systems, and

manage their

organization
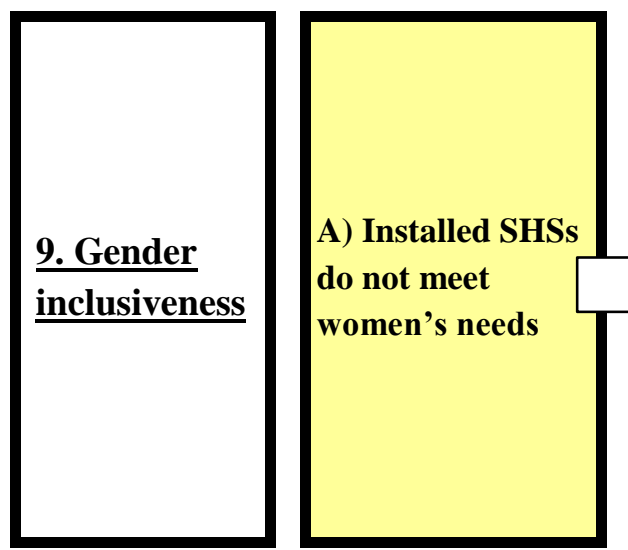

A1) Women may be

\section{do not meet}

women's needs

uninterested in the SHS, and

may not use or take care of it

A2) Women may be further

marginalized if the systems'

productive uses are focused on

men

10.

Affordability

C1) Institutions are unable to fraining and

C2) Systems are inappropriately designed due to poor management, and may not last

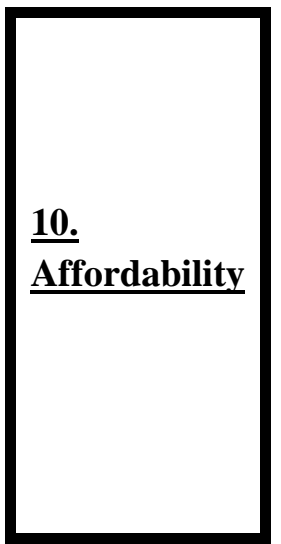

A) End-users are unable to afford a SHS's initial cost
A) Low-income households may not be able to afford the initial cost of a SHS

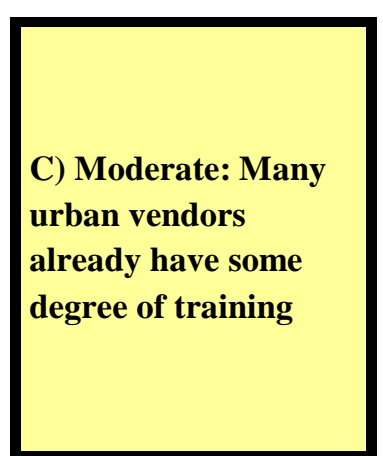

C1) Ensure vendors are on the same level by providing training and certifications C2) Set up courses for business management and provide a business coordinator

\section{A) Moderate:} Although gender inclusiveness is important, it does not often hinder project endurance

A) Very-high:
Affordability is a barrier to widespread SHS usage
A1) Ensure women are included in all project stages

A2) Target women in trainings on how to use and manage their SHSs

A3) Provide separate training sessions for women

A4) Ensure productive uses of projects involve women, through including them in SHS design

A5) Provide national training for women technicians

A1) Provide financing to end-users to allow them to pay for systems over time

A2) Provide subsidies on the initial cost, and consider smart subsidies that are slowly phased out with economies of scale A3) Provide basic financial training to endusers

A4) Consider battery-charging stations and small solar lanterns as more

affordable options

A5) Allow users to pay with crops, by 

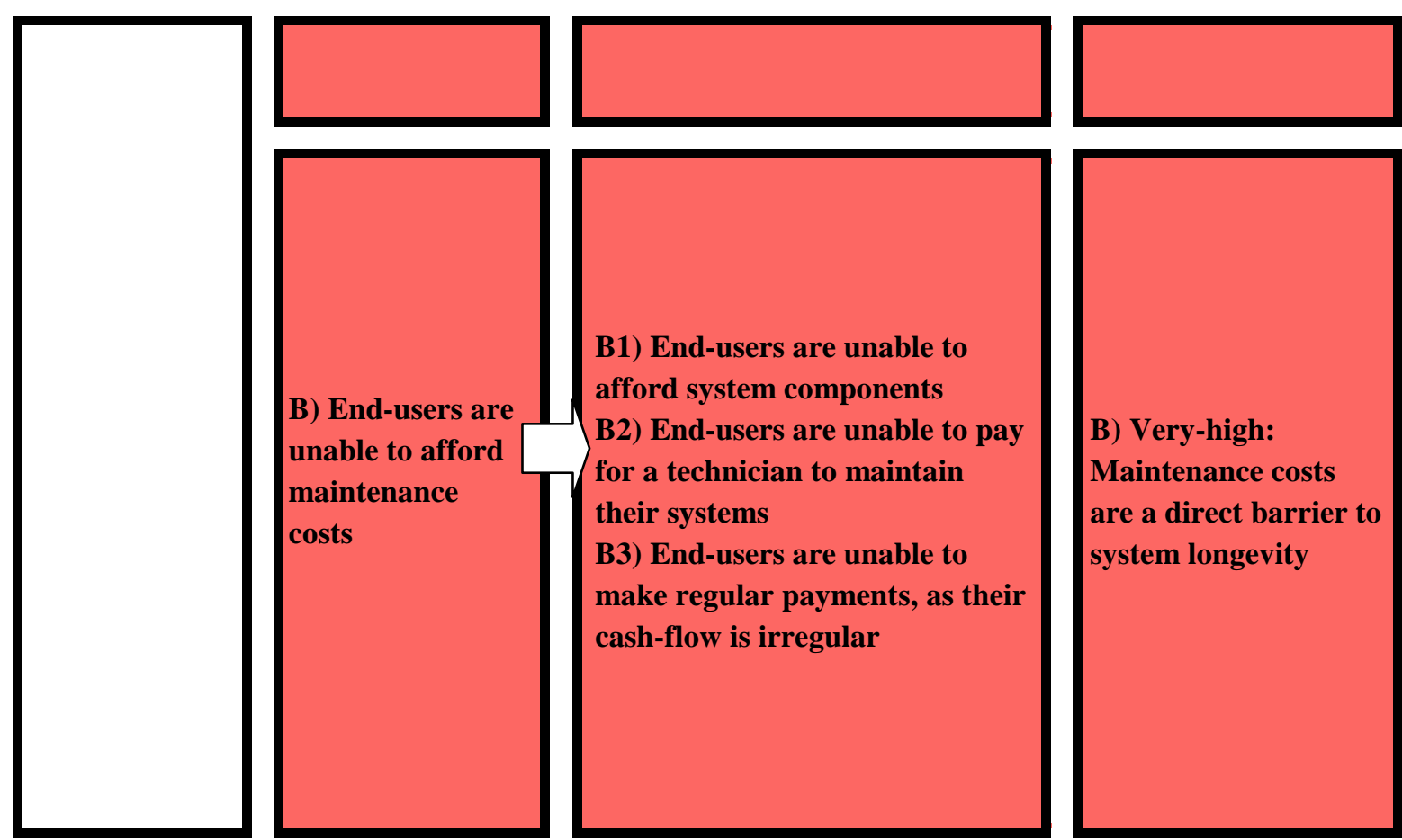

setting up a crops-for-electrification

cooperative
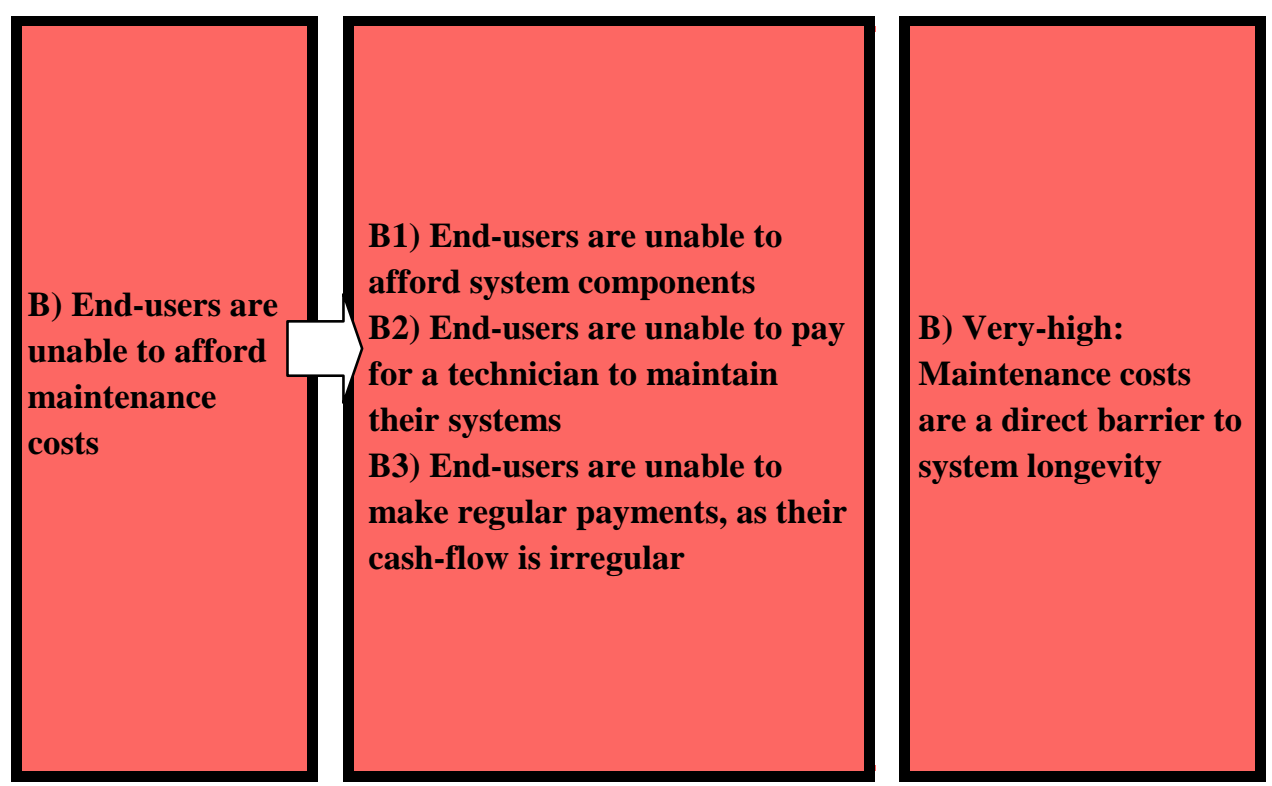

B1) Provide subsidies for expensive

components, especially deep-cycle batteries

B2) Provide financial mechanisms for end-

B1) End-users are unable to afford system components

B2) End-users are unable to pay

for a technician to maintain

their systems

B3) End-users are unable to

make regular payments, as their

cash-flow is irregular

\begin{tabular}{l|} 
11. \\
Familiarity \\
$\frac{\text { with the }}{\text { technology }}$ \\
\hline
\end{tabular}

\begin{tabular}{|l|l|}
\hline & $\begin{array}{l}\text { A1) End-users do not rent or } \\
\text { purchase a SHS } \\
\text { A2) End-users believe SHSs can } \\
\text { provide unlimited power } \\
\text { A3) SHSs are clustered in } \\
\text { Anfamiliar with } \\
\text { solar PV }\end{array}$ \\
& $\begin{array}{l}\text { communities where end-users } \\
\text { have gained familiarity } \\
\text { A4) End-users invest in other } \\
\text { power sources }\end{array}$ \\
\hline
\end{tabular}

12.

A) End-users

A1) End-users may disrespect

Participation

contributed to

users to reserve funds for maintenance

B3) Provide access to funds through SHSs

aimed at productive uses and

microenterprise training

B4) Provide fees-for-service, but ensure costs are practical for end-users without

steady incomes;

options for this include: allowing users to refill their account anytime with

prepayment cards of small values, allowing end-users to make payments through crop

cooperatives, and providing various sized

systems at different costs

A) Moderate:

Familiarity is

important for

widespread SHS

usage, yet this is

steadily increasing in

PICs

A1) Provide training based on end-user's level of technological familiarity

A2) Ensure each community has a

knowledgeable person who is familiar with SHSs

A3) Allow the initial systems in a

community to be purchased/rented at a

discounted rate

A4) Encourage information sharing

A) High: Lack of

involvement has

repeatedly been
A1) Ensure end-users contribute to the cost of their systems initially

A2) Ensure participation is voluntary 


\begin{tabular}{|c|c|c|c|c|}
\hline \multirow[t]{2}{*}{$\begin{array}{l}\text { and } \\
\text { ownership }\end{array}$} & $\begin{array}{l}\text { the cost of their } \\
\text { systems }\end{array}$ & $\begin{array}{l}\text { willing to pay for maintenance } \\
\text { A3) End-users may not have } \\
\text { desired the system initially }\end{array}$ & $\begin{array}{l}\text { shown to lead to } \\
\text { system disrespect }\end{array}$ & \\
\hline & $\begin{array}{l}\text { B) End-users are } \\
\text { not given } \\
\text { ownership of } \\
\text { their systems }\end{array}$ & $\begin{array}{l}\text { B1) End-users may not retain } \\
\text { interest in paying for systems } \\
\text { that they do not own } \\
\text { B2) End-users may be } \\
\text { dissatisfied as they prefer to own } \\
\text { their systems } \\
\text { B3) End-users may disrespect } \\
\text { and overuse their systems }\end{array}$ & $\begin{array}{l}\text { B) Moderate: Lack of } \\
\text { ownership often leads } \\
\text { to system disrespect } \\
\text { and user } \\
\text { dissatisfaction, yet } \\
\text { other models may } \\
\text { work }\end{array}$ & $\begin{array}{l}\text { B1) Give ownership of systems to end- } \\
\text { users } \\
\text { B2) Train end-users to manage their } \\
\text { systems }\end{array}$ \\
\hline & $\begin{array}{l}\text { C) Projects have } \\
\text { not involved end- } \\
\text { users in their } \\
\text { design }\end{array}$ & $\begin{array}{l}\text { C1) End-users may lack interest } \\
\text { or not respect the project } \\
\text { C2) Lack of participation leads } \\
\text { to misconceptions } \\
\text { C3) Stakeholders are unclear of } \\
\text { their roles in the projects } \\
\text { C4) Payment methods do not } \\
\text { match users' abilities to pay }\end{array}$ & $\begin{array}{l}\text { C) High: } \\
\text { Users are likely to be } \\
\text { dissatisfied and } \\
\text { misuse their SHSs }\end{array}$ & $\begin{array}{l}\text { C1) Carry-out an objective assessment of } \\
\text { local needs through survey and } \\
\text { participatory approaches } \\
\text { C2) Base programs on lessons previously } \\
\text { learned } \\
\text { C3) Clearly define roles and ensure } \\
\text { transparency }\end{array}$ \\
\hline $\begin{array}{l}\frac{13 .}{\text { Willingness }} \\
\text { to pay }\end{array}$ & $\begin{array}{l}\text { A) End-users are } \\
\text { dissatisfied with } \\
\text { their systems }\end{array}$ & $\begin{array}{l}\text { A) End-users are not willing to } \\
\text { pay fees or pay to maintain their } \\
\text { systems anymore }\end{array}$ & $\begin{array}{l}\text { A) Very-high: If users } \\
\text { are unwilling to pay } \\
\text { for their SHS, system } \\
\text { failure will likely } \\
\text { result }\end{array}$ & $\begin{array}{l}\text { A1) Ensure payment methods fit cultural } \\
\text { norms } \\
\text { A2) Ensure systems meet users' desires } \\
\text { A3) Ensure adequate support is available } \\
\text { A4) Make systems as cost-effective as } \\
\text { possible } \\
\text { A5) Ensure policies regarding fees, } \\
\text { disconnection, and O\&M are consistent } \\
\text { and transparent } \\
\text { A6) Give end-users ownership so that they } \\
\text { can be responsible for their own systems }\end{array}$ \\
\hline
\end{tabular}



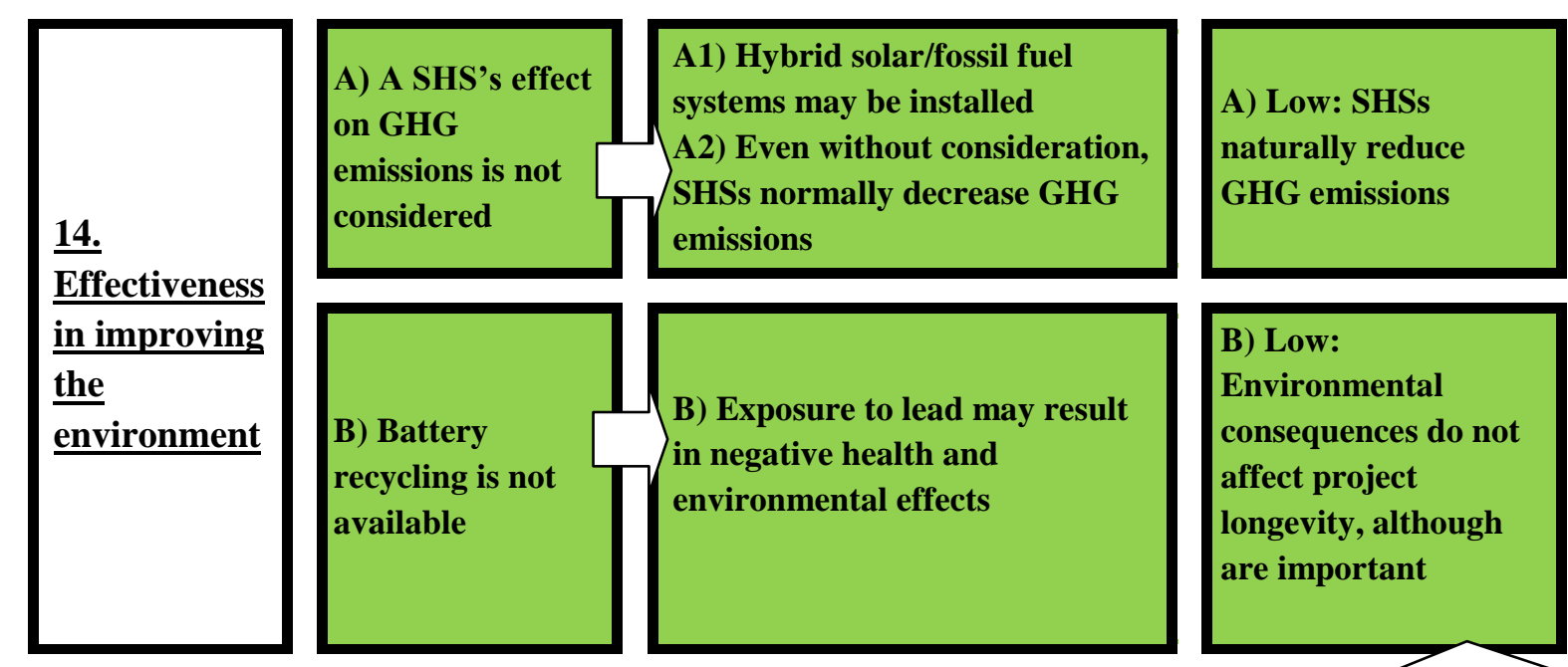

A) Ensure subsidies are biased towards

RE, not fossil fuels

\section{B) Low:}

Environmental

consequences do not

affect project

longevity, although

are important

\section{B1) Set up a national battery recycling} program

B2) If this is not possible, train end-users

that the lead in batteries is toxic

B3) Encourage the use of high-quality

maintenance-free batteries to increase

battery life

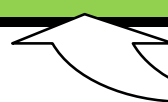




\subsection{Limitations of the Research}

This research was limited by only two case studies, due to time and financial constraints. Therefore, although three models of electrification were represented (selfinitiated, project-initiated, and RESCO), these projects were at different stages, leading to limitations in comparing responses in the questionnaires. Thus, with the long-term effects of two of the projects yet to be seen, some indicators such as cost-effectiveness were difficult to compare. In addition, the RESCO project in Namdrik Atoll was rehabilitated in 2001 and has switched ownership since, making it an imperfect project to study. However, an evaluation of this project was carried out by Empower (2005), which allowed the researcher to grasp the effects of the project at two different points in time.

Also, the author's lack of knowledge of the Marshallese language hindered the research results, in that questionnaires could not be administered verbally in the RMI, and therefore respondents' questions could not be easily clarified. This led to some respondents not returning or completing the questionnaires. In contrast, the author is fluent in Bislama (Vanuatu pigeon), and as such all of the respondent's questions in Vanuatu were answered fully.

In Vanuatu, there was a time constraint for both the interviews and questionnaires, leading to four SHS owners on Akhamb not being included in the research due to their unavailability during the field research period. This also led the author to carry-out five interviews in one day in Port Vila, which led to the interviews not being as in depth as they would otherwise have been.

Thus, repeated evaluations are needed in various PICs in order to fully understand the effects of self-initiated user-owned systems, because data on this method is still limited. However, this research has successfully contributed to closing this gap through its evaluation of the benefits of the SHSs on Akhamb Island. There is also merit in further research to identify the most efficient balance between social and technical development dimensions of project design and implementation. 


\section{Chapter 9: \\ Conclusions}

This research has analyzed the essential criteria and electrification models for rural electrification using solar PV home systems (SHSs) in Pacific Island Countries (PICs), specifically in the Marshall Islands and Vanuatu. A set of fourteen indicators were developed in order to determine these success criteria, which expanded the literature on evaluation indicators to include a set appropriate for evaluating the effects of rural electrification on PIC end-users. The results showed that the most important success criteria for end-users include:

- Technical: Low-maintenance technologies; equipment standards and certifications; conservative system-sizing; and various size availability.

- Economic: Projects cash-flow positive; end-users involved in maintenance; and services linked to productive uses.

- Institutional: Reliable technical support; communication between users and suppliers; support and parts available locally; and training for end-users.

- Socio-cultural: End-user control; services include women's and local needs; and financing available.

- Environmental: Reduction in GHG emissions.

This research proposes that despite the prevalence of Renewable Energy Service Company (RESCO) managed projects in PICs, self-initiated user-owned SHSs are more likely to result in enduring benefits for end-users, (and therefore more cost-effective investments in household solar PV), as they:

1. Provide an economic incentive for end-users to respect their systems

2. Allow for customized systems to address end-users' needs and productive uses

3. Incorporate end-users' desires for participation and ownership

4. Empower end-users to create and be responsible for their own development solutions.

Thus, self-initiated electrification enables end-users to be independent from aid from developed countries, through a transfer of power to beneficiaries, which allows them to control their own development solutions. 
While such benefits are beginning to be acknowledged by the global literature and by respondents, the literature, project documents, and many ongoing projects from PICs generally view rented SHSs as the preferred electrification model. This preference is derived from two concerns: 1. End-users will not be able to afford initial and replacement components without costs being dispersed over time, and 2. End-users in PICs are unable to properly operate and maintain their own SHSs.

The results of this research do not support the view that rented SHSs are the most effective or efficient approach to rural electrification. On the contrary, this research has shown that self-initiated, user-owned approaches have a greater chance of enduring project success if they are well designed. Here, the costs of self-initiated systems can be dispersed over time through providing users with access to financing. Such practices have been successful in many developing countries in other regions and this research did not find any reason why such an approach would not be successful in PICs. In addition, self-initiated systems have the potential to be more cost-effective, through avoiding the need for complex institutional structures, thus increasing affordability.

This research addressed the issue of end-users being unable to properly operate and maintain their own SHS through a case study, while at the same time expanding the current knowledge of the potential of self-initiated SHSs in PICs. The results demonstrated rural end-users' ability and desire to learn how to manage a SHS with limited access to resources and support. These end-users have successfully installed and maintained SHSs themselves with no external initiative, with limited training, and self-organized technical support. In addition, the community has become nearly fossil fuel-free of its own initiative.

Therefore, projects with fewer layers between the funder and beneficiaries, end-user education and participation, and self-initiative often are more successful in making SHSs cost-effective and enduring. The need for such social solutions is well documented in the development literature; yet, these solutions need to be balanced with technical support due to capacity and funding constraints.

This research concludes that a proper balance in the overarching program design between the technical and social focus of projects is required, as each are equally important for project effectiveness and durability. However, many of the electrification programs in PICs did not allocate sufficient funds to understanding and incorporating the social aspects, 
with a general focus on implementing visible technical solutions; yet, this was shown to reduce project longevity. Thus, in applying this research to the realities of community development with its funding constraints, consideration needs to be given as to the optimum balance between the social and technical.

In conclusion, market solutions are the best way forward for future PIC electrification, in that they provide the most cost and time efficient way of maintaining a balance between social and technical needs, because they minimize the need for overinvestment in institutional structures. The funding that would otherwise be spent on building bureaucracy in RESCO models can be more efficiently allocated to the social dimensions of a user-initiated and user-owned market approach. 


\section{References:}

Adams, J., Roberts, N., et al. (2007). Project Appraisal Document on a Proposed GEF Grant to Fiji, Papua New Guinea, Republic Of Marshall Islands, Solomon Islands, and Vanuatu for a Sustainable Energy Financing Project. World Bank: May 16, 2007, 1-139.

ADB (Asian Development Bank) (2011). Project Information Documents: Yap Renewable Energy Development Project: Micronesia. [Online]. Retrieved September 15, 2011, from http://pid.adb.org/pid/LoanView.htm?projNo=44469\&seqNo=01\&typeCd=3

Akker, J. (2006). Final Evaluation of the UNDP/GEF/SPREP Project: Pacific Islands Renewable Energy Project (PIREP), 1-58.

Alphatron (2011). Microgrid: Systems for Stand Alone Power Grids. [Online]. Retrieved June 15, 2011, from http://www.alphatrononline.com/microgrid.cfm

APAN (Asia Pacific Adaptation Network) (2012). Pacific Island Greenhouse Gas Abatement through Renewable Energy Project (PIGGAREP). [Online]. Retrieved March 27, 2012 from http://www.apan-gan.net/adaptation-database/piggarep

APCTT-UNESCAP (2009). Fiji Renewable Energy Report. Asian and Pacific Centre for Transfer of Technology of the United Nations Economic and Social Commission for Asia and the Pacific (ESCAP), 1-63.

Arnstein, S. (1969). A Ladder of Citizen Participation. JAIP, 35 (4): 216-224.

AusAid (2011). Vanuatu Electricity for Rural Development Program - an Australian funded initiative. Draft Program Design Document, June 2011, 1-132.

Barefoot Power Limited (2011). Our Products. [Online]. Retrieved July 11, 2011, from http://barefootpower.com/barefoot-products/\#

Beck, F. \& Martinot, E. (2004). Renewable Energy Policies and Barriers. Encyclopedia of Energy. San Diego: Elsevier Science/Academic Press, 365-383.

Berkes, F. (2007). Community-based conservation in a globalized world. Proceedings of the National Academy of Sciences. Washington, DC: National Academy of Sciences, 104 (39): $15188-15193$.

Bhattacharyya, S. (1972). Community Development in Developing Countries. Calcutta: Academic Publishers, 1-148.

Bollinger, B. \& Gillingham, K. (2011). Peer Effects in the Diffusion of Solar Photovoltaic Panels. New York and Connecticut: NYU Stern School of Business and Yale School of Forestry \& Environmental Studies, 1-42.

BP (British Petroleum) (2009). Statistical Review of World Energy. London, 1-48.

Bryman, A. (2008). Social research methods (3rd ed.). Oxford: Oxford University Press. Ch. 15 and 22: 314-335, 538-552. 
Cabraal, A., Barnes, D., \& Agarwal, R. (2005). Productive uses of energy for rural development. Annual Review of Environmental Resources, 30: 117-144.

Campbell, L. \& Vainio-Mattila, A. (2003). Participatory Development and Community-Based Conservation: Opportunities Missed for Lessons Learned? Human Ecology, 31(3): 417437.

Cecelski (2000). The Role of Women in Sustainable Energy Development. Colorado, USA: National Renewable Energy Laboratory: Subcontractor Report. June 2000.

Chakrabarti, S. (2002). Rural electrification programme with solar energy in remote region-a case study in an island. Energy Policy, 30: 33-42.

Chambers, R. (1994). The Origins and Practice of Participatory Rural Appraisal. World Development, 22 (7): 953-969.

Chaurey, A. \& Kandpal, T. (2009). Solar lanterns for domestic lighting in India: Viability of central charging station model. Energy Policy, 37: 4910-4918.

Chow, J. (2010). Assessment of Solar Home Systems (SHS) for Isolated Rural Communities in Vanuatu Using Project Lifecycle/Sustainability Framework. Masters Thesis, Houghton, Michigan: Michigan Technological University, 1-55.

CIA (Central Intelligence Agency) (2009). The World Factbook: Oceania. [Online]. Retrieved April 2, 2011, from http://www.zaneeducation.com/factbook/maps/refmap_oceania.html

CIA (Central Intelligence Agency) (2009a). The World Factbook: Marshall Islands. [Online]. Retrieved November 10, 2011, from http://www.zaneeducation.com/factbook/maps/maptemplate_rm.html

CIA (Central Intelligence Agency) (2009b). The World Factbook: Marshall Islands. [Online]. Retrieved November 10, 2011, from http://www.zaneeducation.com/factbook/maps/maptemplate_nh.html

Climate Parliament (2009). Renewables: Micro-finance for Solar Lighting Systems. [Online]. Retrieved April 2, 2012, from http://www.climateparl.net/cp/118

Connell, J. \& Waddell, E. (2007). Environment, Development and Change in Rural Asia-Pacific. London: Routledge, Tailor, and Francis Group, 38-55.

D.lite design (2011). Product Line. [Online]. Retrieved August 2, 2011, from http://www.dlightdesign.com/products_product_line_global.php

DOE-EA (Department of Energy-Environmental Assessment) (2009). Environmental Assessment for BP Solar Array Project. New York: Brookhaven National Laboratory, United States Department of Energy: Office of Science, 1-72.

Dornan, M. (2011). Solar-based rural electrification policy design: The Renewable Energy Service Company (RESCO) model in Fiji. Renewable Energy, 36 (2): 797-803. 
E8 (2009). Decreasing Reliance on Fuel and Enhancing Renewable Energy-Based Electrification in the Small Island State of Tuvalu: The Tuvalu Solar Power Project. Montreal, Canada: E8 General Secretariat, 1-32.

Empower (2005). Review of Namdrik Atoll Solar Project, Republic Of The Marshall Islands: Final Report. Pacific Islands Energy Policy and Strategic Action Planning (PIEPSAP) Project Report 50. Empower Consultants Limited, October 2005, 1-66.

ESMAP (2003). Monitoring and Evaluation in Rural Electrification Projects: A Demand-Oriented Approach. UNDP/World Bank Energy Sector Management Assistance Programme (ESMAP): The International Bank for Reconstruction and Development, July 2003.

Europeaid (2009). Kiribati/Solar Energy for Outer Islands: Annex. CRIS No. FED/2009/21-648. European Union Project Reports, 1-6.

Fthenakis,V., Kim, H., \& Alsema, E. (2008). Emissions from Photovoltaic Life. Environmental Science Technology, 42: 2168-2174.

GEF (Global Environment Facility) Council (2005). PIGGAREP Project Executive Summary, GEF Council Work Program Submission. New York: United Nations Development ProgrammeGlobal Environment Facility, 1-50.

GoF (Government of France) (2011). Overseas France: Renewable Energy. [Online]. Retrieved September 13, 2011, from http://www.outre-mer.gouv.fr/?les-outre-mer-a-la-foire-dehanovre.html

GoV (Government of Vanuatu) (2006). House, Income and Expenditure Survey. Port Vila: Vanuatu National Statistics Office, Government of Vanuatu.

GPA (Guam Power Authority) (2008). Integrated Resource Plan FY 2008. Hagåtña, Guam: Guam Power Authority, 1-73.

Gustavsson, M. (2007). With time comes increased loads-An analysis of solar home system use in Lundazi, Zambia. Energy Policy 35: 1292-1299.

Holdren, J., Smith, K., et al. (2000). Energy, the Environment and Health. World Energy Assessment. New York: United Nations Development Programme, United Nations Department of Economic and Social Affairs, and World Energy Council, 61-110.

Ilskog, E. (2008). Indicators for assessment of rural electrification: An approach for the comparison of Apples and Pears. Energy Policy, 36 (7): 2665-2673.

Ilskog, E. \& Kjellstrom, B. (2008). And they lived sustainably ever after? Assessment of rural electrification cases by means of indicators. Energy Policy, 36 (7): 2674-2684.

IPCC (Intergovernmental Panel on Climate Change) (2007). Climate Change 2007: Working Group II: Impacts, Adaptation and Vulnerability Sec. 6.7. IPCC Fourth Assessment Report. Geneva, Switzerland: World Meteorological Organization. 
IRENA (International Renewable Energy Agency) (2011). IRENA Workshop Summary: Accelerated Renewable Energy Deployment on Islands with Emphasis on the Pacific Islands. Sydney: 26-28 October, 2011, 1-6.

IRENA (International Renewable Energy Agency) (2012). Proposed IRENA Activities for the Pacific Region in 2012. Abu Dhabi: IRENA Pacific Region Unit, 1-3.

IRENA (International Renewable Energy Agency) (2012a). IRENA Renewable Energy Country Profiles: Pacific Region. Abu Dhabi: IRENA Pacific Region Unit, 1-35.

Jafar, M. (2000). Renewable Energy in the South Pacific: options and constraints. Renewable Energy, 19 (1): 305-309.

Jochem, E., Adegbulugbe, A., et al. (2000). Energy End-Use Efficiency. World Energy Assessment. New York: United Nations Development Programme, United Nations Department of Economic and Social Affairs, and World Energy Council, 175-211.

Johnston, P. (2004). Pacific Regional Energy Assessment 2004: Fiji National Report, Volume 4. Apia, Samoa: South Pacific Regional Environment Program, 1-117.

Johnston, P. (2004a). Pacific Regional Energy Assessment 2004: Papua New Guinea National Report, Volume 10. Apia, Samoa: South Pacific Regional Environment Program, 1-114.

Johnston, P. (2004b). Pacific Regional Energy Assessment 2004: Vanuatu National Report, Volume 1. Apia, Samoa: South Pacific Regional Environment Program, 1-92.

Jol, J., Mandoc, M., \& Molenbroek, E. (2008). Solar electricity 2008 - A technical and economic overview. Kanaalweg, Netherlands: Ecofys BV, 1-24.

Kopi, I. \& Lloyd, C. (2002). Renewable Energy and Rural Electrification in PNG. Dunedin, New Zealand: Physics Department, Otago University, 1-5.

Krithika, P. \& Palit, D. (2011). Review of Alternative Participatory Business Models for Off-grid Electricity Services. New Delhi: OASYS- South Asia Project, 1-32.

Kua, N. (2010). Request for Tenders: Renewable Energy DVD Documentary for Pacific Islands Countries. PIGGAPEP Project. Apia, Samoa: SPREP. 12 October 2010.

KUTh Energy Limited (2009). KUTh Signs MOU With Vanuatu Electricity Provider. ASX Release: 16th October 2009.

Leonics Co. Limited (2009). Solar Home System. [Online]. Retrieved November 13, 2011, from http://www.leonics.com/system/solar_photovoltaic/solar_home_system/solar_home_syste m_en.php

Lewis, N. (2007). Toward Cost Effective Solar Energy Use. Science. 315, 798-801.

Liebenthal, A., Mather S., \& Wade, H. (1994). Solar Energy: Lessons from the Pacific Experience. World Bank Technical Paper Number 244. Energy Series. Washington, DC: The World Bank. 
Maharaj, R. (1999). Coastal Erosion in Pacific Small Island Developing States (SIDS) - The need for an approach to integrated coastal management (ICM). CoGeonvironment NEWS. Suva, Fiji: SOPAC, 1-5.

Mala, K., Schlapfer, A., \& Pryor, T. (2008). Solar photovoltaic (PV) on atolls: Sustainable development of rural and remote communities in Kiribati. Renewable and Sustainable Energy Reviews, 12: 1345-1363.

Mala, K., Schlapfer, A., \& Pryor, T. (2009). Better or worse? The role of solar photovoltaic systems in sustainable development: Case studies of remote atoll communities in Kiribati. Renewable Energy, 34: 358-361.

Mapako, M. \& Prasad, G. (2007). Rural Electrification in Zimbabwe Reduces Poverty by Targeting Income-Generating Activities. Proceedings of the Fifteenth Conference on Domestic Use of Energy. Cape Town: 11-12 April 2007.

Mario (2003). Renewable Energy Training Needs Assessment in Pacific Island Developing States. South Pacific Applied Geoscience Commission (SOPAC) Technical Report 363, 1-33.

Martinot, E., Cabraal, A., \& Mathur, S. (2001). World Bank/GEF solar home system projects: experiences and lessons learned 1993-2000. Renewable and Sustainable Energy Reviews, 5: 39-57.

Martinot, E., Chaurey, A., et al. (2002). Renewable Energy Markets in Developing Countries. Annual Review of Energy and the Environment, 27: 309-348.

Martinot, E. \& McDoom, O. (2000). Promoting Energy Efficiency and Renewable Energy: GEF Climate Change Projects and Impacts. Washington, DC: Global Environment Facility. June 2000.

Martinot, E. \& Reiche, K. (2000). Regulatory Approaches to Rural Electrification and Renewable Energy: Case Studies from Six Developing Countries. Working paper. Washington, DC: The World Bank. June 2000.

Matakiviti, A. (2006). Vanuatu National Consultation - Back to Office Report. Pacific Islands Energy Policy and Strategic Action Planning (PIEPSAP) Project Report 46: 1-7.

MEC (Marshalls Energy Company) (2005). Facility Data Sheet: Namdrik Atoll Solar Power System. [Online]. Retrieved November 8, 2011, from http://www.mecrmi.net/Namdrik.htm

MEC (Marshalls Energy Company) (2008). Report of the Installation of the EU Rep-5 Solar Project at Ailinglaplap Atoll, Republic of the Marshall Islands. Installed by MEC, 1-18.

MECC (Ministry of Environment and Climate Change) (2012). Tonga Renewable Energy Programs. [Online]. Retrieved March 15, 2011, from http://www.mecc.gov.to/index.php?option=com content\&view=article\&id=204: solarelectrification-programs\&catid=186:renewable-energy\&Itemid=226 
Mimura, N. (1999). Vulnerability of island countries in the South Pacific to sea level rise and climate change. Climate Research, 12: 137-143.

Minton, P. (2007). Wikimedia Commons Map: Namdrik Atoll. [Online]. Retrieved November 10, 2011, from http://en.wikipedia.org/wiki/File:Namorik_Atoll___Map.jpg

Nathan, N. (2010). Ta in Solar Power System. Adapted from UNESCO Solar Technical Training Manual by Herbert Wade. Translated by Nelling Nathan. Majuro, RMI: Island Eco. 1-64.

Nguyen, K. (2007). Alternatives to grid extension for rural electrification: Decentralized renewable energy technologies in Vietnam. Energy Policy, 35(4): 2579-2589.

Nieuwenhout, F., van Dijk, A., et al. (2001). Experience with Solar Home Systems in Developing Countries: A Review. Progress in Photovoltaics: Research and Applications, 9: 454-474.

NZPNGBC (New Zealand Papua New Guinea Business Council) (2011). The Papua New Guinea Energy Sector. [Online]. Retrieved November 2, 2011, from http://nzpngbc.org.nz/index.php?option=com_content\&view=category\&layout=blog\&id=4 $\underline{6 \& \text { Itemid }=63}$

OECD-DAC (Organization of Economic Co-operation and Development: Development Assistance Committee) (2005). The Paris Declaration on Aid Effectiveness. Paris, France. March 2, 2005: 1-23.

OECD-DCD (Organization of Economic Co-operation and Development, Development Cooperation Directorate) (2012). Development Aid at a Glance 2012: Statistics by Region: Oceania. Ch. 6, 1-12.

Origin Energy (2011). Electricity Tariffs: Residential customers. [Online]. Retrieved September 12, 2011, from http://www.originenergy.com.au/2087/Electricity-tariffs-QLD

Painuly, J. (2001). Barriers to renewable energy penetration; a framework for analysis. Renewable Energy, 24: 73-89.

Palaki, A., Tukunga, T., et al. (2009). A Technical, Institutional, Environment and Economic Impacts Assessment of the Mango and Mo'unga'one Solar Photovoltaic Rehabilitation Project. Pacific Islands Greenhouse Gas Abatement through Renewable Energy Project (PIGGAREP), 1-57.

Prasad, K. (2012). Implementation Status \& Results, Pacific Islands Sustainable Energy Finance Project (P098423). The World Bank: Global Environment Facility (GEF) East Asia and Pacific.

PRISM (Pacific Regional Information System) (2010). Urban/ Rural Growth and Household Size. Secretariat of the Pacific Community. [Online]. Retrieved January 30, 2011, from http://www.spc.int/prism/urbanrural-growth-a-household-size

REEGLE (2011). Energy Profile Palau. [Online]. Retrieved August 30, 2011, from http://www.reegle.info/countries/PW\#sources 
REN21 (2011). Renewables 2011: Global Status Report on Local Renewable Energy Policies. Paris: REN21 Secretariat, 1-116.

REP-5 (2010). Support to the Energy Sector in Five ACP Pacific Island Countries. [Online]. Retrieved January 12, 2012, from http://www.rep5.eu/node/48

RMI Census (1999). RMI Census of Population and Housing. Majuro, RMI: Economic Policy, Planning and Statistics Office: Census of Population 1999.

RMI National Energy Policy (2009). Republic of the Marshall Islands National Energy Policy and Energy Action Plan. Majuro, RMI: Energy Planning Division, Ministry of Resources and Development, 1-37.

Robson, C. (1993). Real world research : a resource for social scientists and practitionerresearchers. Oxford, UK: Blackwell.

Roper, T. (2009). Representing the Climate Institute and the Global Sustainable Energy Islands Initiative (GSEII). Pacific Power Association CEO's Conference, American Samoa, August 2009.

Schelling, N., Hasson, M., et al. (2010). SIMbaLink: Towards a Sustainable and Feasible Solar Rural Electrification System. Paper presented at ICTD2010, Royal Holloway, University of London. December 13-16, 2010.

Smith, J. (2000). Solar-Based Rural Electrification and Microenterprise Development in Latin America: A Gender Analysis. National Renewable Energy Laboratory, U.S. Department of Energy, 1-25.

SolarBuzz (2011). Solar Market Research and Analysis: Module Pricing. [Online]. Retrieved September 14, 2011, from http://solarbuzz.com/facts-and-figures/retail-priceenvironment/module-prices

SolarRay (2012). Powerboards: Conversion and Control. [Online]. Retrieved April 22, 2012, from http://www.solarray.com/CompletePackages/Powerboard T.php

Soriano, M. (2007). Project Brief: Pacific Islands Greenhouse Gas Abatement through Renewable Energy Project (PIGGAREP). United Nations Development Programme Global Environment Facility (UNDP-GEF), 1-130.

Sovacool, B. (2008). Valuing the greenhouse gas emissions from nuclear power: A critical survey. Energy Policy, 36: 2940-2953.

Sovacool, B., Agostino, A., \& Malavika, J. (2011). The socio-technical barriers to Solar Home Systems (SHS) in Papua New Guinea: "Choosing pigs, prostitutes, and poker chips over panels.” Energy Policy, 39: 1532-1542.

Sovacool, B., Agostino, A., \& Malavika, J. (2011a). Gers gone wired: Lessons from the Renewable Energy and Rural Electricity Access Project (REAP) in Mongolia. Energy for Sustainable Development, 15: 32-40. 
SPC (Secretariat of the Pacific Community) (2011). Request for Proposal for Solar Photovoltaic Home Systems. North REP Project. Noumea: New Caledonia: SPC Headquarters, 14 May 2011.

SPREP (South Pacific Regional Environment Program) (2009). Factsheet: Climate Change Mitigation. Apia, Samoa: SPREP. July 2009.

SPREP (South Pacific Regional Environment Program) (2010). Pacific Islands Greenhouse Gas Abatement through Renewable Energy Project. [Online]. Apia, Samoa. Retrieved August 10, 2010, from http://www.sprep.org/climate change/piggarep.htm

SPREP (South Pacific Regional Environment Program) (2011). Renewable Energy in the Solomon Islands, making a difference. Press Release: PIGGAREP. [Online]. Rarotonga, Cook Islands. [Online]. Retrieved July 11, 2011, from http://www.sprep.org/article/news_detail.asp?id=952

Subbarao, S. (2010). Renewable Energy Projects under the Clean Development Mechanism (CDM). PhD Thesis, University of Otago, Dunedin, New Zealand, 1-401.

Syngellakis, K., Konings, P., et al. (2010). Renewable Energy Project: Support to the Energy Sector in Five ACP Pacific Islands (REP-5). Programme Management Unit. Pacific Islands Forum Secretariat European Commission - 9th EDF, 1-100.

Toloa, A. (2010). Tokelau National Strategic Plan: 1 July 2010 - 30 June 2015. Apia, Samoa: Government of Tokelau, Office of the Council for Ongoing Government, 1-72.

Trading Economics (2011). Marshall Islands Indicators: IMF and World Bank Data. [Online]. Retrieved October 20, 2011, from http://www.www.tradingeconomics.com/marshallislands/indicators

Trading Economics (2011a). Vanuatu Indicators: IMF and World Bank Data. [Online]. Retrieved October 20, 2011, from www.www.tradingeconomics.com/vanuatu/indicators

Twelve Volt Travel (2012). Twelve Volt TVs. [Online]. Retrieved January 12, 2012, from http://www.12volt-travel.com/12-volt-televisions-c-684.html

Ualesi, S. (2011). Pacific Islands Greenhouse Gas Abatement through Renewable Energy (PIGGAREP) - Implementation. PIGGAREP Project Manager, presented at IRENA Workshop Accelerated Renewable Energy Deployment on Islands with Emphasis on the Pacific Islands. Sydney: 26-28 October, 2011, 1-6.

UK Parliamentary Office for Science and Technology (2006). Postnote: Carbon Footprint of Electricity Generation. Number 268: October 2006.

UN General Assembly (2007). United Nations Declaration on the Rights of Indigenous Peoples. Resolution adopted by the United Nations General Assembly, 2 October 2007, 1-9.

UN Habitat (2005). Vanuatu Demography. [Online]. Retrieved November 10, 2011, from http://ww2.unhabitat.org/habrdd/conditions/melanesia/vanuatu.htm 
UNDP (United Nation Development Programme) (1999). Pacific Human Development Report 1999. Regional Reports: Asia and the Pacific. United Nations: New York.

UNDP (United Nation Development Programme) (2007). Pacific Islands Greenhouse Gas Abatement through Renewable Energy (PIGGAREP) Project Document. Governments of the Cook Islands, Fiji, Kiribati, Nauru, Niue, Papua New Guinea, Samoa, Solomon Islands, Tonga, Tuvalu and Vanuatu; Global Environment Facility (GEF); and Secretariat of the Pacific Regional Environment Programme (SPREP), 1-134.

UNESCAP (United Nations Economic and Social Commission for Asia and the Pacific) (2001). Sustainable Energy Future: Policy Options, Barriers, and Action Plans. Energy Resources Development Series, New York: United Nations. 38: 74-93.

UNICEF (United Nations Children's Fund) (2009). Protecting Pacific Island children and women during economic and food crises. Working Edition One. Suva, Fiji: United Nations Children's Fund Pacific Branch.

Urmee, T. (2009). Solar PV Electrification Programs in Developing Countries: Towards a Holistic Approach. PhD Thesis, Murdock University, Australia, 1-315.

Urmee, T. \& Harries, D. (2009). A survey of solar PV program implementers in Asia and the Pacific regions. Energy for Sustainable Development, 13 (1): 24-32.

Urmee, T., Harries, D., \& Schlapfer, A. (2009). Issues related to rural electrification using renewable energy in developing countries of Asia and Pacific. Renewable Energy, 34: 354357.

USDOE (United States Department of Energy) (2011). State Energy Program (SEP): Territories. Washington, DC. February 28, 2011, 1-11.

USDOS (United States Department of State) (2011). Background note: Vanuatu. Bureau of East Asian and Pacific Affairs. [Online]. Retrieved November 12, 2011, from http://www.state.gov/r/pa/ei/bgn/2815.htm

USDOS (United States Department of State) (2011a). Background note: Marshall Islands. Bureau of East Asian and Pacific Affairs. [Online]. Retrieved November 12, 2011, from http://www.state.gov/r/pa/ei/bgn/26551.htm

USEIA (United States Energy Information Administration) (2007). Independent Statistics and Analysis: Country Energy Profiles. Retrieved June 1, 2010, from http://tonto.eia.doe.gov/country/index.cfm

USEIA (United States Energy Information Administration ) (2011). Independent Statistics and Analysis: Electricity. Washington, D.C.: United States Department of Energy. [Online]. Retrieved August 6, 2011, from http://www.eia.gov/cneaf/electricity/page/at a glance/sales tabs.html

van Alphen, K., Kunz, H., \& Hekkert, M. (2008). Policy measures to promote the widespread utilization of renewable energy technologies for electricity generation in the Maldives. Renewable and Sustainable Energy Reviews, 12: 1959-1973. 
van Alphen, K., van Sark, W., \& Hekkert, M. (2007). Renewable energy technologies in the Maldives - determining the potential. Renewable and Sustainable Energy Reviews, 11: $1650-1674$.

Vanuatu's Energy Roadmap Launch (2011). Program for the Launch of the Development of Vanuatu's Energy Roadmap. Holiday Inn Resort, Port Vila, Vanuatu. October 12-14, 2011.

Vleuten, F., Stam, R., \& van der Plas, R. (2007). Putting solar home system programmes into perspective: What lessons are relevant? Energy Policy, 35 (3): 1439-1451.

VNSO (Vanuatu National Statistics Office) (2009). Vanuatu National Statistics Office: Marriage, families and households. [Online]. Retrieved April 11, 2012, from http://www.vnso.gov.vu/index.php?option=com_content\&view=article\&id=19\&Itemid=26

Wade, H. (2004). Pacific Regional Energy Assessment 2004: Kiribati National Report, Volume 5. Apia, Samoa: South Pacific Regional Environment Program, 1-78.

Wade, H. (2004a). Pacific Regional Energy Assessment 2004: Marshall Islands National Report, Volume 6. Apia, Samoa: South Pacific Regional Environment Program, 1-74.

Wade, H. (2004b). Pacific Regional Energy Assessment 2004: Tonga National Report, Volume 14. Apia, Samoa: South Pacific Regional Environment Program, 1-73.

Wade, H. (2004c). Pacific Regional Energy Assessment 2004: Tuvalu National Report, Volume 15. Apia, Samoa: South Pacific Regional Environment Program, 1-73.

Wade, H. (2005). Renewable Energy Technology Support Programme for the Pacific Islands. Pacific Islands Renewable Energy Project. Apia, Samoa: South Pacific Regional Environment Program, 1-32.

Wade, H. (2005a). Demonstration projects to showcase the business angle of renewable energy service delivery in the Pacific Islands. Pacific Islands Renewable Energy Project. Apia, Samoa: South Pacific Regional Environment Program, 1-44.

Wade, H., Johnston, P., \& Vos, J. (2004). Pacific Regional Energy Assessment 2004: Regional Overview Report. Apia, Samoa: South Pacific Regional Environment Program, 1-106.

Webb, A. \& Kench, P. (2010). The dynamic response of reef islands to sea-level rise: Evidence from multi-decadal analysis of island change in the Central Pacific. Global and Planetary Change, 72 (3): 234-246.

Wikimedia Commons (2006). Wikimedia Commons Map: Malekula. [Online]. Retrieved November 10, 2011, from http://en.wikipedia.org/wiki/File:MalakulaMap.png

Woodruff, A. (2007). An Economic Assessment of Renewable Energy Options for Rural Electrification in Pacific Island Countries. Pacific Islands Applied Geoscience Commission Technical Report 397. Suva, Fiji: SOPAC Secretariat, 1-92. 
World Bank (2003). Monitoring and Evaluations in Rural Electrification Projects: A DemandOriented Approach. Washington, DC, USA: The World Bank, Winrock International, and the Mallika Consultants, 1-151.

WOR (World of Renewables) (2011). News: Noumea Sets Renewable Energy Targets [Online]. Retrieved September 19, 2011, from http://www.worldofrenewables.com/vbnews.php?do=viewarticle\&artid=2390\&title=noume a-sets-renewable-energy-targets

Yu, X., Gilmour, A., \& Taplin, R. (1996). Current limitations on further introduction of renewable energy systems in the South Pacific. Energy Policy, 24(8): 697-711.

Yu, X. \& Taplin, R. (1997). A survey: international aid for renewable energy in the Pacific Islands since the 1970s. Energy Policy, 25 (5): 501-516.

Yu, X., Taplin, R., \& Akura, T. (1997). A framework for energy policy-making in the Pacific Islands. Energy Policy, 25(12): 971-982. 


\section{Personal Communication References:}

Respondent 1 (2011). Vanuatu Energy Unit (VEU). Port Vila, Vanuatu: Vanuatu Nation Government. Interview, October 2011.

Respondent 2 (2011). RMI Energy Services Program (ESP). Majuro, Marshall Islands: RMI National Government. Scoping exercises, February 2011.

Respondent 3 (2011). RMI RE Entrepreneur. Majuro, Marshall Islands. Interview, April 2011.

Respondent 4 (2011). Secretariat of the Pacific Community (SPC) Energy Division. Suva, Fiji: Regional Organization. Scoping exercises, January 2011.

Respondent 5 (2011). Vanuatu RE Entrepreneur \#1. Port Vila, Vanuatu. Interview, October 2011.

Respondent 6 (2011). Akhamb Island Solar Technician. Akhamb Island, Malekula, Vanuatu. Interview, October 2011.

Respondent 7 (2011).Vanuatu AusAid Representative. Port Vila, Vanuatu: Australian Aid Office. Interview, October 2011.

Respondent 8 (2011). Vanuatu RE Entrepreneur \#2. Port Vila, Vanuatu. Interview, October 2011.

Respondent 9 (2011). Ailinglaplap resident, RMI. Majuro, Marshall Islands. Scoping exercises, March 2011.

Respondent10 (2011). RMI Local Government Representative \#1. Majuro, Marshall Islands. Interview, March 2011.

Respondent 11 (2011). RMI Local Government Representative \#2. Majuro, Marshall Islands. Interview, March 2011.

Respondent 12 (2011). RMI National Government Representative. Majuro, Marshall Islands: Ministry of Resources and Development. Interview, March 2011.

Respondent 13 (2011). RMI Local Government Representative \#3. Majuro, Marshall Islands. Interview, April 2011.

Respondent 14 (2011). Vanuatu RE NGO \#1. Port Vila, Vanuatu. Interview, October 2011.

Respondent 15 (2011). Vanuatu RE Entrepreneur \#3. Port Vila, Vanuatu. Interview, October 2011.

Respondent 16 (2011). Vanuatu RE Entrepreneur \#4. Port Vila, Vanuatu. Interview, October 2011.

Respondent 17 (2011). Vanuatu RE Entrepreneur \#5. Port Vila, Vanuatu. Interview, October 2011.

Respondent 18 (2011). Vanuatu RE NGO \#2. Port Vila, Vanuatu. Interview, October 2011.

Respondent 19 (2012). RMI Utility Company. Majuro, Marshall Islands. Electronic communication, April 2012. 


\section{Appendices:}

Appendix 1: Twenty-one PICs and their Renewable Energy Targets.

\section{Pacific Island Nation \\ American Samoa \\ Cook Islands \\ Federated States of \\ Micronesia \\ French Polynesia \\ Fiji}

Guam

Kiribati

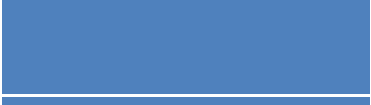

Marshall Islands

Nauru

New Caledonia

Niue

Samoa

Palau

Papua New Guinea

Samoa

Solomon Islands

Tokelau

Tonga

Tuvalu

Vanuatu

Wallis and Futuna

\section{Renewable Energy Target}

Goal of $10 \%$ of its electricity from RE sources.

A target of $100 \%$ of its electricity from RE sources by 2020 .

The draft National Energy Policy sets a target of $30 \%$ of its electricity from RE sources by 2020.

Energy self-sufficiency by 2030.

The Fiji Electricity Authority has a target of generating at least $90 \%$ of its electricity from RE sources by 2012 .

A target of 35\% of its electricity from RE sources by 2035 .

A target of $10 \%$ of its electricity from renewables and Kiribati Solar Energy Company (SEC) has a target of electrification through RE to $70 \%$ of its rural population.

The National Energy Policy set a target of $20 \%$ of its electricity from RE sources by 2020.

The National Energy Strategic Action Plan Framework set a target of $30 \%$ of its electricity from RE sources by 2015 .

Add 75 MW of renewable energy generation by 2015 and energy selfsufficiency by 2030 .

Announced its commitment to achieving a 100\% RE power supply by 2020.

The National Energy Policy set a target of $20 \%$ of its electricity from RE sources by 2030.

A target of $20 \%$ of primary energy from renewables by 2020 .

A target of 1,500 MW of RE and hydropower installed by 2030 .

A target of $20 \%$ of its electricity from RE sources by 2030 .

A target of 50\% of its electricity from RE sources by 2015 .

Has a National Energy Policy that promotes RE, but no specific target.

A target of 50\% of its electricity from RE sources by 2012 .

A target of $100 \%$ of its electricity from RE sources by 2020.

Vanuatu Power Utility (UNELCO) has set itself a goal of 33\% of its electricity from RE sources by 2013.

Energy self-sufficiency by 2030 .

Sources: ADB (2011); GoF (2011); GPA (2008); IRENA (2012a); Kua (2010); NZPNGBC (2011); REEGLE (2011); RMI National Energy Policy (2009); SPREP (2009); SPREP (2011); Toloa (2010); USDOE(2011); WOR (2011). 
Appendix 2: PIC electrification characteristics and opportunities for solar power.

\begin{tabular}{|c|c|c|c|c|}
\hline Countries & $\begin{array}{l}\text { Current } \\
\text { Situation }\end{array}$ & Local Economy & $\begin{array}{l}\text { Solar PV } \\
\text { Opportunities }\end{array}$ & $\begin{array}{l}\text { Barriers to } \\
\text { Growth }\end{array}$ \\
\hline $\begin{array}{l}\text { Papua New } \\
\text { Guinea } \\
\text { (PNG), } \\
\text { Solomon } \\
\text { Islands, } \\
\text { Vanuatu, } \\
\text { and } \\
\text { Fiji }\end{array}$ & $\begin{array}{l}\text {-Large rural } \\
\text { population, } \\
\text { which is mostly } \\
\text { not electrified } \\
\text {-Little prior } \\
\text { exposure to PV }\end{array}$ & $\begin{array}{l}\text {-Rural areas } \\
\text { combine } \\
\text { subsistence and } \\
\text { cash economies } \\
\text {-Commercial and } \\
\text { subsistence } \\
\text { agriculture and } \\
\text { fishing in rural } \\
\text { regions } \\
\text {-Donor support } \\
\text { and foreign } \\
\text { investment relied } \\
\text { upon } \\
\text {-Tourism is } \\
\text { important for Fiji, } \\
\text { while less so for } \\
\text { PNG and Vanuatu }\end{array}$ & $\begin{array}{l}\text {-Off-grid } \\
\text { electrification } \\
\text {-Solar hot water } \\
\text { in urban areas } \\
\text {-Established PV } \\
\text { companies }\end{array}$ & $\begin{array}{l}\text {-Payment is } \\
\text { restricted with } \\
\text { the limited cash } \\
\text { economy } \\
\text {-Poor rural } \\
\text { infrastructure } \\
\text { makes access } \\
\text { difficult and } \\
\text { costly } \\
\text {-Little prior } \\
\text { experience with } \\
\text { PV } \\
\text {-Communities } \\
\text { used to relying } \\
\text { upon donor } \\
\text { support } \\
\text {-Little technical } \\
\text { support outside } \\
\text { of urban areas }\end{array}$ \\
\hline $\begin{array}{l}\text { Kiribati, } \\
\text { RMI, } \\
\text { FSM }\end{array}$ & $\begin{array}{l}\text {-Numerous } \\
\text { isolated } \\
\text { islands and atolls } \\
\text {-Large rural } \\
\text { population that is } \\
\text { mostly not } \\
\text { electrified } \\
\text {-Rural } \\
\text { communities } \\
\text { familiar with PV } \\
\text { for } \\
\text { basic } \\
\text { electrification }\end{array}$ & $\begin{array}{l}\text {-Rural areas } \\
\text { combine } \\
\text { subsistence and } \\
\text { cash economies } \\
\text {-Donor support } \\
\text { relied upon } \\
\text {-Limited economy, } \\
\text { with agriculture } \\
\text { and fishing } \\
\text { prevalent } \\
\text {-Energy demands } \\
\text { in rural areas are } \\
\text { expected to rise } \\
\text { rapidly with } \\
\text { electrification and } \\
\text { strengthened rural } \\
\text { economies }\end{array}$ & $\begin{array}{l}\text {-Off-grid } \\
\text { electrification } \\
\text {-Grid power } \\
\text { from solar } \\
\text {-Solar hot water } \\
\text { in urban areas } \\
\text {-Established RE } \\
\text { service } \\
\text { companies }\end{array}$ & $\begin{array}{l}\text {-Many small, } \\
\text { spread out } \\
\text { islands and } \\
\text { atolls make } \\
\text { access } \\
\text { expensive and } \\
\text { difficult } \\
\text {-Small } \\
\text { populations } \\
\text { make it difficult } \\
\text { to maintain a } \\
\text { PV market } \\
\text {-Little technical } \\
\text { support outside } \\
\text { of urban areas } \\
\text {-Rural areas } \\
\text { have limited } \\
\text { communication } \\
\text { and financial } \\
\text { infrastructure } \\
\text {-Communities } \\
\text { used to relying } \\
\text { upon donor } \\
\text { support }\end{array}$ \\
\hline
\end{tabular}




\begin{tabular}{ll|l|l|l}
\hline Palau, & -Large urban or & -Largely a cash & -Grid power & -Small \\
Nauru, & semi-urban & economy, although & from PV & populations \\
Tuvalu, & population & subsistence & -Some have & limit market \\
Tonga, & -Rural & agriculture and & large PV & growth \\
Samoa, & electrification & fishing is still & -Stlations & -Tokelau's rural \\
Niue, & nearly complete & practiced & -Solar hot water & areas are costly \\
Tokelau & or completed & -Donor support is & in urban areas & to access \\
& -Rural & significant & & -Tonga and \\
communities & -Agriculture and & & Tuvalu have \\
familiar with & fisheries are the & & many isolated \\
PV for basic & basis of the & & islands \\
electrification & economy & -Utilities are \\
-Have had long- & -Tourism is & & limited in size \\
term & significant for & & -Small \\
electrification & Palau, Tonga, and & & economies of \\
projects & Samoale for solar
\end{tabular}

Sources: Adapted from Wade (2005). 
Appendix 3: Ilskog's (2008) thirty-six indicators for evaluating RE projects' effects on sustainable development globally.

\begin{tabular}{|c|c|c|}
\hline $\begin{array}{l}\text { Sustainability } \\
\text { dimension }\end{array}$ & Key variable & Indicator \\
\hline \multirow{7}{*}{$\begin{array}{l}\text { Technical } \\
\text { development }\end{array}$} & \multirow{5}{*}{$\begin{array}{l}\text { Operation and } \\
\text { maintenance }\end{array}$} & Efficiency \\
\hline & & Conformance with national standards \\
\hline & & Technical losses \\
\hline & & Compatibility with future grid service \\
\hline & & Availability of support infrastructure \\
\hline & \multirow{2}{*}{$\begin{array}{l}\text { Technical client- } \\
\text { relation issues }\end{array}$} & Daily operation services \\
\hline & & Availability of services \\
\hline \multirow{9}{*}{$\begin{array}{l}\text { Economic } \\
\text { development }\end{array}$} & \multirow{5}{*}{$\begin{array}{l}\text { Financial } \\
\text { perspective }\end{array}$} & Profitability \\
\hline & & Costs for operation and maintenance \\
\hline & & Costs for capital and installation \\
\hline & & $\begin{array}{l}\text { Share of profit set aside for re-investment in } \\
\text { electricity service business }\end{array}$ \\
\hline & & Tariff lag \\
\hline & \multirow{2}{*}{$\begin{array}{l}\text { Development of } \\
\text { productive uses }\end{array}$} & Share of electricity consumed by businesses \\
\hline & & $\begin{array}{l}\text { Share of electrified households using electricity for } \\
\text { income-generating activities }\end{array}$ \\
\hline & $\begin{array}{l}\text { Employment } \\
\text { generation }\end{array}$ & Business development \\
\hline & Competition & Number of electricity service organizations in the area \\
\hline \multirow{9}{*}{$\begin{array}{l}\text { Social/ethical } \\
\text { development }\end{array}$} & \multirow{3}{*}{$\begin{array}{l}\text { Improved } \\
\text { availability of } \\
\text { social electricity } \\
\text { services }\end{array}$} & Share of health centres and schools with electricity \\
\hline & & Number of street lights in the area \\
\hline & & $\begin{array}{l}\text { Share of public places and specialised businesses } \\
\text { where TV/telecommunication/internet is provided }\end{array}$ \\
\hline & Credit facilities & $\begin{array}{l}\text { Micro-credit possibilities available for electricity } \\
\text { services connection }\end{array}$ \\
\hline & \multirow{5}{*}{$\begin{array}{l}\text { Equal } \\
\text { distribution }\end{array}$} & Share of population with primary school education \\
\hline & & Share of population with access to electricity \\
\hline & & $\begin{array}{l}\text { Distribution of electricity client households in income } \\
\text { groups }\end{array}$ \\
\hline & & Subsidies offered for electricity services \\
\hline & & Share of economically active children \\
\hline \multirow{4}{*}{$\begin{array}{l}\text { Environmental } \\
\text { development }\end{array}$} & \multirow{2}{*}{ Global impact } & Share of renewable energy in production \\
\hline & & Emissions of carbon dioxide from production \\
\hline & \multirow[t]{2}{*}{ Local impact } & $\begin{array}{l}\text { Share of electrified households where electricity has } \\
\text { replaced other energy sources for lighting }\end{array}$ \\
\hline & & Share of electrified households where electricity has \\
\hline
\end{tabular}



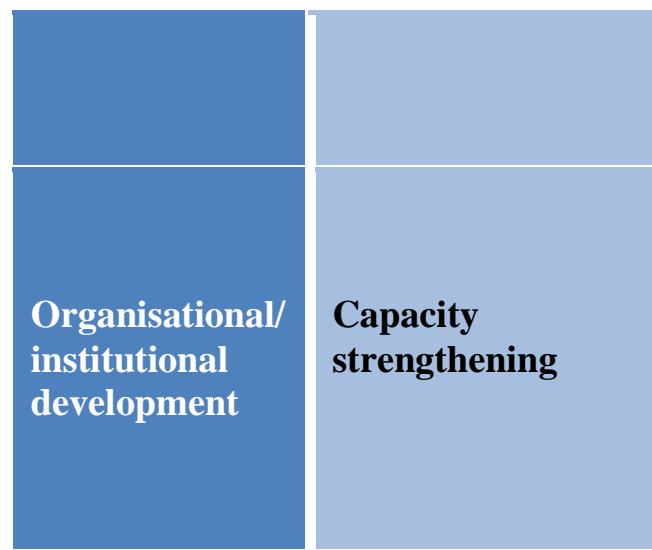

replaced other energy sources for cooking of main meals

Any serious local environment impact identified Share of staff and management with appropriate education

Degree of local ownership

Number of shareholders

Share of women in staff and management

Staff turnover in organisation

Number of years in business

Source: Ilskog (2008). 
Appendix 4: Chow's (2010) five factors for sustainable development, adapted from McConville (2006).

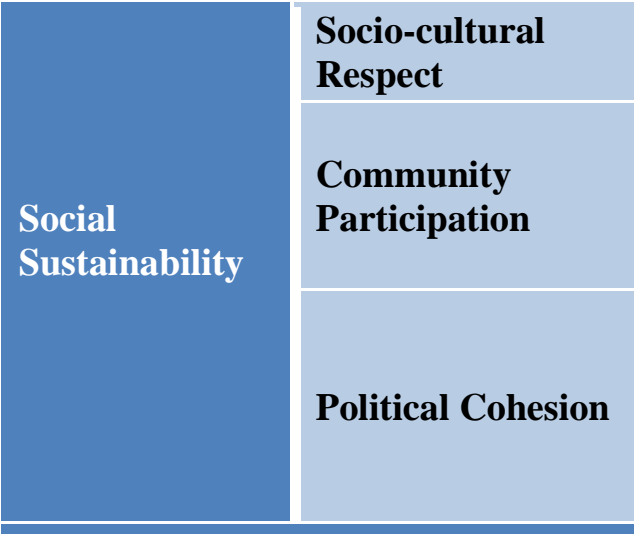

Economic Sustainability

Environmental Sustainability
A socially acceptable project is built on an understanding of local traditions and core values.

A process which fosters empowerment and ownership in community members through direct participation in development decision-making affecting the community.

Involves increasing the alignment of development projects with host country priorities and co-ordinating aid efforts at all levels (local, national, and international) to increase ownership and efficient delivery of services.

Implies that sufficient local resources and capacity exist to continue the project in the absence of outside resources.

Implies that non-renewable and other natural resources are not depleted nor destroyed for short-term improvements.

Source: Chow (2010). 
Appendix 5: Urmee \& Harries' (2009) indicators for successful program implementation.

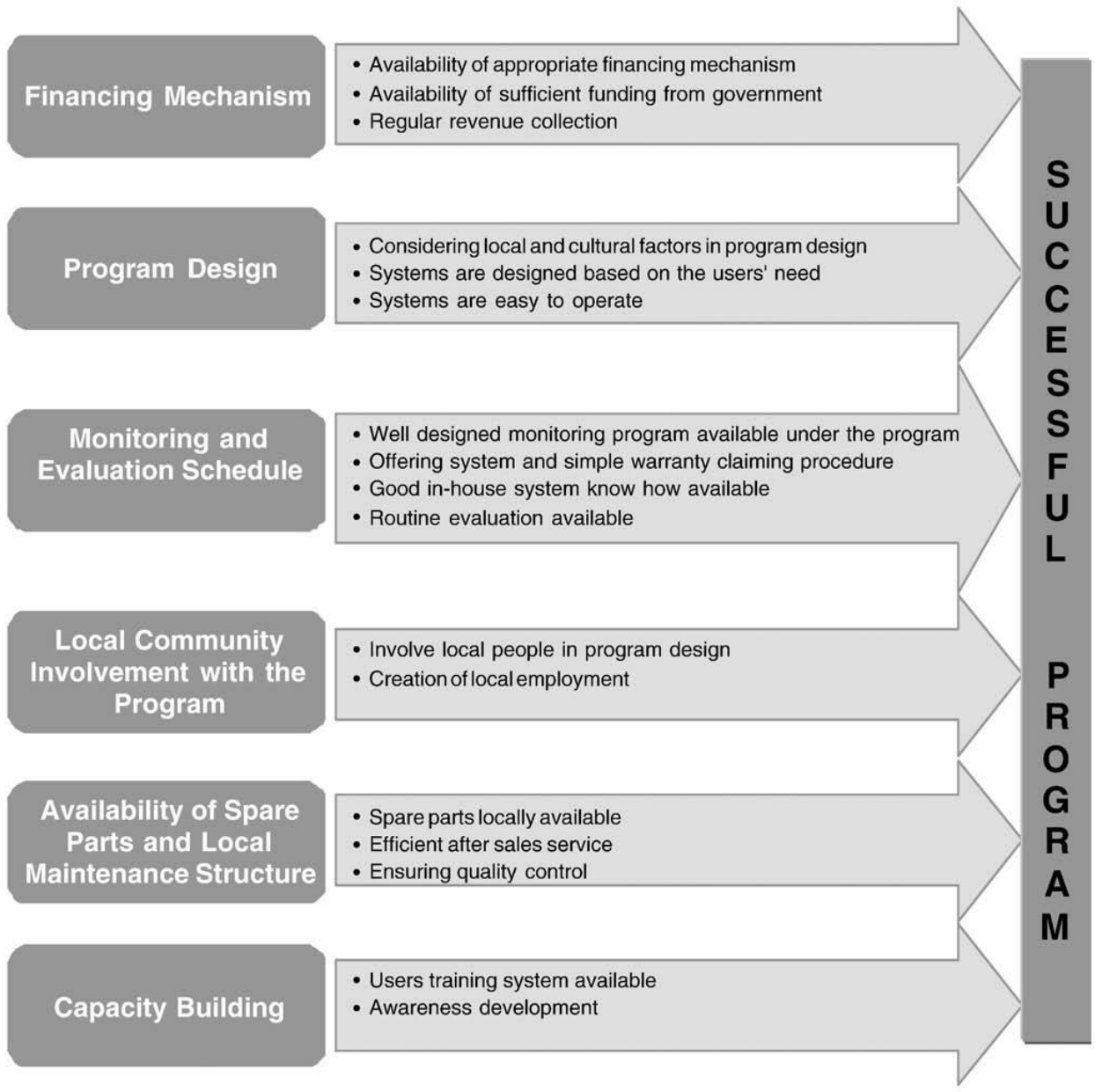

Source: Urmee \& Harries (2009). 


\section{Appendix 6:}

Questionnaires for SHS users in the case study communities of Namdrik Atoll and Akhamb Island. Questionnaires were translated into the local language and a few questions were omitted at each location that were inappropriate for the given projects (see details below). The corresponding indicator is listed in the column on the right.

\section{Please answer these questions about your home:}

\section{What is your gender?}

Male $\square$ Female

2. How many people live in your house?

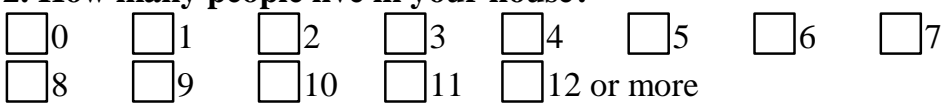

3. How many people in your house are employed?

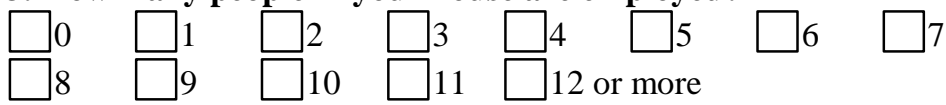

4. What is the average income of your household biweekly in total (USD)?

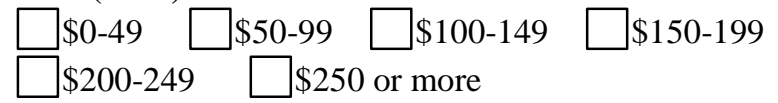

5. What is your household's primary source of income?

\begin{tabular}{ll}
$\square$ teacher & $\square$ health worker \\
\hline$\square$ farmer or fisherman & $\square$ business owner \\
\hline$\square$ council man/local government worker \\
\hline$\square$ construction worker & $\square$ police \\
\hline$\square$ pastor or other church work & $\square$ make handicrafts \\
\hline & judge/chief
\end{tabular}

6. What is the highest level of education of the people in your house?

$\square$ primary $\square$ middle school $\square$ high school

Answer these questions regarding your solar history: 7. Does the house have any other power source currently? What source?

$\begin{array}{ll}\square \text { none } & \square \text { portable solar lantern } \quad \square \text { generator } \\ \square \text { battery } & \square \text { SHS } \quad \square \text { kerosene } \quad \square \text { other }\end{array}$

8. What did the house use for lighting before their most recent SHS?

\begin{tabular}{|l}
$\square$ portable solar lantern $\square$ generator $\square$ kerosene \\
$\square$ battery powered light $\square$ SHS $\square$ other
\end{tabular}
1) Gender inclusiveness

2) Appropriate equipment use

2 - 5) Also, affordability
5) Also, effectiveness in changing community livelihoods

6) Familiarity with the technology

7) Effectiveness in meeting users' needs

7-8) Also, effectiveness in improving the environment

8) Affordability 
9. What do you use your solar powered lights for (you can choose more than one)?

$\square$ cooking $\square$ eating with $\square$ studying $\square$ reading
$\square$ making things to sell
$\square$ selling things at night $\square$ business related work
$\square$ other

10. If you have a freezer, what do you use it for (you can choose more than one)? (this question was excluded for Akhamb, as only 1 user had a freezer).

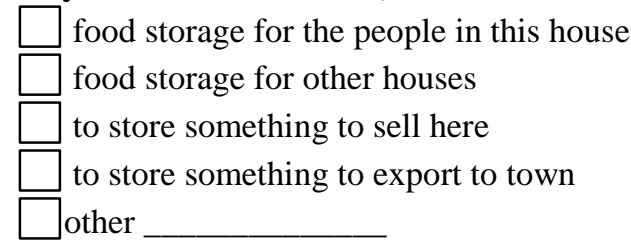

11. Why did your family decide to purchase solar systems (choose one)?

$\square$ Because we thought it would be a cheaper energy source
$\square$ Because we wanted to expand our energy uses
$\square$ Because we thought it could be used to improve our income
$\square$ Because it is easier to use than other power sources
$\square$ Other

12. How many different solar systems has your family had in your house?

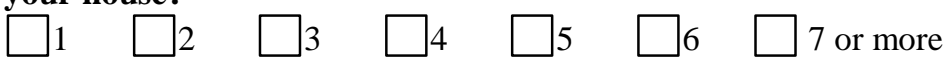

13. How many years ago was your family's first solar system installed?

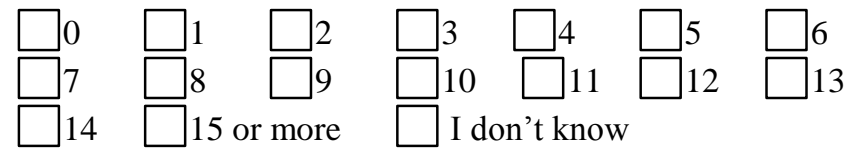

\section{Answer these questions about your current solar} system (some of these questions were omitted for Namdrik Atoll, as they did not apply to the Island Eco installed system):

14. Who is responsible for repairing your current solar system?

\begin{tabular}{|ll}
$\square$ Me or my family & $\square$ The national government \\
$\square$ The local government & $\square$ A solar company \\
$\square$ A community member & $\square$ Someone else
\end{tabular}

15. Were you involved in designing your current solar system to meet your needs?

\footnotetext{
$\square$ No $\square$ A little bit- we could choose options

$\square$ Yes, my family designed it
}

9-10) Effectiveness in changing community livelihoods

10-11) Also, willingness to pay

12-13) Familiarity with the technology

13) Also, effectiveness in improving the environment
15) Also, effectiveness in meeting users' need 
16. Are you allowed to fix or add parts to this system yourself? $\square$ No $\square$ Yes

17. If you are renting your current system, how much money did your family spend per month?

$\$$ / month

18. If you own your current system, how much does your family spend on your solar system per year to fix and maintain it?

$\square$ \$0-49 $\square$ \$50-99 $\square \$ 100-149 \square$ or more
$\square \$ 250$ or

19. Do you think your family now spends more or less on your current solar system than on your previous energy source before solar?

$\square$ More $\square$ Less $\square$ The same

20. Is your current solar system working now?

$\square$ No $\square$ Yes

If Yes:

21. Have any parts been replaced?

\begin{tabular}{l}
$\square$ Yes $\quad$ Which part(s)? \\
\hline No $\quad \square$ I don't know
\end{tabular}

If No:

22. Why is the system no longer working?

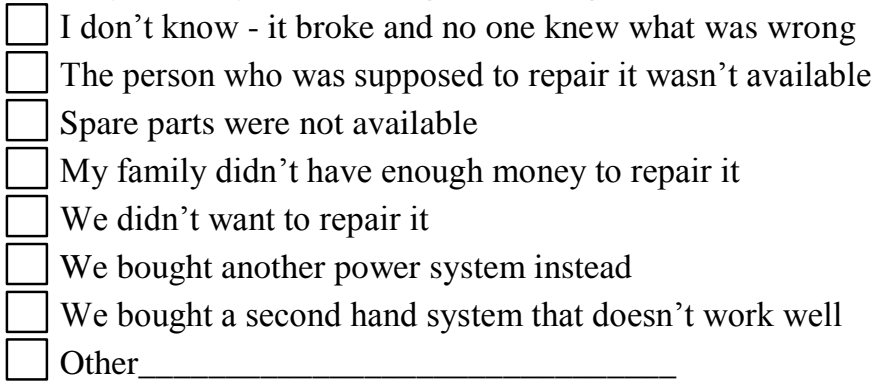

\section{How well is your current solar system repaired and} maintained?

$\square$ Not well $\square$ Somewhat well $\square$ Very well

24. How well overall do the lights work on your current solar system?

$\square$ Not well $\square$ Somewhat well $\square$ Very well
16) Also, ability to satisfy expanding energy demands

17-18) Costeffectiveness; Affordability

19) Affordability; Willingness to Pay

20-21) Appropriate equipment use; Effectiveness in improving the environment

22-24) Availability of resources and support 
25. Current Solar System details:

Solar Panel wattage: W

Battery amps:

Battery type:

$\square$ Solar Battery $\square$ Car Battery

Number of lights: $\square 0 \quad \square 1 \quad \square 2 \quad \square 3 \quad \square 4 \quad \square 5$

$\square 6 \quad \square 7 \quad \square 8$ or more

Other appliances used: $\square$ TV $\square$ Stereo

$\square$ Other

26. What appliance would you like to add to your system if you could-choose only one?

$\square$ More lights $\square$ TV $\square$ Stereo $\square$ Freezer
$\square$ Other

27. Did you or your family participate in the installation of your current solar system?

$\square$ No $\square$ A little bit $\square$ Yes

28. Do you feel sure that you or someone in your family will be able to fix this solar system if it breaks?

$\square$ Not at all $\square$ A little bit $\square$ Somewhat $\square$ Very much

29. Do you feel sure that someone in your community will be able to fix this solar system if it breaks?

$\square$ Not at all $\square$ A little bit $\square$ Somewhat $\square$ Very much

30. If someone in your community were not able to fix it, how sure are you that you could get help from someone in the capital?

$\square$ Not at all $\square$ A little bit $\square$ Somewhat $\square$ Very much

31. How willing are you to spend money to get this solar system fixed if it breaks in the future?

$\square$ Not at all $\square$ A little bit $\square$ Somewhat $\square$ Very much

Answer these questions only if you had a previous solar system before your current one (this section was only relevant for Namdrik Atoll, as only one user on Akhamb had a previous SHS):

32. Who was responsible for repairing your previous solar system?

$\square$ Me or my family
$\square$ The local government
$\square$ A community member

$\square$ The national government

$\square$ A solar company

$\square$ Someone else

33. Were you involved in designing your previous solar system to meet your needs?

$\square$ No $\square$ A little bit - we could choose options
$\square$ Yes, my family designed it
25) Appropriate equipment use; Costeffectiveness; Effectiveness in changing community livelihoods; Gender inclusiveness; Effectiveness in improving the environment

26) Effectiveness in meeting users' needs

27) Capacity building

28) Familiarity with the technology

29-30) Availability of resources and support

31) Willingness to pay

32-33) Participation and ownership

33) Also effectiveness in meeting users' needs 
34. Were you allowed to fix or add parts to this system yourself?

$\square$ No $\square$ Yes

35. If you were renting your previous system, how much money did your family spend per month?

$\$$ / month

36. If you owned your previous system, how much did your family spend on your solar system per year to fix and maintain it?

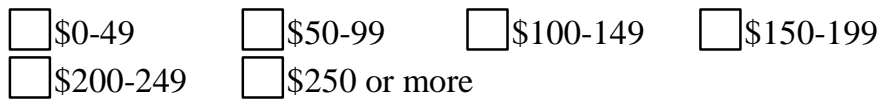

37. Is your previous solar system still working?

$\square$ No $\square$ Yes

If Yes:

38. Have any parts been replaced?

$\square$ Yes Which part(s)?

No $\square$ I don't know

If No:

39. Why is the system no longer working?

$\square$ I don't know - it broke and no one knew what was wrong

$\square$ The person who was supposed to repair it wasn't available

$\square$ Spare parts were not available

$\square$ My family didn't have enough money to repair it

$\square$ We didn't want to repair it

We bought another power system instead

$\square$ We bought a second hand system that doesn't work well

Other

40. How well was your previous solar system repaired and maintained?

$\square$ Not well $\square$ Somewhat well $\square$ Very well

41. How well overall did the lights and appliances work on your previous solar system?

$\square$ Not well $\square$ Somewhat well $\square$ Very well

42. If your previous system is no longer working, how many years did it work for in total?

\begin{tabular}{lllllll}
$\square_{0}$ & $\square_{1}$ & $\square_{2}$ & $\square_{3}$ & $\square_{4}$ & $\square_{5}$ & $\square 6$ \\
\hline$\square_{14}$ & $\square_{15}$ or more & & $\square$ & $\square_{\text {Don't know }}$ &
\end{tabular}

43. How many watts was this previous system? W
34) Ability to satisfy expanding energy demands

35-36) Cost-

effectiveness

37) Effectiveness in improving the environment

37-38) Also, appropriate equipment use

39-41) Availability of resources and support

42-43) Appropriate equipment use

43) Also, costeffectiveness 
Answer these questions regarding your solar knowledge and training (all respondents):

44. How many of the people in your family have been taught to 44) Capacity building maintain and fix solar systems?

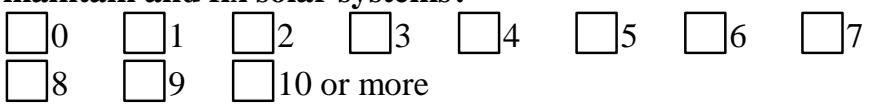

45. How many men in your family feel confident maintaining and fixing a solar system?

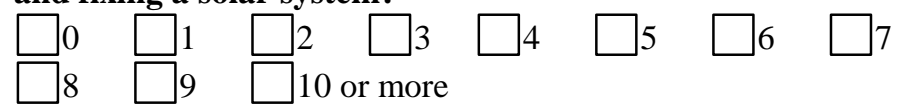

46. How many women in your family feel confident maintaining and fixing a solar system?

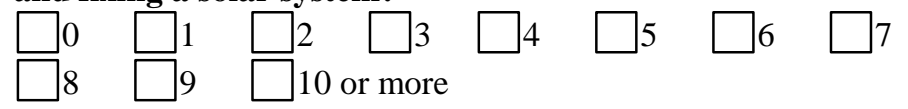

47. If anyone in your family is confident repairing a SHS, where did they learn or gain their confidences?

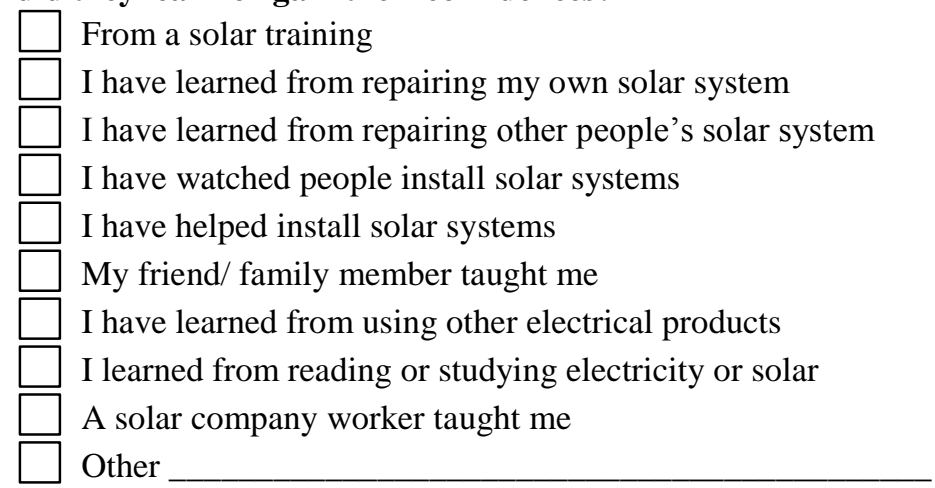

48. If a solar training workshop were to happen in your community, would you come?

$\square$ Yes $\square$ Maybe $\square$ No

Answer these questions regarding your solar preferences:

49. How important is it to you that you own your own solar system and you are responsible for it?

$\square$ Not at all $\square$ A little bit $\square$ Somewhat important

49) Participation and ownership

50. How important is it to you that you know how to repair and maintain your own solar system?

$\square$ Not at all $\square$ A little bit $\square$ Somewhat important

51. How important is it to you that you design your system and can change or add to it (add solar panels/ lights)?

$\square$ Not at all $\square$ A little bit $\square$ Somewhat important
$\square$ Very important

51-53) Effectiveness in meeting users' needs 
52. How important is having a solar system to your family (compared to another power source)?

$\square$ Not at all $\square$ A little bit $\square$ Somewhat important

$\square$ Very important

53. How much do you trust solar as a reliable power source for your house?

$\square$ Not at all $\square$ A little bit $\square$ Somewhat $\square$ Very much 
Appendix 7: Interview questions for key stakeholders in Vanuatu and the Marshall Islands and the indicators each question addressed.

\section{Interview Questions}

1. What household-scale solar projects has your organization been involved in in Vanuatu/ Marshall Islands? What were the size and purpose of these projects?

2. What role did your organization play in developing and implementing these projects?

3. When were these systems installed and by whom? Are they still working properly?

4. Were the household users involved in designing or installing the projects?

How?

5. Did the users pay for their own systems? Do the users own their own systems?

6. Was any training provided? By whom and to whom?

7. Who is responsible for maintaining the systems? Who supplies spare parts?

8. Who pays for the maintenance? Were there any problems with this?

9. In your opinion have the systems been properly maintained?

\section{Indicators Addressed}

1. Appropriate equipment use

2. Effectiveness in meeting users' needs

5. Effectiveness in changing community

livelihoods

14. Effectiveness in improving the environment

6. Availability of resources and support

12. Participation and ownership

1. Appropriate equipment use

2. Effectiveness in meeting users' needs

3. Ability to satisfy expanding energy demands

9. Gender inclusiveness

12. Participation and ownership

3. Ability to satisfy expanding energy demands

4. Cost-effectiveness

10. Affordability

12. Participation and ownership

13. Willingness to pay

6. Availability of resources and support

8. Capacity Building

9. Gender inclusiveness

11. Familiarity with the technology

6. Availability of resources and support

7. Availability of system components

8. Capacity Building

12. Participation and ownership

4. Cost-effectiveness

10. Affordability

2. Effectiveness in meeting users' needs

14. Effectiveness in improving the environment 
10. How do you think these projects could have been improved in order to produce more enduring outcomes?

11. How important do you see participation by users in solar projects to be? How can they best be integrated into project design and implementation?

12. How important do you think it is for users to own their own systems or for utilities/companies to own household solar systems in rural communities in order to make them last?

13. What do you think is the most important factor in making solar projects last in the outer islands?

14. What issues do you see for using solar as a major power source for rural electrification in Vanuatu/ Marshall Islands?

15. Do you have any other comments about solar in Vanuatu/ Marshall Islands?
All

6. Availability of resources and support

9. Gender inclusiveness

11. Familiarity with the technology

12. Participation and ownership

All

All

All

All 
Appendix 8: A summary of the history of SHS projects implemented in the RMI, based on information in the literature and project documents. The indicators addressed by the positive and negative results are referred to by indicator number.

\begin{tabular}{|c|c|c|c|c|c|c|}
\hline Country & $\begin{array}{l}\text { Project, Date, } \\
\text { and Involved } \\
\text { Parties }\end{array}$ & Specifications & Model Used & Positives & Negatives & Lessons Learned \\
\hline \multirow[t]{2}{*}{ RMI } & $\begin{array}{l}\text { Rural } \\
\text { Electrification } \\
\text { 1980s - 1990s } \\
\text { Organizer: } \\
\text { Alternative } \\
\text { Energy Fund } \\
\text { and the RMI } \\
\text { Government } \\
\text { Funding: } \\
\text { US } \\
\text { Government } \\
\text { and the Pacific } \\
\text { Island Forum } \\
\text { Secretariat } \\
\text { (PIFS) }\end{array}$ & $\begin{array}{l}\text {-A micro-grid was } \\
\text { set up on Utrok } \\
\text { Atoll in the } 1980 \text { s } \\
\text { through US funding, } \\
\text { but failed due to no } \\
\text { organized } \\
\text { maintenance } \\
\text {-132 SHSs installed } \\
\text { on various atolls }\end{array}$ & $\begin{array}{l}\text {-Project-initiated } \\
\text { user-owned: rent } \\
\text { to own } \\
\text {-Basic O\&M } \\
\text { was handled } \\
\text { locally with } \\
\text { irregular visits } \\
\text { from a } \\
\text { government } \\
\text { technician } \\
\text {-Most SHSs } \\
\text { until the late } \\
\text { 1990s were } \\
\text { funded through } \\
\text { an Alternative } \\
\text { Energy Fund in } \\
\text { the RMI }\end{array}$ & $\begin{array}{l}\text {-Introduced solar } \\
\text { PV to multiple } \\
\text { atolls so that most } \\
\text { communities were } \\
\text { familiar with solar } \\
\text { PV by } 2000 \text { (11) }\end{array}$ & $\begin{array}{l}\text {-Both technical and } \\
\text { maintenance issues resulted } \\
\text { in many of the systems } \\
\text { failing (6) } \\
\text {-Communities were } \\
\text { responsible for basic } \\
\text { maintenance without any } \\
\text { training (8) } \\
\text {-Users paid a minimal } \\
\text { amount for systems, } \\
\text { resulting in a lack of } \\
\text { ownership (12) }\end{array}$ & $\begin{array}{l}\text {-Training and } \\
\text { familiarity with the } \\
\text { technology is necessary } \\
\text { for users to properly } \\
\text { handle their SHSs } \\
\text {-The lack of a long- } \\
\text { term O\&M policy leads } \\
\text { to project failure } \\
\text {-Users must contribute } \\
\text { to the cost of their } \\
\text { SHSs in order to instill } \\
\text { a sense of ownership }\end{array}$ \\
\hline & $\begin{array}{l}\text { Namdrik } \\
\text { Atoll: 1996 } \\
\text { Organizer: } \\
\text { Marshalls } \\
\text { Alternative } \\
\text { Energy } \\
\text { Company } \\
\text { (MAEC) } \\
\text { Funding: } \\
\text { French } \\
\text { Government }\end{array}$ & $\begin{array}{l}\text {-Provided } 134 \\
\text { SHSs, and six large } \\
\text { refrigerator systems } \\
\text {-Fees were } \$ 8 \text { per } \\
\text { month with no } \\
\text { installation fee }\end{array}$ & $\begin{array}{l}\text {-RESCO, with } \\
\text { MAEC, owning } \\
\text { the systems and } \\
\text { providing } \\
\text { servicing } \\
\text {-Pre-payment } \\
\text { metering was } \\
\text { used to pay fees } \\
\text { and users were } \\
\text { disconnected } \\
\text { after } 3 \text { months of } \\
\text { non-payment }\end{array}$ & $\begin{array}{l}\text {-A pre-feasibility } \\
\text { study and a } \\
\text { survey of } \\
\text { homeowners was } \\
\text { carried out prior } \\
\text { to project } \\
\text { implementation } \\
(2,12) \\
\text {-The RESCO } \\
\text { concept was } \\
\text { introduced to the } \\
\text { locals in a } \\
\text { community } \\
\text { meeting (12) }\end{array}$ & $\begin{array}{l}\text {-The chiefs used the } \\
\text { refrigeration systems for } \\
\text { themselves, when they were } \\
\text { intended to be for the } \\
\text { community }(5,12) \\
\text {-Payments were too } \\
\text { complicated as the } \\
\text { prepayment meters had } \\
\text { technical difficulties, and } \\
\text { there were difficulties } \\
\text { transmitting the codes } \\
\text { through radio to Namdrik } \\
\text { each month (1) } \\
\text {-Non-transparency of } \\
\text { accounts and other issues } \\
\text { led to clashes between the }\end{array}$ & $\begin{array}{l}\text {-Community-shared } \\
\text { systems often do not } \\
\text { work out, due to } \\
\text { ownership being } \\
\text { unclear } \\
\text {-All stakeholders must } \\
\text { be involved in project } \\
\text { planning in order for it } \\
\text { to run smoothly } \\
\text {-Transparency is } \\
\text { necessary to prevent } \\
\text { unnecessary } \\
\text { speculation }\end{array}$ \\
\hline
\end{tabular}




\begin{tabular}{|c|c|c|c|c|c|}
\hline & & & & $\begin{array}{l}\text { Namdrik local government } \\
\text { and MAEC, as the local } \\
\text { government wasn't included } \\
\text { in project planning (12) }\end{array}$ & \\
\hline
\end{tabular}




\begin{tabular}{|c|c|c|c|c|c|}
\hline & & & & $\begin{array}{l}\text { who should pay for spare } \\
\text { lamps, and therefore users } \\
\text { felt the fees were unfair ( } 12 \text {, } \\
\text { 13) }\end{array}$ & $\begin{array}{l}\$ 50 \text { - } 100 \text { each } \\
\text {-System design needs } \\
\text { to consider the } \\
\text { increasing demands }\end{array}$ \\
\hline $\begin{array}{l}\text { REP-5 } \\
\text { Regional } \\
\text { Project: } \\
\text { Organizer: REP } \\
\text { 5 Project } \\
\text { Management } \\
\text { Unit, MEC } \\
\text { Funding: EU }\end{array}$ & $\begin{array}{l}-440 \text { systems of } \\
200 \mathrm{~W} \text { each installed } \\
\text { on Ailinglaplap } \\
\text { Atoll, serving every } \\
\text { household } \\
\text { (approximately } \\
2,000 \text { people) }\end{array}$ & $\begin{array}{l}\text {-RESCO, with } \\
\text { MEC } \\
\text { responsible for } \\
\text { maintaining the } \\
\text { systems and } \\
\text { providing spare } \\
\text { parts } \\
\text {-Fees were } \\
\text { reduced from } \\
\$ 12 \text { per month } \\
\text { to } \$ 5 \text { due to } \\
\text { users not paying } \\
\text {-There was a } \\
20 \% \text { failure rate } \\
\text { on charge } \\
\text { controllers for } \\
\text { unknown } \\
\text { reasons and } 70 \% \\
\text { failure on lights } \\
\text { due to poor } \\
\text { quality lights }\end{array}$ & $\begin{array}{l}\text {-The project } \\
\text { provided spare } \\
\text { parts to MEC, so } \\
\text { equipment was } \\
\text { available for } \\
\text { awhile after } \\
\text { installation (7) } \\
\text {-The people of } \\
\text { Ailinglaplap, } \\
\text { though } \\
\text { discouraged by } \\
\text { this project, still } \\
\text { felt solar PV was } \\
\text { a good technology } \\
\text { for rural } \\
\text { electrification (1, } \\
\text { 2) }\end{array}$ & $\begin{array}{l}\text {-Fee collection was poor, } \\
\text { with fees not being } \\
\text { collected in certain areas, } \\
\text { and disconnection policies } \\
\text { were varying in different } \\
\text { areas (10,13) } \\
\text {-Training to users on how to } \\
\text { read their charge controllers } \\
\text { was not provided ( } 8 \text { ) } \\
\text {-MOUs were signed for } \\
\text { various tasks but the } \\
\text { commitments made were } \\
\text { soon forgotten (12) } \\
\text {-Inappropriate equipment } \\
\text { was used for the climate, as } \\
\text { battery boxes were not } \\
\text { vented, thus causing some } \\
\text { batteries to overheat (1) } \\
\text {-Technicians' wages were } \\
\text { approximately } \$ 110 \text { per } \\
\text { month, meaning } 22 \text { systems } \\
\text { were needed with fees of } \$ 5 \\
\text { just to pay for one } \\
\text { technician (there were } 8 \text { at } \\
\text { the beginning of the project) } \\
\text { (4) }\end{array}$ & $\begin{array}{l}\text {-Project policies need } \\
\text { to be consistent in all } \\
\text { locations } \\
\text {-Basic training needs to } \\
\text { be provided to users } \\
\text { even if they are not } \\
\text { responsible for O\&M } \\
\text {-Users placed indoor } \\
\text { lights outdoors, which } \\
\text { reflected that the } \\
\text { systems were not } \\
\text { meeting their needs } \\
\text {-Project sustainability } \\
\text { is threatened by low } \\
\text { fees and users not } \\
\text { paying } \\
\text {-Equipment should be } \\
\text { tested for durability in } \\
\text { the PICs }\end{array}$ \\
\hline
\end{tabular}

Sources: Ailinglaplap resident, RMI, Respondent 9 (2011); Empower (2005); MEC (2008); Syngellakis et al. (2010); Wade (2004a); Wade (2005) 
Appendix 9: A summary of the history of SHS projects implemented in Vanuatu, based on information in the literature and project documents. The indicators addressed by the positive and negative results are referred to by indicator number.

\begin{tabular}{|c|c|c|c|c|c|c|}
\hline Country & $\begin{array}{l}\text { Project, Date, } \\
\text { and Involved } \\
\text { Parties }\end{array}$ & Specifications & Model Used & Positives & Negatives & Lessons Learned \\
\hline \multirow[t]{2}{*}{ Vanuatu } & $\begin{array}{l}\text { Energy Unit } \\
\text { Electrification } \\
\text { Project, Efate, } \\
\text { Malekula and } \\
\text { Umbae Island: } \\
\text { 1999 - 2001 } \\
\text { Organizer: } \\
\text { Vanuatu } \\
\text { Energy Unit } \\
\text { Funding: } \\
\text { Vanuatu } \\
\text { Energy Unit } \\
\text { and JICA }\end{array}$ & $\begin{array}{l}\text {-100 W systems } \\
\text { installed at } 265 \\
\text { households } \\
\text {-Users paid } \$ 90 \text { US } \\
\text { connection fee and } \\
\text { \$15 per month }\end{array}$ & $\begin{array}{l}\text {-RESCO using } \\
\text { prepayment } \\
\text { meters } \\
\text {-A 'local } \\
\text { caretaker' } \\
\text { handled O\&M } \\
\text {-JICA also } \\
\text { provided a RE } \\
\text { expert to the } \\
\text { Energy Unit for } \\
5 \text { years to help } \\
\text { manage the } \\
\text { projects }\end{array}$ & $\begin{array}{l}\text {-Maintenance was } \\
\text { reliable in Efate } \\
\text { as the systems } \\
\text { were near to the } \\
\text { capital, Port Vila } \\
\text { (6) } \\
\text {-Users } \\
\text { complained that } \\
\text { fees were too high } \\
\text { and the } \\
\text { government } \\
\text { responded by } \\
\text { giving options for } \\
\text { payment } \\
\text { according to how } \\
\text { many lights users } \\
\text { wanted }(2,12)\end{array}$ & $\begin{array}{l}\text {-Nearly } 20 \% \text { of systems } \\
\text { were removed by } 2004 \text { due } \\
\text { to users failure to pay the } \\
\text { fees as users did not } \\
\text { understand why they had to } \\
\text { continue to pay when the } \\
\text { project was donor-funded } \\
\text { (12) } \\
\text {-Prepayment meters } \\
\text { malfunctioned and the } \\
\text { Energy Unit lacked } \\
\text { expertise to fix them, so } \\
\text { they were removed, which } \\
\text { was costly (1) } \\
\text {-Users also said the solar } \\
\text { systems were too small - } \\
\text { only provided lights ( } 2 \text { ) } \\
\text {-Users were not trained } \\
\text { during the project except for } \\
\text { the very basics ( } 8 \text { ) }\end{array}$ & $\begin{array}{l}\text {-Lack of proper } \\
\text { explanations with users } \\
\text { and transparency of } \\
\text { funds hindered project } \\
\text { success } \\
\text {-SHSs need to be sized } \\
\text { to fit user needs } \\
\text {-User training would } \\
\text { have aided in project } \\
\text { longevity } \\
\text {-Complex technologies } \\
\text { which have not been } \\
\text { tested in PICs may } \\
\text { create issues with } \\
\text { maintenance }\end{array}$ \\
\hline & $\begin{array}{l}\text { PREFACE } \\
\text { Regional } \\
\text { Project: } 2001 \\
\text { Organizer: } \\
\text { Vanuatu } \\
\text { government } \\
\text { Funding: } \\
\text { French- } \\
\text { Australian }\end{array}$ & $\begin{array}{l}\text {-Demonstration PV } \\
\text { projects in } 40 \\
\text { government staff } \\
\text { houses (mostly rural } \\
\text { teachers) and public } \\
\text { buildings }\end{array}$ & $\begin{array}{l}\text {-RESCO } \\
\text {-Both Energy } \\
\text { Unit staff and } \\
\text { 'local caretakers' } \\
\text { handled O\&M }\end{array}$ & $\begin{array}{l}\text {-Technical } \\
\text { performance was } \\
\text { high as systems } \\
\text { were designed } \\
\text { and installed } \\
\text { correctly (1) } \\
\text {-Fees were paid } \\
\text { regularly as they } \\
\text { were deducted } \\
\text { from staff salaries } \\
(10)\end{array}$ & $\begin{array}{l}\text {-Fees did not cover the cost } \\
\text { of the project (4) } \\
\text {-Success varied according to } \\
\text { the access to caretakers and } \\
\text { the knowledge of staff, who } \\
\text { were untrained }(6,11)\end{array}$ & $\begin{array}{l}\text {-People with regular } \\
\text { incomes are much more } \\
\text { likely to pay fees on } \\
\text { time } \\
\text {-Technicians need to be } \\
\text { available locally } \\
\text {-User training would } \\
\text { have aided in project } \\
\text { longevity }\end{array}$ \\
\hline
\end{tabular}




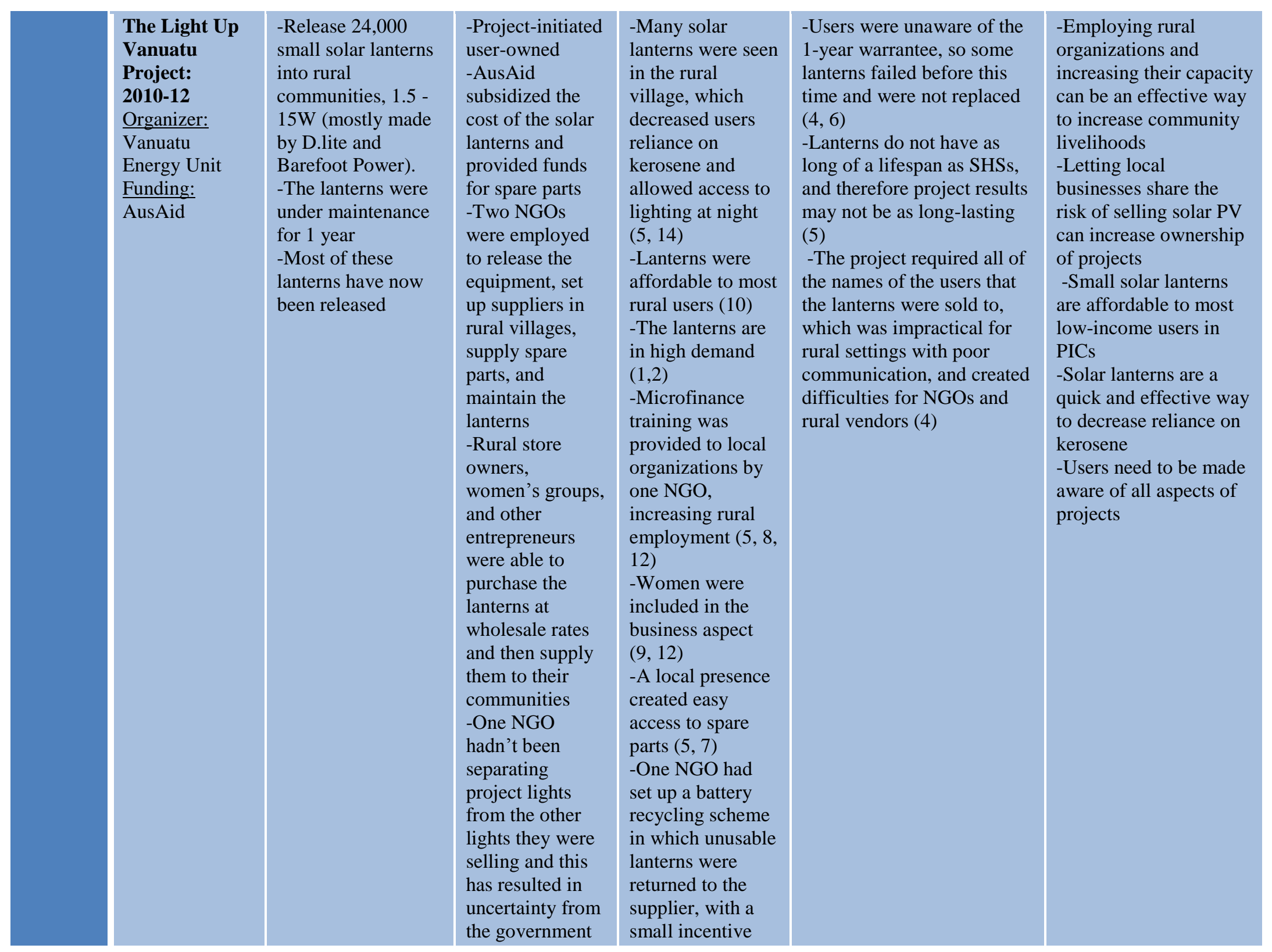




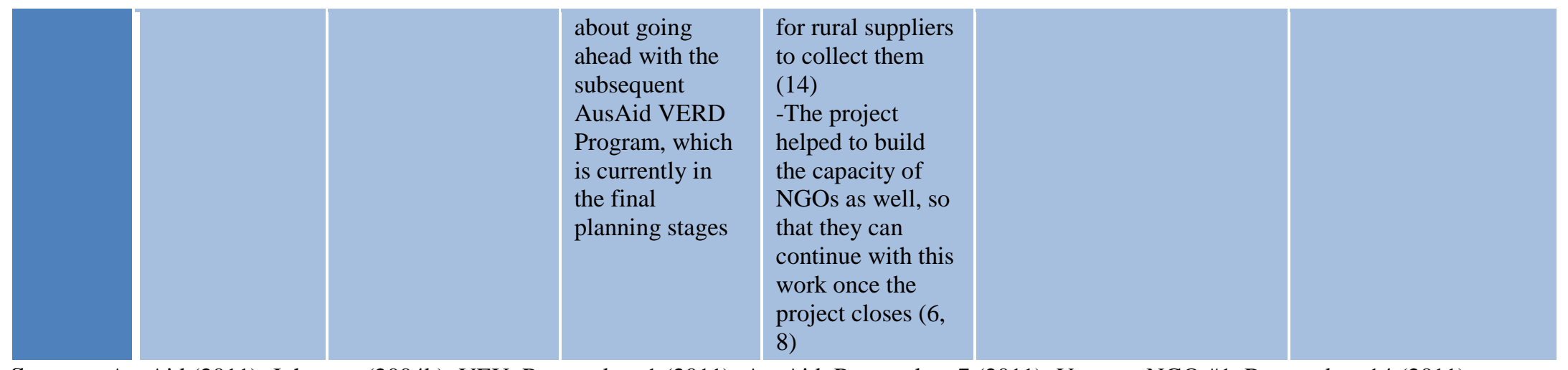

Sources: AusAid (2011); Johnston (2004b); VEU, Respondent 1 (2011); AusAid, Respondent 7 (2011); Vanuatu NGO \#1, Respondent 14 (2011);

Vanuatu NGO \#2, Respondent 18 (2011); Wade (2005). 
Appendix 10: A summary of RESCO projects in 3 PICs utilizing SHSs, based on information in the literature and project documents. The indicators addressed by the positive and negative results are referred to by indicator number.

\begin{tabular}{|c|c|c|c|c|c|c|}
\hline Country & $\begin{array}{l}\text { Project, Date, } \\
\text { and Involved } \\
\text { Parties }\end{array}$ & Specifications & Model Used & Positives & Negatives & Lessons Learned \\
\hline \multirow[t]{3}{*}{ Fiji } & $\begin{array}{l}\text { Namara } \\
\text { Village: } 1992 \\
\text { Organizer: Fiji } \\
\text { Department of } \\
\text { Energy (DOE) } \\
\text { Funding: } \\
\text { European } \\
\text { Union }\end{array}$ & $\begin{array}{l}\text {-Electrified } 60 \\
\text { households with } \\
110 \mathrm{~W} \text { panels } \\
\text {-Users paid FJ } \$ 20 \\
\text { connection fee and } \\
\$ 2 \text { monthly fee to } \\
\text { the technician }\end{array}$ & $\begin{array}{l}\text {-RESCO, with } \\
\text { equipment } \\
\text { handed over to } \\
\text { users after } 10 \\
\text { years } \\
\text {-DOE handled } \\
\text { O\&M through an } \\
\text { on-site } \\
\text { technician }\end{array}$ & $\begin{array}{l}\text {-Highly reliable } \\
\text { systems due to } \\
\text { large system size, } \\
\text { quality parts, and } \\
\text { regular } \\
\text { maintenance }(1,6)\end{array}$ & $\begin{array}{l}\text {-Systems were highly } \\
\text { subsidized and user fees } \\
\text { did not nearly cover the } \\
\text { cost (4) } \\
\text {-Some users did fail to } \\
\text { make payments after some } \\
\text { time, despite systems } \\
\text { working well (13) }\end{array}$ & $\begin{array}{l}\text {-Users are satisfied } \\
\text { when systems are large } \\
\text { and fees are small } \\
\text {-Users may not retain } \\
\text { interest in paying for } \\
\text { systems that they do } \\
\text { not own over a long } \\
\text { period of time }\end{array}$ \\
\hline & $\begin{array}{l}\text { Naroi Village: } \\
1999 \\
\text { Organizer: Fiji } \\
\text { Department of } \\
\text { Energy (DOE) }\end{array}$ & $\begin{array}{l}\text {-Electrified } 170 \\
\text { households with } \\
100 \mathrm{~W} \text { panels } \\
\text {-Users paid FJ } \\
\$ 100 \text { connection fee } \\
\text { and } \$ 4.50 \text { monthly } \\
\text { fee through } \\
\text { prepayment meters }\end{array}$ & $\begin{array}{l}\text {-RESCO } \\
\text {-Tested the } \\
\text { feasibility of } \\
\text { prepayment } \\
\text { meters } \\
\text {-DOE handled } \\
\text { O\&M through a } \\
\text { local technician, } \\
\text { trained during } \\
\text { installation }\end{array}$ & $\begin{array}{l}\text {-Technical } \\
\text { performance } \\
\text { remained } \\
\text { satisfactory as the } \\
\text { technician wasn't } \\
\text { paid until he } \\
\text { provided reports } \\
\text { to DOE about } \\
\text { each system (6) }\end{array}$ & $\begin{array}{l}\text {-Prepayment meters were } \\
\text { unreliable and allowed } \\
\text { power to continue to be } \\
\text { used without payment (1) } \\
\text {-Therefore, users stopped } \\
\text { paying fees and rather } \\
\text { project cost became a } \\
\text { continued burden for the } \\
\text { DOE (4) } \\
\text {-Skilled personnel were } \\
\text { unavailable to fix the } \\
\text { meters (6) } \\
\text {-Spare parts were not } \\
\text { available locally (7) }\end{array}$ & $\begin{array}{l}\text { - Prepayment meters do } \\
\text { not prevent a low rate } \\
\text { of fee collection if } \\
\text { users are unsatisfied } \\
\text {-Lack of skilled } \\
\text { personnel can result in } \\
\text { project failure } \\
\text {-RESCO projects can } \\
\text { become an economic } \\
\text { burden for the } \\
\text { managing organization } \\
\text { if they fail }\end{array}$ \\
\hline & $\begin{array}{l}\text { Vanua Levu } \\
\text { Pilot Project: } \\
2000 \text { and 2002 } \\
\text { Organizer: Fiji } \\
\text { Department of } \\
\text { Energy (DOE) } \\
\text { Funding: } \\
\text { Pacific } \\
\text { International }\end{array}$ & $\begin{array}{l}\text {-Electrified } 60 \\
\text { households initially } \\
\text { and then } 186 \text { later } \\
\text { on with } 100 \mathrm{~W} \\
\text { systems } \\
\text {-Users paid FJ } \\
\$ 14.50 \text { in monthly } \\
\text { fees through } \\
\text { prepayment meters }\end{array}$ & $\begin{array}{l}\text {-RESCO } \\
\text {-Again, tested } \\
\text { the feasibility of } \\
\text { prepayment } \\
\text { meters } \\
\text {-DOE handled } \\
\text { installation and } \\
\text { maintenance } \\
\text { through local }\end{array}$ & $\begin{array}{l}\text {-The level of fees } \\
\text { was expected to } \\
\text { cover the cost of } \\
\text { O\&M if technical } \\
\text { problems did not } \\
\text { occur (4) }\end{array}$ & $\begin{array}{l}\text {-Controllers and } \\
\text { prepayment meters had } \\
\text { technical problems, leading } \\
\text { to O\&M costs being higher } \\
\text { than expected (4) } \\
\text {-Systems were not properly } \\
\text { maintained (6) }\end{array}$ & $\begin{array}{l}\text {-Installing innovative } \\
\text { equipment in an } \\
\text { environment where it } \\
\text { has not been tested is } \\
\text { risky } \\
\text {-Fees should account } \\
\text { for unexpected } \\
\text { technical problems }\end{array}$ \\
\hline
\end{tabular}




\begin{tabular}{|c|c|c|c|c|c|c|}
\hline & $\begin{array}{l}\text { Centre for High } \\
\text { Technology } \\
\text { Research } \\
\text { (PICHTR); and } \\
\text { the Government } \\
\text { of Japan }\end{array}$ & & contractors & & & \\
\hline & $\begin{array}{l}\text { Fiji RESCO } \\
\text { Project, } 12 \\
\text { different } \\
\text { villages } 2003 \text { - } \\
\text { 2009 } \\
\text { Organizer: Fiji } \\
\text { Department of } \\
\text { Energy (DOE) } \\
\text { Funding: } \\
\text { PICHTR; and } \\
\text { Government of } \\
\text { Japan }\end{array}$ & $\begin{array}{l}\text {-Approximately } 950 \\
\text { households were } \\
\text { further electrified } \\
\text { with } 100-110 \mathrm{~W} \\
\text { systems in various } \\
\text { villages } \\
-\$ 1,458 \text { US total } \\
\text { installed cost per } \\
\text { SHS } \\
\text {-Users pay } \\
\text { approximately } 10 \% \\
\text { of the cost with a } \\
\text { FJ } \$ 50 \text { connection } \\
\text { fee and } \$ 14 \\
\text { monthly fee }\end{array}$ & $\begin{array}{l}\text {-RESCO using } \\
\text { prepayment } \\
\text { meters } \\
\text {-DOE handled } \\
\text { installation and } \\
\text { maintenance } \\
\text { through local } \\
\text { contractors }\end{array}$ & $\begin{array}{l}\text {-A different type } \\
\text { of prepayment } \\
\text { meter was used } \\
\text { (Enercash) which } \\
\text { was more } \\
\text { successful (1) } \\
\text {-There is a high } \\
\text { demand for the } \\
\text { systems by end- } \\
\text { users }(2,10)\end{array}$ & $\begin{array}{l}\text {-Communication with } \\
\text { technicians was limited due } \\
\text { to the office being a long } \\
\text { distance from villages and } \\
\text { lack of telecommunication } \\
\text { (6) } \\
-30 \text { - 50\% of the systems } \\
\text { were not working properly } \\
\text { due to lack of regular } \\
\text { O\&M, which was caused } \\
\text { by contrasting interests } \\
\text { between the government } \\
\text { and the RESCO contractor } \\
\text { (6) } \\
\text {-Batteries were not } \\
\text { maintenance-free, causing } \\
\text { many batteries to dry up } \\
\text { and fail (1) } \\
\text {-No training or } \\
\text { consultation was provided } \\
\text { with project } \\
\text { implementation (8) } \\
\text {-Systems were all one size } \\
\text { (3) }\end{array}$ & $\begin{array}{l}\text {-Active government } \\
\text { support is required to } \\
\text { make such programs } \\
\text { sustainable, which is } \\
\text { not always possible in } \\
\text { PICs due to under- } \\
\text { resourced and under- } \\
\text { staffed offices } \\
\text {-Despite failure of } \\
\text { many systems, the } \\
\text { same model continues } \\
\text { to be implemented in } \\
\text { Fiji due to high demand } \\
\text { and lack of resources } \\
\text { without addressing the } \\
\text { underlying issues } \\
\text {-Contrasting interests } \\
\text { or understanding } \\
\text { between stakeholders } \\
\text { can lead to project } \\
\text { failure } \\
\text {-Maintenance-free } \\
\text { batteries are } \\
\text { appropriate for PICs } \\
\text {-Communication } \\
\text { between the project site } \\
\text { and the managing } \\
\text { organization needs to } \\
\text { be available and } \\
\text { systematic }\end{array}$ \\
\hline
\end{tabular}




\begin{tabular}{|c|c|c|c|c|c|c|}
\hline & $\begin{array}{l}\text { Kiribati: } \mathbf{1 9 8 4} \\
\text { - 89 } \\
\text { Organizer: } \\
\text { Kiribati Solar } \\
\text { Energy } \\
\text { Company } \\
\text { (SEC) } \\
\text { Funding:USAid }\end{array}$ & $\begin{array}{l}55 \mathrm{~W} \text { panels } \\
\text {-Peak sales were in } \\
1987\end{array}$ & $\begin{array}{l}\text { USAid } \\
\text {-The government } \\
\text { and other } \\
\text { organizations } \\
\text { had shares } \\
\text {-The } \\
\text { shareholders } \\
\text { pulled out after a } \\
\text { while, thinking } \\
\text { the company was } \\
\text { stable, but they } \\
\text { went bankrupt in } \\
\text { 1989 }\end{array}$ & & $\begin{array}{l}\text { satisfactory O\&M carried } \\
\text { out by users }(8,11) \\
\text {-Users were unwilling to } \\
\text { pay for subsidized } \\
\text { technical support }(13) \\
\text {-Equipment costs and } \\
\text { transportation both for } \\
\text { importing equipment and } \\
\text { transporting to the outer } \\
\text { islands made SHS costs } \\
\text { very expensive }(4,10)\end{array}$ & $\begin{array}{l}\text { replacement } \\
\text { components } \\
\text {-Costs of systems have } \\
\text { become more } \\
\text { affordable and may } \\
\text { affect users' } \\
\text { willingness to pay }\end{array}$ \\
\hline & $\begin{array}{l}\text { Kiribati Solar } \\
\text { Energy Service } \\
\text { Company, } \\
\text { Kiribati: } 1990 \\
\text { - current } \\
\text { Organizer: } \\
\text { Kiribati Solar } \\
\text { Energy } \\
\text { Company } \\
\text { (SEC) } \\
\text { Funding: JICA; } \\
\text { European } \\
\text { Union }\end{array}$ & $\begin{array}{l}\text {-JICA provided the } \\
\text { start-up cost for } \\
\text { changing SEC into } \\
\text { a RESCO } \\
\text {-300 houses } \\
\text { electrified by } 1999 \text {, } \\
\text { with an additional } \\
1,700 \text { in } 2005 \text { and } \\
2,000 \text { in } 2010 \text { (both } \\
\text { with funding by the } \\
\text { EU) } \\
-100 W \text { panels } \\
\text { powered } 3 \text { lights } \\
\text { and a DC socket for } \\
\text { radio } \\
\text {-Users paid AUD } \\
\$ 10 \text { in monthly fees }\end{array}$ & $\begin{array}{l}\text {-Privately run } \\
\text { RESCO } \\
\text {-SEC trained } \\
\text { local technicians } \\
\text { to install, } \\
\text { maintain, and } \\
\text { collect the SHS } \\
\text { fees } \\
\text {-RESCO } \\
\text { decisions were } \\
\text { made by a } \\
\text { committee, } \\
\text { which included } \\
\text { government } \\
\text { representatives }\end{array}$ & $\begin{array}{l}\text {-Able to cover } \\
\text { operating costs } \\
\text { with the current } \\
\text { amount of } \\
\text { systems installed, } \\
\text { although fees may } \\
\text { need to be raised } \\
\text { in the future (4) } \\
\text {-SEC } \\
\text { manufactures its } \\
\text { own controller, } \\
\text { that is designed } \\
\text { with the harsh } \\
\text { oceanic } \\
\text { conditions in } \\
\text { mind (1) }\end{array}$ & $\begin{array}{l}\text {-Capital costs have been } \\
\text { subsidized by donors, and } \\
\text { would have to be so if this } \\
\text { model was reproduced (4) } \\
\text {-O\&M was not always } \\
\text { satisfactory, so the EU has } \\
\text { funded training for more } \\
\text { outer island technicians to } \\
\text { lessen the workload (6) } \\
\text {-Systems are not affordable } \\
\text { to everyone (10) }\end{array}$ & $\begin{array}{l}\text {-Local technicians } \\
\text { living near to the } \\
\text { systems are needed to } \\
\text { reduce costs } \\
\text {-SEC was more } \\
\text { successful using older } \\
\text { people as technicians } \\
\text { who may be less } \\
\text { technically competent } \\
\text { but more respected and } \\
\text { able to collect fees, as } \\
\text { the work didn't require } \\
\text { a high level of technical } \\
\text { knowledge } \\
\text {-Systems are limited to } \\
\text { providing lighting and } \\
\text { powering a radio, thus } \\
\text { limiting possibilities for } \\
\text { productive uses }\end{array}$ \\
\hline Tonga & $\begin{array}{l}\text { The Tonga } \\
\text { Outer Islands } \\
\text { Solar } \\
\text { Electrification } \\
\text { Programme } \\
\text { (TOISEP) } \\
1988 \text { - 1999 }\end{array}$ & $\begin{array}{l}\text {-Nearly } 600 \\
\text { systems installed on } \\
\text { many different } \\
\text { islands } \\
\text {-Most systems were } \\
110-150 \mathrm{~W}, \text { with } \\
\text { good quality solar }\end{array}$ & $\begin{array}{l}\text {-RESCO } \\
\text {-Government } \\
\text { had only an } \\
\text { advisory role; } \\
\text { communities and } \\
\text { co-operatives } \\
\text { own the systems }\end{array}$ & $\begin{array}{l}\text {-The maintenance } \\
\text { and repair fund } \\
\text { collected interest, } \\
\text { to make spare } \\
\text { parts more } \\
\text { affordable (10) } \\
\text {-SHSs were }\end{array}$ & $\begin{array}{l}\text {-O\&M was unsatisfactory } \\
\text { as visits by EPU } \\
\text { technicians were rare, } \\
\text { creating long delays for } \\
\text { systems to be repaired (6) } \\
\text {-This made it hard to } \\
\text { disconnect those who }\end{array}$ & $\begin{array}{l}\text {-Spare parts and } \\
\text { technicians should be } \\
\text { available locally to } \\
\text { avoid delays } \\
\text { - Participation needs to } \\
\text { be voluntary in order to } \\
\text { ensure users have a }\end{array}$ \\
\hline
\end{tabular}




\begin{tabular}{|c|c|c|c|c|c|}
\hline $\begin{array}{l}\text { Organizer: } \\
\text { Energy } \\
\text { Planning Unit } \\
\text { (EPU) } \\
\text { Funding: } \\
\text { EU; AusAid; } \\
\text { Japan; France; } \\
\text { NZ; UNESCO }\end{array}$ & batteries being used & $\begin{array}{l}\text {-Village } \\
\text { committees were } \\
\text { responsible for } \\
\text { collecting fees } \\
\text {-Fees were then } \\
\text { handed to the } \\
\text { EPU to offset the } \\
\text { maintenance } \\
\text { costs } \\
\text {-O\&M was } \\
\text { handled by the } \\
\text { committees, } \\
\text { and EPU staff } \\
\text { aided in more } \\
\text { complex } \\
\text { maintenance }\end{array}$ & $\begin{array}{l}\text { affordable to all, } \\
\text { as the monthly } \\
\text { fees were less } \\
\text { than that of } \\
\text { kerosene (10) } \\
\text {-Despite lack of } \\
\text { maintenance, } \\
\text { some systems } \\
\text { were still working } \\
\text { due to users } \\
\text { managing their } \\
\text { own systems ( } 6 \text {, } \\
11)\end{array}$ & $\begin{array}{l}\text { didn't pay their fees and } \\
\text { thus fee collection was } \\
\text { irregular (less than 40\%) } \\
\text { (13) } \\
\text {-Additionally, fees were set } \\
\text { too low to cover program } \\
\text { costs (4) } \\
\text {-All parts came from the } \\
\text { EPU office, resulting in } \\
\text { delays (7) } \\
\text {-Participation in the } \\
\text { program was not viewed as } \\
\text { voluntary (12) } \\
\text {-The EPU was not } \\
\text { transparent with the funds } \\
\text { in the maintenance account } \\
\text { (13) }\end{array}$ & $\begin{array}{l}\text { desire to pay for and } \\
\text { look after their systems } \\
\text {-Lack of a clear role } \\
\text { and understanding of } \\
\text { responsibilities between } \\
\text { the EPU and local } \\
\text { technicians hindered } \\
\text { project success } \\
\text {-Transparency is } \\
\text { necessary to prevent } \\
\text { unnecessary } \\
\text { speculation } \\
\text {-Participation should be } \\
\text { seen as voluntary }\end{array}$ \\
\hline
\end{tabular}




\begin{tabular}{|c|c|c|c|c|c|}
\hline & & & & $\begin{array}{l}\text { the committee not } \\
\text { enforcing their use (8) } \\
\text {-Technicians were not } \\
\text { committed to their jobs due } \\
\text { to low wages }(4,6)\end{array}$ & $\begin{array}{l}\text { need to be fair } \\
\text {-Spare parts need to be } \\
\text { available locally }\end{array}$ \\
\hline $\begin{array}{l}\text { PIGGAREP } \\
\text { Regional } \\
\text { Project } \\
\text { 2008 - ongoing } \\
\text { Organizer: } \\
\text { Tonga } \\
\text { Government } \\
\text { and Ha'apai } \\
\text { Solar } \\
\text { Electricity } \\
\text { Incorporated } \\
\text { (HSEI), } \\
\text { previously } \\
\text { HSEC } \\
\text { Funding: Italy; } \\
\text { PIGGAREP; } \\
\text { REEEP }\end{array}$ & $\begin{array}{l}\text {-Rehabilitated } 60 \\
\text { systems installed in } \\
1988 \text { and } 1994 \text { in } \\
\text { Mango and } \\
\text { Mo'unga } \\
\text { communities } \\
\text {-Only some solar } \\
\text { panels were able to } \\
\text { be reused } \\
\text {-Users paid a } \\
\text { T\$200 } \\
\text { connection fee and } \\
\text { a \$13 monthly fee }\end{array}$ & $\begin{array}{l}\text {-Followed same } \\
\text { organizational } \\
\text { structure as the } \\
\text { PREFACE } \\
\text { Project, and the } \\
\text { communities } \\
\text { joined HSEI } \\
\text {-Similar projects } \\
\text { with an } \\
\text { additional } 564 \\
\text { systems are } \\
\text { being installed in } \\
2012 \text { with aid } \\
\text { from SPC, } \\
\text { IUCN, and JICA }\end{array}$ & $\begin{array}{l}\text {-Now frequently } \\
\text { needed spare parts } \\
\text { are kept with each } \\
\text { technician (7) } \\
\text {-Improvement of } \\
\text { understanding of } \\
\text { roles helped the } \\
\text { projects to go } \\
\text { ahead more } \\
\text { smoothly (12) } \\
\text {-Strengthened the } \\
\text { capacity of the } \\
\text { HSEI }\end{array}$ & $\begin{array}{l}\text {-Project evaluations are not } \\
\text { yet available to assess the } \\
\text { outcome of the SHSs }\end{array}$ & \\
\hline
\end{tabular}

Sources: APCTT-UNESCAP (2009); Dornan (2010); Europeaid (2009); Johnston (2004); MECC (2012); Nieuwenhout et al. (2001); Palaki et al. (2009); Urmee (2009); Urmee et al. (2009); Urmee \& Harries (2009); Wade (2004); Wade (2004b); Wade (2005). 
Appendix 11: A summary of the private SHS market in PNG, based on information in the literature and project documents. The indicators addressed by the positive and negative results are referred to by indicator number.

\begin{tabular}{|c|c|c|c|c|c|c|}
\hline Country & $\begin{array}{l}\text { Project, Date, } \\
\text { and Involved } \\
\text { Parties }\end{array}$ & Specifications & Model Used & Positives & Negatives & Lessons Learned \\
\hline PNG & $\begin{array}{l}\text { Private } \\
\text { Markets } 1997 \text { - } \\
\text { present } \\
\text { Organizer: } \\
\text { Private sales by } \\
\text { Enertec, TE } \\
\text { (PNG), RDS, } \\
\text { and others } \\
\text { Funding: } \\
\text { The World } \\
\text { Bank and GEF } \\
\text { supported the } \\
\text { private market } \\
\text { in 2007, } \\
\text { otherwise } \\
\text { minimal } \\
\text { external } \\
\text { funding }\end{array}$ & $\begin{array}{l}\text {-Technical, } \\
\text { financial, and } \\
\text { institutional data is } \\
\text { very limited from } \\
\text { 1978, when PV } \\
\text { arrived in PNG, to } \\
\text { now } \\
\text {-The market for } \\
\text { SHSs began in } \\
\text { 1997; systems sold } \\
\text { now range from } 10 \\
\text { to } 480 \text { W or more } \\
\text {-The SHSs are } \\
\text { mostly used for } \\
\text { lighting, radios, } \\
\text { charging mobiles, } \\
\text { TVs, and other } \\
\text { appliances } \\
\text {-It is estimated that } \\
\text { approximately } \\
3,000 \text { SHSs were } \\
\text { sold to individuals } \\
\text { from } 1997 \text { to } 2002 \text {, } \\
\text { after which } 1,000 \text { - } \\
5,000 \text { systems are } \\
\text { being sold each } \\
\text { year }\end{array}$ & $\begin{array}{l}\text {-Self-initiated } \\
\text { user-owned } \\
\text { through three } \\
\text { large private } \\
\text { companies and } \\
\text { other smaller } \\
\text { entrepreneurs and } \\
\text { institutions } \\
\text {-The role of the } \\
\text { Government } \\
\text { Energy Division } \\
\text { has been minimal } \\
\text {-The WB-GEF } \\
\text { project was the } \\
\text { only major donor } \\
\text { effort aimed at } \\
\text { SHSs for } \\
\text { individuals in } \\
\text { PNG } \\
\text {-It attempted to } \\
\text { distribute and } \\
\text { further } \\
\text { commercialize } \\
\text { SHS } 2007, \text { yet it } \\
\text { was met with } \\
\text { limited success }\end{array}$ & $\begin{array}{l}\text {-There is a } \\
\text { thriving and } \\
\text { growing market } \\
\text { for SHSs }(4,6) \\
\text {-RDS marketed } \\
50-150 \text { W SHSs } \\
\text { with an option of } \\
\text { cash sales or a } \\
\text { six-month } \\
\text { payment scheme, } \\
\text { by which they } \\
\text { sold } 5,000 \text { in one } \\
\text { year }(10)\end{array}$ & $\begin{array}{l}\text {-There is limited data by } \\
\text { which to know how many } \\
\text { of the systems are working } \\
\text { (6) } \\
\text {-Equipment is not always } \\
\text { suited for the harsh climate } \\
\text { (1) } \\
\text {-The government supports } \\
\text { expanding use of fossil fuel, } \\
\text { which puts SHSs at a } \\
\text { disadvantage }(4,10) \\
\text {-The importance of culture } \\
\text { and training often has not } \\
\text { been incorporated into sales } \\
\text { and projects }(2,8)\end{array}$ & $\begin{array}{l}\text {-The option of } \\
\text { financing for users can } \\
\text { help increase private } \\
\text { sales } \\
\text {-Users are in need of } \\
\text { training to be able to } \\
\text { maintain their systems, } \\
\text { as many do not have } \\
\text { access to companies } \\
\text { after purchasing due to } \\
\text { long distances, poor } \\
\text { transportation } \\
\text { infrastructure, and poor } \\
\text { telecommunication } \\
\text {-SHSs are still not } \\
\text { affordable or a priority } \\
\text { for many of the poor, } \\
\text { and financial literacy } \\
\text { continues to be an issue } \\
\text {-Systems should be } \\
\text { oversized as users often } \\
\text { share systems with } \\
\text { others, which is a part } \\
\text { of their culture }\end{array}$ \\
\hline
\end{tabular}

Sources: Johnston (2004a); Kopi \& Lloyd (2002); Sovacool (2011); Wade (2005). 
Appendix 12: A summary of the co-operative model implemented in Tuvalu, based on information in the literature and project documents.

\begin{tabular}{|c|c|c|c|c|c|c|}
\hline Country & $\begin{array}{l}\text { Project, Date, } \\
\text { and Involved } \\
\text { Parties }\end{array}$ & Specifications & Model Used & Positives & Negatives & Lessons Learned \\
\hline Tuvalu & $\begin{array}{l}\text { Tuvalu Solar } \\
\text { Energy Co- } \\
\text { operative } \\
\text { Electrification, } \\
\text { Tuvalu: 1984- } \\
\text { 1994 } \\
\text { Organizer: } \\
\text { Tuvalu Solar } \\
\text { Electricity Co- } \\
\text { operative } \\
\text { Funding: } \\
\text { USAid; EU; } \\
\text { and the French } \\
\text { Government }\end{array}$ & $\begin{array}{l}\text {-Over } 400 \\
\text { members by } 1994 \\
\text {-Systems for solar } \\
\text { lighting } \\
\text {-One of the first } \\
\text { countries in the } \\
\text { world to use solar } \\
\text { PV for rural } \\
\text { electrification }\end{array}$ & $\begin{array}{l}\text {-Co-operative, } \\
\text { with initial } \\
\text { system costs } \\
\text { covered by } \\
\text { donors } \\
\text {-After failure, the } \\
\text { systems were } \\
\text { mostly replaced } \\
\text { by diesel power } \\
\text { grids in } 2000 \\
\text {-Diesel-powered } \\
\text { grids are now } \\
\text { being converted } \\
\text { into hybrid } \\
\text { systems, with a } \\
40 \mathrm{~kW} \text { and a } 46 \\
\mathrm{~kW} \text { array already } \\
\text { having been } \\
\text { installed }\end{array}$ & $\begin{array}{l}\text {-Local technicians } \\
\text { were trained to } \\
\text { maintain the } \\
\text { systems } \\
\text {-For the first } 10 \\
\text { years the project } \\
\text { had strong } \\
\text { institutional } \\
\text { support, which } \\
\text { helped with project } \\
\text { endurance }\end{array}$ & $\begin{array}{l}\text {-Systems were highly } \\
\text { subsidized } \\
\text {-The co-operative fell apart } \\
\text { because the funds collected } \\
\text { for O\&M disappeared } \\
\text {-After the co-operative } \\
\text { failure, there was a low- } \\
\text { level of user satisfaction due } \\
\text { to lack of maintenance } \\
\text { support and spare part } \\
\text { availability }\end{array}$ & $\begin{array}{l}\text {-The co-operative } \\
\text { model is weak in fiscal } \\
\text { discipline and this } \\
\text { problem caused the } \\
\text { co-operative to } \\
\text { dissolve }\end{array}$ \\
\hline
\end{tabular}

Sources: E8 (2009); Wade (2004c); Wade (2005). 
Appendix 13: Descriptions of four ongoing regional projects and efforts in PICs which directly affect rural RE electrification.

\section{PIGGAREP}

The aim of the Pacific Islands Greenhouse Gas Abatement through Renewable Energy Project (PIGGAREP) is to reduce $\mathrm{CO}_{2}$ emissions in eleven PICs by two million tons in total by 2015. In order to achieve this, the project is focusing on addressing policy barriers, building RE capacity, improving access to funding, enhancing local markets for RE, creating regulations and standards for RE uptake, increasing knowledge of RE resources, and raising awareness of key stakeholders (UNDP, 2007). It includes demonstration RE technologies and training for government staff and RE technicians. Specific activities which address the use of solar PV for rural electrification include:

1. A training for solar PV users in community high schools in the Solomon Islands

2. Financial training for 5 RESCOs in Tonga

3. Tonga SHS assessment and standardization

4. Solar PV systems for rural electrification of Tuvalu (Ualesi, 2011)

The five-year project was due to be completed in 2012; however, there have been some delays in implementation, due to lack of government staff to work with, time-consuming community consultations, and inadequately planned financial procedures, and thus the project has been extended (APAN, 2012).

\section{IRENA}

The global International Renewable Energy Agency (IRENA) has recently entered the Pacific region in order to aid in the uptake of RE. In 2012 the organization plans to assist in the following activities, in order to augment off-grid RE development in PICs:

- To develop a web-based platform to provide information on the cost and performance of RE technologies in PICs, and on successful RE projects in the region and globally

- To make the existing knowledge contained in PIC energy studies widely available

- To strengthen the role of the private sector by providing advice in developing viable business models and sharing information among organizations regarding successful approaches found in PICs

- To support organized training activities, including vocational programmes, in order to build capacity in PICs. Training could be based on the proposed Pacific Renewable Energy Training Initiative (PRETI), which is a model that develops existing educational programs to become 'centres of excellence' for RE technologies

(IRENA, 2011; IRENA, 2012)

\section{GEF Sustainable Energy Financing Project}

The GEF Sustainable Energy Financing Project aims to encourage local financial institutions to participate in RE finance, in order to enhance RE markets (Adams et al., 2007). This project has been operating in Fiji, PNG, RMI, Solomon Islands, and Vanuatu from 2007 to 2012, after which it will support technical assistance and information sharing from Fiji until 2017 (Prasad, 2012). 


\section{The Pacific Micro Energy Service Companies (PMESCO) Project}

This project was jointly developed by the Renewable Energy and Energy Efficiency Partnership (REEEP) and the South Pacific Applied Geoscience Commission (SOPAC), to establish a Micro Credit Facility and demonstrate its ability to help replace kerosene for lighting in the Solomon Islands and Kiribati. In the Solomon Islands, a 'cash for crops' centre has allowed customers to pay their instalments through crops, as access to markets is limited in rural areas. Its activities include:

- To engage with local entrepreneurs to establish and operate a micro-energy service company

- To install 'Light Up The World' SHSs for lighting 3 communities in the Solomon Islands and 3 communities in Kiribati, including technical training for vendors

- To establish a micro-credit facility, including training for vendors

- To identify ways of measuring emission reductions

- To support the activities through voluntary carbon markets (Climate Parliament, 2009) 